\title{
ORIGEN DE UN IMPERIO: CÓMO EL ESTADO RUSO LLEGÓ A LA CUENCA DEL PACÍFICO
}

\author{
MARTHA ORTEGA SOTO
}

TESIS PARA OPTAR AL GRADO DE DOCTORA EN HUMANIDADES LÍNEA DE HISTORIA

UNVERSIDAD AUTÓNOMA METROPOLITANA, UNIDAD IZTAPALAPA

ASESOR: DR. LOTHAR KNAUTH MÜLINGH

Noviembre de 2014. 
An

UNIVERSIDAD AUTÓNOMA METROPOLITANA

Unidad Iztapalapa

Fecha : $04 / 11 / 2014$

Página : $\quad 1 / 1$

CONSTANCIA DE PRESENTACION DE EXAMEN DE GRADO

La Universidad Autónoma Metropolitana extiende la presente CONSTANCIA DE PRESENTACION DE DISERTACIÓN PÚBLICA de DOCTORA EN HUMANIDADES (HISTORIA) de la alumna MARTHA ORTEGA SOTO, matrícula 208381541, quien cumplió con los 360 créditos correspondientes a las unidades de enseñanza aprendizaje del plan de estudio. Con fecha seis de noviembre del 2014 presentó la DEFENSA de su DISERTACIÓN PÚBLICA CuYa denominación es:

ORIGEN DE UN IMPERIO: COMO EL ESTADO RUSO LLEGO A LA CUENCA DEL PACIFICO.

Cabe mencionar que la aprobación tiene un valor de 90 créditos y el programa consta de 450 créditos.

El jurado del examen ha tenido a bien otorgarle la calificación de:

$$
\text { Aprobar }
$$

JURADO

Presidente

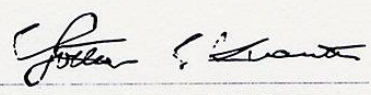

DR. LOTHAR GUNTHER FRANZ KNAUTH MÜHLING

Vocal

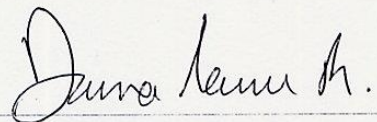

DRA. DANNA ALEXANDRA LEVIN ROJO
Secretaria

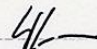

DRA. SILVIA PAPPE WILLENEGGER

vocal

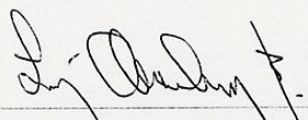

DR. LUIS AARAHAM BARANDICA MARTINEZ

Coordinación de Sistemas Escolares

Av. San Rafael Atlixco 186. Col.,Vicentina, México, D.F. C.P. 09340 Tels. 5804-4880 y 5804-4883 csera@xanum.uam.mx www,izt.uam.mx 
A mi Papá quien siempre confió en mí. 


\section{AGRADECIMIENTOS}

La Historia es una diciplina que requiere un gran cúmulo de información y exige la capacidad de procesarla y analizarla. Cultivarla, invita al trabajo en conjunto tanto para allegarse datos como para discutir el análisis de los procesos. A lo largo de mi carrera he recibido múltiples enseñanzas de mis maestros, mis colegas y mis alumnos, a todos ellos mi reconocimiento.Agradezco especialmente la formación que recibí de dos maestros que han dejado una huella muy honda en mi comprensión y análisis de la Historia: en primer lugar, el Dr. Lothar Knauth Mülingh quien se ha ocupado de mi formación desde que inicié la Licenciatura en Historia hasta el día de hoy. Al Dr. Serigo Ortega Noriega, con quien aprendí Historia regional y también me enseñó a trabajar en equipo.

Desde que egresé de la Licenciatura de Historia, el trabajo en equipo me ha impulsado en todos los proyectos que he emprendido. El primer equipo en el que participé fue el Seminario de Relaciones Transpacíficas de la Facultad de Filosfía y Letras de la Universidad Autónoma de México (UNAM) bajo la dirección del Dr. Knauth. Poco después me sumé al Seminario de Historia del Noroeste de México, en el Instituto de Investigaciones Históricas de la UNAM que co-dirigía el Dr. Sergio Ortega Noriega. Estas experiencias fueron decisivas cuando me incorporé como profesora-investigadora la la Universidad Autónoma Metropolitana, unidad Iztapalapa donde, desde el principio y hasta 
la actualidad, he formado diferentes grupos de trabajo siempre con el Dr. Federico Lazarín Miranda. Muchos colegas dentro y fuera de la UAM Iztapalapa han trabajado con nosotros.

Los compañeros de los Seminarios de Historia Mundial y de Historia de la Ciencia que coordinamos el Dr. Lazarín y yo, han sido determinantes para la realización de esta investigación. Gracias a la Dra. Blanca García Gutiérrez, al Mtro. Hugo Pichardo Herández, al Dr. Luis Abraham Barandica Martínez, a la siempre ingeniosa Lic. Teresa Pacho Rodríguez y a los alumnos/colegas Andrea Torres Alejo y Tadeo H. Liceaga Carrasco.

No sólo he encontrado colegas en Iztapalapa, también agradezco todo el apoyo del Área de Historia e Historiografía de la UAM Azcapotzalco, especialmente a la Dra. Danna A. Levin Rojo, a la Dra. Silvia Pappe y a la Mtra. Carmen I. Valdés Vega. Tampoco puedo dejar de mencionar las discusiones y el trabajo compartido con la Dra. Lucila del Carmen León Velasco del Instituto de Investigaciones Históricas, de la Universidad Autónoma de Baja California.

También les agradezco a mis alumnos, a quienes no me es posible mencionar uno a uno, pero que a lo largo de mi carrera me han nutrido día con día con sus preguntas, comentarios, críticas y apoyo.

Por último, de todo corazón, le agradezco a mi hija María del Carmen, su presencia. Ser su mamá es el mayor reto de mi vida frente al cual cualquier empresa de investigación, como la presente, representa una meta sencilla de alcanzar. 


\section{ÍNDICE}

\section{INTRODUCCIÓN}
A propósito de las fuentes
Datos calendáricos

\section{CAPÍTULO I. EL ORIGEN DEL ESTADO RUSO}

\subsection{El espacio \\ Los ríos}

1.2 Los primeros habitantes

El idioma eslavo

1.3 Los eslavos del este

CAPÍTULO II. LA RUS DE KIEV (siglo IX-c. 1230)

2.1 Kiev, primer estado de los eslavos del este 
2.2 La decadencia de Kiev. Periodo de fragmentación

2.3 El noreste de la Rus

CAPÍTULO III. LA RUS BAJO EL DOMINIO MONGOL ( $c$.

1230- c.1300)

3.1 La Rus como parte del Janato Kipchak

3.1.1 Viajeros y emisarios

3.1.2 La frontera occidental

3.2 El reacomodo socioeconómico

Monasterios

\section{CAPÍTULO IV. DEL ASCENSO DE MOSCOVIA A LA TERCERA ROMA (c.1300-1584)}

4.1 Moscovia: la ofensiva contra los mongoles y los principados rusos.

El papel de la iglesia ortodoxa

4.2 La unificación de todas las Rusias.

4.2.1 Política y gobierno

4.2.1.1 Una iglesia ruso-ortodoxa

4.2.1.2 La burocracia

4.2.1.3 Codificación jurídica

4.2.2 Las transformaciones socioeconómicas

4.2.3 Los cosacos

4.3 Incursiones allende los Urales y la conquista del janato de Sibir 


\section{CAPÍTULO V. LA INSTAURACIÓN DE LA DINASTÍA ROMANOV (1584-1676)}

5.1 La época de las tribulaciones: crisis dinástica

5.2 La agricultura

5.3 Manufactura y comercio

CAPÍTULO VI. LA EXPANSIÓN HACIA EL ESTE POR EL NORTE DE ASIA

6.1 Exploración y explotación

6.1.1Instancias administrativas

6.1.2 Exploración y establecimientos rusos

6.1.3 Emprendedores y campesinos

6.2 Interrelaciones con los pueblos del norte de Asia

6.2.1 Los habitantes de Siberia

6.2.2 El proceso intercultural en Siberia

6.3 La llegada al norte del Pacífico

CONCLUSIONES

APÉNDICES

ÍNDICE DE MAPAS

BIBLIOGRFÍA 


\section{INTRODUCCIÓN}

El objetivo de esta tesis es reconstruir la integración de la sociedad y la organización del

Estado rusos que sentaron las bases para la expansión sobre el norte de Asia hasta llegar a la cuenca del Pacífico. La investigación llevó mucho tiempo, así como como prolongado fue el proceso desde la aparición de una entidad cultural que se autodenominaba rod raíz que dio origen a la palabra rusa narod que significa pueblo ${ }^{1}$. De hecho, Rusia en ruso se escribe Rossiya. Los documentos bizantinos y musulmanes se refieren a ellos como ros o rus $^{2}$. Es probable que las comunidades finesas designaran a los navegantes vikingos que llegaron por el golfo de Finlandia en el siglo VI como rus, palabra que en su idioma significa "hombres que venían del mar"3. Al parecer el gentilicio se aplicó después a los grupos de vikingos, eslavos, fineses y bálticos y, finalmente, a los eslavos del este. Por tanto, existen dos teorías plausibles del origen del gentilicio ruso. En cualquier caso los ros o rus formaron un Estado, después éste se fragmentó en diversas entidades cuyos habitantes también se consideraban rus y se referían a los territorios que ocupaban como la tierra rusa. La escisión de los rus o eslavos del este en tres comunidades diferentes ocurrió durante el periodo de la conquista mongola. Aquellos que quedaron bajo el dominio mongol empezaron a denominarse rusos. Cuando ocurrió el proceso de unificación bajo el principado de Moscovia, cada una de estas entidades fue considerada como una parte de Rusia, de ahí que se enunciara la unificación de todas las Rusias. Al centralizarse el poder,

\footnotetext{
${ }^{1}$ Manfred Hellmann (1912-1992), C. Goehrke, P. Schubert, et al., Rusia. Trad. María Noela. Madrid, Siglo XXI, 1975. 370 p., mapas. (Historia Universal Siglo Veintiuno, 31), p. 24; Preobrazhensky, A. G. (18861937), Etymological Dictionary of the Russian Language. Nueva York, Columbia University Press, 1951. 416/144 pp., pp. 208-209.

${ }^{2}$ Más adelante se analizarán estas fuentes; Rus es un término de origen turco que pasó al finés del cual fue transmitido al eslavo. Significa navegar y navegante, al parecer así se llamaban a sí mismos los eslavos Preobrazhensky, op. cit., p. 226.

${ }^{3}$ Peter Heather (1960-), Emperadores y bárbaros. El primer milenio de la historia de Europa. Trad. Teófilo de Lozoya y Juan Rabasseda-Gascón. Barcelona, Critica, 2010, (Serie mayor), pp. 533-534.
} 
en breve, el gobernante se denominó zar de Rusia. Al continuar la expansión territorial se formó el Estado imperial ruso. Una de las paradojas que tuvo lugar en este proceso expansivo consistió en que las migraciones mediante las cuales se añadieron nuevos territorios al Estado, fueron más numerosas precisamente en los momentos de graves crisis políticas. La solución a éstas produjo el fortalecimiento del Estado ruso. La heredera de esta historia es la actual República Federada Rusa que comprende una parte del territorio de Europa del este y del norte de Asia. En esta tesis reconstruir y analizar el origen de la sociedad y el Estado rusos constituyó el paso indispensable para explicar cómo fue posible que, en un momento de la historia, el imperio abarcara desde Europa oriental hasta la costa del noreste de Asia que baña el océano Pacífico y que los pueblos que habitan ese territorio tan extenso, pese a los cambios culturales ocurridos como consecuencia de la convivencia, hayan conservado en parte sus costumbres y tradiciones pero también se consideren rusos. Desde luego, se incluyen aquellas comunidades que desaparecieron en el curso de este proceso, pues ellas también contribuyeron a forjar al pueblo y al Estado ruso.

Construir mi objeto de investigación significó un proceso intelectual largo. Cuando estudiaba la licenciatura en Historia, se despertaron en mí dos intereses: estudiar la historia de Europa oriental, esa parte del continente tan poco tratada en los cursos de Historia Universal e incluso en los de Historia de Europa. Consideraba importante comprender la capacidad de sobrevivencia de los pueblos eslavos, que a lo largo de su historia tuvieron experiencias de independencia y autonomía pero también de sujeción a Estados más fuertes que los suyos y, más aún, que enfrentaron políticas de integración cultural y, no obstante, han mantenido sus costumbres particulares hasta el presente. Juzgaba que estudiar esa historia me llevaría a descubrir y analizar los mecanismos por los cuáles una comunidad 
conserva sus tradiciones y costumbres aunque haya formado parte de Estados multiétnicos ${ }^{4}$. Bajo esta perspectiva enfocar mi atención en el imperio ruso resultó aún más atractivo ya que, según mi visión inicial, esos eslavos, a diferencia de sus vecinos, crearon un Estado lo suficientemente poderoso como para expandirse y colonizar a otros pueblos en Europa y Asia, encabezando, a su vez, un Estado multiétnico.

El otro interés era enfocar mis esfuerzos a investigar sobre la historia de la conquista y colonización de América. No me inclinaba por estudiar el caso del centro de la Nueva España pues hay muchos historiadores en México capaces de reconstruir y explicar esta historia. Sin embargo, descubrí que las llamadas Provincias Internas recibían poca atención por parte de mis colegas. Así, empecé a adentrarme en la investigación en este campo.

De inmediato, con la ayuda de mi preceptor, Lothar Knauth, encontré un tema que satisfacía ambos intereses: la colonización rusa en América. Indagar sobre él no ha sido tarea sencilla porque he tenido muy pocos interlocutores en mi medio académico, sin embargo, sigue siendo un problema de análisis histórico recurrente en mi trabajo, aunque no he podido dedicarle el tiempo y los recursos que hubiera deseado. Por fin, decidí hacer una investigación sistemática sobre el tema que me permitiera, al mismo tiempo, graduarme como doctora en historia. De esta manera, revisé la información reunida para reconstruir el proceso que dio por resultado la llegada de los rusos a las costas americanas y la historia que protagonizaron éstos y los nativos americanos.

\footnotetext{
4 Concepto elaborado por Otto Bauer (1881-1938) en su libro Die Natiohalitätenfrage und die Sozialdemokratie (1924) para analizar la historia de Europa central y oriental en http://www.iisg.ne/archives/en/files/b/ARCH00026full.php\#N10CB9 consultado 1 de mayo de 2013.
} 
Durante mucho tiempo, centré mi atención en los aleutianos, los inuit de Alaska y los tinglit con quienes se interrelacionaron los rusos, y en las expediciones de descubrimiento y conquista. Poco a poco, las fuentes consultadas me indicaron que no podía prescindir de analizar cómo habían llegado los rusos al norte del Pacífico pues en los primeros contactos éstos comparaban a los nativos americanos con los habitantes de Kamchatka en particular y con otros pueblos de la taiga y la tundra asiáticas, en general. Como muestra basta mencionar que el nombre que los rusos les dieron a los habitantes de las islas aleutianas, es decir, aleutianos, derivó del parecido que les encontraron con los teleuty ${ }^{5}$, un pueblo mongol que habitaba el norte de Asia. Además, en gran medida gracias a la información que les dieron los nativos de la península de Chukota los rusos supieron de las tierras habitadas al otro lado del mar en dirección al este.

Así, fue necesario investigar acerca de la expansión rusa en Asia. Pronto comprendí que las redes tejidas por los emprendedores -comerciantes, cazadores e inversionistas- rusos en el norte de Asia fueron la plataforma desde la cual incursionaron en América y realizaron sus operaciones, no sólo comerciales sino de colonización. Al acercarme a la historia del norte de Asia como parte del imperio ruso, saltó a la vista un asunto que era indispensable escudriñar: la expansión rusa en dirección al este ¿Fue un proyecto autónomo del Estado ruso o no?

Una respuesta afirmativa me conducía a desentrañar la organización del Estado y cómo había sido capaz de promover la ocupación e integración de tan vasto territorio. La

\footnotetext{
${ }^{5}$ P.A. Tikhmenev (i-1888), A History of the Russian-American Company. Trad. y ed. Richard A. Pierce y Alton S. Donnelly. Seattle y London, Prensa de la Universidad de Washington, 1978. 552 pp., ils., mapas, p. 402
} 
respuesta negativa implicaba entonces establecer qué grupos y con qué intereses habían realizado tal empresa.

La reflexión sobre el asunto, me llevó a plantear que la ocupación del norte del continente asiático, así como la del noroeste de América tuvo ambos componentes: el de la participación de tramperos, cazadores comerciantes, cosacos, agricultores, en fin, una gran variedad de miembros de distintos grupos sociales rusos; pero que sin la protección y la administración del Estado esta empresa no hubiera dado por resultado la integración del territorio asiático y, por una época, de una porción del noroeste americano, al imperio ruso. Cuando investigué acerca de la construcción del Estado ruso me encontré con un problema más: ¿quiénes son los rusos? Desde un principio fue evidente que quienes en un principio se autodenominaron rusos eran producto de la integración de diversos pueblos, es decir, la etnogénesis ${ }^{6}$ del pueblo ruso implicó la participación de varios pueblos que convivían en un mismo territorio. Este conglomerado de grupos humanos que paulatinamente se fusionaron, al mismo tiempo recibieron influencias de otros pueblos hasta que en un momento de su historia se distinguieron a sí mismos de otros, llamándose rusos y a su territorio Rusia, en otras palabras esta comunidad cobró certeza de su especificidad. Ésta se definió en contraste con otros que se concebían como diferentes, es decir, a partir de la alteridad

...definimos a la alteridad como el producto de una situación sociohistórica que ha ubicado a un sujeto cognoscente absoluto en un lugar coincidente con un centro político, económico y cultural particular, por lo que los otros a los que se refieren en términos relacionales, son conceptualizados en dos sentidos. Primero, porque ha sido materialmente reconocido u objetivamente integrado a una historia que lo ha transformado. Segundo, porque su categorización ha estado sujeta a la categorización del nosotros. De esta forma, más allá de que sean o no diferentes formaciones

\footnotetext{
${ }^{6}$ Walter Pohl (1954-), "Conceptions of Ethnicity in Early Medieval Studies” en Lester K. Little y Barbara H. Rosenwein, Debating the Middle Ages: Issues and Readings, [s. 1.], Blackwell Publishers, 1998, pp. 13-24 consultado en http://www.kroraina.com/bulgar/pohl_etnoicity.html 16 de septiembre de 2011.Para la explicación de este concepto con base en el autor citado véase el capítulo I. La tesis en su conjunto se refiere a la construcción histórica del pueblo ruso.
} 
culturales específicas, son las prácticas propiamente dichas y la representaciones mentales de ese otro las que han quedado irremediablemente sumidos en esa alteridad diferente frente una identidad ${ }^{7}$.

Esta tesis es el resultado de muchas de mis incursiones en archivos, bibliotecas y, en los últimos años, la internet. En vista de lo complejo y dilatado del proceso histórico estudiado, decidí limitarme a exponer el origen y desarrollo del pueblo y del Estado ruso y concluir con la ocupación, conquista y colonización de la franja norte de Asia. Pero la razón más importante por la que la tesis se centra en este segmento de la historia es porque el último problema que descubrí cuando inicié el doctorado consiste en que los rusos también incluyen a la población de Siberia.

Lo ruso parece tan difuso que es fundamental comprender cómo ha ocurrido esta construcción histórica de manera que incluya una comunidad multinacional ${ }^{8}$, intercultural y transcultural. El concepto intercultural

...se refiera a las interacciones sociales y a las prácticas y representaciones que se generan a partir de las relaciones de convivencia social y cultural. Estas se expresan a través de formas de integración y respeto de las diferencias culturales o a través de modos de comportamientos violentos y/o discriminativos respecto de un grupo social, etnia, clase o género, anteriores e independientes de las decisiones modernas de promoverlas, por lo que nos preguntamos sobre el espesor de su historicidad. Desde nuestra perspectiva, esto supone la especial relevancia por comprender las formas primarias en

\footnotetext{
${ }^{7}$ Algunos conceptos manejados en esta tesis se han tomado de José Miguel Hernán Zepeda [no se encontraron datos], "Los inkas frente al problema de la interculturalidad. Una introducción al estudio de la configuración del Tawantisuyu en contextos de diversidad étnica y cultural. Siglos XIV-XVI" en Antítesis, vol. 3. N.5, enero-junio de 2010. Http://www.uel.br/revistas/uel/index.php/antítesis, consultado en julio de 2010. En este artículo se encontraron procesos históricos muy semejantes en la construcción del Tawantisuyu y en la del imperio ruso hasta el periodo que abarca esta investigación porque en ambos casos nos referimos a imperios tradicionales con base agrícola en los que no había un proyecto de homogenizar a los pueblos que los integraban. pp.19-20. En cuanto al fenómeno de la identidad, se tratará en el capítulo I, apartado El idioma eslavo en donde se explicará cómo se construyó en el caso objeto de análisis.

${ }^{8}$ En esta investigación el término nación se utiliza de acuerdo con el castellano de la época en la que una nación no implicaba la existencia de un Estado: "Nación del nombre latino natío. Is. Vale Rey, o provincia estedida [extendida]..." en Tesoro de la lengua castellana o española. Compuesto por el licenciado Don Sebastian de Cobarruvias Orozco, Capellan de Su Magestad, Maestreescuela y Canonigo de la Santa Iglesia de Cuenca, y consultor del Santo Oficio de la Inquisicion. Dirigido a la Magestad Católica del Rey Don Felipe III nuestro señor con Pivilegio, por Luis Sanchez,impresor del Rey N. S. año del Señor MDCXI. 1403 pp. en Http://www.fondosdigitales.us.es/fondos/libros/765/1158/tesoro-de-la-lengua-castellana-o-española consultado 13 de agosto de 2013.
} 
que los distintos grupos humanos han interactuado a través de diferentes patrones relacionales, pensando que dichos fenómenos no son 'nuevos', o por lo menos, pueden leerse a través del paso de las sociedades desde una clave que contemple los problemas del poder, las identidades y las alteridades ${ }^{9}$.

En cuanto al concepto de transculturación se utiliza de acuerdo con la definición de su creador Fernando Ortiz:

Entendemos que el vocablo transculturación expresa mejor las diferentes fases del proceso transitivo de una cultura a otra, porque éste no consiste solamente en adquirir una distinta cultura, que es lo que en rigor indica la voz anglo-americana aculturation, sino que el proceso implica también necesariamente la pérdida o desarraigo de una cultura precedente, lo que pudiera decirse una parcial desculturación, y, además, significa la consiguiente creación de nuevos fenómenos culturales que pudieran denominarse de neoculturación. Al fin, como bien sostiene la escuela de Malinowski, en todo abrazo de culturas sucede lo que en la cópula genética de los individuos: la criatura siempre tiene algo de ambos progenitores, pero también siempre es distinta de cada uno de los dos. En conjunto, el proceso es una transculturación, y este vocablo comprende todas las fases de su parábola ${ }^{10}$.

Los resultados que aquí presento ya me han planteado nuevos problemas de investigación sobre Rusia y aun nuevos enfoques para analizar la colonización rusa en América.

Así pues esta tesis inicia con la exposición sistematizada de los datos que se han encontrado sobre los primeros habitantes de lo que hoy se denomina la Rusia europea y concluye con el descubrimiento y la exploración de las penínsulas de Chukota y Kamchatka durante el gobierno del zar Aleksei (1645-1676).

Este corte temporal se justifica por dos razones: la primera porque fue durante su gobierno cuando los rusos llegaron a la costa del Pacífico. La segunda porque en ese periodo se consolida la autocracia rusa con la dinastía Romanov ${ }^{11}$. Los fenómenos de

\footnotetext{
9 Hernán, op. cit., p. 4

10 Ortiz, Fernando, (1881-1969) Contrapunteo cubano del tabaco y el azúcar. Prolg. y cronología Julio le Riverend. Caracas, Biblioteca Ayacucho, [1978]. 600 pp., ils., pp. 96-97

${ }^{11}$ La periodización de la historia rusa, como muchos otros problemas de la historia en general, sigue debatiéndose. Para el tema de la tesis este corte parece el más adecuado sin que por ello se suponga que los procesos ulteriores estuvieron desarticulados de los que les precedieron e inician un proceso sin continuidades. Para un acercamiento a los problemas de periodización en la historia rusa vid., Nancy S. Kollmann, [Actualmente profesora en el Departamento de Historia de la Universidad de Stanford] "Comment:
} 
apropiación territorial y colonización implican en primer lugar movimientos migratorios que provocan interrelaciones entre las sociedades emisoras y los que habitan en el punto de llegada de los primeros, es decir, los pueblos y territorios receptores.

A partir de ese momento ocurre el fenómeno de interculturalidad, relación que da lugar a un forcejeo cuyo resultado puede concretarse en la expulsión de los migrantes, el mestizaje con los nativos y la subyugación de éstos; asimismo es posible que algunos pueblos sean absorbidos de tal manera que desaparecen, aunque siempre queda algún rastro de ellos. En cualquier caso, la convivencia entre diferentes comunidades da pie a una influencia mutua, casi siempre asimétrica, la cual produce transformaciones culturales recíprocas a pesar de que los grupos humanos preserven rasgos culturales diferentes.

En estos casos se aprecia la emergencia de sociedades multiétnicas y multiculturales en las que se siguen desarrollando fenómenos de interculturalidad. ¿Cuáles fueron los motivos por los que diversos pueblos que habitaban el extremo oriental de Europa y el norte de Asia establecieron relaciones entre sí y cómo lo hicieron? Ésas son las preguntas que me propuse contestar en esta investigación, para ofrecer una explicación sobre cómo se integró el imperio ruso que se extendió hasta el Pacífico.

Para responder a estas preguntas, se caracterizó a cada uno de los actores que participaron en el proceso siempre tomando en cuenta que ningún pueblo es homogéneo. Por ello, se presenta una descripción de las comunidades que participaron en esta historia y de las estructuras sociales que tenían tan detallada como las fuentes lo permitieron. Considero que logré el objetivo de esclarecer quiénes lograron avanzar desde la Rusia

Divides and Ends-The Problem of Periodization"en Slavic Review, Vol. 69, No. 2 verano de 2010, pp. 439447 en http://www.jstor.org/stable/25677107, consultado 1 de noviembre de 2012. 
europea hasta la costa noroccidental del Pacífico, cómo lo hicieron y el papel que desempeñaron los pueblos que se encontraron en periodos diferentes desde el extremo nororiental de Europa hasta el noreste de Asia. De manera paralela se ha reflexionado sobre las características del pueblo ruso, de lo ruso.

Vale la pena destacar que el espacio en el que ocurrieron los procesos que se analizan continúa formando una sola entidad en la actualidad. En efecto, la República Federada Rusa incluye en sus territorios un segmento nororiental de Europa y el norte de Asia, pero su antecesora, la Unión de Repúblicas Socialistas Soviéticas (URSS) (19181991) logró recuperar la mayor parte de los territorios que habían formado el imperio ruso, al finalizar la Gran Guerra Patria (1941-1945). En la actualidad, la República Federada Rusa ejerce su influencia sobre los Estados que se formaron como consecuencia de la caída de la URSS principalmente en Asia; en Europa oriental la mayoría están integrados a la Unión Europea (1993-) y a la Organización del Atlántico Norte (1949-). Sin embargo, no han logrado sustraerse por completo a la influencia rusa. En el mapa 1 se muestra la extensión territorial de la URSS, en él puede distinguirse claramente el territorio que integra a la República Federada Rusa. 
Mapa 1. La URSS en 1991

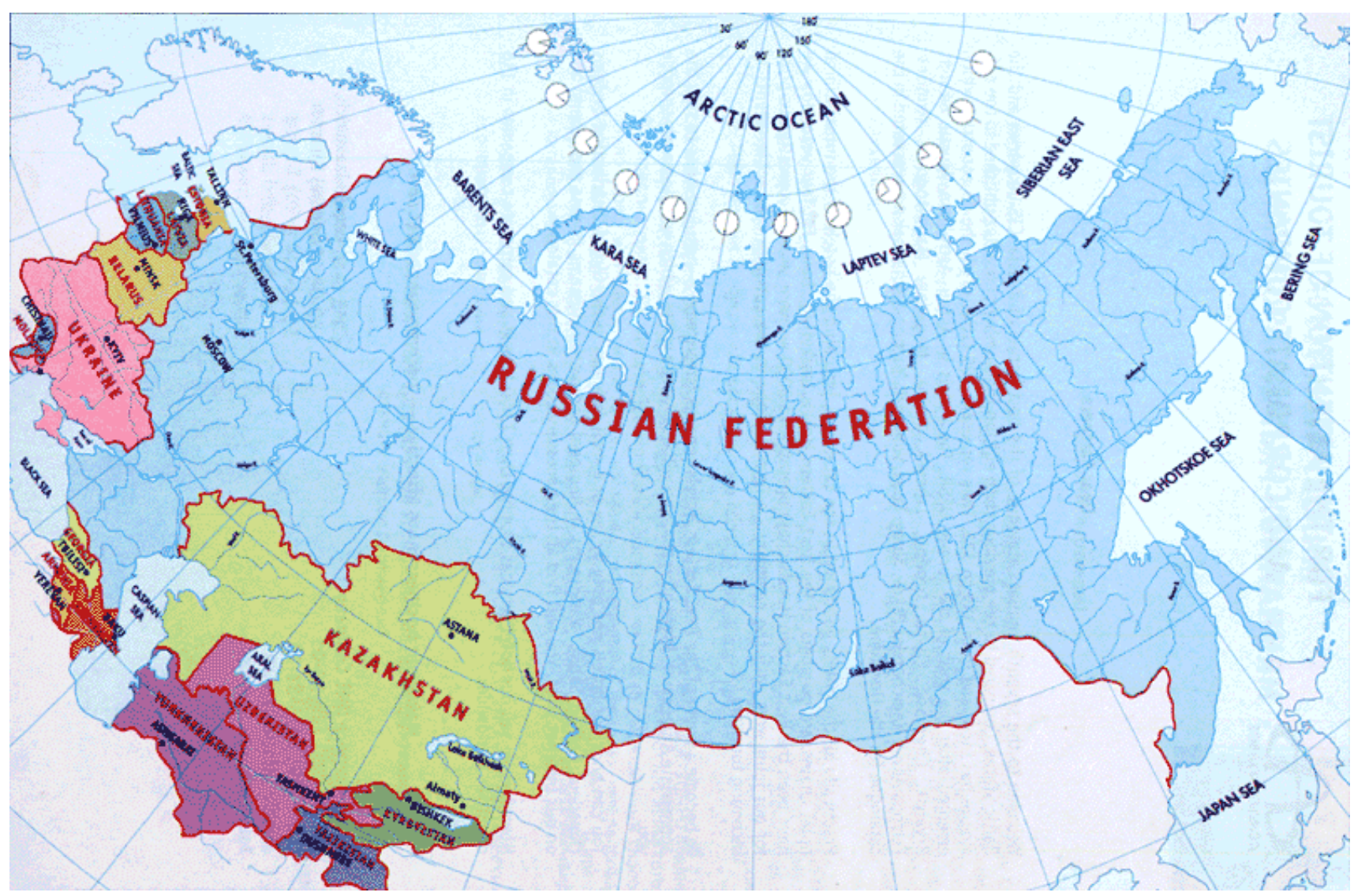

Fuente: www.todoatlas.com/union-sovietica.html consultado 7 de junio de 2014

\section{A propósito de las fuentes}

Cuando visité los archivos rusos en 1988 y 1996 mi objetivo era estudiar sólo la expansión rusa en América. Debido a ello esta investigación tuvo que apoyarse en la bibliografía que encontré en México sobre el tema y en las fuentes primarias y secundarias a las que pude acceder vía internet o adquiriéndolas en el extranjero. Las fuentes primarias tienen ediciones recientes protegidas por derechos de autor así que, en la mayoría de los casos, se recurrió a ediciones de finales del siglo XIX o principios del XX muchas de ellas traducidas al ruso moderno -ya fuera el ruso escrito de acuerdo con la reforma de Pedro el Grande 
(1672-1722) o con la soviética (1918)- o al inglés, pues los originales fueron escritos en griego, eslavo antiguo o cualquier otra lengua utilizada en la Edad Media. La fuente más antigua y mejor conocida que menciona a los eslavos es el texto de Jordanes el godo (vivió en el siglo VI sin que se conozcan sus fechas de nacimiento y muerte). Jordanes era funcionario en la administración del imperio romano de oriente, escribió su texto a petición de otro funcionario que deseaba conocer mejor la historia de los godos ${ }^{12}$.

Cuando Ucrania oriental fue incorporada al imperio ruso (siglo XVII), parte de los monjes cristiano-ortodoxos emigraron de Kiev a Moscú y difundieron el estudio del griego y el eslavónico antiguo. En 1682, se fundó la Academia de Eslavo, Griego y Latín, ahí iniciaron los estudios sobre el idioma ruso y se formaron filólogos y traductores. Podemos considerar que fue entonces cuando inició el rescate y la traducción al ruso de fuentes escritas en griego y eslavónico antiguo aunque su objetivo principal fuera la investigación teológica ${ }^{13}$. Las crónicas más antiguas que se refieren a la historia del pueblo ruso fueron escritas en eslavónico antiguo por monjes de la iglesia ortodoxa o en griego por funcionarios del imperio bizantino. Estas crónicas intentaban reconstruir la historia de los rusos desde sus orígenes hasta el momento en que fueron redactadas; las explicaciones o juicios que emiten son de carácter religioso o político para exaltar a Dios, a los príncipes de Moscovia y más tarde a los zares. Este tipo de crónicas se utilizaron en la tesis.

En cuanto a los textos escritos en árabe y otros idiomas utilizados por los musulmanes, Vasili V. Bartlod (1869-1930) fue el primer historiador ruso en especializarse

${ }^{12}$ Vid. The Gothic History of Jordanes in English version with an introduction and commentary by C. C. Mierow. Princeton, Princeton University Press, 1915.188 pp. en http://openlibrary.org/books/OL7152708M/the gothic history of Jordanes consultado 12 de octubre de 2012.

13 http://www.es.wikipedia.org/wiki/Filología, $\quad$ http://es.wikipedia.org/wiki/Idioma_ruso $\quad$ y http://www.en.wikipedia.org/wiki/Slavic_Greek_Latin_Academy consultados el 7 de junio de 2014. 
en la turcología. Él rescató por vez primera la información de los árabes sobre la Rus de Kiev y la tradujo al ruso. Asimismo escribió la primera historia sobre el Turquestán en la época del imperio mongol, así como sobre el "orientalismo" en Rusia y el resto de Europa $^{14}$. Desde entonces se ha desarrollado una escuela rusa sobre los pueblos musulmanes y la relación histórica que tuvieron y tienen con Rusia.

Uno de los retos al utilizar las crónicas consiste en que las fuentes fueron escritas por individuos que pertenecían a una cultura diferente a la cual describían. Para el periodo previo a la utilización de la escritura, las únicas fuentes escritas sobre los eslavos no las produjeron ellos. Las pocas fuentes con las que se cuenta o las redactaron los musulmanes o los bizantinos; las runas nórdicas ofrecen muy pocos datos sobre este tema ${ }^{15}$. Por tanto, las descripciones que existen sobre los eslavos del este, los fineses, los bálticos y los escandinavos que habitaban la Rus están hechas por personajes que partieron del supuesto de que estos pueblos tenían una cultura inferior a la propia, sus costumbres les parecían poco refinadas pero lo más importante: eran infieles.

Tanto los musulmanes como los bizantinos profesaban una religión monoteísta y estaban ciertos de que la Revelación divina los ponía por encima de cualquier otro pueblo que no conociera al único y verdadero Dios. El lugar social desde donde escribieron los autores musulmanes y bizantinos los inducía a menospreciar y tal vez por esa misma razón a tergiversar y no comprender la cultura de los pueblos que no profesaban alguna religión de El Libro. No obstante, no se debe prescindir de ellas porque a pesar de todo las

14 http://www.es.wikipedia.org/wiki/Vasily_Bartold consultado 7 de junio de 2014; https://openlibrary.org/...Vasiii_Vladimirovich_Bartold... Consultado 7 de junio de 2014; véase el capítulo I, apartado 1.3.

15 "Runic Inscriptions on Viking Stellae in Western Europe (Eleventh Century)" en Daniel H. Kaiser [Ph D University of Chicago, 1977] y Gary Marker [Ph D, Barkeley University, 1977] (comps.), Reinterpreting Russian History. Readings, 860-1860s. Nueva York, Oxford, Oxford University Press, 1994. 446 pp., p. 13 
representaciones que fijaron de los pueblos con quienes se relacionaban fueron elaboradas también a partir de las prácticas que observaron, algunas de las cuales hasta adoptaron, por tanto, estas fuentes proporcionan evidencias de las culturas que describieron.

La crónica más antigua escrita en el eslavo que decantaría en el ruso es La primera crónica rusa (Povest' vremennyj let ${ }^{16}$, fue redactada a fines del siglo XI o en las primeras décadas del XII, es decir, tiempo después de los sucesos que consigna. Esto es así porque los habitantes de Kiev adoptaron la escritura en el siglo X cuando la evangelización cristiana ortodoxa tuvo lugar. En efecto, el alfabeto galgolítico que Cirilo (827-869) y Metodio (815-885) emplearon para escribir el eslavónico, fue adaptado por un misionero búlgaro, probablemente por Clemente de Ohrid (n. c. 840) apoyado en los caracteres griegos, coptos y hebreos para escribir las lenguas eslavas. El primer idioma eslavo que se escribió con el alfabeto cirílico fue el búlgaro ${ }^{17}$. Fue esta escritura la que los monjes ortodoxos emplearon para escribir otros idiomas afines, en este caso el ruso antiguo. Por lo tanto, esta crónica recogió la tradición oral que los propios habitantes de la Rus tenían sobre la fundación de su Estado condimentada con la interpretación cristiana de los monjes que la redactaron. A pesar de que este documento sea tardío, permite conocer la versión que los

\footnotetext{
${ }^{16}$ En un primer momento sólo logré acceder a fragmentos de este documento a través del internet, la crónica completa puede consultarse en línea en la siguiente dirección http://clover.slavic.pitt.edu/pvl/ost1.html, The Russian Primary Chronicle. Laurentian Text. Ed. y trad. Samuel Hazzard Cross (1891-1946) y Olgerde P. Sherbowizt-Wetzor, Cambridge, Massachusettrs, The Medieval Academy of America, [2013]. 340 pp. (The Medieval Academy of America Publication No. 60). También me apoyé en una selección transcrita al ruso contemporáneo y en otra traducida al inglés, las referencias exactas las citaré en su oportunidad. Cito la página que me permitió tener un panorama de las crónicas más antiguas sobre la historia rusa. Daniel C. Waugh (PhD 1972), $\quad$ Primary $\quad$ Sources, $2002-2004 . \quad 3$ pp. http://faculty.washington.edu/dwaugh/rus/rusprim.html consultado 28 de septiembre de 2011 y en las compilaciones de Serge A. Zenkovsky (1907-1990), (ed., trad., introd.), Medieval Russia's Epics, Chronicles and Tales. Estados Unidos, A Meredian Book, [1974]. 526 pp., ils. y mapa y Kaiser y Marker op. cit.. Finalmente conseguí la crónica completa en una reimpresión de la traducción de Cross y Sherbowizt-Wetzor, op.cit., de 2013 del documento conocido como códice Laurentino, copia elaborada en 1377 para el príncipe de Suzdal por un monje de nombre Lorenzo. Además de este texto se cuenta con el códice Hypatian pues fue descubierto en el monasterio del mismo nombre localizado en Kostroma. Esta última copia data de 1425.

${ }^{17}$ http://www.es.wikipedia.org/wiki/Alfabeto_cirílico consultado 21 de junio de 2014.
} 
príncipes de la Rus y los monjes tenían sobre su historia y, contrastando sus datos con los aportados por las investigaciones arqueológicas sobre los asentamientos humanos antiguos en el territorio de lo que hoy es Rusia iniciadas desde el siglo XX, intentar comprender cómo nació la sociedad rusa y el primer Estado ruso.

La primera crónica es considerada una fuente para la historia del primer Estado que dio origen a la Rusia actual por la historiografía rusa. Una vez que se independizó la república de Ucrania del Estado soviético en 1991, los ucranianos también la consideran como la fuente más antigua que da cuenta de la formación inicial de su propio Estado. En efecto, ellos se han esforzado por reconstruir su propia historia para legitimar su Estado nacional. Dado que el texto se refiere a la historia de Kiev, actual capital de Ucrania, éstos interpretan como indiscutible que la Rus de Kiev también constituye el antecedente de su propio Estado. En una traducción apegada al título que tiene La primera crónica se llama Crónica de los años antiguos (Povest' vremennyj let) y se refiere a los rus. De manera que la situación política contemporánea ha propiciado que los ucranianos, uno de los pueblos en los que se dividieron los eslavos del este, reinterpreten estos textos antiguos a la luz de la situación actual ${ }^{18}$. En este caso y ya que el objeto de estudio de esta tesis es la formación del Estado ruso, se utilizará como tradicionalmente lo ha hecho la historiografía rusa. Sin embargo, para evitar polémicas se le llamará La Primera Crónica. Esta decisión se toma porque este trabajo no está dirigido a dirimir conflictos de carácter nacionalista y, por tanto, se comprende que rusos y ucranianos comparten un pasado común. De hecho, esta investigación tiene por objeto mostrar cómo el "pueblo ruso" ha sido el resultado de la

\footnotetext{
${ }^{18}$ Barbara Skinner reseña del libro "Ukraine and Russia: Representations of the Past" por Serhii Plohy en Slavic Review, 68:3, otoño de 2009, pp. 680-681 en http://www.jstor.org/stable/25621676 consultado 1 de noviembre de 2012; Vid. http://litopys.org.ua/ consultado 19 de octubre de 2012. En esta página se puede acceder a los documentos que se consideran fuentes para la historia de Ucrania.
} 
convivencia, el intercambio cultural, la fusión y la disgregación de comunidades humanas inmersas en una gran red social y que, por ende, han compartido un pasado gracias al cual se identifican como rusos.

Como es de suponerse, la crónica aludida ha sido estudiada con mucha acuciosidad $^{19}$, hay analistas que consideran que las historias de los príncipes rus de Kiev se asemejan a las historias y leyendas sobre otros personajes de la historia medieval europea. Aunque no se han podido aclarar los canales exactos a través de los cuáles la narración de las vidas de los gobernantes fundadores de las dinastías medievales siguen patrones similares, lo que parece claro es que la similitud entre diversas crónicas es una manifestación del intercambio cultural que existió entre los pueblos de la Europa medieval.

Gran parte de las crónicas medievales se refieren a acontecimientos que ocurrieron siglos atrás del momento en que los relatos se fijaron por escrito. Los juglares (menestel') que recitaban cantos épicos en las cortes medievales seguramente recurrían a estructuras fijas para recordar los relatos. Así, la transmisión oral bien pudo propiciar que las hazañas de algunos personajes fueran atribuidas a otros de manera que, pasado el tiempo, ya no era posible distinguir los hechos de una persona particular de los de otros. En el caso de $\underline{\text { La }}$ Primera Crónica se han detectado semejanzas entre las historias de los príncipes de Kiev y las de los escandinavos, mismas que pueden explicarse debido a los estrechos vínculos entre éstos y los eslavos del este. Ahora bien, como los vikingos se expandieron tanto en la

\footnotetext{
${ }^{19}$ Vid. la introducción de Cross y Sherbowizt-Wetzor, op. cit., pp. 3-50.
} 
Rus como en otros territorios, se pueden identificar estructuras narrativas similares sobre los príncipes de otras zonas de la Europa medieval ${ }^{20}$.

A propósito de estas semejanzas, se considerará que la historia desde las migraciones eslavas hasta la unificación realizada por el principado de Moscovia constituye el periodo medieval de la Rus. Por tanto, es posible encontrar rasgos en la sociedad de los eslavos del este, que comparte con otras sociedades de Europa occidental, de manera que si bien las influencias asiáticas son claras en la formación de las estructuras políticas y en la organización social de los rus también lo son las europeas. No está por demás subrayar este punto porque definir a Rusia como una entidad euroasiática no implica inclinar la balanza en favor de lazos históricos más fuertes con los pueblos europeos o con los asiáticos ${ }^{21}$.

La copia más antigua de una crónica sobre los eslavos del este es la de La Crónica de Novgorod (Novgorodskaya perbaya letopis') ${ }^{22}$. En efecto, la copia del Sínodo que contiene el relato sobre Novgorod fue escrita en la segunda mitad del siglo XIII mientras que el Códice Laurentino, que es la copia más antigua de La primera crónica, data de 1377.

${ }^{20}$ Vid. Christian Raffensperger [actualmente profesor en la Universidad de Wittenberg], "Shared (Hi)Stories: Vladimir of Rus' and Harald Fairhair of Norway" en The Russian Review, no. 68, octubre de 2009, pp.569582 en http://onlinelibrary.wiley.com/doi/10.1111/j.1467-9434.2009.00539.x/abstract consultado 28 de septiembre de 2011; Francis Butler [PhD 1991], "A Woman of Words: Pagan Ol'ga in the Mirror of Germanic Europa" en Slavic Review, 63:4, otoño, 2004, pp. 771-793 en http://www.jsotr.org/stable/1520420 consultado 2 de noviembre de 2012.

${ }^{21}$ Russel E. Martin [actualmente profesor en Wesminster College], "The Petrine Divide and the Periodization of Early Modern Russian History" en Slavic Review, 69:2, verano 2010, pp. 410-425 en http://www.jstor.org/stable/25677105 consultado 1 de noviembre de 2012. Esta precisión es importante ya que en la arena política se han enfatizado las influencias asiáticas para justificar la existencia de un Estado centralizado dirigido con "mano de hierro"; Martin Sixsmith (1954-), Russia a 1, 000 Year Chronicle of the Wild East, Nueva York, The Overlook Press, 2012. XI/612 pp., ils., pp. IX-XX.

${ }^{22}$ The Chronicle of Novgorod 1016-1417. Trad. del ruso de Robert Michell y Nevill Forber [1883-1929]. Introd. Raymond Beazby en http://faculty.washington.edu/dwaugh/rus/texts/MF1914.pdf consultada 28 de noviembre de 2012; Paul Halsall Mar [PhD Fordham University 1999], Medieval Sourcebook: The Novogorod Chronicle: Selected Annals. 1996, 6 pp. en http://www.forham.edu/halsall/source/novgorod1.asp consultada 28 de septiembre de 2011 apud. Robert Michell and Nevill Forbes, (translators) The Chronicle of Novgorod, 1016-1417. Camden Third Series. Vol. 25. London: The Camden Society, 1914. Passim et seriatim, reimpresa en Warren Walsh, Reading in Russian History, (Syracuse NY: Syracuse University Press, 1948). 
En fechas posteriores los monjes de la iglesia de Santiago, en donde estaba el arzobispado, reelaboraron la crónica agregándole más información. En el siglo XV se hizo una última versión en Moscovia a la que le añadieron la conquista de la república de Novgorod por Iván III (1440-1505). Esta crónica fue una fuente fundamental para esta investigación.

Fragmentos de otras crónicas así como breves documentos contemporáneos a los sucesos que tratan fueron consultados en antologías y en internet. La que fue más rica para la investigación de esta tesis fue la de Serge A. Zenkovsky. En ella se encuentran textos de carácter religioso, político, poemas épicos y piezas literarias. Por ejemplo entre los poemas épicos se incluyó la Zadonshshina (Relato de los eventos más allá del Don) atribuida a Sofonii de Riazan, aunque en realidad está en discusión quién redactó el poema y cuándo, pero todo parece indicar que se escribió antes de $1390^{23}$. Esta antología reúne documentos escritos hasta la primera mitad del siglo XVII. El último que se utilizó en esta tesis fue la “Autobiografía del Arcipreste Avvakum escrita por él mismo ${ }^{24 ”}$ que es un testimonio de uno de los cabecillas del movimiento de los viejos creyentes cuando fue deportado a Siberia. Este texto se considera uno de los más completos y fidedignos escrito por un miembro de esta secta.

También se utilizaron algunos cantos épicos denominados bylinas. Estos cantos recogen la tradición oral rusa. Si bien fueron rescatados hasta el siglo XIX por Pavel Nikolaevich Rybnikov (1831-1885) ${ }^{25}$ y a pesar de que no den cuenta exacta de los acontecimientos y en ocasiones no se encuentren otras fuentes que hablen sobre algunos de

\footnotetext{
23 "Sofony of Riazan: Zadonshchina" en Zenkovsky, op. cit., doc. 38, pp. 211-223.

24 “The Life of Archiprest Avvakum by Himself” en Zenkosvsky, op. cit., pp.399-448.

${ }^{25}$ Cantos épicos rusos. Ciclo mitológico, ciclo de Kíev, ciclo de Novgorod. Introd., trad. y notas Susana Torres Prieto (doctorada en 2001). [Madrid], Edit. Gredos, 2003. 240 pp. (Biblioteca universal Gredos), pp. 7 17.
} 
los personajes cuyas proezas relatan, pueden ilustrar la memoria colectiva del pueblo ruso.

En ese sentido, es pertinente utilizarlas para conocer, al menos, aquellos sucesos que el pueblo ruso ha incorporado a su tradición para representarse su pasado. A pesar de que el paso del tiempo y la trasmisión oral han dado lugar a que se introdujeran interferencias de otros tiempos y otros sucesos, proporcionan elementos para reconstruir, en parte, el mito de origen del Estado ruso. Como apunta Bronislaw Baczko:

A lo largo de la historia, las sociedades se entregan a una invención permanente de sus propias representaciones globales, otras ideas-imágenes a través de las cuales se dan una identidad...Estas representaciones de la realidad social (y no siempre simples reflejos de ésta) inventadas y elaboradas con materiales tomados del caudal simbólico, tienen una realidad específica que reside en su misma existencia, en su impacto variable sobre las mentalidades y los comportamientos colectivos. En las múltiples funciones que ejercen en la vida social... ${ }^{26}$

El autor denomina a estas representaciones imaginarios colectivos. Las bylinas son una expresión clara de estos imaginarios que han contribuido a construir la identidad del pueblo ruso a través de su devenir histórico. Una de las bylinas más conocidas es El cantar ${\underline{\text { de la hueste de } \operatorname{Igor}^{27}}}$. Actualmente se debate la autenticidad de este manuscrito en cuanto a que haya sido redactado pocos años después del suceso que narra. Muchos filólogos consideran que el cantar fue redactado hasta finales del siglo XVIII poco antes de ser descubierto. El debate continúa ya que el lenguaje coincide con el habla medieval, sin embargo se han detectado interferencias posteriores. No obstante, auténtico o apócrifo,

\footnotetext{
${ }^{26}$ Bronislaw Baczko (1924-), Los imaginarios sociales. Memorias y esperanzas colectivas. Trad. Pablo Betesh. Buenos Aires, Ediciones Nueva Visión, 1991. 200 pp., p. 8

${ }^{27}$ Cantar de la hueste de Ígor. Trad. Antonio Contreras Martín. Madrid, Gredos, 1997. 75 pp. (Clásicos medievales). Vid. Charles J. Halperin reseña del libro "Todas las interpretaciones sobre la tierra rusa...: personajes y mentalidades rusas medievales: ensayos" (Vsego esi ispolnena zemlia russkaia... ': Lichnosti $i$ mentl'nost' russkogo srednevekov'ia: Ocherki) de Anton Anatolévich Gorskii en Russian Review, 61:4, octubre 2002, pp. 641-643 en http://www.jstor.org/stable/3664762, consultado 9 de noviembre de 2012, p. 642, la traducción del título es propia; Ireneusz Szaryez reseña del libro "Josef Dobrovský and the Origins of the Igor's Tale" por Edward L. Keenan en Slavic Review, 64:1, primavera, 2005, pp. 218-219 en http://www.jstor.org/stable/3650116 consultado 2 de noviembre de 2012.
} 
permite analizar aquello que las comunidades campesinas conservaron en su memoria colectiva sobre la actuación de los antiguos príncipes.

Prácticamente no se emplearon obras escritas en los siglos XVIII y XIX porque la mayoría de ellas se refieren a sucesos contemporáneos ya que se planteaba que la historia moderna de Rusia iniciaba con el gobierno de Pedro el Grande. También se ocuparon de rescatar crónicas medievales, algunas de ellas se emplearon en esta tesis. Por otra parte, las historias de los siglos XVIII y XIX tratan sobre los acontecimientos políticos y prestan poca atención a otros aspectos de la historia. Tampoco se enfocaban a escribir sobre los pueblos del norte de Asia que formaban parte del imperio ruso. Por tanto, la mayor parte de los artículos y libros utilizados en la investigación fueron escritos en el siglo XX o en el XXI. Sin embargo, no se debe ignorar que la intelectualidad rusa se ha dividido en torno a la percepción de la esencia de lo ruso. Ha existido una corriente, desde mediados del siglo XIX, que ha insistido en que la cultura y la historia de Rusia están más ligadas a Europa que a Asia. En efecto, la religión cristiana ortodoxa ha sido una noción cultural definitiva para la sociedad rusa y para la construcción del Estado. A pesar de que el cristianismo tuvo su origen en Asia suroccidental, la adopción de esta fe por el imperio romano le brindó a la sociedad europea un principio unificador en la Edad Media. La característica universalizante del cristianismo así como la institución eclesiástica que se creó en torno a él, aportó prácticas y creencias primordiales a la cultura europea. En estos términos Rusia no fue la excepción. El cristianismo en su vertiente ortodoxa vinculó, entre otros factores, al germen de la sociedad rusa a la tradición europea. Ya que la mayoría de los pueblos de Asia central y oriental no han profesado esta fe, una parte de la inteligencia rusa vio en el 
este de Asia, específicamente en China y Japón, un peligro para Rusia ${ }^{28}$. Esta tesis no toma una posición en esta controversia, sino que explica la formación del Estado ruso y su capacidad de expansión enlazando el papel que han desempeñado los elementos exógenos procedentes de Asia y de Europa- y los endógenos que combinados han dado por resultado la entidad que actualmente designamos como Estado y sociedad rusas.

Por otra parte, es preciso señalar que la interpretación de Rusia como un ente euroasiático se inserta en una corriente política nacida a finales del siglo XIX que postulaba a la entidad como un pueblo distinto al resto de los Estados europeos inclinada, debido a sus lazos históricos con Asia, a formar un Estado centralizado, fuerte, con un control social autoritario. Esta interpretación rechazaba la adopción del modelo democrático en Rusia debido a una tradición política derivada de su interrelación con las formas del ejercicio del poder en los Estados asiáticos. Para esta corriente conocida como Euroasiática el momento de definición del ser ruso había sido el de la dominación mongola sobre los principados de la Rus ocurrida en el siglo XIII ${ }^{29}$. La interpretación euroasiática de la historia de Rusia ha tenido un uso político recurrente, su actual presidente Vladimir Putin enarboló este discurso desde el inicio de su primer mandato en el año 2000 para justificar el establecimiento de un

\footnotetext{
${ }^{28}$ Para una visión más amplia sobre esta postura véase Susan Soojung Lim [PhD 2006, California, Davis] "Between Spiritual Self and Other: Vladimir Solov'ev and the Question of East Asia" en Slavic Review, 67:2, verano de 2008, pp. 321-341 en http://www.jstor.org/stable/2762846 consultado 1 noviembre 2012; acerca del papel desempeñado por el cristianismo en la cultura europea véase Leopold von Ranke (1795-1886), Pueblos y Estados en la historia moderna. Estudio de C.P. Gooch. Trad. Wenceslao Roces, 2a reimp., México, Fondo de Cultura Económica, 1986. 544 pp., pp. 473-480; Jacques Le Goff (1924-), La Baja Edad Media. Trad. Lourdes Ortiz. 4a ed. España, Siglo XXI, 1974. 336 pp. (Historia universal siglo veintiuno, 11), pp. 1-9; David Tablot Rice (1903-1972) (dir.), Historia de las civilizaciones 5.La Alta Edad Media. Hacia la formación de Europa. Trad. Mirela Bofill, México, Alianza Editorial/Edit. Labor, 1989. 520 pp., ils. y mapas (El libro de bolsillo, 1330), pp.486-507, entre otros.

${ }^{29}$ Vid. Charles J. Halperin [actualmente investigador en el Department of Russian and East European Institute, University of Indiana], "George Vernadsky, Eurasianism, the Mongols, and Russia" Slavic Review, 41:3, otoño, 1982, pp. 477-493 en http://www.jstor.org/stable/2497020 consultado el 3 de noviembre de 2012 y Sixsmith, op. cit., pp. VII-XI.
} 
gobierno de mano dura encabezado por él mismo ${ }^{30}$. El objetivo de esta tesis consiste en analizar cuáles han sido los factores históricos que explican la capacidad expansiva del pueblo y el Estado rusos.

Respecto de los estudios recientes, tampoco fue fácil acceder a ellos. Sin embargo, con el material que se consultó tuve las herramientas suficientes para emprender el análisis y aventurar explicaciones sobre mi objeto de estudio. Existe una producción historiográfica muy vasta sobre el origen y el desarrollo histórico del imperio ruso que desde el siglo XVII constituye uno de los Estados territoriales más extensos que han existido en la historia mundial. Por otra parte, su carácter multinacional y multicultural también ha incitado a plantear diversos enfoques analíticos para explicar su construcción y permanencia a pesar de todos los avatares que enfrentó en el siglo XX. La historiografía más abundante es la de los investigadores rusos pero les siguen muy de cerca los estadounidenses y los ingleses, estos últimos seguramente para descifrar los enigmas históricos del enemigo durante la Guerra Fría (1946-1991) y en la actualidad. Asimismo, existen estudios históricos sobre Rusia o al menos relacionados con ella prácticamente en todo el orbe ${ }^{31}$.

Uno de los problemas que se ha tratado de resolver con más insistencia es el de la “esencia" del Estado ruso. El debate se ha centrado sobre la cuestión de si la verticalidad en el ejercicio del poder que inició con la consolidación de la autocracia y continúa en la actualidad se debe a la huella histórica del imperio bizantino o del imperio mongol. Jerome

\footnotetext{
${ }^{30}$ Mark Bassin reseña del libro "Russian Eurasianismo: An Ideology of Empire" por Mischa Gabowitsch en Salvic Review, 68:4, invierno de 2009, pp. 1016-1017 en http://www.jstor.org/stable25593850 consultado 1 de noviembre de 2012.

${ }^{31}$ Véase la bibliografía al final de esta tesis.
} 
Blum $^{32}$, en cambio, planteó la hipótesis de que las características del imperio ruso a partir del siglo XVI fueron producto de la instauración de la servidumbre, institución que históricamente apareció por vez primera en Europa occidental y central. A lo largo de esta tesis se tratará sobre este debate ya que es fundamental para comprender como se formó y consolidó la autocracia rusa.

Por supuesto la historiografía trata de muchos otros problemas y tiene diversos enfoques. Después de la instauración del sistema comunista en Rusia, los historiadores soviéticos se ocuparon de estudiar la historia económica y, con base en ella, caracterizar y analizar al Estado, el ejercicio del poder, las clases sociales en diferentes periodos, las relaciones sociales de producción, por mencionar algunos problemas, pero siempre bajo el dogma de demostrar el camino progresivo del pueblo ruso hacia el comunismo. Sin embargo, fue esta historiografía la que se ocupó sistemáticamente de los pueblos siberianos. A partir del supuesto de que gracias a los rusos los siberianos habían transitado de un modo de producción inferior a uno superior, la arqueología y la antropología se dieron a la tarea de rescatar su pasado. De inmediato, estudios históricos, arqueológicos y antropológicos estadounidenses principalmente, se enfocaron hacia los nativos de Siberia con el objetivo de reinterpretar los datos recopilados por la arqueología y la antropología rusa.

Hoy en día herederos de los pueblos de Siberia también se dedican a reconstruir y explicar su historia desde los primeros habitantes de la región hasta la actualidad tanto para reivindicar sus derechos como minorías dentro de la República Federada Rusa como por contribuir a explicar su historia. Ya que se parte de la consideración de que Rusia es un ente

\footnotetext{
32 Jerome Blum (1913-1993), Lord and Peasant in Russia. From the Ninth to the Nineteenth Century.
} Princeton, Nueva Jersey, Princeton University Press, 1972. 656 pp., cuads. y mapas. 
euroasiático se utilizaron fuentes primarias y secundarias sobre los pueblos asiáticos y los eslavos en Asia. Para empezar se consultó El libro secreto de los mongoles ${ }^{33}$. Esta obra se refiere a la época de Gengis Jan (c. 1162-1227) y da cuenta de la cultura que prevalecía entre los mongoles y de cómo se construyó el imperio. Por tanto, se encuentra información sobre la conquista de algunos principados de la Rus que formaron parte del imperio mongol.

Cuando los rusos iniciaron su expansión en el extremo nororiental de Europa y después al este de los Urales, sus actividades fueron incorporadas a crónicas como La Crónica de Novgorod, consultada para esta investigación, La Crónica de Nikón (Russkaya lyetopis po Novakum Spisku), La Crónica del gran Ustyug (Lyetopis Velik Ustyuzhsakoya) y

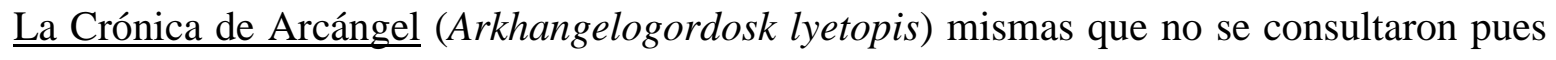
no se encontraron en línea. Para esta investigación se utilizaron textos que estudian la expansión rusa sobre el norte de Asia atendiendo a las relaciones que los conquistadores establecieron con los nativos. Se evitaron los estudios apoteóticos en favor del "pueblo ruso", antes bien se usaron investigaciones que se enfocaran en los nativos y el impacto que los conquistadores y colonizadores provocaron en sus formas de vida. En este tenor, el texto de James Forsyth publicado en $1994^{34}$ sirvió de base para identificar a los pueblos que habitaban en la tundra y la taiga y el momento en que los emprendedores rusos incursionaron en su territorio. Para analizar la importancia del comercio de pieles finas para el Estado ruso y las instituciones que se establecieron para controlarlo y mantener

\footnotetext{
${ }^{33}$ The Secret History of the Mongols. The Life and Times of Chinggis Khan, Trans., notas e introd. Urgune Onon. Londres y Nueva York, RoutledgeCurzon, Taylor and Francis Group, 2001. 307 pp. ,mapa e ils. Y El libro secreto de los mongoles. Versión e introd. José Manuel Álvarez Flórez. Barcelona, Muchnik editores, 1985. 240 pp., mapa.

${ }^{34}$ James Forsyth (1928-), A History of the Peoples of Siberia. Russian North Asian Colony 581-1990. Gran Bretaña, Cambridge University Press, 1994. 456 pp., ils. y mapas.
} 
sometidos a los pueblos siberianos, se recurrió al estudio de Raymond H. Fisher ${ }^{35}$, considerado un clásico por los investigadores sobre Siberia. A estas obras fundamentales, se sumaron otras más ${ }^{36}$. Las fuentes que existen para investigar la historia de la incorporación de Siberia a Rusia son de dos tipos: 1) las que generó la burocracia local, parte de las cuales están en los archivos de los distritos de Siberia y otra se localiza en los archivos de Moscú y San Petersburgo. La burocracia en Moscú elaboraba también informes con base en los que recibía. 2) Documentos de carácter comercial de negocios realizados en Siberia o bien de mercancías que se trasladaban de ahí a la Rusia europea y viceversa, los cuales se localizan en los $\operatorname{archivos}^{37}$. Conviene enfatizar que los archivos rusos están excelentemente organizados ya que la información ha jugado un papel valioso en el control de la población en beneficio del Estado. Para elaborar esta tesis no fue posible consultar estas fuentes pero los textos utilizados se apoyan en ellas.

La caída del régimen comunista abrió la posibilidad a los investigadores rusos de utilizar nuevas metodologías y otros enfoques al mismo tiempo que de establecer un debate más amplio con sus colegas estadounidenses y europeos. Actualmente tenemos libros que reúnen artículos de investigadores de diversos orígenes, así como reseñas críticas de unos y otros publicadas en revistas de historia rusas, europeas $y$, en mayor medida, estadounidenses. Existen estudios de historia política, de cultura política, de historia

\footnotetext{
${ }^{35}$ Raymond H. Fisher (1908-1994), The Russian Fur Trade 1500-1700. Reimpresión History E-Book Project, Berkeley y Los Angeles, University of California Press, 1943. XII/276 pp., ils. y cuadros.

${ }^{36}$ Véase la bibliografía de esta tesis.

${ }^{37}$ Patricia Kennedy Grimsted, Archives and Manuscript Repositories in the USSR. Moscow and Leningrad. Princeton, Columbia University, Studies of the Russian Institute, 1972. 440 pp.; Patricia Kennedy Grimsted, Archives and Manuscript Repositories in the USSR. Moscow and Leningrad. Supplement 1, Bibliographical Addenda. Switzerland, Inter Documentation Company Agzug Switzerland, [1976] . XIV-204 p. (Bibliotheca Slavica, 9), las guías son útiles a pesar de la transformación política pues los archivos tan sólo cambiaron el nombre de la URSS por el de Rusia. Svetlana Yangulova de C., "Visita de archivistas mexicanos al Servicio Archivístico de la Federación Rusa" en Secretaría de Gobernación, Archivo General de la Nación, Boletín 7. México, $6^{a}$ época, enero-marzo 2005, pp. 137-155.
} 
cultural, de género, de economía, de historia social, en fin de las diversas corrientes que se han desarrollado en los últimos 50 años ${ }^{38}$.

Investigadores de Japón, China y otros países asiáticos también estudian la historia de Rusia pero estas fuentes son todavía más inaccesibles aunque en ocasiones se encuentran algunos trabajos traducidos al inglés. El número de investigaciones realizadas por historiadores hispanoparlantes sobre historia de Rusia es infinitamente inferior a las que encontramos en ruso e inglés. En los últimos años la historiografía ibérica se ha ocupado más de la historia de Rusia medieval y contemporánea probablemente debido a su ingreso a la Unión Europea, algunos de cuyos miembros mantienen una relación geoestratégica y de conflicto con la República Federada Rusa. Es menester apuntar, además, que se encuentra muy poca información, incluso en la internet, sobre la producción historiográfica en América Latina sobre el tema, situación provocada por los escasos recursos con los que contamos hasta para comunicarnos entre colegas de la región.

Ante la enorme cantidad de investigaciones sobre el tema de estudio, esta tesis ha implicado realizar una síntesis de muchas investigaciones y propone la explicación del

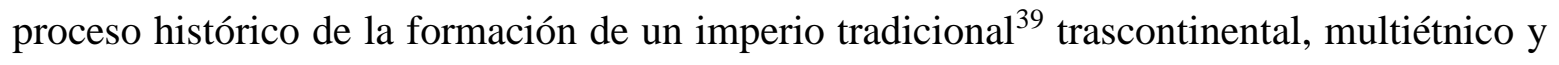
multicultural que participe del debate en torno a los fenómenos interculturales, de

\footnotetext{
${ }^{38} \mathrm{El}$ artículo de Robert O. Crummey [actualmente adscrito a UC Davis, EE UU], "The Latest from Muscovy" en Russian Review, 60:4, octubre, 2001, pp. 474-486 en http://www.jstor.org/stable/2679362 consultado 9 de noviembre de 2012 presenta una revisión de lo que se escribió desde finales de la década de 1980 hasta el 2000 tan sólo referente a Moscovia. Este balance historiográfico constituye una muestra la numerosa producción de libros y artículos sobre la historia de Rusia.

${ }^{39}$ Se entiende por imperio tradicional aquel que tenía un gobierno centralizado y que abarcaba territorios en los que habitaban naciones diferentes a la que gobernaba. La riqueza fundamental de estos imperios era agrícola, por ello conquistar territorio nuevo no era un fin en sí mismo sino subyugar nuevos tributarios que aumentaran la riqueza que el gobierno podía concentrar para después redistribuirla entre todos sus súbditos, no equitativamente sino de acuerdo a las necesidades. Desde luego, la mayor porción de la riqueza quedaba en manos de la elite gobernante. Esta caracterización se apoya en la bibliografía utilizada en esta tesis.
} 
transculturación, de conquista y de colonización, presentes en el devenir humano, pero no abarca todo el universo historiográfico existente.

El problema de la mayor parte de la historiografía sobre la historia rusa consiste en que se estudia como si la parte europea tuviera una historia diferente a la de la parte asiática. Aun en las historias generales, Siberia se trata de manera tangencial para aludir a la capacidad de expansión de Rusia a partir del gobierno de Iván IV (1530-1584) y suele ponerse más atención en lo ocurrido en la estepa como si únicamente esta región hubiese sido importante para la historia de la Rusia europea. Las investigaciones sobre Siberia, en cambio, la tratan con un enfoque regional en virtud de que, en efecto, es así como se ha integrado a Rusia. En esta tesis se estudia la historia de los rusos en Europa y se explica cómo fueron extendiéndose en el norte de Asia y llegaron a la costa del Pacífico incorporando nuevas tierras a Rusia.

\section{Datos calendáricos}

Un aspecto formal que debe considerarse es el problema de las fechas. Cuando el príncipe de la Rus de Kiev se convirtió al cristianismo ortodoxo fue adoptado el calendario juliano con la salvedad de que el año iniciaba el 1 de septiembre. Durante el régimen de Pedro el Grande la fecha de inicio del año se pasó al 1 de enero. Este calendario juliano reformado se conservó hasta 1918, fecha en la que se implantó el calendario gregoriano. En las crónicas se databan los sucesos a partir de una fecha era que se consideraba como la de la creación del mundo por el Dios padre cristiano y se añadía la fecha equivalente en el calendario juliano. No es común que los historiadores, aun en la actualidad, ajusten las fechas de las crónicas y otros documentos generados a partir de la conversión al 
cristianismo, a las fechas del calendario gregoriano. Hay colecciones documentales en las que aparece la fecha del calendario juliano y la del calendario gregoriano entre paréntesis, pero no es una norma. Como la diferencia entre ambos calendarios es de diez días el margen de diferencia no es tan grande y en muchos casos poco significativo. Dado que la tesis termina alrededor de 1676 la datación corresponde al calendario juliano.

Es mi intención que esta tesis sirva para motivar a colegas y futuros historiadores a estudiar los procesos históricos en el marco de la historia mundial. El reto para realizar la investigación es más arduo ya que la información requerida es muy voluminosa al mismo tiempo que es indispensable habilitarse, al menos mínimamente, para comprender idiomas diferentes al materno, pero con voluntad y con una utilización ingeniosa de los recursos con los que contamos es posible historiar a otras sociedades diferentes a la nuestra. 


\section{CAPÍTULO I. EL ORIGEN DEL ESTADO RUSO}

\subsection{El espacio}

Rusia se encuentra en un territorio conocido como Eurasia porque abarca porciones tanto de Asia como de Europa. Su extensión territorial se ha modificado a través de su historia. La paulatina expansión territorial a lo largo de su existencia nos sirve para reconstruir la historia de la formación del pueblo y el Estado rusos. De esta forma podremos identificar a los pueblos que habitaron en él y cómo fueron relacionándose unos con otros hasta formar un Estado que, en el siglo XVIII, se extendió hasta el norte del Pacífico. Para el concepto de "Estado", partimos de Poulantzas quien en 1968 lo entendió como: la organización que adopta un grupo social para ejercer el poder sobre otro u otros en su beneficio ${ }^{40}$.

El estudio de los habitantes en los territorios en donde se formó el primer Estado ruso es el punto nodal de esta investigación. Para comprender mejor este proceso es indispensable describir de forma breve el espacio geográfico en el cual se desarrolló. La importancia de las condiciones geográficas llevaron a historiadores como George Vernadsky $^{41}$ a explicar la historia de Rusia en función de la capacidad de su pueblo y quienes con ellos han convivido para integrar tres regiones diferentes y crear una economía única en la que la producción humana en estos climas diversos se complementa. Vernadsky no consideraba que el entorno determinara la historia de los pueblos pero su interpretación

\footnotetext{
40 "No todas las acciones del Estado se reducen a la dominación política, pero todas están constitutivamente marcadas por esa dominación.” En Nicos Poulantzas (1936-1979), Estado, poder y socialismo. Trad. Fernando Claudín. 6a Ed. México, Siglo XXI editores, 1986. 328 pp. (Sociología y Política), p. 9.

${ }^{41}$ George Vernadsky (1887-1973), A History of Russia. Sixth Revised ed. New Haven, Yale University Press, 1969. 532 pp., cuads. y mapas, Introducción, pp. 1-19. Si bien es cierto que el autor adoptó esta interpretación más por motivos ideológicos que conceptuales, los argumentos en torno a la integración de distintos ecosistemas en un solo Estado se considera acertada.
} 
de la historia rusa tomaba ya en cuenta una de las preocupaciones que nació en la antropología e impactó a la historia.

La antropología ecológica consideraba indispensable analizar los ecosistemas definidos como “...el total de organismos vivientes y substancias no vivientes ligados por intercambios materiales dentro de cierta porción delimitada de la biósfera."42 Se consideraba que estos ecosistemas tenían la capacidad de autorregularse y adaptarse a los cambios que ocurrieran ya fuera por razones endógenas o exógenas. Un elemento constitutivo de estos ecosistemas es también la población humana. Ésta, a diferencia del resto de los elementos que forman un ecosistema, crea y adquiere una cultura. La cultura implica un sistema de creencias, convencionalismos, patrones de conducta, conocimientos técnicos y símbolos -entre los que se encuentra el lenguaje. La cultura si bien se enmarca en las condiciones del ecosistema, lo hace a través de un sistema simbólico de manera que las prácticas humanas no se limitan a una mera relación causal entre necesidades materiales y solución práctica para ellas utilizando los recursos del medio ambiente ${ }^{43}$.

La cultura, por tanto, también se refiere a la manera en la que los grupos humanos interaccionan con su ecosistema, asunto del que se ocupa la ecología cultural. Por lo común, en esta relación las poblaciones humanas perciben dicho ecosistema parcialmente ya que no son conscientes de cada uno de los elementos que los componen sino que lo captan como una unidad. Con ello elaboran sus maneras de relacionarse tanto en términos operativos como también simbólicos. La acción humana, contribuye a la reproducción de

\footnotetext{
42 Roy A. Rappaport (1926-1997), "IX. Naturaleza, cultura y antropología ecológica" en Harry L. Shapiro (1902-1990), Hombre, cultura y sociedad. $1^{a}$ reimp. De la 1a ed. en español, México, Fondo de Cultura Económica, 1980. 480 pp. (Sección obras de antropología), pp. 261-292, p. 261. Las categorías que se presentan a continuación están basadas en este estudio a menos que se indique otra fuente.

${ }^{43}$ Marshall Sahlins (1930-), Cultura y razón práctica. Contra el utilitarismo en la teoría antropológica. Trad. Gregorio Valdivia. Barcelona, Edit. Gedisa, 1988, 243 pp., ils., pp. 9-11.
} 
los mismos pero también puede perjudicarlos. En este último caso el quehacer humano deberá adaptarse a la transformación de su medio ambiente, aunque no debemos perder de vista que éste cambia independientemente de la intervención de los grupos humanos. Por ejemplo, la última glaciación (c. 120 000-10 000 AEC) afectó a las comunidades humanas que trataremos en este trabajo independientemente de sus acciones.

En la década de los años treinta del siglo pasado, Julian Steward ${ }^{44}$ planteó una metodología de análisis para explicar la conducta de los grupos humanos a partir de su relación con su medio ambiente. Primero tenía que establecerse la conexión entre los procesos de subsistencia de una comunidad y la explotación que hacían de los recursos que le brindaba su medio ambiente, después debía elucidarse el tipo de tecnología que desarrollaba para el efecto y por último se analizaba qué influencia tenían los patrones de subsistencia en el resto de los fenómenos culturales. En un principio, la propuesta fue ampliamente aceptada pero pronto mostró sus limitaciones porque presuponía un alto grado de determinismo del ecosistema en el desarrollo cultural de los pueblos. En poco tiempo estos debates antropológicos influyeron en la práctica de la disciplina de la historia. Desde luego para la historia, la geografía había constituido un elemento fundamental en la explicación del devenir pues el espacio ha sido el escenario del quehacer humano ${ }^{45}$. Desde que la historia empezó a practicarse como una disciplina, se ha aceptado la influencia del medio ambiente en las características de las sociedades humanas pero sin percatarse

\footnotetext{
${ }^{44}$ J. Steward, (1902-1972) "The Concept and Method of Cultural Ecology". Theory of Culture Change, 1955 citado en Emilio F. Moran (PhD 1975), "Ecosystem Ecology in Biology and Anthropology: A critical Assessment" en Emilio F. Moran (Ed.) The Ecosystem Approach in Anthropology. From Concept to Practice. Estados Unidos, Ann Arbor/The University of Michigan Press, 1990. 478 pp., pp.3- 40, p. 10. Este texto nos presenta un panorama amplio y completo del tema y los debates en torno a él.

${ }^{45}$ Para muestra basta una cita de Herodoto (484-425 AEC) "Creso, de nación lidio e hijo de Alyates, fue señor y tirano de aquellas gentes que habitan de esta parte del Halys, que es un río, el cual corriendo de Mediodía a Norte y pasando por entre los sirios y paflagonios, va a desembocar en el Ponto que llaman Euxino." Herodoto, Los nueve libros de la historia. Introd. Edmundo O'Gorman, 2a ed. México, Edit. Porrúa, 1974. 442 pp. (“Sepan cuantos...”, 176), p.3
} 
cabalmente del impacto que la acción humana tiene sobre la naturaleza. Durante mucho tiempo, para los historiadores, la naturaleza no tenía historia. Fue a partir del siglo XVII que la filosofía europea comprendió que la naturaleza y, por tanto, el espacio geográfico también se transforman ${ }^{46}$.

Se puede decir que el concepto de ecosistema desarrollado en la antropología concebido por Julian Steward, utilizado por Rappaport y desarrollado por Moran ${ }^{47}$ en su tesis doctoral en 1975, abrió la posibilidad de comprender que el devenir humano también cambia a la naturaleza estableciéndose así una relación dialéctica entre los grupos humanos y su entorno. Actualmente, la historia ambiental se ha enfocado a analizar el efecto que los grupos humanos producen sobre su hábitat o medio ambiente Uno de los ejemplos, mejor acabados, es el de Alfred Crosby $^{48}$. La historiografía contemporánea ha introducido el concepto de paisajes culturales para designar esos ambientes naturales en los que transcurre la historia humana pero que a su vez son modificados por ella más allá de la mera depredación ${ }^{49}$. Por tanto, la cita anterior de Vernadsky debe tenerse presente para comprender la singularidad de la formación y desarrollo posterior del Estado ruso.

Las regiones -entiéndase por región los amplios paisajes culturales integrados por diversos ecosistemas interconectados gracias a los intercambios de todo tipo, incluida la

\footnotetext{
${ }^{46}$ Vid. F. Engels (1820-1895), "Introducción a La dialéctica de la naturaleza" en C. Marx y F. Engels, Obras escogidas. Moscú, Edit. Progreso, s.d. 832 pp., pp. 354-370.

${ }^{47}$ Moran, op. cit., capítulos 1 a 3, pp. 3-90.

48 Alfred W. Crosby (1931-), Imperialismo ecológico. La expansión biológica de Europa, 900-1900. Trad. Montserrat Iniesta. Barcelona, Edit. Crítica, 1988. 352 pp., ils., cuads., mapas (Historia y teoría).

${ }^{49}$ Cynthia Radding [PhD, 1990], Paisajes de poder e identidad. Fronteras imperiales en el desierto de Sonora y los bosques de la Amazonia. Trad. Rose Marie Vargas Jastram. México, El Colegio de Sonora, CIESAS, Universidad Autónoma Metropolitana Azcapotzalco, 2005. 524 pp., ils. y mapas, vid. Especialmente la introducción pero el libro es un ejemplo muy bien logrado de las posibilidades de análisis histórico que brinda este tipo de enfoque.
} 
información, entre diversos grupos humanos ${ }^{50}$ - que abarcó el imperio ruso a finales del siglo XVIII, época en la que se extendía hasta la costa americana eran, de norte a sur: la tundra, la taiga y la estepa. En esta investigación se tratará principalmente sobre las dos primeras y sólo se hará referencia a la región de la estepa en la medida que sea útil para comprender la expansión en dirección al este.

La tundra abarca aproximadamente desde los $67^{\circ}$ latitud norte, donde inicia el círculo polar ártico, y termina alrededor de los $75^{\circ}$. Se puede concebir como un desierto de nieve pues su vegetación es muy escasa, al sur crecen arbustos un poco altos pero su tamaño va disminuyendo a medida que se avanza hacia el norte. En el extremo norte las plantas crecen al ras del suelo, predominan los líquenes y los musgos. Como el suelo está permanentemente congelado, los musgos no echan raíces y son perennes, durante el invierno la nieve los protege. Los nutrientes del suelo son muy escasos pues provienen de la descomposición de los organismos muertos. En cuanto a la fauna costera, hay peces y una gran variedad de mamíferos marinos. En el interior hay renos, caribú, liebres, ardillas, osos polares, lobos, zorros y aves como el cuervo y diferentes variedades de gaviotas, también hay aves de presa. La mayoría de las aves migran hacia el sur en el invierno. En la tundra prácticamente sólo hay dos estaciones: el verano y el invierno. Durante la primera la temperatura oscila entre los 3 y los $12^{\circ} \mathrm{C}$, la luz del sol billa todo el día, esto permite que incluso algunas plantas florezcan. Es el tiempo en el que los dañinos mosquitos y las abejas, tan útiles para los seres humanos por la miel que producen, pululan. Algunos mamíferos tienen su pelaje color marrón. En el invierno, en cambio, la temperatura media baja a los menos $34^{\circ} \mathrm{C}$, los vientos soplan con mucha fuerza. Algunos animales migran

\footnotetext{
${ }^{50}$ Roy A. Rappaport, "Ecosystems, Populations and People” en Moran, The Ecosystem..., op.cit., pp. 41-71.
} 
hacia el sur y otros, como la zorra, cambian su pelaje a plateado, ninguno puede hibernar porque el suelo no lo permite, el alimento para todos ellos es escaso ${ }^{51}$. La población humana es pequeña debido a las características del ecosistema, los pueblos se dedican a la cacería, a la pesca y a la recolección.

La taiga, palabra que en ruso significa "bosque de hojas perennes", se localiza a ambos lados del paralelo de los $60^{\circ}$ latitud norte que, de hecho la cruza, y termina donde empieza la tundra. Es una región que registra bajas temperaturas en el invierno que pueden llegar hasta los menos $60^{\circ} \mathrm{C}$, la luz del sol se mantiene por pocas horas. En el verano la temperatura puede alcanzar hasta $\operatorname{los} 40^{\circ} \mathrm{C}$ lo que provoca deshielos, que el suelo se vuelva pantanoso y se reproduzcan una enorme cantidad de mosquitos, la luz solar brilla la mayor parte del día y la oscuridad en las noches es breve. Al lado de los musgos que crecen junto a las ciénagas, las plantas forman un bosque de coníferas también llamado boreal, prevalecen los abedules y los pinos. En el verano abundan los insectos y las aves como los gorriones y los cuervos. Entre los mamíferos se encuentran: los conejos, los ratones de campo, los castores, las zorras, el armiño, la marta cibelina y, en Asia, el tigre siberiano. La taiga es la biotropo más grande del planeta $^{52}$. Esta región tampoco puede soportar una densidad de población alta. No obstante, algunos habitantes han transitado de la cacería, la pesca y la recolección a practicar la agricultura. En la zona sur de la taiga el clima es más benigno de manera que se ha podido desarrollar la agricultura. De hecho es una de las

51 http://www.jmarcano.com/nociones/bioma/tundra.html consultado 22 de noviembre de 2011; ucmp en http://www.ucmp.berkeley.edu/exhibits/biomes/tundra.php consultado 22 de noviembre de 2011.

$52 \mathrm{http} / / \mathrm{www}$.windows2universe.org/earth/Taiga_ecosystem.html consultado 23 de noviembre de 2011; http://www.ri.net/schools/west_warwick/manateeproject/taiga/land.htm consultado 23 de noviembre de 2011. 
regiones con más alta densidad de población en el mundo. Esta franja apta para el cultivo se continúa con la zona norte de la estepa ${ }^{53}$.

La estepa se ubica aproximadamente entre $\operatorname{los} 50^{\circ}$ y $\operatorname{los} 40^{\circ}$ latitud norte. La estepa tiene un clima árido continental cuya media anual de temperatura es de menos $12^{\circ} \mathrm{C}$. Los inviernos son fríos y largos y los veranos son secos. En la estepa el agua escasea porque la lluvia es torrencial y la temporada es breve. La vegetación es de hierbas bajas y matorrales, algunas plantas tienen raíces muy profundas o crecen en forma de bulbos para retener agua y soportar la sequía prolongada. Los suelos tienen poca materia orgánica pero son ricos en recursos minerales, se clasifican como chernozem o tierra negra. La fauna incluye caballos, águilas, roedores, lobos, zorros, reptiles y gran variedad de insectos ${ }^{54}$. La estepa asiática ha sido una región muy propicia para la ganadería. De hecho, una de las características de los pueblos esteparios ha sido la cría del ganado equino. Acto seguido a la domesticación del caballo (c. 3600 AEC), los pueblos esteparios han tenido a lo largo de la historia una gran movilidad y un gran potencial de violencia. Aunque la población, también limitada, se dedicó a criar ganado, poco a poco, expandió sus actividades a la agricultura. Los tres biomas descritos pueden visualizarse en el mapa 2.

\section{Los ríos}

Tanto en la tundra como en la taiga euroasiática existen sistemas fluviales, originados en las elevaciones, que permiten la comunicación durante el verano. Los ríos y sus afluentes así como los lagos alcanzan a extenderse hasta la estepa pues suelen tener un

\footnotetext{
${ }^{53}$ Walter G. Moss, A History of Russia. Vol I: to 1917. $2^{\text {nd }}$ ed. Londres, Anthem Press, 2005. 638 pp., ils. y mapas, p. 6.

54 http://www.barrameda.com.ar/ecologia/estepas.htm consultado 23 de noviembre de 2011; http:/geografia.laguia2000.com/biogeografia/la-estepa consultado 23 de noviembre de 2011.
} 
gran caudal. Todos ellos, excepto el río Volga corren de sur a norte y desembocan en el Mar Ártico. El Volga, en cambio, tiene su delta en el mar Caspio. Los sistemas fluviales han tenido una importancia fundamental en el devenir histórico de los pueblos que han habitado el territorio que hoy conocemos como Rusia. Por otra parte, los vientos que bajan del polo norte no chocan con sierras altas, de manera que estas corrientes provocan que el clima sea extremadamente frío. Desde el este europeo hasta la costa del Pacífico la tundra, la taiga y la estepa forman una enorme planicie en la que los montes constituyen obstáculos fáciles de franquear como se muestra en el mapa $2^{55}$. Éste es pues el ecotropo en el que se ha desarrollado el pueblo ruso.

\footnotetext{
${ }^{55}$ Nicholas V. Riasanovsky (1923-2011), A History of Russia. 5th ed. Nueva York/Oxford, Oxford University
} Press, 1993. 712 pp., ils., mapas, fotografías, pp. 3-9. 


\section{Mapa 2. MAPA FÍSICO DE LA FEDERACIÓN RUSA Y TERRITORIOS ALEDAÑOS}

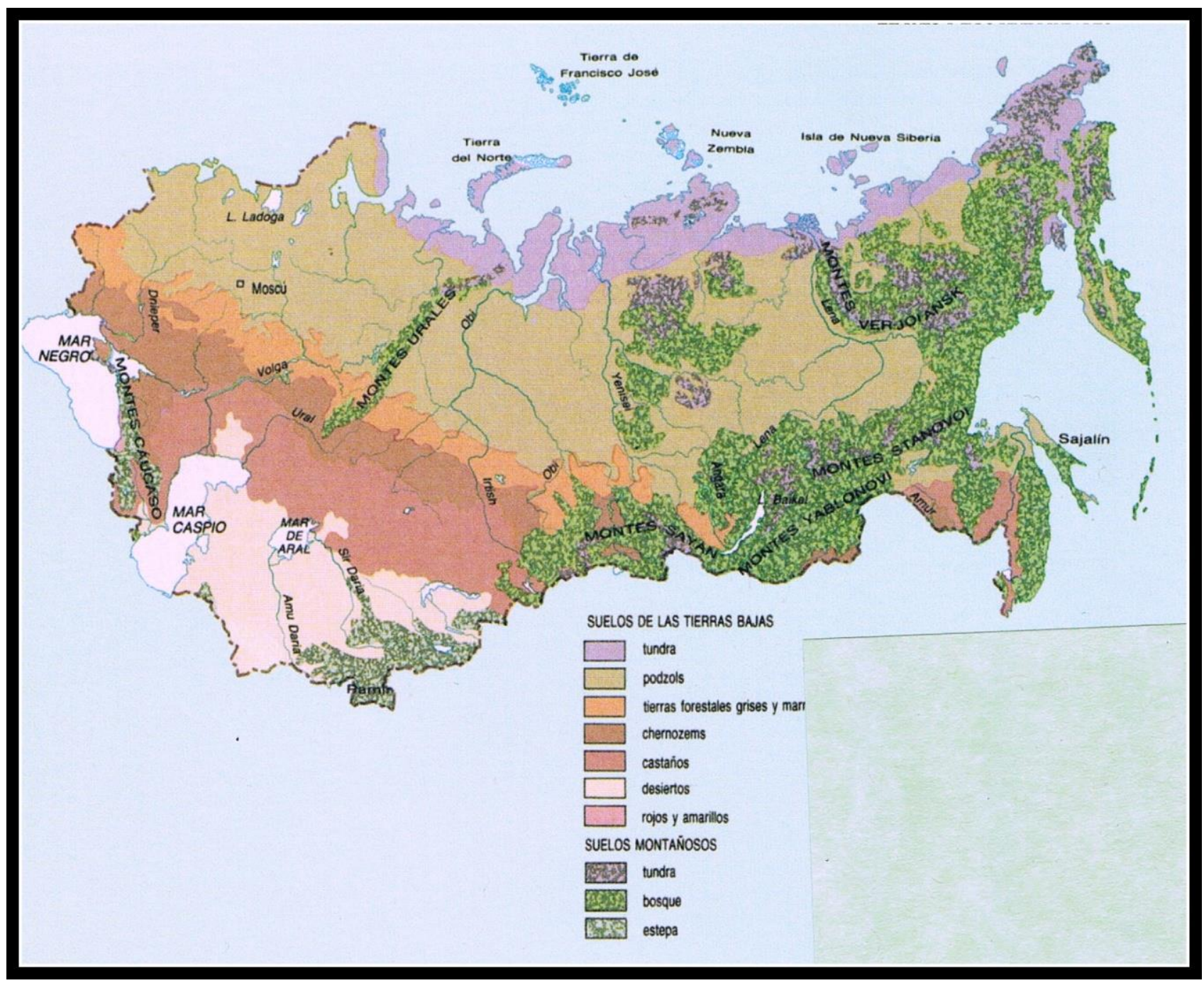

Fuente: Milner-Gulland, Robin y Nikolai Dejevsky, Rusia y la antigua Unión Soviética. Barcelona, Ediciones Folio, 2007. 240 pp., ils., cuadros y mapas (Grandes civilizaciones del pasado), p.23.

En términos geográficos e históricos, los hombres que han habitado este territorio y que formaron su Estado y su sociedad han aprendido a manejarse en dos continentes diferentes: el asiático y el europeo para hacer la suya una historia euroasiática ${ }^{56}$. Tal condición ha sido definitiva en el proceso histórico ruso. En esta tesis no se opta por

\footnotetext{
${ }^{56}$ Vernadsky, op.cit., p. 7.
} 
ninguna de las dos grandes corrientes de interpretación histórica que explican la historia de Rusia a partir fundamentalmente de la influencia cultural europea o de la asiática. Esta historia euroasiática implica concebir el desarrollo histórico del pueblo ruso con la confluencia de elementos culturales de los pueblos del norte y el este de Asia, con los que ha convivido, y de los europeos, en ambos casos los rusos tienen prácticas culturales que comparten con ellos.

Por mencionar un factor, las fronteras hacia el este y el sureste pusieron en contacto a los pueblos eslavos con los pueblos trashumantes de la estepa quienes, casi siempre, representaron el peligro de una confrontación violenta ${ }^{57}$. Asimismo, la expansión territorial del pueblo y el Estado rusos han sido elementos importantes que ayudan a identificar y entender sus características.

\subsection{Los primeros habitantes}

Los pueblos que dieron origen al Estado ruso se localizaron, en un principio, en parte del territorio de lo que hoy son la Rusia europea y Ucrania. Según los datos arqueológicos la zona cercana a la ribera oriental de rio Volga y al norte del Mar Negro tuvo sus primeros habitantes entre 26000 y 20000 AEC. Pero durante el periodo más álgido de la última glaciación (c. 18000 años), los humanos migraron hacia el sur. Al terminar la glaciación, hace aproximadamente 10000 años, el norte del planeta volvió a habitarse pero con una densidad de población muy baja. Fue así como regresaron al norte y noreste del Mar Negro grupos caucásicos, provenientes de la meseta del Irán, que se han identificado como

\footnotetext{
${ }^{57}$ Riasianovsky, op.cit., pp. 9-10.
} 
ancestros de los eslavos ${ }^{58}$. Los datos arqueológicos muestran que estos grupos se mezclaron con comunidades mongolas, sin embargo, predominó la herencia caucásica pues conservaron, en gran medida, el tipo de sangre B Rh positivo. Por tanto, a pesar del intercambio genético con comunidades mongolas, en los primeros milenios AEC, los antecesores de los eslavos siguieron siendo básicamente caucásicos ${ }^{59}$.

Estas comunidades practicaban la cacería y la recolección y, a medida que el clima se tornó más benigno y la población creció, empezaron a migrar hacia el norte hace aproximadamente 7500 años. Este fenómeno ocurrió entre diversos pueblos que habitaban Europa central y fue así como llegaron nuevos grupos al territorio de la costa este del Mar Báltico procedentes de aquella zona, al mismo tiempo algunas comunidades de ancestros de los eslavos penetraron en los bosques boreales ${ }^{60}$. De acuerdo con los estudios lingüísticos realizados desde el siglo XIX, estos pueblos hablaban idiomas protourálicos, que en algún momento, que no ha podido precisarse, fueron sustituidos por lenguas urálicas ${ }^{61}$.

Las agrupaciones humanas que habitaban el norte, eran cazadores- recolectores y pescadores, utilizaban herramientas de piedra, madera y hueso para cazar renos, castores, jabalíes y focas y se vestían con pieles. Preservaban la carne simplemente exponiéndola a la intemperie en el invierno, pero en el verano la secaba o la salaban. La costumbre de salar la carne dio lugar a que apareciera la extracción de sal como una actividad importante pues

\footnotetext{
${ }^{58}$ Sobre el origen de esta denominación trataremos más adelante.

${ }^{59}$ Luigui Luca, Cavalli-forza, Paolo Menozzi, Alberto Piazza, The History and Geography of Human Genes, Princeton, 1994, pp. 3-59 y mapa 5.2.7 citado en Philip Longworth (1933-), Russia. The Once and Future Empire from Pre-history to Putin. Nueva York, St. Martin's .Press, 2005. 398 pp., ils. y mapas, pp. 5-7 ${ }^{60} \mathrm{http}: / /$ www.telefonica.net/web2/jgarciaf/cambio_climatico/glaciaciones.htm, consultado 23 de octubre de 2011.

${ }^{61}$ Juna Janhunen (1952-) "Proto-Uralic- what, where, and when?" en The Quasquicentennial of the FinnoUngrian Society. Suomalais-Ugrilaisen Seuran Toimituksi=Mémories de la Societé Finno-Ougrienne 258. Helsinki 2009, pp. 57-78 en www.sgr.fi/sust/sust258 janhunen.pdf consultado 20 de julio de 2013; Kalevi Wiik (1932-), “¿La lengua más antigua de Europa” en www.angelfire.com/folk/celtiberia/eurolenguas.html consultado 19 de julio de 2013
} 
también la intercambiaban con otros pueblos. Al parecer, estos grupos levantaban unos campamentos en invierno y otros en verano.

En tanto en el norte se conservaba este tipo de vida, en el sur al este del río Dniéper y hasta la margen oeste del Volga empezó a practicarse la agricultura alrededor del 4000 AEC. No queda claro cómo empezó a desarrollarse, si fue adquirida y, en ese caso, de dónde provino. Los estudios lingüísticos apuntan a que llegó con pueblos de habla indoeuropea de la rama preiraní, esto implica que la agricultura se extendió desde la meseta del Irán, a las márgenes del Mar Negro y desde ahí a la zona mencionada ${ }^{62}$. Esta teoría es la más aceptada en la actualidad.

De acuerdo con los datos arqueológicos disponibles ${ }^{63}$, hubo aldeas y algunos centros protourbanos que llegaron a contar con 10000 habitantes. Cultivaban cebada, mijo, trigo y criaban cerdos, ganado menor y ganado mayor. Las viviendas estaban construidas con madera y fabricaban cerámica. Es probable que estos agricultores se aventuraran en los bosques para obtener recursos como la miel y la madera. Cuando la población aumentaba mucho y las tierras abiertas al cultivo eran insuficientes, algunas familias emigraban al norte donde desmontaba una pequeña porción de los bosques para cultivarla. Es necesario señalar que los restos arqueológicos nos brindan indicios de cómo se vinculaban los grupos humanos con su entorno pero no podemos saber cómo era su cultura más allá de los rasgos que podemos elucidar sobre su cultura material ${ }^{64}$.

\footnotetext{
62 Janhunen, op. cit., p. 73; Wiik, op.cit., p. s/n.

${ }^{63}$ Longworth, op.cit., pp. 10-12.

${ }^{64}$ Vid. Karl W. Butzer (1934-), “A Human Ecosystyem Framework for Archaeology” en Moran, The Ecosystem..., op.cit., pp. 91- 130, p. 102.
} 
Ni las comunidades de agricultores ni las de cazadores-recolectores vivían aisladas, los ríos servían como rutas de comunicación, las vías fluviales tenían especial importancia en las relaciones entre el norte y el sur y ponían en contacto a estos pueblos con el Mar Negro y el Báltico. En la región europea ríos como el Dvina y el Péchora desembocan en el océano Ártico, mientras que el Volga desemboca en el gran lago que es el Mar Caspio. En Asia, la mayoría de los ríos también desembocan en el Ártico. En ambos casos son navegables en verano y en el invierno se congelan, de manera que siempre sirven como vías de comunicación pues el trineo constituye un eficiente medio de transporte ${ }^{65}$.

\section{Mapa 3. RÍOS DE RUSIA}

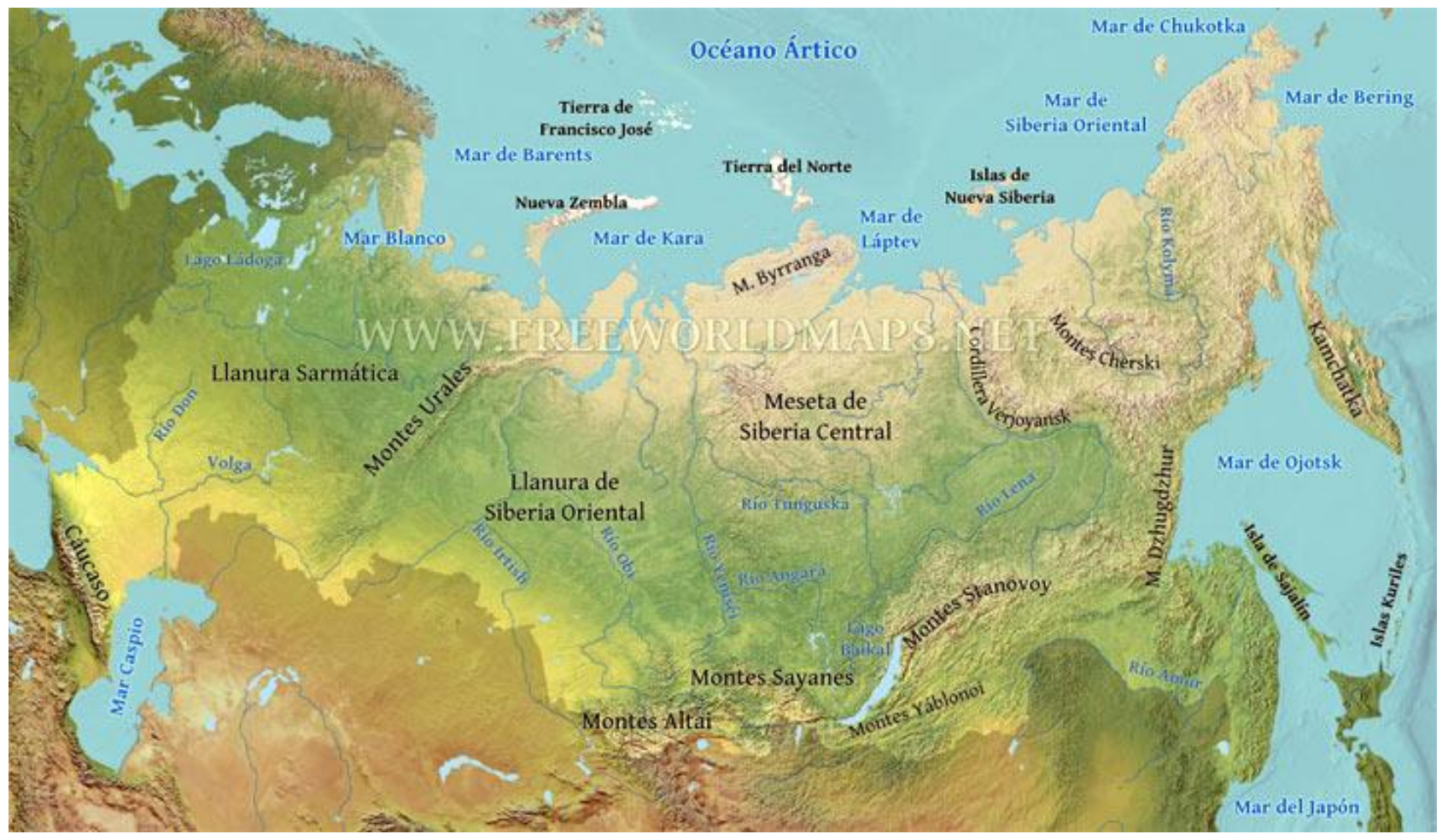

Fuente: http://www.freeworldmaps.net/e/rusia-mapa.jpg consultado 8 de junio de 2014

${ }^{65}$ Moss, op. cit., pp.6-8. 
En la comunicación este-oeste existieron rutas terrestres de intercambio que también fueron utilizadas por las corrientes migratorias.

Gracias a estas posibilidades de comunicación, hace 3500 años aproximadamente, aparecieron instrumentos de cobre fruto del intercambio en la cuenca del Volga y en la costa del Báltico, poco después de bronce y 500 años más tarde se inició el uso del hierro. Las herramientas de hierro hicieron que el cultivo de roza y quema fuera más productivo y también facilitaron la vida en el bosque pues con las hachas de hierro era más sencillo derribar árboles. Incluso, las comunidades campesinas empezaron a roturar los bosques menos espesos.

Los movimientos de la población dieron por resultado la convivencia de los pueblos que hablaban idiomas del tronco lingüístico urálico-altaico -la familia urálica ya se había dividido en sus dos grandes ramas: la fino-úngara y la samoyeda, la primera ubicada al oeste de los Urales y la segunda al este- localizados desde la costa del Báltico hasta la frontera natural de Europa con algunos grupos indoeuropeos de la estepa, quienes más tarde dieron origen a los lituanos. Todos ellos convivían con pueblos mongoles y turcos ${ }^{66}$, además compartían formas de vida semejantes.

\section{El idioma eslavo}

Hasta el momento no se ha podido precisar ${ }^{67}$ cuándo se desarrolló la lengua eslava y, por tanto, podemos hablar de protoeslavos. Es posible que los pueblos que habitaron en

\footnotetext{
${ }^{66}$ Longworth, op. cit., pp. 12-15, Vernadsky, op.cit., p.25; Janhunen, op. cit., pp. 61-66.

67 http://wwwooaties.org/linguaeimperii/Slavic/slavic_es.html consultado 19 de julio de 2013; http://www.es.wikipedia.org/wiki/Pueblos_bálticos consultado 19 de julio de 2013; http://www.es.wikipedia.org/Lenguas_ugrofinesas consultado 19 de julio de 2013. Para facilitar nuestra
} 
la región que nos ocupa primero se separaran entre los de habla eslava y los de lengua báltica y mucho tiempo después se diferenciaran entre sí los de habla eslava. En términos lingüísticos el eslavo es una lengua indoeuropea lo mismo que el lituano y el letón. Las dos últimas se agrupan entre las lenguas bálticas a las que también se añaden el estonio y el finlandés pero éstos pertenecen a la rama lingüística finoúngara. El eslavo, por su parte, es un idioma indoeuropeo tal vez derivado del escito-sármata, también indoeuropeo. Todos estos idiomas muestran influencias entre sí. En todo caso, las investigaciones arqueológicas y lingüísticas no han logrado precisar si los pueblos mencionados en este periodo son protoeslavos o éstos aparecieron siglos después ${ }^{68}$.

Lo que la arqueología y la filología han podido establecer con cierto grado de certeza es que algunos pueblos eslavos antiguos estaban ubicados en el territorio comprendido entre el río Vístula y el curso medio del río Dniéper al norte de los Cárpatos y otros al sureste de dicha cordillera, antes de que se desplazaran hacia la cuenca del Danubio en el primer milenio AEC. Las aldeas que ocupaban tenían una economía pastoril y agrícola $^{69}$.

De hecho, no existe acuerdo acerca del origen del etnómino eslavo. Al parecer deriva de una raíz indoeuropea ḱlew slověne que significa "personas que hablan la misma lengua”. Sin embargo, también se postula que deriva de la palabra slova que significa palabra, por lo que su acepción sería "los que hablan la misma palabra". Hay una tercera hipótesis que sugiere que eslavo deriva de la palabra slava que se traduce como gloria, por tanto significaría "pueblos que son gloriosos". Como podemos observar, no existe consenso

exposición designaremos a los pueblos que vivían en los actuales territorios de Ucrania y la Rusia europea como protoeslavos.

${ }^{68}$ Heather, op. cit., pp. 455-459.

${ }^{69}$ Hellmann, op. cit., p. 14. 
respecto del significado originario del apelativo de estos pueblos pero las raíces son indoeuropeas ${ }^{70}$. Lo que queda claro es que los fenómenos migratorios y la convivencia de los grupos humanos de distintos troncos lingüísticos ha sido una constante en las tierras en las que nació el Estado ruso. Este fenómeno no es exclusivo de esta región, lo que le imprime su particularidad son las características de los pueblos que se encontraron y mezclaron en ella y el trasfondo del ecosistema que propició formas de apropiación y de producción adecuadas al clima, el biotropo y los suelos del lugar en el que vivían.

A pesar de las evidencias arqueológicas que nos permiten conocer los movimientos de la población en las regiones de la estepa y la taiga europeas poco sabemos sobre su cultura, tenían distintos lenguajes a partir de los cuales crearon un universo de significados simbólicos que apenas conocemos. Por ejemplo, en la región del Mar Báltico se han encontrado entierros, los difuntos tienen el rostro colocado hacia el este y están cubiertos de ocre, en las tumbas se encuentran cuchillos, garfios, arpones y joyería de ámbar y marfil pero estos hallazgos no son suficientes para conocer el rito sobre la muerte y cómo la concebían. Aunque no es posible acceder a la cosmovisión de los pueblos aludidos hasta el momento, lo que es posible asegurar es que desde muy temprano se formaron redes de intercambio de bienes al menos materiales, de algunas prácticas y expresiones lingüísticas para asegurar la sobrevivencia de los grupos. La creación de estas redes humanas de intercambio de bienes materiales y de información muestra que desde un principio las

\footnotetext{
${ }^{70} \mathrm{http} / / /$ es.wikipedia.org/wiki/pueblos_eslavos\#origen_del_t.c3.A9rmino_eslavo consultado 11 de octubre de 2012; http://etimologias.dechile.net/?eslavo consultado11 de octubre de 2012; http://eslavoteca.blogspot.mx/2009/02/origen_del_termino_eslavo.html consultado 11 de octubre de 2012; Preobrazhnensky, op. cit., pp. 317-318
} 
distintas comunidades que habitaron estas regiones participaron de un proceso recíproco de adquisición de bienes culturales a través de la cooperación y tal vez de la competencia ${ }^{71}$.

La identidad que les adjudicamos a los protoeslavos que a su vez dieron origen a los eslavos, es una construcción histórica. Las sociedades humanas se transforman en pueblos diferenciados en la medida en que crean una cultura la cuál enseñan a sus descendientes y que les permite excluir a otros que no comparten elementos tales como el lenguaje, las creencias y las relaciones que establecen con su medio ambiente. Si bien no se conoce todo el universo simbólico que tenían estas comunidades, los datos arqueológicos permiten señalar ciertas prácticas relacionadas fundamentalmente con su cultura material. La filología también ha aportado datos para afirmar que las comunidades ubicadas en la taiga de Europa oriental hablaban lenguas de la rama ungro-finesa, por lo tanto es posible que, por lo menos a partir del idioma, pudieran tener identidades distintas. La identidad es un fenómeno social que le permite a un grupo humano reconocerse a sí mismo como diferente de otro. Esto implica la exclusión de las comunidades consideradas distintas a ellos.

La identidad no se construye a partir de la raza, en el caso que aquí se estudia, convivían en el mismo espacio cuando menos pueblos caucásicos, mongoloides y fineses, que vivieron un proceso de mestizaje. La identidad se construye a partir de las prácticas que los conjuntos humanos desarrollan para sobrevivir y la carga simbólica que les atribuyen, de cómo representan su entorno y de las relaciones establecidas con su ecosistema, entre ellos mismos y con los otros que excluyen y consideran ajenos. Ahora bien, debemos

\footnotetext{
71 J. R. McNeill (1954-) y William H. Mc Neill (1917-), Las redes humanas. Una historia global del mundo. Trad. Jordi Beltrán. Barcelona, Crítica, [2003]. 412 pp., cuads y mapas, pp. 1, 6, 11-12; Longworth, op.cit., p.12.
} 
considerar que el fenómeno de la exclusión no implica necesariamente considerar a los otros como inferiores sino sencillamente como distintos.

En consecuencia, la etnicidad, a partir de la cual se ha clasificado a los pueblos, es también una construcción histórica relacionada con el mito de origen de la comunidad en cuestión que se conjuga con los elementos que nutren su identidad y que se articulan con base en un pasado común ${ }^{72}$. Es menester señalar que con los datos reunidos hasta el momento ni siquiera se puede saber cómo se denominaban a sí mismos los pueblos sobre los que se ha tratado ni si unos ejercían algún tipo de poder sobre otros.

Lo que se ha podido establecer es que alrededor del 1000 AEC, las aldeas campesinas de la cuenca del Dniéper tuvieron que defenderse de los cimerios, pueblos esteparios provenientes de Irán, quienes les robaban su ganado aunque sus relaciones no se limitaron a los asaltos. Los cimerios, establecidos en el territorio del Cáucaso, los Cárpatos, Asia menor y Tracia, vendían objetos de cobre y bronce que ellos producían a los campesinos protoeslavos. Las investigaciones arqueológicas indican que los cimerios practicaron la agricultura en algunas zonas de la estepa durante el siglo VIII AEC.

A fines de ese mismo siglo, los cimerios fueron conquistados por los escitas. Éstos eran indoeuropeos de la rama iraní, guerreros y jinetes, trashumantes, criadores de ganado equino, costumbres adoptadas de los pueblos turco-mongoles. Los escitas transitaban la ruta comercial que comunicaba a Grecia con China cruzando Asia central. Más tarde cayeron bajo el dominio de los persas, quienes consideraban a los cimerios y a los escitas

\footnotetext{
${ }^{72}$ Stuart Hall (1932-), "Introduction: Who Needs 'Identity'?” en Stuart Hall y Paul du Gay, Questions of Cultural Identity. Gran Bretaña, The Cromwell Press, 1996. Pp. 1-17, pp. 2-5; Homi K. Bhabha (1949-), "Culture's In-Between" en ibidem, pp. 53-60, passim; Pohl, op. cit., pp. 16-18.
} 
como un mismo pueblo ${ }^{73}$. Después Alejandro Magno (356-323 AEC) conquistó a los pueblos de la región.

Por otra parte, desde el siglo VII AEC existieron algunas colonias griegas entre las costas del Mar Negro y el Mar de Azov. Las más importantes fueron Olbia y Quersoneso, estos enclaves comerciaban con los pueblos que habitaban al norte. Tras el colapso del imperio de Alejandro Magno (323 AEC), los sármatas, también de la rama indoiraní y criadores de ganado, se apoderaron de toda la zona (siglo III AEC). Todos estos pueblos mantuvieron relaciones de intercambio y realizaron asaltos aleatorios en contra de los cultivadores del norte. Es posible que los alanos, uno de los pueblos sármatas, hayan sometido a los cultivadores del norte, de esta conjunción resultaron los pueblos conocidos como protoeslavos que habitaban al este de la costa del Mar Negro.

Tal vez como consecuencia de la convivencia con los pueblos llegados de la estepa iraní y de Grecia, a lo largo del primer milenio AEC los campesinos protoeslavos enriquecieron su cultura material. Las casas habitación adicionaron la cocina y el cuarto para comer, al mismo tiempo diversificaron sus herramientas. Se han encontrado instrumentos de hierro en estas aldeas ha llevado a suponer que mantenían intercambio con los ancestros de los samoyedos que extraían ese metal en los montes Urales. ${ }^{74}$.

El número de habitantes en las aldeas aumentó y aparecieron las "jefaturas", concepto acuñado por Elman Service (1915-1996) ${ }^{75}$ para designar a las sociedades en las que hay una diferenciación social, existe un liderazgo, casi siempre legitimado por la

\footnotetext{
${ }^{73} \mathrm{http}$ ://www.es.wikipedia.org/wiki/Cimerio consultado 12 de junio de 2013; Moss, op. cit., p. 9.

${ }^{74}$ Longworth, op.cit., pp. 17-19.; Vernadsky, op.cit., pp. 21-22.

${ }^{75}$ Elman R. Service, Origins of the State and Civilization. The Process of Cultural Evolution. Nueva York, W. W. Norton \& Company Inc., 1975. XIX/361 pp., apéndices, pp. 8-16 y 71-102
} 
protección de una deidad, y el o los líderes se encargan de organizar la redistribución de la riqueza. Las normas que las rigen son reconocidas por todos los miembros de la jefatura y, en conjunto, sancionan a quien las infringe. Este tipo de organización precede a la aparición del Estado. Las jefaturas o sociedades de rango están integradas por clanes o linajes, es decir, grupos que reconocen un ancestro común y por tanto sus miembros se consideran parientes directos. Uno de estos linajes detenta el liderazgo político centralizado cuya manifestación fundamental es la mediación entre los diversos clanes que pertenecen a la misma comunidad. Esta autoridad organiza la economía del grupo, designa, por ejemplo, los sitios que cada linaje tiene el derecho de explotar no importa si todavía son sociedades de recolectores y cazadores o de cultivadores, y tiene la misión y el poder para redistribuir la riqueza entre los miembros de la jefatura. La autoridad que detenta no está respaldada por el monopolio del uso de la violencia sino por su prestigio; el origen del prestigio no es el mismo en todas las jefaturas, éste puede radicar en sus habilidades como cazador, como consejero, como guerrero o cualquier otra que el grupo considere importante. En tanto el linaje tenga la capacidad de mantener a la comunidad unida gracias a su mediación, conservará el liderazgo. Estas sociedades no son igualitarias en términos de organización social, por eso se les ha caracterizado como sociedades de rango. Sociedades con estas características también existían en otras partes del mundo.

Las comunidades que habitaban desde la cuenca del Dniéper hasta la región media del Volga se transformaron paulatinamente en sociedades más complejas, tal vez se encontraban organizadas en jefaturas pues hay datos arqueológicos que muestran entierros diferenciados. Estos pueblos vivían en la periferia de los Estados antiguos como el imperio romano de oriente (330-1453) y el imperio sasánida (226-651) cuya cultura irradiaba hacia 
ellos a través de las rutas de intercambio. Algunos cronistas, como Jordanes ${ }^{76}$, de aquellos antiguos Estados que ya habían desarrollado la escritura, aludieron a los pueblos que nos ocupan pero estos datos no son suficientes para reconstruir su historia con cierto grado de continuidad y verosimilitud. Por ello, es necesario complementar la información de estas fuentes con la proporcionada por los descubrimientos de la arqueología. Ambas fuentes muestran que en el siglo $\mathrm{V}$, los pueblos que dieron origen a los eslavos se ubicaban en la periferia del imperio romano de oriente. Fue precisamente el colapso del imperio romano de occidente (siglo V) y las corrientes migratorias germanas hacia el occidente las que propiciaron a su vez la migración de los esclavenos y antas, quienes llegaron a la frontera norte del imperio romano de oriente en el siglo $\mathrm{VI}^{77}$.

Las crónicas de la época y los datos arqueológicos indican que la expansión de los pueblos de la estepa hacia el occidente -los hunos en el siglo V- motivaron la migración de diversos pueblos a los que la historiografía europea denomina de manera genérica germanos quienes huían de la amenaza de los mongoles y los turcos. Al penetrar en Europa derribaron las fronteras del imperio romano de occidente. El reacomodo facilitó que muchas comunidades del norte del Mar Negro se recorrieran al espacio que habían ocupado los germanos. Jordanes llamó a los pueblos que paulatinamente migraron desde el río Vístula y el noroeste del Mar Negro hacia el Danubio, veneti. Decía que estaban divididos en clanes diferentes: los esclavenos se encontraban en la cuenca del Dniéster y se extendían al norte hasta el Vístula, los antas a quienes consideró los más aguerridos, se localizaban en la costa del Mar Negro entre el Dniéster y el Dniéper, menciona a otras tribus ubicadas al norte de éstas y termina diciendo que al este del Dniéper y al norte del Mar Negro se

\footnotetext{
${ }^{76}$ Véase la introducción.

77 Vernadsky, op. cit., pp. 21-23.
} 
encontraban los búlgaros justo en el territorio en el que se detuvieron los hunos antes de atacar el occidente ${ }^{78}$. Fue probablemente durante estos reacomodos que las jefaturas descritas empezaron a identificarse entre sí $\operatorname{como~eslavos~}^{79}$. Pero la gran migración eslava ocurrió cuando los ávaros, otro pueblo de la estepa procedente de la región de Altai, aparecieron en la frontera del imperio romano de oriente y avanzaron hasta Europa central. Los ávaros se alquilaron al imperio romano de oriente para ayudarle a combatir a los pueblos que amenazaba sus fronteras. Ante la presión de los ávaros, los eslavos abandonaron los Cárpatos y la cuenca del río Dniéper para esquivarlos. Las tres rutas de migración que siguieron fueron: 1) hacia los Balcanes, 2) al oeste y el norte ocupando la cuenca del Elba y la costa del Báltico y 3) hacia el este y el norte en la cuenca del Volga hasta llegar al Ártico ${ }^{80}$. Esta tesis se ocupará de las tribus, como los designa la historiografía europea, que siguieron el tercer camino mencionado.

\subsection{Los eslavos del este}

La caída del imperio romano de occidente y los fenómenos migratorios que ocurrieron entre los siglos V y VIII provocaron que individuos y familias pasaran de una comunidad a otra cambiando de referente de pertenencia o bien conservaron el que tenían a pesar de permanecer con el grupo que los había adoptado. Por tanto, cuando se hace referencia de los pueblos que más o menos han podido identificarse con base en los restos arqueológicos y las crónicas, hay que tener presente que no eran grupos homogéneos, estaban unidos por sus tradiciones, sus costumbres pero, sobre todo, por la posibilidad de sobrevivir

\footnotetext{
${ }^{78}$ Jordanes, op.cit., pp. 59-60.

${ }^{79}$ Peter Bogucki reseña del libro "Culture and Society in Early Medieval Eastern Europe" de P. M. Barford en Slavic Review, 61:2, invierno de 2002, pp. 817-818 en http://www.jstor.org/stable/3090393, consultado 2 de noviembre de 2012.

${ }^{80}$ Heather, op.cit., p. 459, 462-463, 507-509; Hellmann, op.cit., p. 15; Pohl, op.cit., pp.18-19.
} 
adaptándose a las opciones que se les presentaban. Este proceso en el que los individuos se reconocen como integrantes de un grupo se denomina etnogénesis. Es decir, la pertenencia a una etnia es resultado de un proceso histórico en el que la etnia es una construcción conceptual de los símbolos culturales que aglutinan a sus miembros ${ }^{81}$. Ahora bien, en apartados anteriores se ha hablado de las comunidades que tal vez dieron origen a los protoeslavos las cuales ocupaban el territorio en el que se asentaron los eslavos del este. Al parecer, los movimientos migratorios iniciados en el siglo $\mathrm{V}$ favorecieron el desplazamiento hacia el este del río Elba y la cuenca del Danubio de gran parte de esta población, fue en ese movimiento en el que adquirieron las características que permiten denominarlos eslavos. Al entrar en contacto con diversos pueblos germanos y con los romanos de oriente quienes habían rescatado la tradición griega, los eslavos adquirieron mejores técnicas de cultivo, de fabricación de cerámica y de herramientas de metal. El desplazamiento de retorno hacia el este de la ribera del Dniéper de algunas comunidades eslavas provocada por la presencia de los ávaros y tal vez porque muchas de ellas decidieron regresar a los ecosistemas de la estepa y la taiga que ya conocían, dieron paso a la aparición de los eslavos del este ${ }^{82}$. Los restos arqueológicos encontrados hasta el momento sostienen esta teoría pero, una vez más, no se ha tenido la capacidad de acceder a su cultura y por tanto tampoco se pueden asegurar los motivos que condujeron a los eslavos a dirigirse primero al oeste y después regresar al este de dónde todo indica que eran originarios y transformarse así de protoeslavos, en eslavos y después en eslavos del este. Veamos cómo ocurrió este último proceso.

\footnotetext{
${ }^{81}$ Vid., Pohl, op.cit., pp. 21-23.

${ }^{82}$ Hearther, op.cit., pp. 510-515.
} 
En el siglo VI, los eslavos del este se localizaban a lo largo de la cuenca del río Dniéper. Al parecer formaban una especie de confederación de jefaturas. Cada jefatura comprendía varios linajes emparentados entre sí, aunque podían integrar a familias que no fueran parientes suyas, se denominaban rod. Practicaban la agricultura, en este periodo se inició el cultivo de centeno de invierno el que constituye todavía hoy en día uno de los cereales más importantes en la dieta rusa ya que se puede sembrar en la taiga. También pescaban, cazaban y recolectaban productos del bosque boreal. En este periodo, el territorio donde se encontraba una comunidad le pertenecía, pero cada jefe de familia tenía asignada una parcela que trabajaba por su cuenta. Sin embargo, si las cosechas no eran abundantes, los miembros de la comunidad ayudaban a sobrevivir a la familia afectada ${ }^{83}$. En los asentamientos de la región, se encuentran algunas diferencias en el tipo de cerámica, en algunos casos estaba fabricada en tornos y en otros no, los productos metalúrgicos en algunos sitios eran más abundantes, en cuanto a la construcción de las viviendas, en algunas comunidades son semisubterráneas y tienen hornos de piedra y en otras están sobre el suelo.

En el siglo VII se construyeron fortalezas. Los poblados eslavos siguieron extendiéndose y en el siglo X ya habían llegado hasta la cuenca del Oka. Al parecer, el flujo migratorio en la taiga siguió el esquema de jefaturas de varios centenares de personas que fundaban un poblado en sitios fáciles de defender. Las cabañas estaban semienterradas, seguramente para soportar el frío, cercanas las unas a las otras y rodeadas por una muralla. Algunas de estas aldeas dieron lugar más tarde a la aparición de ciudades.

\footnotetext{
${ }^{83}$ Hearther, op. cit., pp. 483-485.
} 
Los eslavos rápidamente empezaron a participar en el comercio de pieles -uno de los recursos más preciados que proporciona la taiga- y de esclavos. Es necesario recordar que este territorio estaba ocupado por pueblos bálticos y tal vez por algunos protoeslavos que no se movieron de su hábitat. Estas comunidades convivieron y se mezclaron con los eslavos, los encuentros tal vez no fueron pacíficos pero no se puede precisar la violencia de los conflictos que surgieron entre ellos. En cualquier caso, en el siglo $\mathrm{X}$ los eslavos predominaban en toda la región y se habían extendido a la parte alta del río Volga. Los bizantinos llamaban a estas comunidades antas, como los llamó Jordanes, o rus. De cuando en cuando, los rus guerreaban con sus vecinos. Sin embargo, el botín que obtenían no alteró su modo de subsistencia y tampoco se consolidaron liderazgos de carácter guerrero. Ya que las jefaturas no tenían una gran fuerza militar, los ataques en contra de Constantinopla tan sólo les proporcionaron botín ${ }^{84}$.

El reacomodo poblacional de los siglos V a VIII también propició que otros pueblos se avecindaran en la región. Los jázaros y los búlgaros del Volga, con mayor fuerza militar que los eslavos del este porque eran jinetes esteparios, pronto recuperaron las rutas comerciales, el camino de la seda, que comunicaban a Bizancio con la meseta del Irán y Asia Central hasta llegar a China. Poco después aparecieron desde el noroeste los vikingos, conocidos en la región como varegos ${ }^{85}$, quienes trazaron la ruta del Báltico y el Lago Ladoga hasta Bizancio y el Mar Caspio. Los eslavos del este de inmediato se involucraron en este tráfico mercantil. Para comprender el proceso esbozado es conveniente describir brevemente a los jázaros, los búlgaros del Volga y los varegos y analizar la influencia que

\footnotetext{
${ }^{84}$ Pohl, op.cit., p.20; Hearther, op.cit., pp. 476-490, 499, 509, 774; Longworth, op.cit., pp.19-22

${ }^{85}$ Del ruso varyag' que significa buhonero. Históricamente fue tomada del germano se empleaba para designar a los guardias extranjeros del emperador (vaeringi) bizantino, Preobrazhensky, op. cit., pp. 66-67.
} 
tuvieron en la formación del primer Estado de los eslavos del este. A pesar de que esta tesis no se centra en la expansión rusa en la estepa es indispensable referirse a algunos pueblos como el jázaro que fueron de suma importancia en la formación del Estado ruso.

Desde luego, no debemos perder de vista la enorme influencia del imperio romano de oriente o bizantino en toda esta historia, no solamente porque era uno de los mercados más importantes del periodo sino también porque su cultura se difundió en toda la región. Asimismo, aunque de manera indirecta, el califato abasí (750-1258), jugó un papel destacado al menos en el desarrollo de las rutas comerciales.

También es necesario puntualizar que la génesis del Estado de $\mathrm{Kiev}^{86}$ constituye, al mismo tiempo, la génesis de los eslavos del este como tales, es decir, los eslavos de esta región se diferenciaron paulatinamente de los eslavos septentrionales ubicados en Europa centro-oriental y de los eslavos del sur localizados en la península de los Balcanes ${ }^{87}$.

En el siglo VII, los jázaros de origen turco ocuparon el territorio comprendido entre la ribera sur del río Don y la ribera sur del Volga y el Mar Negro y el Mar Caspio, es decir, vivían en el norte y centro del Cáucaso. Como puede apreciarse en el mapa 4 llegaron a controlar un territorio extenso al norte del Mar Negro y del Mar Caspio lo que explica su contribución a la formación del principado de Kiev.

\footnotetext{
${ }^{86}$ En el capítulo II se discutirán las características de este Estado.

${ }^{87}$ D. Kaliskov, J., Smernov, A. Kopaniov (et al.) [no se encontraron datos sobre los redactores], Historia de la URSS. Primera parte. Desde la antigüedad hasta la Revolución Socialista de Octubre. $2^{\text {a }}$ ed. Trad. L. Vladov. Presentación M. Shlosberg. Moscú, Edit. Progreso, [1977] 384 pp., ilus., pp.31-33.
} 


\section{Mapa 4. EL JAGANATO JÁZARO EN EL SIGLO IX}

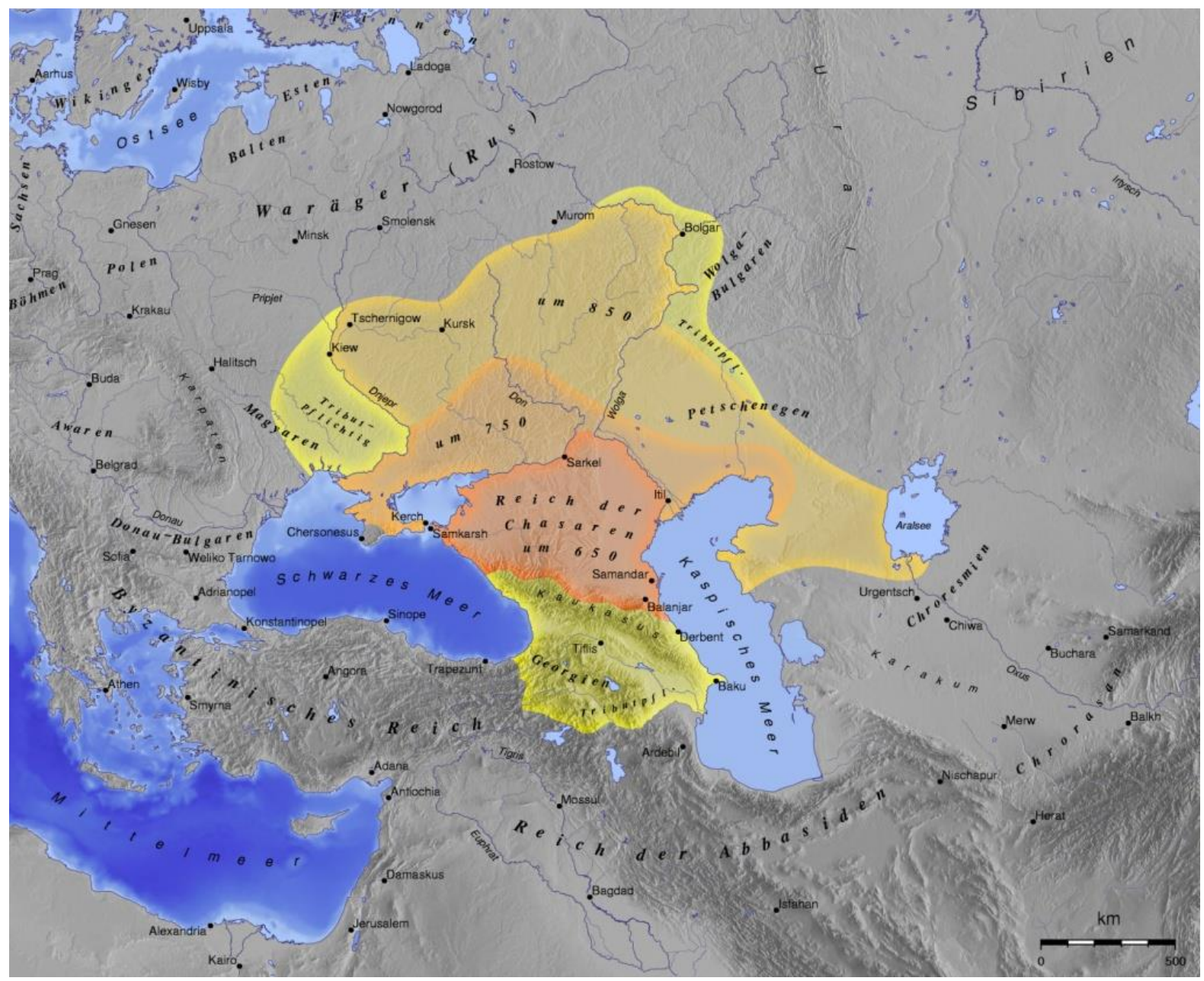

Fuente: http://www.commons.wikimedia.org/wiki/File:Chaseren.jpg consultado 3 de mayo de 2013

A finales del siglo VII lograron detener el avance de los musulmanes del califato Omeya (661-759) con lo que impidieron que invadieran Bizancio por su frontera oriental. Formaban un Estado encabezado por un jagan, título equivalente al de máximo gobernante $^{88}$, y un beg ${ }^{89}$ quien hacía las veces de primer ministro. El gobierno estaba respaldado por un ejército regular cuyos integrantes recibían un salario. Eran pueblos

${ }^{88}$ Ésta es una palabra de origen turco mongol vid. http://es.wikipedia.org/wiki/kan consultado 16 de octubre de 2012.

${ }^{89}$ Palabra de origen turco que se utilizaba para designar al segundo en el mando del gobierno vid. http://es.wikipedia.org/wiki/bey consultado 16 de octubre de 2012. 
trashumantes criadores de ganado y comerciantes, controlaban las rutas de intercambio que cruzaban su territorio. Gracias al comercio, el jaganato era rico, vendían esclavos, pieles, miel, centeno -productos que recibían como tributo de las comunidades eslavas y bálticas del norte- y las manufacturas que ellos producían, a cambio obtenían monedas de plata acuñadas en el califato Abasí (750-1258).

El jaganato de Jazaria era un Estado multiétnico y multicultural pues ahí habitaban grupos de iraníes, algunos griegos, pueblos de habla urgo-finesa como los mari o los komi y eslavos. Por supuesto no todos se dedicaban a criar ganado o al comercio, también cultivaban -cereales y vid-, cazaban, recolectaban, pescaban y fabricaban cerámica. Fundaron ciudades como la capital Atil/Itil y Sarkel. Entre los siglos VIII y X se convirtieron al judaísmo y permitieron que los judíos de la diáspora se asentaran en su territorio. Turcos y judíos se mezclaron y así la cultura judía se impuso en la elite de la región, tal vez esta conversión también tuvo motivos políticos pues los Estados vecinos eran cristianos y musulmanes. Pero no todos los habitantes de Jazaria se convirtieron al judaísmo, ahí vivían paganos, musulmanes y cristianos. El Estado jázaro practicaba la tolerancia, necesaria para salvaguardar sus intereses comerciales. La paz que impusieron en la estepa facilitó el asentamiento de los eslavos del este y de los búlgaros del Volga quienes localizados en la periferia de Jazaria le pagaban tributo además de los derechos por pasar sus mercancías por su territorio.

Cuando surgió el principado de Kiev algunos comerciantes jázaros se mudaron a la ciudad. Es probable que unos cuantos emparentaran con los primeros gobernantes de Kiev. Esto puede indicar la relevancia de la actividad comercial jázara en la formación del primer Estado de los eslavos del este pues a través de ellos éstos pudieron comerciar con el califato 
abasí y con Asia central. Esta convivencia dejó huella en la lengua eslava que tomó algunos términos de las lenguas turcas. Jazaria sucumbió como un Estado poderoso en 965, víctima de los ataques de los pechenegos, otro pueblo de la estepa que pertenecía a los cumanos y hablaban una lengua de la familia lingüística turca, y de los rus de Kiev. La pérdida del poder de Jazaria facilitó que diversos pueblos de la estepa cruzaran el Cáucaso en sus rutas migratorias o al menos para realizar sus asaltos en contra de los pueblos agrícolas, como los rus $^{90}$.

Alrededor de 900, los búlgaros del Volga se convirtieron al islam, en consecuencia poco a poco sustituyeron a los jázaros como intermediarios en el intercambio entre el mundo musulmán y los eslavos del este. Algunos estudiosos suponen que los búlgaros son los descendientes de los hunos, cuando los ávaros se agruparon y formaron una sola entidad, algunos grupos se desprendieron de ellos y se les conoció como búlgaros. Mientras el jaganato jázaro estaba en su apogeo, algunas comunidades búlgaras se ubicaron en la ribera del Volga y otros emigraron a los Balcanes. En el mapa 5 se muestra la ubicación de los búlgaros del Volga. Como los búlgaros eran guerreros, algunos servían al Estado jázaro y otros al bizantino. En el siglo X, los búlgaros del Volga tenían como centro principal de intercambio la ciudad de Bulgar a donde acudían mercaderes musulmanes y rus. Para ese momento, el jaganato jázaro ya se había transformado en un intermediario incómodo al que además debían tributo, seguramente por eso fue destruido.

\footnotetext{
${ }^{90}$ Riasanovsky, op.cit., pp. 17-19; Vernadsky, op.cit., pp. 27-31; Kevin Alan Brook (1975-), "Los khazares: un experimento europeo de construcción de un Estado judío”, trad. Central Pedagógica Hebraica en http://www.khazaria.com/espanol/jazaros1.html consultado 28 de septiembre de 2011; Roman K. Kovalev [PhD 2002], "Khazars" en Encyclopedia of Russian History, 2004 en http://www.encyclopedia.com/utility/printdocument.aspx?id=1G2:3404100647 consultado 28 de septiembre de 2011; Gwyn Jones (1907-1999), A History of the Vikings. 2a ed. reedición 2001. Gran Bretaña, Oxford University Press, 1984. 504 pp., ils. y mapas, pp. 148-149, p. 248; Longworth, op. cit., pp. 27-31; Matthew P. Romaniello reseña del libro "Nomads and Their Neighbors in the Russian Steppe: Turks, Khazars, and Qipchags" por Peter B. Golden, Russian Review, 63:2, abril de 2004, pp. 328-329 en http://www.jstor.org/stable/3664094 consultado 9 de noviembre de 2012, p. 328.
} 


\section{Mapa 5. UBICACIÓN DE LOS BÚLGAROS DEL VOLGA c. SIGLO X}

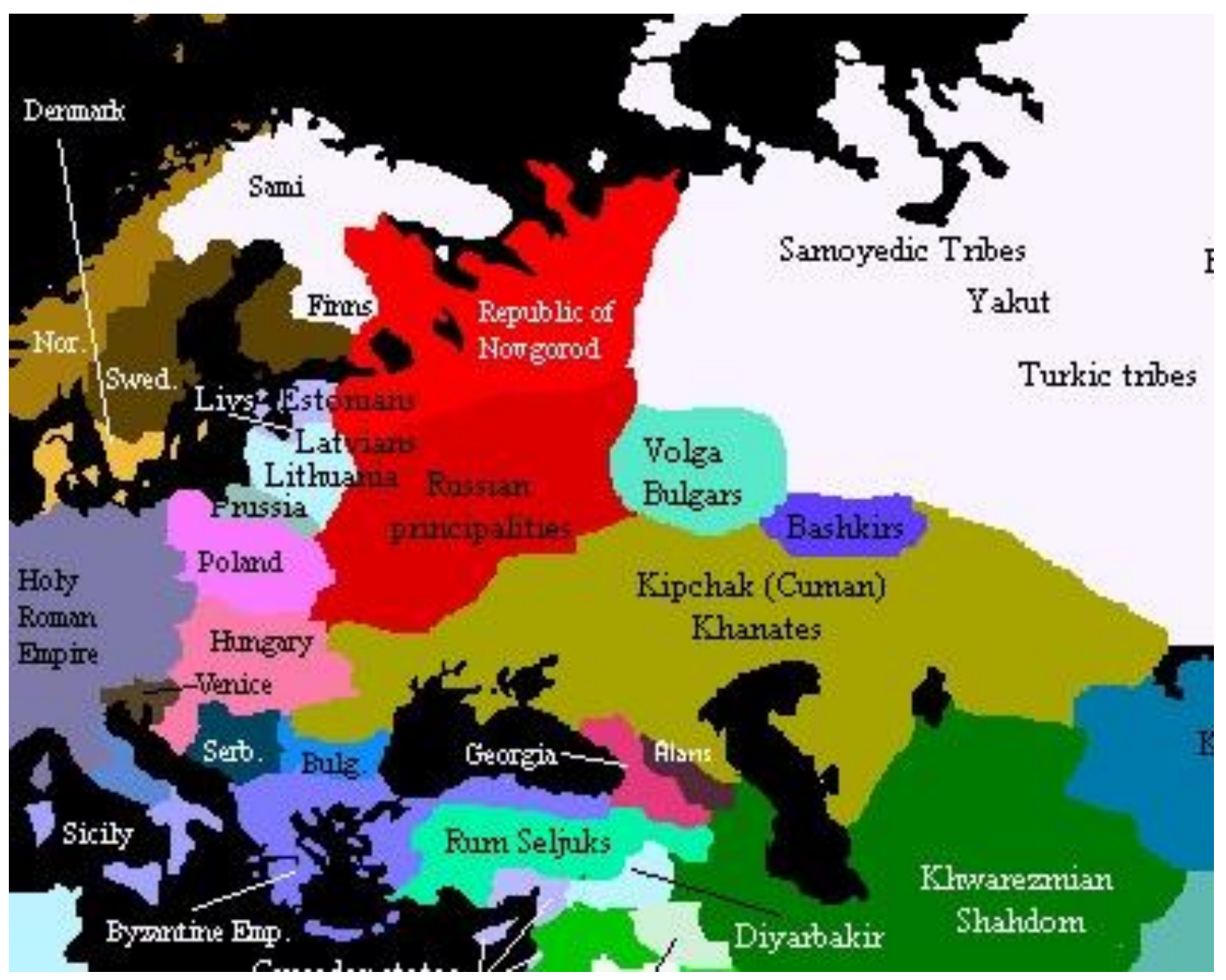

Fuente: http://www.wikimedia.org/wikipedia/commons/f/f8/premongolEurasia.png consultado 4 de mayo de 2013

Cuando los rus adquirieron la fuerza suficiente, sometieron a los búlgaros del Volga y se adueñaron de las rutas comerciales que tenían en su poder. Los mercaderes rus a quienes los musulmanes conocieron en la ciudad de Bulgar asistían en grupos comandados por jefes escandinavos acompañados por eslavos ${ }^{91}$. Veamos cómo se creó esa asociación.

Desde el siglo VI aparecieron, primero en las costas del Báltico y, a través del golfo de Finlandia, en el Lago Ladoga, los vikingos procedentes de la parte oriental de la

\footnotetext{
${ }^{91}$ Vernadsky, op.cit., p.27, 30; Phol, op.cit., pp.19-20; Hearther, op.cit., p. 530-531; Jones, op.cit., p.249.
} 
península escandinava ${ }^{92}$. A estos vikingos se les ha llamado suecos y también se les conoce como varegos. Los vikingos estaban interesados en extender su comercio desde Escandinavia hacia el este. El intercambio era fundamental para ellos pues obtenían de las regiones templadas metales y vino que no producían, entre otros bienes tal vez no tan importantes, y vendían pieles, marfil, madera, en fin artículos propios del bosque boreal. Fundaron una factoría a orillas del Lago Ladoga llamada Staraia Ladoga. Acostumbrados a vivir en la taiga, sabían navegar en aguas frías. Al arribar a la orilla opuesta del Báltico se encontraron con aldeas de baltos y eslavos a quienes de inmediato incluyeron en sus expediciones de saqueo y comerciales. Una vez en la región, los emprendedores varegos empezaron a navegar en los ríos en busca de nuevas oportunidades comerciales y, por tanto, de enriquecimiento. Los ríos Voljov, Oka y la parte alta del Volga fueron los primeros en formar parte de sus nuevas rutas comerciales. Siguiendo el curso del Volga en poco tiempo extendieron sus operaciones hacia el sur, en un principio con la anuencia de los jázaros y más tarde por su propia cuenta. Después utilizaron los ríos Don y Dniéper para llegar al Mar Negro y el Volga para arribar al Mar Caspio, desde ambos mares establecieron relaciones de intercambio con Bizancio y el califato abasí respectivamente. Fueron los musulmanes y los bizantinos quienes designaron a estos comerciantes como rus. En las riberas de los ríos había aldeas habitadas por baltos y eslavos, el impulso que los varegos dieron al comercio propició el florecimiento de algunos de estos asentamientos entre ellos la ciudad de Kiev. En efecto, la población local los abastecía de comida, les sirvieron de guías y les ayudaron a construir y mantener los muelles. Los varegos buscaron en la taiga

\footnotetext{
92 Jones, op.cit., p. 242, el autor menciona que la Saga Tnglinga alude vagamente a que Ivar Vidfadmi ( $c$.
} 650-700) tenía posesiones cerca del Lago Ladoga. 
rusa los productos del bosque que también había en su lugar de origen y sabían en dónde venderlos: pieles $^{93}$, miel, ámbar, cera y esclavos.

Los esclavos eran esenciales en la economía de los vikingos. En un principio los trasladaban a la península escandinava pero cuando abrieron las rutas hacia el sur ofrecieron esa misma mercancía a musulmanes y bizantinos quienes demandaban una gran cantidad de ellos. Los vikingos obtenían la mayoría de los esclavos en los asaltos a las poblaciones localizadas entre el Vístula y el Dniéper. Las pieles y el resto de los productos del bosque también eran apreciados. El contacto con los musulmanes brindó a los varegos la oportunidad de adquirir, además de la plata, seda de China, cristal de Persia, recipientes de cobre elaborados en el este del Mar Caspio y hasta especies de la India. Estas mercaderías llegaron no solamente a la Rus sino a Escandinavia y hasta Europa occidental $^{94}$. En el mapa 7 se ubican los centros comerciales más importantes de los vikingos y las dos rutas mencionadas

${ }^{93}$ La mayor parte de las pieles que vendían eran de animales con pelaje como ardillas, zorros y martas cibelinas. Las formas más sencillas y antiguas de curar estas pieles para que no se deterioren son: 1) el curado por salazón, las pieles son dejadas en la playa y la sal del mar impide sus descomposición, 2) curado por secado, se dejan las pieles descarnadas secar al aire y 3) curado por ahumado, el humo contribuye a impedir la descomposición de las pieles. La piel se expone protegiendo el pelaje y por lo común se detiene con estacas para que seque estirada. Véase Josuah, "Secado de piles de animales", 16 de agosto de 2008, 10 pp. en http://foro.fuentedepermacultura.org/index.php consultado 24 de noviembre de 2011.

${ }_{94}$ Vernadsky, op.cit., pp. 28-32; Hearther, op.cit., pp. 532-536, 640-641; Jones, op.cit., p. 157, 252-253; Longworth, op.cit., p. 24. 


\section{Mapa 7. CENTROS COMERCIALES EN LAS RUTAS DE LOS VAREGOS}

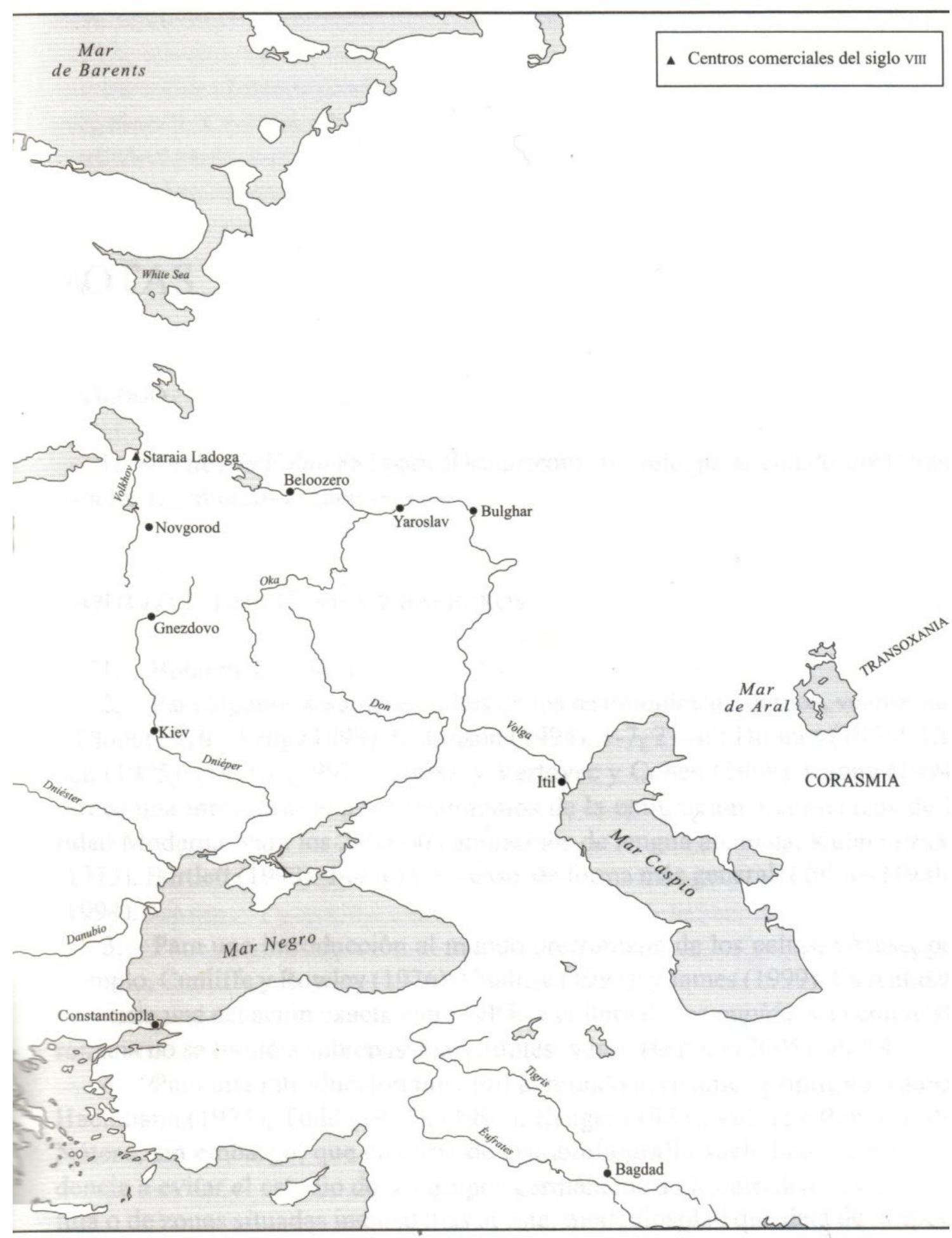

Fuente: Hearther, op. cit., p. 725 
Las fuentes musulmanas, entre las que destaca la de Ibn-Fadlan ${ }^{95}$, indican que los escandinavos obtenían las mercancías del bosque cobrando tributo a las aldeas ahí asentadas. Pero si consideramos que éstos llegaron en grupos muy pequeños y que en la mayoría de los casos no se avecindaban en el territorio, probablemente concertaron acuerdos con la población local para obtener las mercancías que ellos, gracias a su pericia como navegantes, podían conducir a los mercados más importantes.

\begin{abstract}
Debemos considerar la explotación escandinava de los bosques del norte en forma de una serie de pequeñas compañías que tenían diversos derechos negociados y/o afirmados de cualquier manera sobre los distintos territorios que producían sus mercancías. La población local suministraba las mercancías, o muchas de ellas, y los escandinavos la organización, el transporte y los conocimientos necesarios para llevar esos productos a mercados distantes y para regresar con un beneficio sustancioso [...] Los siglos IX y X no fueron una época de enfrentamiento entre escandinavos y eslavos, sino de pequeños productores mutuamente competitivos en términos económicos. Cada empresa comercial, compuesta por escandinavos y población indígena (ya fueran fineses, baltos o eslavos), vendían los mismos productos en el mismo mercado ${ }^{96}$.
\end{abstract}

El sitio en donde los varegos paraban para iniciar sus operaciones tanto en la taiga como en la estepa era Staraia Ladoga, ahí cambiaban sus embarcaciones propias para navegar en el mar por otras adecuadas para navegar por los ríos, desde ahí bajaban por el Dniéper o el Volga recogiendo las mercancías que trasladaban al sur. Hasta el momento, las investigaciones arqueológicas y las fuentes escritas indican que en la región ya se construían embarcaciones antes de la llegada de los vikingos. Éstas eran pequeñas y servían para navegar distancias cortas en los ríos y los lagos, es posible que la tecnología para construirlas combinara una tradición finesa con una eslava. Cuando los varegos llegaron, su tecnología náutica se combinó con la local. A partir del siglo VIII empezaron a construirse naves más grandes. El emperador Constantino VII Porfirogeneta (905-959) relató en su

\footnotetext{
${ }^{95}$ Turkic World, “Ahmad Ibn-Fadlan, Rislaya. Ibn-Fadlan's Travel to Bulgaria. Edition: Ibn-Fadlan's Travel to Volga". Trad. y comentario basados en la edición del académico I. Yu. Krachkovsky (1883-1951), MoscúLeningrado, 1939. http://s155239215.onlinehome.us/turkic/10_History/IbnFadlan.htm, consultado $29 \mathrm{de}$ noviembre de 2011.

${ }^{96}$ Herther, op.cit., p. 539.
} 
texto De aministrando Imperio ${ }^{97}$ que los rus llegaban a la desembocadura del Dniéper en unas embarcaciones que denominó monoxyla. Según el emperador, los aldeanos las construían con un solo tronco y las llevaban a Kiev para venderlas a los mercaderes. Sin embargo, los restos arqueológicos ${ }^{98}$ no permiten establecer cómo eran exactamente. A pesar de que existen ilustraciones en monedas, las imágenes no son nítidas. Sin embargo, ha sido posible elucidar que desde la desembocadura del río Neva -por el que se comunicaban del golfo del Finlandia al Lago Ladoga- y hasta Staraia Ladoga se construían embarcaciones para navegar en el mar, los ríos y los lagos, las cuales eran más dúctiles que las largas que se usaban en el Don, el Dniéper y el bajo Volga porque en el norte los ríos tienen más rápidos y la altura es irregular. Lo único que hasta el momento se puede afirmar es que la tecnología local fue influida por la tecnología que los varegos llevaron consigo.

Estos mismo datos arqueológicos muestran que la ruta del Volga era más importante que la del Dniéper porque llevaba al corazón del califato abasí -donde predominaba la tradición persa- y porque el río tenía menos obstáculos naturales para navegarlo. En el siglo X, la presencia de los varegos en la taiga de la Rus se modificó. En algún momento, Staraia Ladoga fue atacada y se le reconstruyó con viviendas de piedra, también se levantó una muralla del mismo material rodeada por un pantano. Al mismo tiempo aparecieron otros poblados donde existen evidencias de haber sido habitados por escandinavos. El más importante, que ya se había ocupado algunas décadas más temprano, fue el de Gorodishche cerca del río Voljov. En este pueblo vivían grupos eslavos y fineses y probablemente fue el

\footnotetext{
${ }^{97}$ Constantine Porphyrogenitus, De Administrando Imperio. Trad. R. J. H. Jenkings, editor GY. Moravcsik, reimp. De la 2a ed., Washington, Dumbarton Oaks, 2006. 354 pp. (Harvard University Center for Byzantine Studies, I), pp. 57-58.

${ }^{98}$ Petr Sorokin [actualmente trabaja en el Instituto de Historia de Cultura Material, San Petersburgo], "Waterways and Shipbuilding in North-western Russia in the Middle Ages", 13 pp. en http://www.abc.se/ pa//mar/rus-ship.htm consultado 14 de septiembre de 2011.
} 
origen de Novgorod. Se han encontrado otros asentamientos: Timerevo que más tarde se convirtió en Yaroslav, Sarskoe después llamado Rostov, Mijailovskoe, Petrovkoe, Pskov, y Murom, entre otros. Las viviendas y los cementerios demuestran que, a partir del siglo X la presencia de los varegos implicó mucho más que incursiones temporales de asalto y comercio, desde entonces establecieron aldeas en las que vivían también mujeres y niños. Para ese periodo, los escandinavos llegaban con regularidad al centro comercial de los búlgaros del Volga y ahí realizaban las operaciones en las que obtenían monedas de plata acuñadas por los musulmanes. De hecho, la presencia de estas monedas en los sitios de la taiga de la Rus es la evidencia más clara de la estancia de los varegos. En la cuenca del Dniéper, los escandinavos tenían otro poblado importante, Gnezdovo después Smolensk, el cual a través del lago Ilmen facilitaba la comunicación entre el río y el Lago Ladoga.

En los sucesos del siglo $\mathrm{X}$ aparece una divergencia entre el relato de La Primera Crónica Rusa (Povest'vremennyj let ${ }^{99}$ ), el primer documento escrito por los eslavos sobre la formación de su propio Estado, y los datos arqueológicos. De acuerdo con La Primera Crónica Rusa, Kiev fue fundada en el siglo IX por Ryurik, un príncipe vikingo, a reserva de retomar este tema más adelante, por el momento importa destacar que, según las fuentes escandinavas y los datos arqueológicos, Gnezdovo e incluso Shestovista que después cambió su nombre a Chernigov eran poblaciones más importantes que Kiev. Además, todo parece indicar que el asentamiento principal era el del Volga no el del Dniéper. De

\footnotetext{
${ }^{99}$ Esta crónica puede consultarse en línea en la siguiente dirección http://clover.slavic.pitt.edu/pvl/ost1.html , The Russian Primary Chronicle. Laurentian Text. Ed. Y trad. Samuel Hazzard Cross (1891-1946) y Olgerde P. Sherbowizt-Wetzor, Cambridge, Massachusettrs, The Medieval Academy of America, [2013]. 340 pp. (The Medieval Academy of America Publication No. 60) los comentarios sobre ella se encuentran en la introducción.
} 
cualquier manera, las fuentes musulmanas describen a los rus o varegos organizados en pequeños reinos unos independientes de otros pero relacionados entre sí ${ }^{100}$.

Antes de estudiar al Estado de Kiev conviene recapitular lo que se analizó sobre la vida de los escandinavos en la región para establecer, en la medida de lo posible, sus aportaciones a la formación del Estado de Kiev y de la cultura de los eslavos del este. En un principio, los varegos no llegaron con ejércitos de conquista sino en pequeñas unidades dedicadas al saqueo, en primera instancia, y al intercambio comercial; cabe subrayar que como los esclavos eran la mercancía más redituable -los utilizaban en sus propias tierras en Escandinavia y tenían mucha demanda tanto en el imperio bizantino como en el califato abasí-, los obtenían mediante el asalto a las aldeas campesinas. En el siglo X, cuando los escandinavos ya conocían los sistemas fluviales de la región, los productos que ofrecían, a sus habitantes baltos, fineses y eslavos, fundaron poblados a los que migraron familias completas; es probable que algunas de ellas se dedicaran al cultivo y no al comercio. Estos asentamientos se encontraban en las márgenes de los ríos utilizados para comerciar. En el oeste siguiendo el curso del río Voljov, Gorodishche era el centro más poderoso, en la zona se han encontrado restos de viviendas, murallas y cementerios. Por este río los navegantes se comunicaban con el Lago Ladoga y de ahí con el mar Báltico.

En el curso alto del Volga el poblado de Timerevo tuvo una extensión de diez hectáreas mientras que en Mijailovskoe se halló un cementerio con 400 tumbas. Esta era la ruta que los llevaba al jaganato búlgaro. En la parte alta de Dniéper se calcula que Gnezdovo tuvo una población aproximada de 1000 habitantes. En esta región existen

\footnotetext{
${ }^{100}$ Hearther, op.cit., pp. 542-547.
} 
tumbas en las que hay mujeres que no llevan adornos propios de las escandinavas lo que lleva a suponer que tal vez eran eslavas.

En Kiev, ubicada al sur, casi no se han encontrado rastros de los varegos, sin embargo ésta era la ruta que conducía al imperio bizantino. Conviene destacar que algunos de estos centros ocupados por los escandinavos más tarde cambiaron su nombre a medida que éstos se fueron fundiendo con los eslavos del este ${ }^{101}$.

Los relatos que describen la llegada de los rus al jaganato de los búlgaros del Volga y al norte del Mar Negro con séquitos numerosos son de este período lo que confirma el supuesto de que en ese momento había una población escandinava de miles de personas, quizás rebasaban los 10 000. Al parecer, los mercaderes emprendedores más prósperos lograron acumular una gran riqueza con la que sostenían a sus séquitos. Los varegos organizaron esta red comercial apoyándose en la población local, por ejemplo, para establecer los muelles en los que se detenían los barcos para recoger mercancía ya fuera como tributo o por compra-venta eran necesarias instalaciones y mantenimiento que seguramente estaban a cargo de los lugareños. Los escandinavos usaban embarcaciones fabricadas por los eslavos para navegar por los ríos que estos últimos utilizaban con anterioridad. En suma, los conocimientos geográficos que los varegos debieron obtener para trazar las rutas fluviales de comercio, la organización de esa red comercial, así como la aparición de estructuras de poder reflejadas en los séquitos fueron elementos de suma importancia para que los eslavos del este se afianzaran como el pueblo predominante

\footnotetext{
${ }^{101}$ Simon Franklin reseña del libro "Les Centres proto-urbains russes entre Scandinavie, Byzance et Orient" por M. Kazanski, A. Nercessian y C. Suckerman" en Slavic Review, 61:2, verano de 2002, p. 401 en http://www.jstor.org/stable/2697155 consultado 2 de noviembre de 2012.
} 
cuando los varegos regresaron al oeste, quienes permanecieron en la región se subsumieron

en la cultura de los eslavos orientales ${ }^{102}$.

En el siguiente fragmento del escrito de Ibn-Fadlan quien fue enviado en misión

oficial por el califa de Bagdad a Bulgar, en 922, se describe una expedición vikinga:

Yo vi a los rus cuando vinieron en sus viajes comerciales y arribaron a Atil [Itil, capital del jaganato jázaro]. Yo nunca había visto cuerpos más perfectos que los de ellos, son tan altos como palmeras, rubios y rojizos; no llevaban qurtaqs [túnicas] ni caftanes, pero cada hombre llevaba una capa que cubría la mitad de su cuerpo dejando uno de sus brazos descubierto. Cada uno de ellos portaba un hacha, una espada y una daga y nunca dejaban ninguna de las armas que he mencionado. Sus espadas eran del tipo franco con una hoja ancha y ondulada. Cada hombre tenía desde las uñas de los pies hasta el cuello, líneas verde oscuro y dibujos. Cada una de sus mujeres llevaba un pequeño collar en su pecho hecho con hierro, plata, cobre u oro, su valor iba de acuerdo con la riqueza de su marido. Cada collar tenía una funda en la que había una daga que también descansaba en su pecho. Alrededor de su cuello llevaban gargantillas de oro y plata. Si un hombre tenía diez mil dirhams, hacía una gargantilla para su esposa; si tenía veinte mil dirhams hacía dos gargantillas para ella, por cada diez mil dirhams le daba una gargantilla a su esposa. Una mujer podía tener muchas gargantillas. Los adornos que ellos apreciaban más eran las cuentas de cerámica verde oscuro que llevaban en sus barcos: compraban una cuenta por un dirham cada pieza y hacían con ellas collares para sus esposas [...] ellos llegaban de su país y anclaban en el Atil [Volga], que es un río largo, y construían en la ribera largas casas de madera. En cada casa vivían diez o veinte de ellos, a veces más, a veces menos [...] En cuanto sus barcos arribaban al muelle cada uno de ellos desembarcaba llevando pan, carne, cebollas, leche y nabidh [una bebida embriagante elaborada con uvas o dátiles] e iba ante un tronco alto que tenía la cara de un hombre rodeado de pequeñas imágenes cada una de las cuales tenía detrás de ella largas piezas de madera enterradas. El rus se postraba ante la escultura y decía: "Oh señor, vine de una tierra distante trayendo muchas muchachas esclavas, muchas, muchas cabezas [de ganado] y muchos sables y muchas, muchas pieles." Continuaba enumerando toda la mercancía que llevaba y entonces decía "Yo te traigo esta ofrenda", dejaba lo que traía enfrente del pedazo de madera diciendo "Deseo que me proveas de un mercader que tenga muchos dinares y dírhams y que me compre todo lo que quiero sin regatear" [...] a veces la venta le resultaba sencilla y vendía todo rápido, entonces decía, "Mi Señor ha satisfecho mi petición, debo recompensarlo". Reunía cierto número de ovejas o de reses y los sacrificaba, distribuía una parte de la carne y el resto la ponía enfrente de los troncos de madera. Colgaba las cabezas de las reses o las ovejas en el tronco. En la noche los perros se comían todo. Entonces el hombre decía "Mi Señor está contento conmigo y se comió mi regalo". 103

El pasaje evoca más a los escandinavos que a los eslavos. Pero lo más importante del

fragmento es que se refiere a una sociedad jerarquizada con base en la riqueza que

${ }^{102}$ Hearther, op.cit., pp. 559-583; Jones, op.cit., pp. 255-256.

${ }^{103}$ Traducción propia basada en el texto Turkic World, "Ahmad Ibn-Fadlan, Rislaya. Ibn-Fadlan's Travel to Bulgaria. Edition: Ibn-Fadlan's Travel to Volga”, op. cit., p. 18. Se cotejó el fragmento con el citado en Jones, op.cit., pp. 164-165 apud. 'Ibn Fadlan's Account of the Rus with Some Commentary and Some Allusions to Beowulf', in Medieval and Linguistic Studies in Honour of Francis Peabody Magoun. New York, 1965, pp. 92-119. Un dirham equivalía a una décima parte de un dinar de oro, éste pesaba 4 grs. aproximadamente. 
acumulaba cada mercader la cuál le daba prestigio. Eso explica por qué entre más bienes acumularan los hombres, más gargantillas llevaban las mujeres, ése era el símbolo del prestigio. Sin embargo, no menciona que hubiera alguno de ellos que concentrara el poder político o militar. Los séquitos también daban prestigio y son una forma de redistribución de la riqueza, es decir, había un líder al que seguían otros tantos que estaban armados igual que él. Cuando se realizaba el rito de agradecimiento a los dioses parte de la carne, es decir, de la riqueza obtenida, se repartía entre los rus. Esto permite suponer que los rus estaban organizados en jefaturas pues existían jefes, rangos, es decir una diferenciación social pero la riqueza se redistribuía entre los miembros del grupo ${ }^{104}$.

Por otra parte, podemos observar que los rus conocían a los mercaderes musulmanes quienes acostumbraban obtener la mayor ventaja posible en sus transacciones. El texto pues es una muestra de las relaciones interculturales que existían entre los habitantes de la taiga y los de la estepa, enmarcadas en una red de intercambio que se formó durante muchos siglos y que diversos pueblos contribuyeron a tejer.

Es interesante llamar la atención sobre la insistencia del autor en que los rus presentaban sus ofrendas y hacían peticiones a troncos y pedazos de madera ¿qué otra cosa podía escribir un musulmán? Por su parte Constantino VII Porfirogeneta realizó una descripción similar sobre los rus que viajaban por el Dniéper. Brevemente describe los puntos en los que los mercaderes debían detenerse para salvar los accidentes del río.

${ }^{104}$ Para profundizar en la utilización de este concepto en las sociedades a las que nos referimos vid. Nikolay N. Kradin (1962-) "Cultural Complexity of Pastoral Nomads", 22 pp. En http://en.wikipedia.org/wiki/Nikolay_Kradin, consultado 11 de diciembre de 2012 y del mismo autor "Nomadism, Evolution and World-Systems: Pastoral Societies in Theories of Historiacal Development" en http://intersci.ss.uci/wiki/ebooks/Artickles/Nomadism\%20kradin.pdf, consultado 11 de diciembre de 2012. De acuerdo con este autor, los pueblos nómadas en Asia también se consideran jefaturas complejas puesto que existían jefes y linajes emparentados con ellos e incluían a numerosos pueblos. La riqueza se redistribuía en función del rango que tuviera cada linaje dentro de la estructura social. 
Entonces bajaban parte de las mercancías y a los esclavos encadenados. Debían transportar los monoxyla por tierra. En ese momento, podían ser atacados por los pechenegos -pueblo originario de la estepa de Asia central que hablaba una lengua turca ${ }^{105}$ - quienes realizaban correrías de pillaje tanto en las tierras de la Rus como en los territorios de los búlgaros. Cuando por fin alcanzaban la parte baja del Dniéper, en la isla de San Gregorio presentaban también ofrendas en el lugar donde había un gran roble. Cabe destacar que el emperador no expresa ninguna opinión sobre las ofrendas que los rus hacían una vez que llegaban a su destino, sin embargo en su texto aconseja cómo utilizar a unos pueblos contra otros para garantizar la paz en el imperio ${ }^{106}$.

Para cerrar este capítulo cabe reflexionar en torno a los debates sobre la importancia que tuvieron los varegos en la fundación del primer Estado en el territorio habitado por los rus. Al parecer obedecen a la interpretación que los rusos hacen de su propia historia y no constituye un problema histórico que las fuentes no permitan resolver. La participación de los vikingos en este proceso parece incuestionable como también es evidente que los varegos se mezclaron con los eslavos quienes, como se ha visto a lo largo de esta exposición, eran el resultado de la integración de pueblos muy diversos; de estas múltiples fusiones culturales emergieron los eslavos del este o rus como un pueblo que se consideraba a sí mismo diferente a sus vecinos ${ }^{107}$ y que siglos más tarde lograron consolidar un Estado fuerte y poderoso: el imperio ruso.

\footnotetext{
${ }^{105} \mathrm{http}$ ://www.es.wikipedia.org/wiki/Pechenego consultado 20 de junio de 2014.

${ }^{106}$ Constantine Porphyrogenitus, op. cit., pp. 49-63.

${ }^{107}$ Longworth, op.cit., p. 25.
} 


\section{CAPÍTULO II. LA RUS DE KIEV (siglo IX-c. 1230)}

\subsection{Kiev, el primer Estado de los eslavos del este}

En el entendido de que Kiev surgió como un Estado al mismo tiempo que los varegos, jázaros y búlgaros mantenían relaciones de intercambio de bienes culturales y materiales con los eslavos del este, en este capítulo se elucidará cómo fue que estos últimos lograron encabezarlo y, al mismo tiempo, caracterizarse como un pueblo. Para comprender mejor las características de este primer Estado conviene señalar algunas de las características comunes a los Estados preindustriales. Para iniciar hay que considerar que en un Estado un grupo ejerce el dominio sobre las personas y sobre las cosas ${ }^{108}$. Se concentra en este grupo la capacidad de movilizar tanto recursos humanos como materiales. Es decir, las relaciones de carácter personal se transforman en relaciones impersonales. Sin embargo, quienes ejercen el dominio sobre las personas también las protegen con el fin de beneficiarse de ellas sin destruirlas. De esta manera quienes ejercen el dominio logran que los productores primarios, en el caso de la Rus, la mayoría campesinos pero también había pescadores, criadores de ganado y cazadores, dependieron en gran medida de aquellos que los dominaban y extraían de ellos una cuota de explotación para su propio beneficio. Esta situación supone la existencia de una sociedad estratificada tanto social como económicamente, lo que no sucede en las sociedades de rango o jefaturas.

La concentración del poder también es resultado del aumento de la población y de la necesidad de distribuir tareas de todo tipo entre los distintos grupos sociales que forman

\footnotetext{
108 Las características que a continuación se proporcionan se tomaron de David Christian (1946-), Mapas del tiempo. Introducción a la <<Gran Historia $>>$. Prefacio William H. McNeill, Trad. Antonio Prometeo Maya. Barcelona, Crítica, 2007. 726 pp., ils., cuads., grafs. y mapas, pp. 299-308, 329-341
} 
parte del Estado. El Estado cumple por tanto, también una función de organizador y coordinador de las actividades humanas para administrar, tanto en el ámbito de la producción como de la distribución, lo que generan. Además, facilita las redes de distribución de las innovaciones tecnológicas así como de los conocimientos, fomenta el aprendizaje colectivo. A partir del papel que desempeña el grupo dirigente aparece la desigualdad ya que los gobernantes utilizan los recursos que administran para coaccionar a los gobernados. Así, se arrogan el uso de la violencia tanto al interior del Estado que gobiernan como al exterior. La complejidad del Estado tradicional depende del número de personas de que disponga y de los recursos que explote en el territorio en el que ejerza su dominio. Las redes de intercambio y control serán más o menos tupidas y complejas a medida que sume más recursos bajo su control.

De acuerdo con La Primera Crónica, la ciudad de Novgorod fue fundada por los eslavos antes que Kiev. Era tan antigua que el apóstol Andrés la había visitado utilizando las rutas de comercio que la conectaban con las colonias griegas del Mar Negro. Kiev fue fundada por tres hermanos polianos (un subgrupo de los eslavos del este) llamados Kii, Shchek y Joriv. La crónica menciona la llegada de los varegos y enumera a diferentes pueblos eslavos que hablaban el mismo idioma de los pobladores de Kiev, pero cada uno de ellos se diferenciaba de los demás; de hecho, la palabra eslavo deriva de una raíz del eslavo antiguo que significa "los que hablan la misma palabra" $"$. Además de la lengua,

\footnotetext{
${ }^{109}$ El nombre completo de La Primera crónica es He aquí la guía de los años pasados, de dónde vinieron los paisanos rusos, quiénes fueron los primeros príncipes en Kiev y cómo surgió la tierra rusa (Vot povesti minubshij let, otkuda poshla russkaya zemlya, kto v Kieve stal pervim knyiyit' i kak voznikla russkaya zemlya) en http://www.drevne.ru/lib/pvl_1.htm?print consultado 28 de septiembre de 2011, 11 pp. la traducción del título es propia; Russian Primary Chronicle (Selections), Trad. Samuel H. Cross (1891-1946), Harvard Studies y Notes in Philology and Literature, vol. 12, 1930 en Zenkovsky, Medieval Russia's Epics, Chronicles, and Tales. NY, Meredian Books, 1974 en http://web.ku.edu/russcult/culture/handouts/chronicle_all.html consultada 28 de septiembre de 2011.
} 
compartían costumbres y normas sociales. Incluso consigna los nombres de algunos dirigentes aunque no residieran en Kiev. Es decir, a pesar de que los eslavos del este todavía conservaban los nombres de sus jefaturas, estaban en un proceso de integración en un solo pueblo. La Primera Crónica relata cómo los eslavos se convirtieron en tributarios de los jázaros. Según el documento, en $862^{110}$ los eslavos se percataron de que su tierra era rica pero vivían en desorden, por ello decidieron partir hacia la Rus cruzando el Mar de los Varegos, como llamaban al Báltico, donde habitaban los suecos. Ahí seleccionaron a tres hermanos para que los acompañaran y los gobernaran. Al mayor, Ryurik (c. 862-879), le asignaron Novgorod, a Sineus, Beloozero y a Truvor, Izoborsk. Los dos últimos murieron y Ryurik quedó como gobernante de todo el territorio que a partir de entonces se denominó Rus en razón del origen de sus gobernantes y a sus habitantes los rus ${ }^{111}$. Ryurik les asignó a miembros de su linaje el gobierno de algunas ciudades en las que habitaban los eslavos.

Más tarde, Ryurik les permitió a dos de sus boyardos, es decir, hombres de su séquito, emigrar a Constantinopla. En el camino Askol'd y Dir, los susodichos boyardos, encontraron el poblado de Kiev, entonces tributario de los jázaros. Reunieron algunos escandinavos y se apoderaron de él sometiendo a los polianios. En 866, los hermanos organizaron una expedición en contra de Bizancio pero fracasaron ${ }^{112}$. Esta aventura permite entrever que los habitantes de Kiev - eslavos y escandinavos- intentaban obtener beneficios mayores de sus relaciones con Bizancio, tal vez las negociaciones no fueron suficientes y

\footnotetext{
${ }^{110}$ Las fechas no coinciden en las fuentes consultadas. Las diferencias se deben en parte a que el calendario adoptado por los rusos fue el juliano y no el gregoriano. Además las fechas que se consignan en La Primera Crónica parten de la creación del mundo, por tanto la conversión de esas fechas a las de los calendarios juliano o gregoriano no es exacta. Se ha optado por tomar las fechas que aparecen en La Primera Crónica. ${ }^{111}$ Hay estudiosos de la historia rusa como Nicolás Riasanovsky que se niegan a aceptar la participación de los escandinavos en la fundación del Estado ruso vid. Riasanovsky, op.cit., pp.24-27. El nombre de Ryurik equivale en español a Rodrigo y significa líder famoso vid. http://es.wikipedia.org/wiki/Ri\%C3\%BArik consultado 19 de octubre de 2012.

${ }^{112}$ Cross y Sherbowizt-Wetzor, The Russian..., op. cit., p. 60.
} 
por eso se decidieron a atacar al imperio. Al parecer la presencia de los rus en Bizancio fue uno de los factores que indujeron a los emperadores a dirigir sus esfuerzos para integrar a su esfera de influencia cultural a los eslavos del este así como a los eslavos asentados al sur del Danubio e incorporarlos a la ecúmene cristiana ${ }^{113}$. Tras la muerte de Ryurik, heredó el poder en Novgorod, Oleg (879-912) quien era oriundo de Noruega.

Oleg, cuyo nombre en nórdico significa sacerdote ${ }^{114}$, inició la conquista de varias ciudades de la Rus cuyo gobierno entregaba a alguno de sus boyardos. En Kiev después de vencer a Askol'd y Dir se impuso como príncipe y presentó a Igor, hijo de Ryurik, como su sucesor, llevó a su nueva residencia hombres provenientes de Novgorod. Es muy probable que el cambio de residencia del príncipe haya obedecido a que Kiev se encontraba en un sitio donde la tierra era más fértil que en el norte. La producción agrícola era la actividad económica más importante pues generaba la mayor cantidad de riqueza ${ }^{115}$. Los campesinos pagaban en especie al príncipe o boyardo que los protegía y, por supuesto, los alimentos fundamentales eran los cereales. Si bien el comercio había instigado la fundación de ciudades en las márgenes de los ríos, sin la producción agrícola es imposible mantener una población creciente. Oleg consiguió que los poblados de eslavos del este y algunos fineses tributarios de los jázaros se sometieran a él (885). Así pues, los pueblos de la estepa no sólo asaltaban a las comunidades agrícolas sino que, como hemos visto, tenían una participación activa en la economía de los rus: haciéndolos sus tributarios o convirtiéndose en tributarios

\footnotetext{
113 José Ángel García de Cortázar y José Ángel Sesma Muñoz, Historia de la Edad Media. Una síntesis interpretativa. Madrid, Alianza Editorial, 1997. 1000 pp. (Alianza Universidad, 894), pp. 123-124; John Meyendorff (1926-1992), Byzantium and the Rise of Russia. A Study of Byzantino-Russian Relations in the Forteenth Century. Reimp. Nueva York, ST. Vladimir's Seminary Press, 1989. 326 pp., p.5.

${ }^{114} \mathrm{http}$ ://es.wikipedia.org/wiki/Oleg_de_N\%C3\%B3vgorod consultado 19 de octubre de 2012.

${ }^{115}$ Hearther, op.cit., p. 625.
} 
de ellos, además de las relaciones de intercambio que tenían. La conquista de Kiev les brindó a los rus del norte el acceso a la ruta comercial con el imperio bizantino ${ }^{116}$.

Por consejo de Oleg, Igor (912-945) contrajo matrimonio en 903, con una mujer de Pskov llamada Olga de origen escandinavo ${ }^{117}$. Otro acto importante atribuido a Oleg fue encabezar una expedición en contra de los bizantinos. Según La Primera Crónica, Oleg llevó 2000 barcos, mercaderías para vender, pero también hombres para pelear. Los emperadores León y Alejandro accedieron a firmar la paz con él, a regular las relaciones comerciales no sólo con Kiev sino también con otras ciudades de la Rus e incluso lo invitaron a la capital del imperio ${ }^{118}$. Al parecer las negociaciones del príncipe de Kiev con el gobierno de Bizancio son una evidencia de que la jefatura se estaba transformando en Estado puesto que habló tanto en nombre de los comerciantes de Kiev como de otras ciudades como Chernigov o la misma Novgorod a las que controlaba, además tenía pueblos tributarios, por tanto el imperio debió reconocerle un poder político y militar capaz de quebrantar su estabilidad. Otra evidencia de que el principado de Kiev había rebasado la organización de jefatura estriba en que Oleg recaudaba el tributo suficiente como para mantener a un ejército o séquito el que a su vez le daba la fuerza necesaria para someter a otras comunidades y obligarlas a pagarle tributo, es decir, el tributo ya no se daba por consentimiento como en las jefaturas sino por coacción ${ }^{119}$. De ahí que se pueda considerar a

\footnotetext{
${ }^{116}$ Romaniello, op. cit., p. 328; Longworth, op.cit., p.30.

${ }^{117}$ Nombre de origen escandinavo que significa "la que es invencible", http://es.wikipedia.org/wiki/Olga consultado 15 de noviembre de 2012; Preobrazhensky, op. cit., p. 648.

${ }^{118}$ Russian Primary Chronicle, op.cit., pp. 3-5; Vot povesti minubshij let, op.cit., pp. 7-11; Vernadsky, op.cit., pp. 29-32. De acuerdo con las cronologías dinásticas del imperio bizantino los emperadores eran Romano I entre 920 y 944 y Constantino VII Porfirogeneta de 944 a 959, los nombres que se consignan en La Primera crónica no coinciden seguramente por la antigüedad del suceso narrado. http://www.remilitari.com/cronolog/bizancio.com consulado 21 de junio de 2014.

${ }^{119}$ Christian, op. cit., pp. 329-333.
} 
Oleg como el fundador del Estado, aunque todavía era necesario crear nuevas instituciones para consolidarlo.

A pesar de los logros de Oleg, el principado estaba constantemente amenazado por el sureste debido a las correrías de los pechenegos ${ }^{120}$. Constantino VII Porfirogeneta escribió acerca de los ataques que hacían a los mercaderes de la Rus cuando viajaban por el Dniéper. A decir del emperador, los pechenegos estaban dispuestos a atacar a los rus sirviendo al imperio romano a cambio de dinero ${ }^{121}$.

A la muerte de Oleg, Igor se convirtió en el gobernante de Kiev y sus dominios. En La primera Crónica se menciona que los pechenegos pasaron por las tierras de la Rus en dirección al Danubio y poco después Igor se enfrentó a ellos sometiéndolos. También se alude a que Igor firmó un tratado comercial con el imperio bizantino por el que además se obligaba a enviar tropas cuando el emperador se lo solicitara como muestra de alianza. Esta cláusula nos indica la fuerza militar que para ese momento se le reconocía a Kiev ${ }^{122}$.

De acuerdo con el texto del tratado se estipulaba que estaban obligados a cumplirlo tanto los rus paganos como los cristianos pues gran parte de los varegos que formaban parte de los seguidores de Igor eran cristianos. Es probable que tal información correspondiera a la realidad o bien que los redactores quisieran mostrar que el cristianismo se extendía lentamente entre los rus. Más tarde, Igor atacó Dereva para convertirla en su tributaria, pero

\footnotetext{
${ }^{120}$ Hellmann, op.cit., pp. 25-28, 30; Riasanovsky, op.cit., p. 31; en Cross, The Russian..., op. cit., pp. 60-71 se encuentra la historia de Oleg, el traductor señaló que tal vez el tratado que se reproduce en la crónica no se redactó al mismo tiempo que el texto en griego. También menciona que algunos investigadores cuestionaban el ataque de los rus a Bizancio, vid. pp. 235-236.

${ }^{121}$ Constantine Porphyrogenitus, op. cit., pp. 53, 57.

122 Jones, op.cit., pp. 259-260; Hearther, op. cit., pp.594, 597.
} 
fueron tan exageradas sus exigencias y su ambición que cuando viajaba de regreso a Kiev fue $\operatorname{asesinado}^{123}$.

Olga (945-957), su viuda, tomó las riendas del principado como regente de su hijo. Su primer objetivo fue vengar la muerte de su marido, esta actitud tiene semejanza con las de otras mujeres protagonistas de las crónicas medievales quienes asumían la responsabilidad de vengar a sus parientes cuando en su linaje no había ningún hombre que cumpliera con ese deber. Esto muestra una vez más la importancia que en esta época tenían todavía los linajes y las mujeres de alto rango tanto en la organización social como en el ejercicio del poder.

Las acciones que ordenó realizar para castigar a los derevlianos significaron la muerte de gran parte de la población. Acompañada por su hijo Svyatoslav ${ }^{124}$ (957-972), conquistó Dereva a cuyos sobrevivientes impuso un tributo oneroso en pieles y miel. La historia de Olga refleja las costumbres paganas que todavía dominaban en la sociedad kievana. Por una parte, la viuda logró evitar su casamiento con el príncipe de Dereva y, de esta manera, protegió los intereses de su hijo para acceder al gobierno de Kiev e impidió que su pueblo quedara sometido a dicho príncipe. Los asesinatos que ordenó y ejecutaron los principales de Kiev estaban justificados de acuerdo con el derecho de sangre que regía las relaciones entre los linajes eslavos. Además, su matrimonio implicó que Pskov, ubicada en el noroeste, pasara a formar parte de los dominios de los Ryuríkidas. El resultado de estos actos fue que Kiev conservó su autonomía y la dinastía de los Ryuríkidas fue

\footnotetext{
${ }^{123}$ Cross, The Russian..., op. cit., pp. 71-78, 238, al parecer los vikingos eran cristianos romanos y no ortodoxos.

${ }^{124}$ Slav, como hemos visto puede significar gloria o pueblo eslavo, Svyat deriva de svet luz. Así Svyatoslav significa la luz de los eslavos o la luz gloriosa. Vid. http://etimologias.dechile.net/?eslavo consultado11 de octubre de 2012; Preobranzhensky, op. cit., p. 318.
} 
preservada. De ahí que su historia tenga un lugar destacado en La Primera Crónica. Los redactores suavizaron la personalidad de Olga al mencionar su conversión al cristianismo ${ }^{125}$ cuando visitó Bizancio en 957.

La regente, aparece como una heroína cultural pues se le atribuye la fundación de ciudades, puntos para recolectar el tributo, mercados y la demarcación de los territorios para practicar la cacería. Asimismo emitió regulaciones para cobrar el tributo, todas estas acciones implicaron introducir un cierto orden en la economía de $\mathrm{Kiev}^{126}$. Aunque se convirtió al cristianismo, el Estado en ciernes no adoptó oficialmente tal religión pero letrados bizantinos se mudaron a Kiev ${ }^{127}$.

Cuando Svyatoslav tuvo la edad suficiente, se convirtió en príncipe (knyaz ${ }^{128}$ ). Riasanovsky señala que este nuevo gobernante se vestía y comportaba como hombre de la estepa $^{129}$. Esta apreciación puede indicar, una vez más, la estrecha relación entre los habitantes de la taiga y la estepa y refuerza la afirmación sobre la influencia simultánea de los vikingos y los pueblos de la estepa europea en los eslavos del este. Svyatoslav emprendió campañas en contra de los jázaros, cuyo Estado destruyó, y atacó a los búlgaros del Volga, vencerlos expuso todavía más a Kiev a los ataques de los pechenegos.

Estas victorias significaron el control de Kiev de la ruta del Volga hacia el Mar Caspio, es decir, tuvo bajo su dominio territorios en la taiga y en la estepa. Cuando

\footnotetext{
${ }^{125}$ Bulter, op.cit., passim.

${ }^{126}$ Russian Primary..., op. cit., pp.6-8; Hearther, op. cit., p. 601; Longworth, op. cit., p. 36.

${ }^{127}$ Cross, The Russian..., op. cit., pp. 78-84, 86-87, se encuentra la historia de Olga. Hay que señalar que a partir de la historia de Olga, gran parte de los datos proporcionados por la crónica están reportados también en documentos bizantinos.

${ }^{128}$ Significa "el que tiene el gobierno de la región” o "señor", Preobrazhensy, op. cit., p. 324 que se ha traducido al español como príncipe.

${ }^{129}$ Riasanovsky, op.cit., pp. 32-33; según Vernadsky, Svyatoslav inició la expansión de Kiev con la conquista de los jázaros, op.cit., p. 33.
} 
Svyatoslav venció a los jázaros adoptó el título de jagan ${ }^{130}$ y Kiev el de jaganato, lo que prueba la contribución de los Estados esteparios a la transformación política de Kiev. Svyatoslav creyó tener el poder suficiente como para dominar al reino búlgaro de los Balcanes, según La Primera Crónica, sometió algunos asentamientos y empezó a gobernarlos en Peresyaslav.

Cuando los pechenegos atacaron Kiev, Olga, su madre, lo mandó llamar. Svyatoslav venció a los pechenegos y anunció que no estaba interesado en gobernar Kiev sino que deseaba regresar a los Balcanes en donde se encontraba la mayor parte de su riqueza. Antes de partir asignó a su hijo Yaropolk (c.958/960-980) ${ }^{131}$ el principado de Kiev y a Oleg (c. 962-976/977), Derevna.

Los novgorodianos le solicitaron que les diera por príncipe a su hijo Vladimir $^{132}$ (980-1015) engendrado con una concubina tal vez escandinava. Entonces se fue a Bulgaria, no logró conquistarla, guerreó contra soldados de Bizancio y al parecer hizo las paces con ellos. De todas maneras, decidió ir a la Rus por refuerzos para asentarse en los Balcanes pero cuando regresaba al principado, los pechenegos lo asesinaron en una de las cataratas del Dniéper ${ }^{133}$. La muerte de Svyatoslav merece una reflexión.

El emperador Constantino VII Porfirogeneta en su texto De Adminstrando Imperio, escribió que los rus compraban caballos, ganado vacuno y borregos a los pechenegos porque ellos no los criaban. Por esta razón procuraban mantener la paz. No obstante,

\footnotetext{
${ }^{130}$ Jagan en lenguas turca y mongola significa emperador y jaganato imperio http://en.wikipedia.org/wiki/Khagan, consultado 11 de diciembre de 2012.

${ }^{131}$ Nombre que proviene del eslavónico y significa "pueblo golpeador o que ataca" en http://www.first_names.enacademic.com/2361/Jaropelk consultado 1 de agosto de 2013.

132 Vladimir significa el hombre excelente del mundo en Prvobrazhensky, op.cit., p. 87.

133 Vernadsky, op. cit., pp. 33-35; Jones, op. cit., p. 261; Longworth, op. cit., p. 37; Cross, The Russian..., op. cit., pp. 84-90.
} 
cuando navegaban por el Volga o el Dniéper tenían que cuidarse de los ataques pechengos. Cuando los rus llegaban a las cataratas desembarcaban y trasladaban mercancías y embarcaciones por tierra, mientras realizaban estas operaciones los pechenegos aprovechaban para asaltarlos. Si alguna embarcación naufragaba y debían ocuparse en recuperar las mercaderías, la situación era aún más peligrosa. Por tanto, las partidas comerciales tenían que procurarse ayuda mutua para defenderse de los ataques de este pueblo $^{134}$.

Vale la pena destacar que a pesar de los asaltos y las pérdidas que podían ocasionar, las flotillas de vikingos, eslavos del este y fineses producían la riqueza suficiente como para que todos salieran beneficiados. El emperador sugería utilizar a los pechenegos en contra de los rus y también de los búlgaros. El reino de los búlgaros en los Balcanes se había convertido en un dolor de cabeza para el imperio pues sus gobernantes deseaban autonomía frente al emperador e incluso llegaron a proclamarse zar (Simeón I en 925), vocablo eslavo que significa césar. Si Svyatoslav había conseguido apoderarse de una porción del reino búlgaro tal vez los bizantinos lo veían con buenos ojos en tanto que implicaba debilitarlo. Sin embargo, los planes de Svyatoslav de convertirse en el gobernante de la región ${ }^{135}$, representaba también un peligro para la estabilidad del imperio bizantino pues los Balcanes formaban parte de su territorio. Por tanto, es probable que los bizantinos aún con apoyo de los búlgaros hayan pagado a mercenarios pechenegos para que asesinaran a Savyatoslav.

\footnotetext{
${ }^{134}$ Daniel C. Waugh selección de pasajes de Constantine Porphyrogenitus De Adminstrando Imperio, ed. Gy. Moravcsik (1929/30-1967), trad. R. J. H. Jenkins [en activo]. Nueva ed. Washington D. C., Dumbarton Oaks Center for Byzantine Studies, 1967, pp. 49-51, 57-63 y 167-171 en http://faculty.washington.edu/dwaugh/rus/texts/constp.html consultado 18 de noviembre de 2012. ${ }^{135}$ Meyendorff, op. cit., pp.4, 14.
} 
Como Savyatoslav no tuvo la precaución de designar a su sucesor, cuando lo asesinaron se desató una lucha entre sus hijos por la sucesión en Kiev. La guerra intestina estuvo acompañada por la defensa en contra de los pechenegos. Los pueblos esteparios obligaron a los kievanos a retroceder hacia el oeste ${ }^{136}$. Finalmente, Vladimir resultó victorioso, en gran medida gracias al apoyo militar de su tío materno, Dobrynya. En la Rus de Kiev existía la costumbre de que los hermanos heredaran el principado y de no haberlos entonces heredaba el hijo. Por otra parte, los tíos maternos jugaban un papel muy importante como consejeros y apoyo de sus sobrinos ${ }^{137}$. Esta relación ovuncular constituye un resabio del reconocimiento del parentesco por línea materna si en una sociedad todavía se practica la poliginia, como ocurría entre los príncipes eslavos. Hay que recordar que Vladimir no era hijo de la madre de Yaropolk y Oleg.

La Primera Crónica intentó mostrar a Kiev como un reino consolidado, sin embargo, al considerar la herencia que los príncipes repartían entre sus descendientes y la conquista de ciudades en el mismo territorio de la Rus al frente de las cuales colocaban a sus parientes o miembros de su séquito, se evidencia la existencia de entidades autónomas que, en ocasiones, reconocían la primacía de Kiev y en otras se oponían a ella. Los enfrentamientos ocurrían a pesar de que la mayoría de los knyazya ${ }^{138}$ eran miembros del mismo linaje pero cada cual ambicionaba someter al resto, es decir, los gobernantes de Kiev no lograron consolidar la unificación económica y política del territorio que juzgaban formaban parte de sus dominios considerados como patrimonio del príncipe más que como

\footnotetext{
${ }^{136}$ Vernadsky, op. cit., p. 37.

${ }^{137}$ Raffensperger, op.cit., p. 571, en este artículo se discute ampliamente la participación de los tíos maternos en la consolidación del poder de los príncipes de Kiev, hasta el momento no se ha llegado a conclusiones contundentes.

${ }^{138}$ Las crónicas le dan el título de knyaz a los príncipes, knyazya es el plural de estos príncipes emparentados entre sí que tenían la capacidad de sostener una clientela. Los knyaz podían cambiar de señor y sus tierras seguían perteneciéndoles.
} 
Estado $^{139}$. Esta unidad fue frágil pero sentó las bases de la formación posterior del Estado ruso.

Vladimir es considerado también como fundador de un Estado al estilo europeo porque creó una dinastía emparentada con los emperadores bizantinos gracias a su matrimonio con Ana Porfirogeneta (963-1011) y adoptó el cristianismo ortodoxo, lo que implicó que Kiev se integrara a la ecúmene cristiana medieval. Tal vez esa atribución sea el motivo por el que gran parte de las bylinas se refieren a Vladimir como el príncipe a quien los bogatyres le prestan lealtad ${ }^{140}$. Cuando tomó el poder, Vladimir era pagano y tenía muchas concubinas. Al mismo tiempo se percató de que la administración del principado requería de instituciones y herramientas para controlar a sus súbditos y a las riquezas que se producían en el territorio bajo su dominio. La iglesia ortodoxa podía proporcionar algunos de estos recursos: era una institución capaz de contribuir a unificar a los habitantes en tanto todos profesaran una misma fe. Además, la iglesia contaba con hombres ilustrados que practicaban la escritura mediante la cual se hacían registros de todo tipo, incluso históricos.

Pero la decisión no fue tomada a la ligera, según La Primera Crónica, Vladimir recibió tanto las propuestas de los búlgaros musulmanes en el este, como de los cristianos romanos del imperio sacroromano y hasta de los judíos para que se convirtiera a sus respectivas religiones. Es interesante señalar que Vladimir respondió al enviado musulmán que no adoptaba su fe porque el islam prohibía tomar bebidas alcohólicas y, según el

\footnotetext{
${ }^{139}$ Hearther, op. cit., pp. 606-609; Longworth, op. cit., p. 33.

${ }^{140}$ Raffensperger, op. cit., pp. 574-575, Cantos épicos..., op.cit., p. 13. No es posible asegurar que las bynilas se refieran a este Vladimir o a uno de sus sucesores, Vladimir Monómaco, de quien se tratará más adelante. No obstante, es interesante observar que en el imaginario social sea Vladimir el príncipe a quien los bogatyres o miembros de su séquito, servían y al servirlo a él defendían a Kiev.
} 
príncipe, ésa era la mayor alegría para los rus ${ }^{141}$. Esta pequeña referencia permite identificar un rasgo cultural muy arraigado entre los rusos hasta la actualidad.

Vladimir reunió a sus boyardos y les tomó su parecer. Éstos le aconsejaron que enviara emisarios a observar las prácticas religiosas. Entre los boyardos y el pueblo eligieron diez emisarios par a visitar el jaganato de los búlgaros, el imperio germánico y el bizantino, a su regreso los enviados presentaron sus informes ante el príncipe, los boyardos y los ancianos, los boyardos opinaron que se optara por la religión de Bizancio. Vladimir les preguntó si estarían dispuestos a bautizarse, ellos contestaron que la decisión la tenía Vladimir. El príncipe decidió convertirse al cristianismo ortodoxo ${ }^{142}$.

La manera en que el príncipe resolvió adoptar el cristianismo ortodoxo muestra que Vladimir gobernaba con el consejo de sus boyardos, es decir, aquellos miembros de su séquito quienes paulatinamente se transformaron en la capa social privilegiada, pero no sólo participaban ellos. Cuando La Primera Crónica habla de los ancianos posiblemente se refiere a los jefes de los linajes más alejados del príncipe quienes realizaban las tareas productivas. Esto significaría que durante el proceso de formación del primer Estado de los eslavos del este, el knyaz convocaba a los principales, nobles o plebeyos, para que participaran, al menos expresando su opinión, en la toma de decisiones. Más aún, el documento consigna que cuando se convirtió al cristianismo consultaba a sus seguidores en asuntos de administración, guerra y gobierno.

Pasó un año sin que los emperadores de Bizancio atendieran el deseo de los rus de bautizarse. Vladimir se dirigió a tomar la ciudad de Quersoneso en manos de los bizantinos.

\footnotetext{
${ }^{141}$ Cross, The Russian..., op. cit., p. 97.

142 Ibidem, pp. 110-111, 122.
} 
Una vez que logró someterla, envió una embajada a los emperadores Basilio II (958-1025) y Constantino VIII (960-1028) solicitándoles a su hermana en matrimonio, de no concedérsela atacaría Constantinopla. Los emperadores accedieron y el príncipe de Kiev se casó con Ana Porfirogeneta. El matrimonio implicó la conversión de Vladimir al cristianismo ortodoxo en 988 y con él todo su pueblo pues los plebeyos debían profesar la fe de sus príncipes. Al ser bautizado Vladimir recibió el nombre de Basilio, el mismo del emperador bizantino que fue su padrino ${ }^{143}$.

A partir de ese momento la influencia de la cultura griega y del cristianismo ortodoxo fue determinante en la sociedad y en el ejercicio del poder en Kiev y toda la Rus. No está por demás enfatizar que los ritos y el trabajo de los clérigos se realizó en el idioma eslavo. Para ello, los bizantinos se apoyaron en el trabajo de escritura que habían desarrollado en el reino de Bulgaria. De acuerdo con La Primera Crónica, Vladimir obligó a los hijos de las familias de mayor rango social a instruirse en la nueva religión, en otras palabras a que se habilitaran en la escritura y la lectura. Ya que la iglesia contribuyó a crear las instituciones y a formar los cuadros que poco a poco reforzaron el poder del príncipe, los religiosos al mismo tiempo, ocuparon el lugar de consejeros. El influjo político del clero ortodoxo fue inmediato, de hecho, como es evidente, la adopción misma del cristianismo ortodoxo fue un acto político que alineó al naciente Estado con aquellos que practicaban la misma fe. Vladimir mandó construir la Iglesia de los Diezmos dedicada a la virgen, para decorarla hizo llevar artesanos del imperio bizantino. Al parecer, el príncipe concedió a la iglesia tierras, el cobro del diezmo y las ganancias que se obtuvieran de la cría de ganado y

${ }^{143}$ Primary Chronicle..., op.cit., pp.8-12. 
el comercio; así los templos cristianos pronto se convirtieron en centros de intercambio. Más tarde, Vladimir fue canonizado por la iglesia ortodoxa ${ }^{144}$.

Para incrementar la producción agrícola, trasladó a algunos pueblos a las tierras cultivables aledañas a Kiev, a estos campesinos se les impuso tributo con base en los arados que tenían. También fundó la ciudad de Belgorod. Al mismo tiempo mandó construir una cadena de cinco fortificaciones para proteger a sus súbditos del ataque de los pechenegos. En esta ocasión, Vladimir recurrió a una enseñanza tomada de los escandinavos para intentar defenderse de los pueblos de la estepa: levantar líneas fortificadas, ejemplo que siguieron sus sucesores.

Vladimir tuvo 12 hijos y todavía en vida, les asignó a algunos de ellos determinadas parcialidades como se muestra en la siguiente tabla:

\begin{tabular}{|l|l|}
\hline Vysheslav $^{145}(977-1010)$, el mayor & Novgorod \\
\hline Izyaslav $^{146}(979-1001)$ & Polotsk \\
\hline Svyatopolk $^{147}(c .980-1019)$ & Turov \\
\hline Yaroslav $^{148}(c .978-1054)$ & $\begin{array}{l}\text { Rostov. A la muerte de su hermano mayor } \\
\text { recibió Novgorod y perdió Rosotv. }\end{array}$ \\
\hline Boris $^{149}(986-1015)$ & Rostov \\
\hline Gleb $^{150}(987-1015)$ & Murom \\
\hline Svyatoslav $(982-1015)$ & Dereva \\
\hline Vsevolod $^{151}(984-1013)$ & Vladimir \\
\hline
\end{tabular}

\footnotetext{
${ }^{144}$ Jones, op.cit., p. 263; Hearther, op.cit., p. 587; Hellman, op.cit., p. 36; Riasanovsky, op. cit., pp. 34-36; Franz Goerg Maier (1926-), Las transformaciones del mundo mediterráneo del siglo III / VIII. $11^{\text {a }}$ ed. en español. Trad. Pedro de Viadero. México, Siglo XXI, 1986. 416 pp., mapas (Historia Universal Siglo veintiuno, 9), pp. 165-166.

${ }^{145}$ Vysheslav significa "gran gloria" en Paul Wickenden of Thantet (1967-) A Dictionary of Russian Names en http://www.heraldy.sca.org/names/paul/h-j.html consultado 3 agosto de 2013

${ }^{146}$ Izyaslav significa "viniendo de la gloria" en Wickenden, op. cit.

${ }^{147}$ Svyatopolk significa "misa bendita" en Wickenden, op. cit.

${ }^{148}$ Yaroslav deriva de las raíces yarilo que significa dios y slav gloria. Por tanto el nombre significa "el que da gloria a dios"; si se toma la raíz slav como el nombre del pueblo eslavo su significado sería "el eslavo de dios" Preobrazhensky, op. cit., p. 318; http://etimologíasdechile.net/?eslavo consultado 11 de octubre de 2012. ${ }^{149}$ Boris significa "guerrero glorioso" en Wickenden, op. cit.

${ }^{150}$ Gleb significa "pan" en Wickenden, op. cit.

${ }^{151}$ Vsevolod significa el que "gobierna todo" en Wickenden, op. cit.
} 


\begin{tabular}{|l|l|}
\hline Mstislav $^{152}(983-1036)$ & Tmutorakan’ \\
\hline
\end{tabular}

El resto lo conservó para sí. Este reparto muestra cómo los príncipes consideraban al territorio como su patrimonio y por tanto lo repartían entre sus herederos como mejor les parecía. Como Vladimir todavía vivía, sus hijos debían pagarle tributo. Entre 1012 y 1014 Yaroslav no pagó a su padre el tributo que le correspondía. Vladimir, indignado, se preparó para atacar a su hijo pero cuando todo estaba listo, cayó enfermo y murió ${ }^{153}$.

A la muerte de Vladimir se desató una nueva lucha por el poder entre sus herederos. Svyatoslav, reunió a los habitantes de Kiev quienes lo aceptaron como el príncipe, pero los miembros del séquito de Vladimir urgieron a Boris, quien había permanecido al lado de su padre al morir, a proclamarse príncipe. Boris no quiso enfrentarse a su hermano mayor Svyatosloav, sin embargo, éste receloso de su hermano menor lo mandó matar. Boris no opuso resistencia. Svyatopolk decidió liquidar también a su hermano Gleb y lo mandó llamar en nombre de su padre. Cuando llegó a Smolensk, recibió un mensaje de su hermano Yaroslav. De acuerdo con La Crónica de Novgorod (Novgorodskaya pervaya letopis' $)^{154}$, Yaroslav se encontraba en esa ciudad cuando le informaron de la muerte de su padre y de que su hermano Svyatopolk se había declarado príncipe de Kiev. Convocó a los habitantes de la ciudad para que le ayudaran a echar a Svyatopolk del poder. Sus tropas sumaban 3000 hombres de Novgorod, lo que significa eslavos, fineses y 1000 varegos. Antes de iniciar la lucha envió su mensaje a Gleb en el que lo instaba a no acudir a Kiev ya

\footnotetext{
${ }^{152}$ Mstislav significa "vengador glorioso" en Wickenden, op. cit.

${ }^{153}$ Hearther, op. cit., p. 623, Hellmann, op. cit., p.37; Longworth, op. cit., pp. 31-32; Paul Dukes, A History of Russia. Medieval, Modern, Contemporary. 2a ed., [Hong Kong], MacMillan, 1990. 426 pp., mapas, p. 11; Cross, The Russian..., op. cit., pp. 91-124 se encuentra el relato de la vida de Vladimir, ahí pueden leerse extensos párrafos que dan cuenta del adoctrinamiento cristiano que el príncipe recibió.

${ }^{154}$ Halsall Mar, op. cit., passim.
} 
que su padre había muerto. Gleb se detuvo a rezar pos su padre y por Svyatoslav. En ese momento los sicarios de su hermano mayor lo asesinaron. La Primera Crónica enaltece a Boris y Gleb por haberse negado a luchar en contra de su hermano y morir como mártires. Svyatopolk empezó a planear cómo liquidar al resto de sus hermanos para quedarse con todo el principado de su padre.

Por su parte, Yaroslav el Sabio con anterioridad a estos hechos, había reunido un gran número de escandinavos, al parecer para resistir el ataque que su padre tenía planeado en contra de Novgorod por no pagar su tributo. Hubo problemas en la ciudad porque los habitantes se quejaban de los abusos de los varegos y mataron a muchos de ellos. Mas cuando sobrevino la muerte de Vladimir tanto los novgorodianos como los escandinavos sobrevivientes se unieron para ayudar a su príncipe a enfrentar a su hermano. Svyatopolk reunió un ejército conformado por kievanos y pechenegos y poco después se alió con Boleslav I (967-1025), el gobernante de Polonia. Yaroslav obtuvo la victoria gracias, en parte, a la incorporación de más mercenarios varegos que los propios escandinavos pagaron, seguramente porque estaba casado con la hija del rey de Suecia ${ }^{155}$.

Cuando se sentó en el trono (1019), según La Crónica de Novgorod distribuyó entre su séquito el pago en plata a cada quién según su calidad ${ }^{156}$. Por el momento, el séquito o druyina no recibía tierras por sus servicios. De acuerdo con estas fuentes se reafirma la participación de los varegos en la formación del Estado de Kiev así como la existencia de los séquitos. Ésta es la última referencia que aparece en La Primera Crónica sobre el

\footnotetext{
${ }^{155}$ Raffensperger, op.cit., p. 576, 580; Jones, op.cit., p.263. Los matrimonios entre las princesas vikingas y los príncipes eslavos del este eran frecuentes en este periodo, éste es otro elemento que refuerza la interpretación de la influencia de los varegos en la formación del Estado de Kiev; "King Harald's Saga: Harald Hardradi of Norway" en Kaiser, op. cit., pp.11-13 habla sobre la relación de este rey y Yaroslav en Novgorod. ${ }^{156}$ Cross, The Russian..., op. cit., pp.126-134; Primary Chronicle..., op.cit., pp. 11-12; Halsall, op.cit., p.2.
} 
vínculo entre los eslavos del este y los vikingos. Lo más probable es que a partir de ese momento, los varegos que habitaban en la Rus se hayan integrado por completo a los eslavos del este.

No obstante, el poder de Yaroslav sobre el principado de Kiev no estaba consolidado. Su hermano Mstislav organizó un ejército conformado por kasogianos, pueblo que habitaba al norte del Cáucaso, y jázaros para enfrentarse a Yaroslav. Cuando éste se encontraba en Novgorod, Mstislav atacó Kiev. Yaroslav no pudo enfrentarse de inmediato a su hermano porque debió atender a la población de Suzdal que había sido atacada por algún pueblo pagano que no ha podido ser identificado. Una vez resuelto el problema se dirigió a combatir a Mstislav. Yaroslav perdió la batalla y se refugió en Novgorod. El hermano menor sugirió un acuerdo: él gobernaría en Chernigov y Yaroslav en Kiev, las tierras del principado fueron divididas entre ambos tomando como frontera el rio Dniéper. Cuando Mstsilav murió sin herederos, Yaroslav quedó como único príncipe de $\mathrm{Kiev}^{157}$.

De acuerdo con las fuentes bajo su gobierno, Kiev alcanzó su máximo esplendor. Seguramente para proteger su frontera occidental fomentó las relaciones de Kiev con reinos vecinos, como Polonia y Bohemia y más alejados, como Francia. También realizó campañas hacia el occidente en contra de los fineses que habitaban la costa del Báltico: estonios, mazovianes y yam' así como en contra de aldeas lituanas. Estas incursiones tal vez tenían el objetivo de proteger el comercio de Novgorod. De igual manera, repelió a los pechenegos y, según La Primera Crónica, se dispersaron y no se volvió a saber de ellos ${ }^{158}$.

${ }^{157}$ Cross, The Russian..., pp.134-136; La Crónica de Novgorod no se refiere a este arreglo.

158 Cross, The Russian..., op. cit., p.136-139. 
Para consolidar su principado, Yaroslav ordenó escribir el primer Código de los Rus (Russkaya pravda) en el que se recogieron gran parte de las costumbres de los eslavos del este, por ejemplo, el artículo primero sanciona el derecho de sangre. También se ocupa de las compensaciones que recibirían las víctimas de daño en su propiedad fueran bienes inmuebles o muebles, incluidos los esclavos. Pero la mención expresa de los vikingos en este código nos sugiere que su tradición también fue incluida. De acuerdo con él, los séquitos se dividieron en dos segmentos de nobles: el integrado por los boyardos ${ }^{159}$ más importantes (staraia druyina) y el formado por los hijos de los boyardos quienes eran reclutados individualmente (men'shaya druyina). También se le atribuye la redacción de un Estatuto en el que reglamentaba las sanciones que se le impondrían a quienes ofendieran o abusaran de alguna mujer de acuerdo con el rango de la familia de ésta. Asimismo prohibía y sancionaba cualquier tipo de relación que algún rus, cristiano por supuesto, tuviera con judíos, musulmanes o paganos. De las multas, una parte debía pagársele al príncipe y otra al Metropolitano porque, en la mayoría de los casos, era la iglesia la que juzgaba estos delitos $^{160}$. Aquí se pueden apreciar los nexos entre el Estado de Kiev y la iglesia ortodoxa que tenía cada vez mayor presencia en la sociedad de los rus.

Yaroslav promovió asimismo la traducción de obras griegas al eslavo, él mismo leía y escribía en griego y eslavo. Toda su biblioteca la depositó en la iglesia de Santa Sofía. Al

\footnotetext{
${ }^{159}$ Boyardo en ruso boyarin' deriva de la palabra turca boila voz que se utilizaba para designar a un notable o noble, no ha podido precisarse cómo se transformó para dar lugar a la voz boyarin', ésta aparece por primera vez en el eslavo antiguo en los escritos del siglo X de la Gran Moravia. Pasó prácticamente a todos los idiomas eslavos, incluido el ruso. Preobrazhensky, op. cit., pp. 40-41.

${ }^{160}$ Código ruso (Ruskaia Pravda) tomada de The Russian Primary Chronicle en http://www.dur.ac.uk/a.k.harrington/russprav.html consultada 28 de septiembre de 2011; "Pravda Russkaia: The Short Redaction" y "The Statute of Grand Prince Iaroslav” en Kaiser, op. cit., pp. 26-29, 50-54; Charles J. Halperin reseña del libro "Law in Medieval Russia” por Ferdinand Feldbrugge en Slavic Review, 69:1, primavera de 2010, pp. 245-246 en http://www.jstor.org/stable/25621774, consultado 1 de noviembre de 2012 , p.246.
} 
parecer, La Primera Crónica atribuyó a Yaroslav una sapiencia que no tenía pues los estudios de filología más recientes muestran que la mayoría de las fuentes de origen griego traducidas al eslavo antiguo hablado por los rus fueron una retraducción de los textos escritos en búlgaro, lo que indica que la élite letrada de la Rus, incluyendo a los clérigos, no sabían griego. Además si bien gran parte de las sagradas escrituras y la hagiografía llegaron a Kiev no ocurrió lo mismo con los tratados teológicos ya que el eslavo antiguo tenía un lenguaje limitado para traducir este tipo de trabajos, pero la fe fue aceptada a pesar de ello pues la iglesia ortodoxa no impuso el idioma griego a sus seguidores ${ }^{161}$.

Al parecer, Yaroslav el Sabio llegó a un acuerdo con el emperador bizantino en 1037 respecto a los prelados que regirían a la iglesia ortodoxa de Kiev. Quedó establecido que el patriarca de Constantinopla nombraría al metropolitano de Kiev pero el príncipe designaría a los obispos. En aquel momento existían diez obispados en Kiev. Los obispos fueron originarios del principado mientras que los patriarcas eran griegos con la única excepción de Hilarión (siglo XI, m. c. 1054), quien por cierto sí sabía griego, y Clemente (siglo XII, en el cargo entre 1147-1154). Yarosalv mandó construir templos al estilo bizantino tanto en Kiev como en Novgorod, entre ellos Santa Sofía. También fundó los monasterios de San Jorge y Santa Irene.

Para incrementar la identificación de los eslavos del este con la iglesia ortodoxa fomentó el culto a los primeros mártires Boris y Gleb quienes fueron asesinados por su hermano Svyatopolk. Se decía que Boris y Gleb se habían rehusado a atacar a Svyatopolk siguiendo las enseñanzas de Jesucristo. A la larga este sacrificio había beneficiado a

\footnotetext{
${ }^{161}$ Cross, The Russian..., op. cit., p.137-138; Meyendorff, op. cit., pp. 22, 25-26; Liliana Simenova reseña del libro de Francis J. Thompson, "The Reception of Byzantine Culture in Medieval Russia" en Russian Review, 60:2, abril 2001, pp. 284-285 en http://www.jstor.org/stale/2679552 consultado 1 de noviembre de 2012.
} 
Yaroslav, quien no se había manchado las manos con la sangre de sus devotos hermanos. La veneración a estos mártires no sólo les dio a los rus, santos de su pueblo sino que también fomentó entre la población la práctica cristiana de la humildad y el rechazo al uso de la violencia ${ }^{162}$. Es necesario mencionar que la conversión de los grupos sociales menos favorecidos requirió de al menos una generación, ya que los propios clérigos no comprendían por completo la teología ortodoxa por lo cual tenían muchas deficiencias para comunicarla a los demás. De ahí que persistieran prácticas y creencias paganas combinadas con las cristianas ${ }^{163}$.La subordinación de la iglesia kievana a la bizantina explica el enorme impacto cultural de Bizancio entre los eslavos del este no sólo porque pudieron escribir con un alfabeto propio sino porque el bagaje simbólico cristiano que adquirieron fue griego ortodoxo. Esta influencia a su vez dejó su impronta en la organización del Estado ${ }^{164}$.

A la muerte de Yaroslav el principado de Kiev se fragmentó según la herencia que le dejó a cada uno de sus vástagos: a su hijo mayor, Izyaslav (1024-1078), le asignó el principado de Kiev, a Svyatoslav (1027-1073), Chernigov, Pereyaslav fue para Vsevolod (1030-1093), para Igor (1036-1060), Vladimir y para Vyacheslav (1034-1057), Smolensk. Los herederos de sus herederos fueron incapaces unirse para enfrentarse al ataque de los polovtsianos -pueblo de la estepa también llamados cumanos quienes hablaban una lengua

\footnotetext{
162 Vernadsky, op. cit., pp. 39-41; Longworth, op. cit., p. 39; Hellmann, op. cit., pp. 41-45; Meyendorff, op. cit., pp.19, 25; Boris y Gleb en http://orthodoxworld.ru/es/sviatye/2/index.htm consultado 28 de noviembre de 2012; "The Martyyrdom of Boris and Gleb" en Zenkovksy, op. cit., pp. 101-105.

${ }^{163}$ Chris J. Chulos reseña del libro "Popular Religion in Russia: 'Double Belief' and the Making of an Academic Myth" por Stella Rock en Slavic Review, 68:2, verano de 2009, pp. 431-432 en http://www,jstor.org/stable/27697990, consultado 1 de noviembre de 2012, p. 432.

${ }^{164}$ Este último punto se trata con mayor profundidad en los capítulos IV y V.
} 
de la familia turca-, ubicados en el territorio que fue de los pechenegos, y de sus enemigos del occidente ${ }^{165}$

Para cerrar este apartado cabe precisar las características del primer Estado de los eslavos del este. Kiev fue una ciudad poderosa cuyo príncipe ejerció su autoridad sobre los gobernantes de otras ciudades, pero lo más importante era el tributo que le pagaban, fuente primordial de su riqueza. Sus dominios abarcaban desde esa ciudad hasta Novgorod y del Dniéper al Volga. A partir de Svyatoslav, los nombres de sus gobernantes fueron eslavos, sin embargo, es innegable la fusión con los escandinavos, tanto con los que migraron a la región como con las mujeres que llegaron a casarse con los boyardos. Pero la etnogénesis de los eslavos de este fue mucho más complicada. En primer lugar, se debe recordar que estaban organizados en jefaturas diferentes: la de los polianos, la de los derevlianos, la de los severianos, la de los kriviches, la de los radmiches y la de los dregoviches, según menciona La Primera Crónica. Poco a poco todas fueron incorporadas al primer Estado de los eslavos del este. Tampoco se debe olvidar que en esta etapa los propios eslavos colonizaron y conquistaron zonas ocupadas por otros pueblos, especialmente, baltos y fineses. En algunos casos, estas comunidades se fundieron con los rus hasta desaparecer y en otros se mezclaron con ellos pero conservaron algunas prácticas culturales propias. Los chud, por ejemplo, actualmente identificados como los estonios, fueron conquistados por Yaroslav al que le pagaron tributo; este pueblo hasta el día de hoy se afana en expulsar a los eslavos de su territorio. De cualquier manera, los tributarios poco a poco fueron conocidos

\footnotetext{
${ }^{165}$ Cross, The Russian..., op. cit., p. 142; Hellmann, op. cit., pp. 47-64; Riasanovsky, op. cit., pp. 37-39; Dukes, op. cit., p.13; Charles J. Halperin reseña del libro "Las rutas internacionales en la Rus antigua: ensayos interdisciplinarios de comunicaciones culturales, comerciales y políticas IX-XII" (Drevniaia Rus' na mezhdunarodnykh putiakh: mezhdistsiplinal'nye ocherki kul'turnykh, torgovykh, politicheskikh sviazei IX-XII) de Aleksander Vasil'evich Nazarenko en Slavic Review, 61:2, verano de 2002, pp. 401-403 en http://www.jstor.org/stable/2697156 consultado 2 de noviembre de 2012, la traducción del título es propia.
} 
por otros pueblos como rus. Hay que subrayar que, sin embargo, los únicos que se arrogaban el derecho de gobernar en Kiev y en otras ciudades subordinadas a ella eran los descendientes del linaje de Ryurik quienes encabezaron al gobierno obligado a defender el territorio del Estado. Para el efecto, los Ryuríkidas contaban con sus boyardos quienes a cambio de luchar a su lado recibían buena parte del botín. Cuando era necesario, también se empleaban mercenarios, como fue el caso de los vikingos y también de los pueblos de la estepa como los propios pechenegos ${ }^{166}$, basta con recordar el enfrentamiento entre los hijos de Vladimir I El Grande.

El príncipe no tomaba sus decisiones al margen de su séquito ni de los habitantes plebeyos del territorio bajo su jurisdicción. Por lo menos convocaba a los miembros de su séquito, los boyardos, para solicitar su consejo y opinión. En asuntos de gran importancia llamaba a los “ancianos" o principales, jefes de los linajes plebeyos quienes todavía conservaban un gran peso en la sociedad de la Rus. Al parecer, en las urbes existía una asamblea ciudadana (veche), la cual tenía una participación más activa en las decisiones del príncipe cuando era indispensable reforzar su poder. Ésta tenía capacidad de decidir asuntos concernientes a la misma ciudad ${ }^{167}$. Asimismo las comunidades campesinas contaban con una asamblea, misma que repartía las tierras entre sus miembros, reunía el tributo que pagaban al príncipe y ayudaba a las familias nucleares ${ }^{168}$ de los linajes que la formaban, si era necesario. Lo que no queda claro en las fuentes es si en la asamblea urbana participaban miembros de las asambleas campesinas que abastecían a las ciudades.

\footnotetext{
${ }^{166}$ Moss, op. cit., pp. 38-39.

${ }^{167}$ I. Ia. Froianov [historiador en activo, sus primeras publicaciones aparecieron en la década de 1980] y A. IU. Dvornichenko [Historiador en activo, su última publicación apareció en 2013], "The City-State in Kievan Rus"” en Kaiser, op. cit., pp. 30-32.

${ }^{168}$ La familia nuclear está integrada por el padre, la madre y los hijos. Cuando varias familias nucleares emparentadas entre sí viven juntas, se le denomina familia extensa.
} 
Kiev y algunas otras ciudades estaban fortificadas a la usanza escandinava para defenderlas de los asaltos de los pueblos de la estepa. En el siglo XI fue levantada la "Muralla de la Serpiente" para proteger a los poblados del este de la Rus de los ataques de los pechenegos ${ }^{169}$. Los pueblos esteparios no sólo realizaban correrías en el territorio del Kiev, también comerciaban con los rus y se mezclaron con ellos.

Este primer Estado eslavo consiguió establecer relaciones culturales y comerciales con el imperio bizantino. El vínculo con Bizancio facilitó que el cristianismo ortodoxo, así como la cultura griega se difundieran entre los eslavos del este. Desde luego, el proceso fue lento y afectó primero a los miembros de los séquitos quienes debían profesar la misma fe que su príncipe y capacitarse para entrar a su servicio en la administración de su patrimonio. Muchos griegos también contribuyeron a administrar el Estado, además ocupaban los altos cargos eclesiásticos. La conversión de los plebeyos llevó más tiempo ya que la iglesia ortodoxa no se distingue por su vocación pastoral. A ello hay que añadir que las rutas comerciales se ampliaron hacia el sur. Esta relación implicó que, a pesar de la cristianización de los rus, mantuvieran un contacto continuo y rara vez violento, con los musulmanes. El poder de los Ryuríkidas se consolidó a lo largo de los siglos X y XI basta con señalar que en ese tiempo los rus de Kiev estaban comprometidos a enviar tropas para servir al emperador siempre que éste lo solicitara.

Los príncipes residían en ciudades como Kiev, la más importante, Novgorod, Polotsk, Peresyaslav, Vladimir, Smolensk y Chernigov, entre las más destacadas. Algunas de ellas fueron fundadas por los vikingos pero al parecer en estos sitios había aldeas eslavas que, en ocasiones, aglutinaban a otros pueblos. Durante el periodo de Kiev, la mayoría

${ }^{169}$ Moss, op. cit., pp. 22-32. 
estaban fortificadas, es decir, tenían un kremlin ${ }^{170}$. Alrededor se ubicaban los barrios en los que habitaban mercaderes y artesanos. La mayoría de las construcciones eran de madera, incluso las calles se recubrían con este material; solo edificios importantes como algunas iglesias y las fortalezas eran de piedra. La madera era, desde luego, la materia prima que los bosques proporcionaban en abundancia. Las ciudades constituían los centros administrativos seculares y eclesiásticos, en ellas se concentraba el tributo que recibía el príncipe. Asimismo, eran los centros comerciales tanto del mercado interno como del externo $^{171}$.

Una de las fuentes de poder de los príncipes de Kiev era su capacidad para vencer y, si era posible someter, a los pueblos que habitaban al este y al oeste de su frontera. Este poder militar se tradujo también en una ampliación de las rutas comerciales. En su momento de esplendor, el principado de Kiev utilizaba una ruta desde el Báltico hasta el Mar Negro, así los emprendedores de la Rus mantuvieron relaciones de intercambio con las ciudades comerciales del norte del Sacro Imperio Romano Germánico y al sureste la ruta comercial por el Volga llegaba hasta el Mar Caspio ${ }^{172}$. Al parecer, en este periodo, en las ciudades de la Rus había artesanos cuyos productos también se vendían en el exterior, tal era el caso de los lienzos de lino y lana así como de las pieles finas. Es probable que el príncipe, fundara pequeñas aldeas artesanales dedicadas a ejercer oficios específicos. De cualquier forma, los productos de exportación más importantes eran los esclavos y las pieles finas. Al parecer, el príncipe Igor acordó con los bizantinos que, en caso de que algún rus estuviera esclavizado en el imperio ya fuera por compra o como botín de guerra,

\footnotetext{
${ }^{170}$ Kreml' significa fortaleza interior, cada ciudad de los eslavos del este tenía uno, Preobrazhensky, op. cit., p. kremlin es el vocablo castellanizado.

${ }^{171}$ Moss, op. cit., pp. 34-37.

172 Riasanovsky, op. cit., pp. 29 passim; Hearther, op. cit., p. 590, 592-594.
} 
podría rescatársele pagando el precio a su dueño ${ }^{173}$. Hay que recordar que era posible que los propios rus hubiesen esclavizado a miembros de algún pueblo eslavo del este o finés de los que poco después quedaban bajo el dominio de Kiev.

La mayoría de los bienes importados como caballos, sedas, especies y joyas, eran suntuarios y solo los adquirían los príncipes y los boyardos. También existía el intercambio interno de productos del bosque con los de la estepa. Los comerciantes más importantes en la Rus de Kiev eran el príncipe y su séquito, mismos que en muchas ocasiones acudían personalmente a los puntos de intercambio cada primavera. Esta participación indica que el control del comercio era una de las fuentes de financiamiento con las que contaba el príncipe $^{174}$. Gracias al intercambio comercial, la taiga y la estepa se comunicaban entre sí por vía fluvial especialmente por el Dniéper. En el mapa 7 se puede observar la extensión de la antigua Rus en el siglo XI.

${ }^{173}$ Cross, The Russian..., op. cit., p. 75.

${ }^{174}$ Vernadsky, op. cit., pp. 45-46; Blum, op. cit., pp.14-16, 20-21; Hearther, op. cit., pp.622-623; Hellmann, op. cit., p. 46; Moss, op. cit., pp.36-37. 


\section{Mapa 7. EL PRINCIPADO DE KIEV}

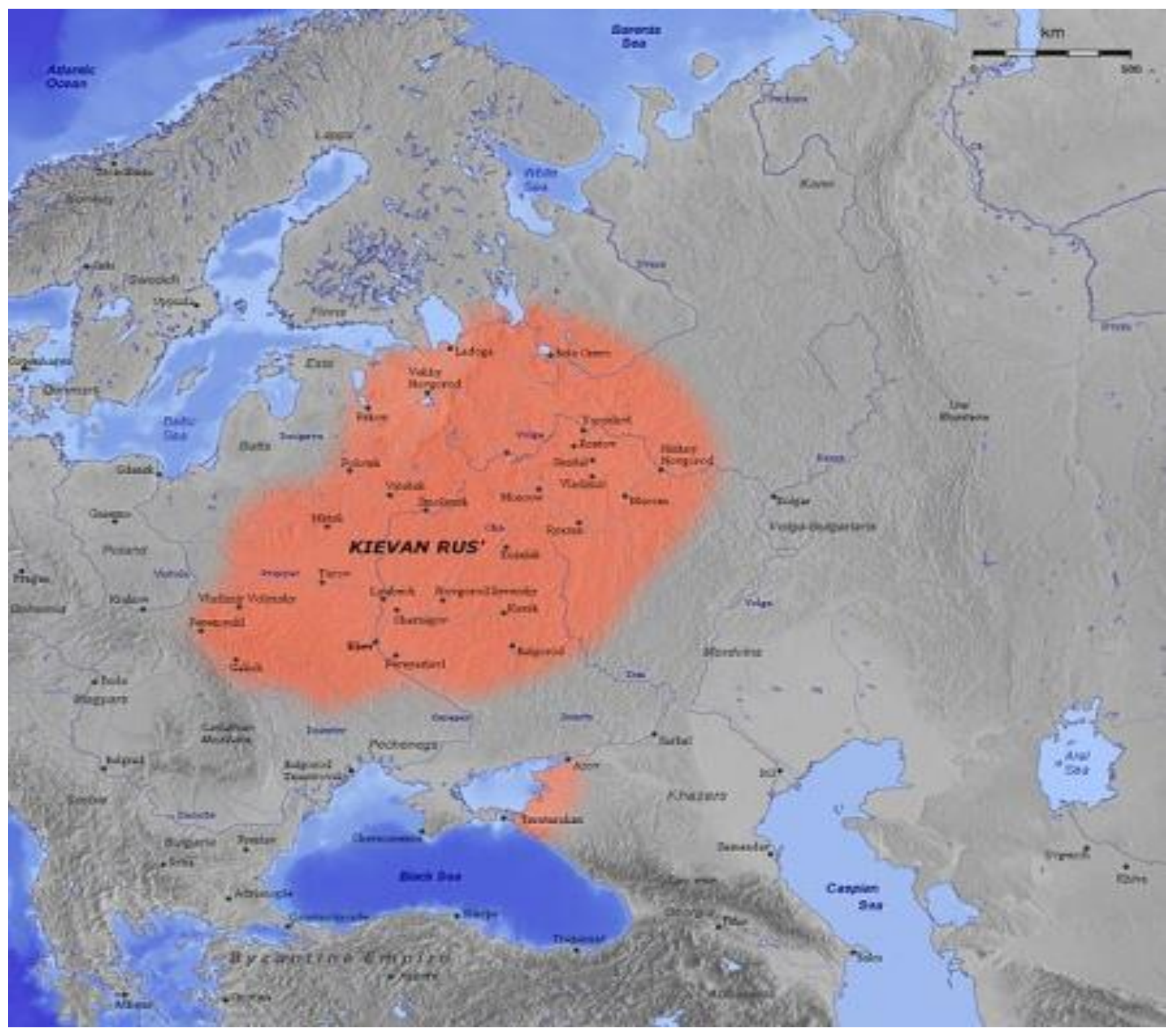

Fuente: http://www.es.wikipedia.org/wiki/Rus_de_Kiev consultado 8 de agosto de 2013

Desde luego, no hay que olvidar que la riqueza más importante para el knyaz y sus allegados era la tierra y sus habitantes. No se ha logrado establecer con certeza la relación que éste tenía con su séquito más allá de que sus miembros formaban parte de su ejército y gozaban de prestigio y riqueza a la sombra de su señor. Algunos de ellos se convirtieron en 
terratenientes aunque no tan poderosos como su príncipe, es probable que ya fueran propietarios individuales de las tierras que les concedía su príncipe pero este régimen de propiedad no puede fecharse antes del siglo X. Ellos fueron el germen de la nobleza boyarda. Los monasterios, casi siempre ubicados en los territorios fronterizos, también fueron acumulando tierras de labor. Las recibían por donaciones del príncipe y su séquito, por lo común las tierras de la iglesia eran trabajadas por quienes no tenían familia (izgoi) y quedaban bajo la protección del clero. El príncipe, por su parte, era el terrateniente más importante, la extensión de sus posesiones era tal que las empezó a dividir en unidades más pequeñas denominadas selo. En cada una de estas unidades menores tenía un mayordomo. En términos económicos y sociales el séquito del príncipe así como los hombres de la iglesia constituían los grupos privilegiados que lo ayudaban a administrar sus dominios y se reunían en la druyina la cual hacía las veces de consejo nobiliario.

La mayor parte de la población de la Rus eran campesinos plebeyos eslavos agrupados en comunidades de hombres libres emparentados entre sí quienes pagaban un tributo al príncipe con productos del bosque y también con parte de su cosecha. Si era necesario, el príncipe los reclutaba para nutrir sus fuerzas militares. Hasta el momento, no se ha podido aclarar si eran dueños de sus tierras o, en todo caso, cuál era el régimen de tenencia de la tierra. Esta situación tampoco permite establecer si el tributo lo daban al príncipe por la protección recibida o si también lo hacían como pago por la posesión de las parcelas. Al interior de la comunidad cada familia nuclear cultivaba una parcela y compartía con sus vecinos los bosques, los pastos y el agua ${ }^{175}$. Estas comunidades poseían la mayor parte de las tierras laborables. Si alguna de ellas quedaba sujeta al dominio de un

\footnotetext{
${ }^{175}$ Hellman, op.cit., pp. 22-31, 45-47; Herther, op.cit., p. 614; Moss, op. cit., pp.37-38.
} 
noble o de un monasterio porque se apoderaban de las tierras o se las asignaba el príncipe, los campesinos mantenían su libertad, por lo tanto conservaban su personalidad jurídica y eran dueños de casi toda su cosecha. Los campesinos constituían un segmento social muy bajo y despreciado socialmente por los señores, se les llamaba smerdy, en singular smerd; pero por debajo de ellos existían otros dos grupos sociales.

Ya que el señor no podía disponer a su antojo ni del trabajo ni de los productos generados por las comunidades campesinas, las grandes propiedades eran trabajadas por esclavos y peones cuya producción sí pertenecía a su señor. Los peones (zakupy) eran hombres libres que habían perdido sus tierras por no pagar sus deudas, esto implicaba que dejaban de pertenecer a la comunidad campesina y por eso debían trabajar para su acreedor en el campo o en los talleres artesanales abonándole el sueldo que debían recibir. En la práctica no tenían ninguna protección social y quedaban a merced del señor -aunque legalmente fueran libres y no pagaran tributo. Había otros tipos de trabajadores que constituían una minoría: quienes habían perdido a su familia, los que recibían una ayuda la cual agradecían con trabajo (vdachi) y quienes tenían contrato con sus patrones (riadovichi). Sin embargo, la producción de las grandes propiedades recaía fundamentalmente sobre los esclavos, la mayor parte de esta producción estaba destinada al mercado pues los terratenientes la vendían en las ciudades y hasta en el exterior donde también se vendían gran número de esclavos obtenidos como botín de guerra ${ }^{176}$. En la Russkaya pravda se establecieron en diferentes artículos las medidas que los dueños de los esclavos podían adoptar para recuperarlos y en los acuerdos firmados con el imperio bizantino se estipulaba que si un rus reclamaba a un esclavo que estuviera ahí debería

\footnotetext{
${ }^{176}$ Blum, op. cit., pp.24-56; Vernadsky, op. cit., pp. 51-52; Hearther, op. cit., pp. 613-619.
} 
regresársele a su dueño ${ }^{177}$, esto demuestra su importancia como fuerza de trabajo. Como se desprende del análisis, el código de Yaroslav el Sabio estableció un orden legal que sancionaba el predominio de unos grupos sociales sobre otros y el derecho a la propiedad, es decir, esos grupos tenían la capacidad de movilizar recursos humanos y materiales obteniendo el beneficio mayor, elementos que permiten considerar que al menos desde el gobierno de Vladimir, Kiev era un Estado.

Las técnicas de cultivo cambiaban si se laboraban tierras ubicadas en la estepa o en la taiga. En la estepa donde la tierra es más fértil se utilizaba el método de barbechado. En este caso era necesario arar la tierra con la ayuda de animales de tiro. Existían arados ligeros y arados pesados, todos ellos tenían punta de hierro. También contaban con un instrumento sencillo que servía para trillar el grano. En el bosque se empleaba el método de roza y quema por eso, debían desmontar continuamente nuevas parcelas para dejar descansar los terrenos agotados. En este caso no era indispensable utilizar animales de tiro pues no se requería voltear la tierra. Levantaban una cosecha al año. Para que los campos de cultivo se repusieran dejaban crecer pasto con el que alimentaban a los pocos animales que poseían. En algunos suelos menos fríos, como en los territorios aledaños a Riazan y Suzdal, fue posible utilizar, más tarde, el arado ${ }^{178}$.

Éstas fueron pues, las características del principado que la historiografía sobre la historia de Rusia y Ucrania consideran el primer Estado que formaron los eslavos del este conjugando todos los elementos, llamémosles exógenos, que participaron en la conformación de los rus. Es necesario mencionar que no existe un consenso acerca del

\footnotetext{
${ }^{177}$ Ruskaia Pravda, op. cit., passim; Cross, The Russian..., op. cit., p. 68.

${ }^{178}$ V. P. Levasheva [Se encontraron obras de arqueología publicadas por la autora entre 1957 y 1967]

“Agriculture in Rus' (Tenth-Thirteenth Centuries)" en Kaiser, op. cit., pp. 39-44.
} 
momento en que aparece el Estado ni cuáles son los antecedentes del mismo. Mientras que estudiosos como I. Ia. Froianov postulan que el Estado apareció a partir de la unión tribal en contra de elementos exógenos, N. F. Kotliar, en cambio, establece que fue a partir del dominio de unas jefaturas sobre otras que apareció la organización estatal. De acuerdo con este autor, cuando Oleg sometió a algunas jefaturas y les impuso el pago de tributo ocurrió el cambio ya que éste se recaudó bajo el principio de que la tierra pertenecía a quien la había conquistado ${ }^{179}$. Como ha podido apreciarse a lo largo del análisis expuesto, esta tesis coincide con la de este último autor que a su vez concuerdan con el esquema de Service y Christian acerca de la transición de las sociedades igualitarias a las jerarquizadas y de éstas a la aparición del Estado.

\subsection{La decadencia de Kiev. Periodo de fragmentación}

En el periodo anterior, Kiev no era el único centro urbano y comercial de la Rus pero sí el más poderoso, lo que le permitió imponer su supremacía sobre otras ciudades. De cualquier manera, cada una de las urbes tenía a su propio knyaz que era pariente del de Kiev pero le pagaban tributo. Novgorod, por su parte, tuvo un papel destacado en la integración de la Rus. A partir de la segunda mitad del siglo XI, algunas de las ciudades de la Rus -como la propia Novgorod o Vladimir-Suzdal- le disputaron su hegemonía a Kiev y disfrutaron de una autonomía completa.

Izyaslav se quedó en Kiev pero al parecer no fue tan buen soldado como su padre Yaroslav pues ante un ataque de los polovotsianos (1068-1069), la asamblea de la ciudad,

\footnotetext{
${ }^{179}$ Simon Franklin [Actualmente profesor en el Departamento de Estudios Eslavos en la Universidad de Cambridge], 'Pre-Mongol Rus': New Sources, New Perspectives?” en Russian Review, 60:4, octubre de 2001, pp.465-473 en http://www.jstor.org/stable/2679361, consultado 9 de noviembre de 2012, pp.471-472; el texto de Kotliar, El antiguo Estado ruso (Drevnerusskoe gosudarstvo) fue publicado en 1998.
} 
que al parecer cobró más poder, le exigió que la armara. Los kievanos se encargaron de defender su ciudad. Desde ese momento, los príncipes de Kiev perdieron poder por dos razones: Una, porque la asamblea ciudadana -en la que participaban también los campesinos cuyas tierras se consideraban parte de Kiev- se encargó con gran diligencia de defender la principalidad al grado de aceptar o rechazar a los príncipes que se adueñaban de ella. Incluso en ocasiones la asamblea kievana dispuso de las riquezas del príncipe para utilizarlas en beneficio de toda la comunidad. Es importante destacar que la gran mayoría de sus decisiones eran avaladas por el obispo de la ciudad, de esta forma la iglesia ortodoxa fortaleció su poder político. Es más, La Primera Crónica atribuyó la victoria de los polovotsianos a que los rus, especialmente los príncipes, no cumplían cabalmente con sus deberes cristianos ${ }^{180}$. La iglesia fue un factor de unidad pues facilitó que los rus pudieran reconocerse al menos como practicantes de la misma fe. La segunda razón consistió en que los príncipes de otras ciudades luchaban por ostentar el título de príncipes de Kiev al margen del parentesco que hubiera entre ellos, esto lo condenaban los prelados. Tal vez por ello, los príncipes apoyaban la construcción de iglesias y el establecimiento de monasterios.

La fragmentación del principado de Kiev resultó del reparto que Yaroslav hizo entre sus hijos. En esta ocasión, no hubo hermanos que se dejaran matar o que murieran sin descendencia. El periodo de la fragmentación abarca desde la segunda mitad del siglo XI, todo el siglo XII y el primer tercio del siglo XIII; se caracterizó por la intensa lucha entre los gobernantes de diferentes principados de la Rus por someterse unos a otros. La guerra

\footnotetext{
${ }^{180}$ Froianov, op. cit., p.32 passim; Cross, The Russian, op. cit., pp. 146-150.
} 
incluía desde luego, obtener botín. En varias ocasiones los mercaderes que seguían la ruta del Dniéper fueron asaltados por los enemigos de sus amigos ${ }^{181}$.

Tan sólo Vladimir Monómaco (1053-1125) consiguió reunificar a todos los territorios de la Rus bajo su mando. La asamblea de Kiev le ofreció el cargo a través de sus representantes. El príncipe aceptó ${ }^{182}$. Fue durante su gobierno que la iglesia ortodoxa local logró la canonización de los mártires Boris y Gleb cobrando cada vez mayor influencia cultural y política. Vladimir Monómaco también se distinguió como legislador: el Reglamento sobre los réditos estableció las normas de los créditos mercantiles, lo que nos habla de la importancia del comercio; además emitió el Reglamento sobre los smerdyzakupy que regulaba las relaciones entre los terratenientes y los campesinos libres que laboraban en sus dominios. En la "Instrucción para sus hijos" dejó constancia de haber firmado 19 tratados de paz con los cumanos en los que invirtió gran parte de su ganado vacuno y de sus vestiduras, bienes que seguramente fueron enviados como regalos. Asimismo menciona que capturaba gran número de caballos salvajes en la estepa. Al parecer los rus también hacían correrías en las planicies para apoderarse de los caballos que criaban los pueblos turco-mongoles. Por último, cabe llamar la atención sobre el consejo que dio a sus hijos para que aprendieran otros idiomas pues así honrarían otras tierras, su padre, decía, hablaba cinco lenguas. A su muerte, la Rus volvió a fragmentarse ${ }^{183}$.

En este momento, se desarrollaron otras regiones en el norte y en el noreste y alcanzaron gran poder principados como Vladimir-Suzdal o Murom-Riazan. Se fundaron

\footnotetext{
${ }^{181}$ La Primera Crónica narra las luchas intestinas por apoderarse de Kiev hasta el año de 1100 en el que termina el documento laurentino, Vid. Cross, The Russian..., op. cit., pp. 164 passim.

182 Froianoiv, op. cit., p. 34.

${ }^{183}$ Longworth, op. cit., p.43; Kalistov, op. cit., p. 38;"Vladimir Monomakh: Instruction to His Children” en Zenkovsky, op. cit., pp. 98-100.
} 
nuevos asentamientos como Niyni Novgorod, Moscovia o Ustiug, como se ve en el mapa 8. Esta expansión fue favorecida por la migración de familias del sur las cuales veían en la fortaleza creciente de las ciudades norteñas la oportunidad de tener mejores condiciones de vida. Fue tal el empuje de esta migración que los rus llegaron hasta las costas de Mar Blanco, es decir, a la tundra, donde se mezclaron con los pueblos que se encontraban ahí. Podemos hablar en muchos casos de transculturación ya que los inmigrantes aprendieron las técnicas de caza y pesca de los naturales de la zona. No cabe duda que el comercio de pieles atraía también a los cazadores y comerciantes a estas tierras recién ocupadas. De hecho, los habitantes de las ciudades y de las avanzadas en el norte constituían un grupo social ubicado por debajo de los príncipes y su séquito pero por encima de los campesinos, no se conoce con certeza las divisiones sociales entre ellos pero todos eran plebeyos que se dedicaban a la cacería, la pesca, la artesanía y el comercio. Si bien es cierto que se ha estudiado con mayor profundidad la colonización hacia el noroeste, hoy en día se destaca que también fueron fundadas nuevas ciudades en el noreste ${ }^{184}$.

\footnotetext{
${ }^{184}$ Franklin, "Pre-mongol..., op. cit., p.468
} 


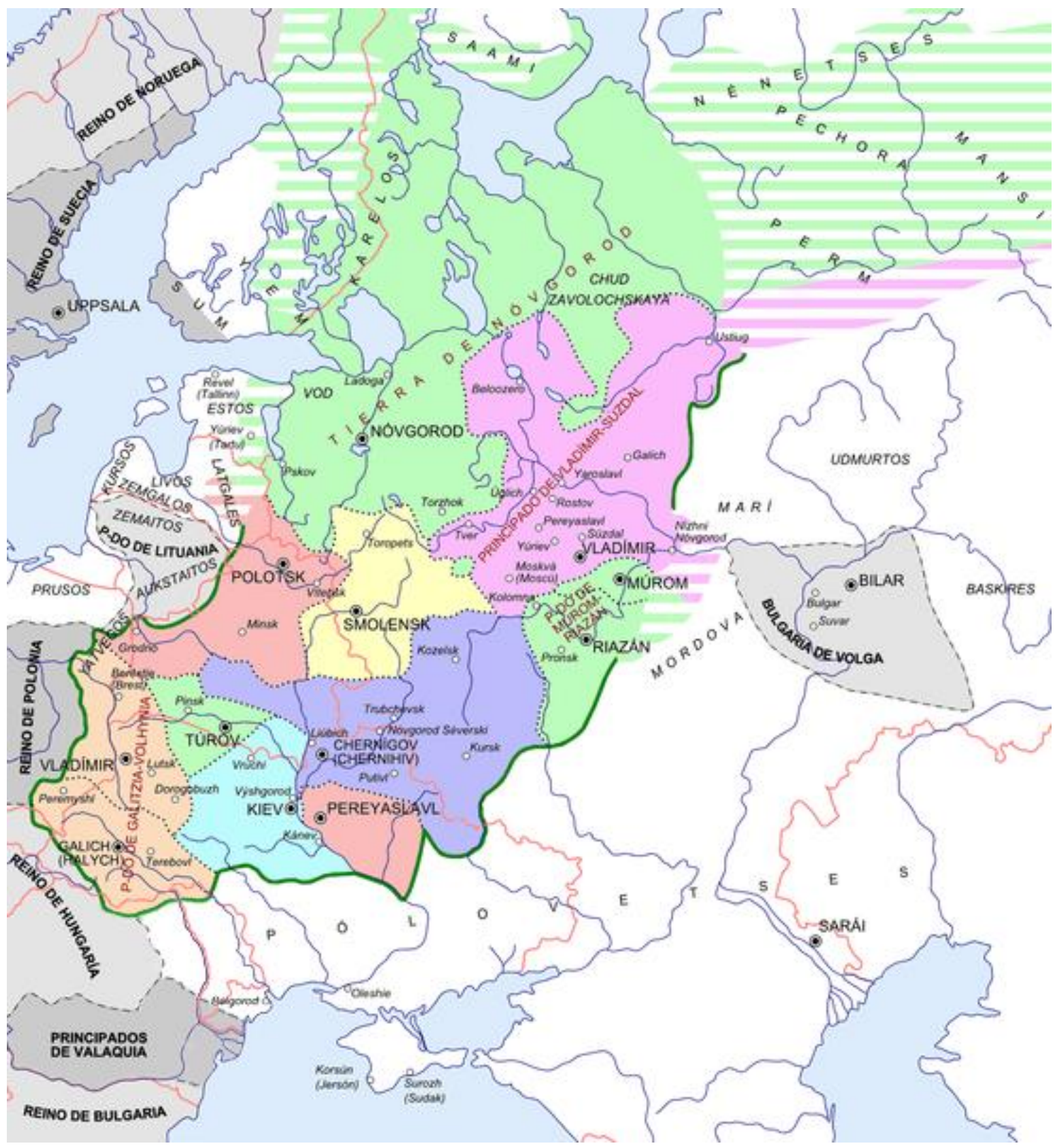

Fuente: http://www.es.wikipedia.org/wiki/Rus_de_Kiev consultado 8 de agosto de 2013

El poder de los principados que se muestran en el mapa 8, se aprecia, por ejemplo, en el hecho de que Novgorod (en color verde) cobraba tributo a algunos pueblos más allá 
de los Urales, (en el mapa 8 el territorio en cuestión está marcado con líneas verdes) ${ }^{185}$ mientras que Yuri Dolgoryukii ${ }^{186}$ (1154-1157), príncipe de Vladimir-Suzdal (en el mapa 8 en color lila), fue quien decidió fortificar el naciente poblado de Moscovia. Las urbes eran gobernadas por la veche o asamblea de la ciudad y un príncipe quien contaba con la druyina. El equilibrio del poder entre la veche y el knyaz variaba en cada ciudad.

El caso de Novgorod fue notable ya que en esa ciudad la veche fue el órgano de gobierno más importante justamente cuando tuvo su periodo de mayor florecimiento comercial pues en varias ocasiones expulsaron a sus knyazya, así que cuando los aceptaron de nuevo prácticamente no tenía poder alguno; incluso ni ellos ni su séquito podían poseer tierras en la región, menos aún despojar a algún novgorodiano de su propiedad ni podían participar en el comercio con la Hansa. Por tanto, en Novgorod no había una dinastía gobernante, invitaban a los príncipes a ocupar el cargo. Cada barrio (knosty) tenía su gobierno local, había cinco, y controlaba no sólo el territorio que ocupaba sino también una extensión boscosa, aunque el territorio más alejado era jurisdicción de la veche. La asamblea elegía a dos funcionarios: el posadnik ${ }^{187}$ cuya tarea consistía en defender los intereses de la ciudad frente al príncipe y el tysiatskii ${ }^{188}$ quien dirigía las tropas de la ciudad y resolvía los conflictos comerciales. Las asambleas se hacían en el mercado y podía convocar a la veche cualquier persona tocando una campana instalada para el efecto. Las decisiones debían ser unánimes. Designaba al arzobispo quien era su representante en el exterior y actuaba como su consejero. La veche tenía un Consejo de Notables al que pertenecían todos aquellos de mayor calidad social, como el príncipe y el arzobispo, los

\footnotetext{
${ }^{185}$ Este tema se tratará en el apartado 2.3.

${ }^{186}$ Su sobrenombre significa "el del brazo largo", le decían así porque intervino en Kiev.

${ }^{187}$ Deriva de la raíz posaditi que significa designar, posadnik significaba "el designado" en http://en.wikipedia.org/wiki/Posadnik consultado 28 de noviembre de 2012.

${ }^{188}$ Significa “padre del cultivo", Preobrazhensky, op. cit., anexo, p. 27.
} 
hombres más acaudalados, los jefes de barrio y los funcionarios, este Consejo gobernaba cotidianamente. Los dokladchiki o jueces impartían justicia con base en leyes escritas pero también consuetudinarias ${ }^{189}$. En Novgorod la pena de muerte no se aplicaba como castigo. Pero tampoco hay que suponer que no había disputas internas o enfrentamientos entre distintos grupos sociales. La base del poder de Novgorod estaba en los tributos que exigía a quienes vivían en sus dominios, en las artesanías que se elaboraban en su territorio y en el comercio $^{190}$.

Por otra parte, también subsistieron principados que tuvieron un gobierno semejante al que había ostentado Kiev, como en el noreste Vladimir-Suzdal, por ejemplo. Su territorio aunque ubicado en la taiga, era una especie de oasis donde la tierra era muy fértil. Además lo atravesaba la cuenca alta del río Volga lo que le permitía beneficiarse del comercio novgorodiano por esa ruta. Asimismo sirvió de enclave para el comercio con Asia. Sus vecinos en el este eran los búlgaros del Volga ya para ese entonces muy debilitados. En Vladimir-Suzdal los eslavos del este se encontraron con los mordavos comunidades de ugro-finesas a las que fueron sometiendo. Este fue uno de los principados más beneficiados con la migración de los eslavos desde Kiev hacia el norte. La mezcla entre ellos y los mordavos dio lugar a que lentamente sus habitantes fueran diferenciándose del resto de los eslavos del este. En un principio, la ciudad donde residía el príncipe fue Rostov, Yuri Dolgorukii se transladó a Suzdal en 1125 y en 1155, su hijo Andrei Bogolyubski (11111174), sentó su corte en Vladimir. De hecho, a finales del siglo XII su príncipe era el más poderoso de toda la Rus y manejaba su principado como su patrimonio ${ }^{191}$.

\footnotetext{
189 “The Laws of Rus' (Tenth to Fifteenth Centuries)” en Kaiser, op. cit., p. 85.

${ }^{190}$ Vernadsky, op. cit., pp. 47-49.

${ }^{191}$ Moss, op. cit., pp. 57-59.
} 
El caso de Chernigov (en el mapa 8 coloreado de azul) ha sido estudiado con atención recientemente. Tres dinastías, dos de ellas emparentadas con Vladimir Monómaco de Kiev, se disputaban el gobierno de la ciudad al mismo tiempo que luchaban por consolidar su primacía, apoderándose de Kiev. En este periodo Kiev todavía representaba el lugar que los príncipes querían controlar para mostrar su fuerza pues se mantenía como símbolo de poder sobre toda la Rus. Es decir, en cada ciudad y principado había luchas internas por el predominio político y, paralelamente, desarrollaban acciones militares o alianzas matrimoniales entre ellos a fin de imponerse sobre el resto ${ }^{192}$.

En los principados del oeste la situación fue muy diferente. La política inaugurada por Svyatopolk I de Kiev de aliarse con los polacos en contra de sus parientes se repitió varias veces. Esto llevó a que en breve, no sólo Polonia sino también el Ducado de Lituania y hasta al reino de Hungría intentaran apoderarse de los principados de la Rus. Es probable que el contacto con los nobles polacos y lituanos haya influido en esta pérdida del poder de los príncipes frente a los miembros de su séquito. Tanto en Lituania como en Polonia la nobleza intervenía en las decisiones del príncipe o duque e incluso se oponían a ellos abiertamente. Esto mismo empezó a ocurrir en Galitsiya, Volynia y Polotsk (en el mapa 8 de color rosado, los primeros más claros que el tercero) ${ }^{193}$. Estos últimos principados eran las que con mayor frecuencia solían aliarse con los polacos, los húngaros o los lituanos. Galitsiya era la ciudad más importante y gracias a las fértiles tierras que poseía, tenía una población abundante. Los boyardos de Volynia no eran tan poderosos como los de Galitsiya por ello, Roman de Volynia (c. 1168-1205) pudo controlarlos bajo su mando entre 1173 y

\footnotetext{
${ }^{192}$ Franklin. "The Pre-mongol..., op. cit., p. 469; Francis Butler reseña del libro "Dynasty of Chernigov, 1146-1246" por Martin Dimnik en Slavic Review, 64:1, primavera de 2005, pp. 188-189 en http://www.jstor.org/stable/3650092 consultado 2 de noviembre de 2012, p. 189.

193 "Southwest Rus': Extracts from the Galician-Volhynian Chronicle (1240-41)" en Kaiser, op. cit., pp. 8587.
} 
1205. Sin embargo, a su muerte los boyardos expulsaron a su viuda y a sus hijos a Galitsiya. En el siglo XIII polacos y húngaros estuvieron involucrados en los acontecimientos ocurridos en Galitsiya y Volynia. A esta historia de alianzas y rivalidades hay que añadir que muchos príncipes rus se casaron con mujeres oriundas de los Estados occidentales, Así, no solo el poder centralizado que Kiev había ostentado desapareció sino que los propios príncipes de la Rus propiciaron que los Estados vecinos intervinieran en sus guerras intestinas aprovechando cualquier oportunidad para apoderarse de territorio ${ }^{194}$.

Al mismo tiempo que el poder de Kiev declinó, las rutas comerciales del sur decayeron en virtud de la presencia de comerciantes venecianos y genoveses en los puertos del Mediterráneo oriental como Acre o Constantinopla. Los comerciantes procedentes de la península itálica pudieron trasladar por ese mar productos que recorrían las rutas del Dniéper, el Volga y el Neva. Por supuesto el comercio no desapareció pues los boyardos consumían objetos suntuarios. Así Polotsk (en el mapa 8 de rosa encarnado) debía en parte su riqueza a que ahí había un portazgo en la conjunción del Dvina y el Dniéper donde los comerciantes debían pagar por pasar sus mercancías ${ }^{195}$. Por otra parte, los mercaderes de las ciudades de la Hansa ${ }^{196}$, cada vez más poderosos, remplazaron en el Mar Báltico a los escandinavos. La ciudad de Lübeck, fundada en 1158, prácticamente monopolizaba el comercio con Novgorod que en el siglo XIII se convirtió en la ciudad comercial más importante de la Rus. De hecho, Novgorod logró controlar la ruta comercial desde el Neva

\footnotetext{
${ }^{194}$ Vernadsky, op. cit., pp. 47-49; Longworth, op. cit., pp. 43-44; Moss, op. cit., pp.31-32, 60.

${ }^{195}$ Cross, The Russian..., op. cit., p. 255.

${ }^{196}$ En 1161 se organizó una cooperativa mercantil germana (Hansa) a la que se unieron ciudades que realizaban operaciones utilizando puertos del Báltico. Herman Kinder y Werner, Hilgemann. Altas histórico mundial. De los orígenes a la Revolución Francesa. Trad. Carlos Martín Álvarez, Antón Dietrich Thomas. Cartografía Herald y Ruth Bukor. Realizado por A. Campos J. Díaz del Valle y F. Romero. Madrid, Ediciones Istmo, 1970. 312 pp., mapas, cuadros. (Colección fundamentos, 1), p. 189.
} 
hasta el Volga ${ }^{197}$ hacia el Cáucaso y el Caspio durante el periodo de fragmentación, de manera que el comercio con los musulmanes no cesó. De acuerdo con el testimonio de Abu Hamid al Garanti -quien visitó la Rus en 1150- los habitantes de la costa del Mar Blanco usaban espadas fabricadas en Azerbaiyan para cazar ballenas, las espadas las obtenían al cambiarlas por pieles de marta cibelina. En los primeros siglos de la Rus, el ámbar que se compraba en Novgorod provenía del sur, es decir, de Kiev y sus alrededores, en el siglo XII el consumo de este ámbar en el norte alcanzó su cúspide. Pero en el siglo XIII, por razones que se explicarán en el siguiente capítulo, el consumo de ámbar proveniente del sur vía la ruta del Dniéper cayó rápidamente ${ }^{198}$.

Lübeck introducía en los principados de los eslavos del este vino pero sobre todo paños; a cambio importaba pieles, cera y algunos artículos suntuarios provenientes de Asia. El comercio era tan importante que había una colonia germana (nemtsy) en Novgorod; su situación jurídica así como el comercio estaban regulados por los tratados firmados entre esta ciudad y sus socios de la Hansa. Por ejemplo, en 1229 los mercaderes de Novgorod firmaron un tratado con los de Lübeck, Hamburgo y Wisby. En él se establecían las facilidades de transporte y alimentación que debían brindarse a los germanos cuando visitaran Novgorod y viceversa. Los pagos para los comerciantes rutenos, como fueron designados los habitantes de Novgorod, se fijaron en pieles de marta cibelina. Asimismo, se acordó la protección que los mercaderes de ambas partes debían recibir cuando viajaran a las ciudades de sus contrapartes a comerciar, se señalaba que serían libres de moverse en las ciudades e incluso cómo se llevarían a cabo los juicios en caso de que el visitante fuera

\footnotetext{
${ }^{197}$ Sorokin, op.cit., pp. 3-4.

198 Ángel Luis Encinas Moral, La Rus vista por el viajero andalusí Abu Hamid al Garnati (1080-1169), 10 pp. en WebIslam.com consultado 24 de septiembre de 2010, p.4-5; E. A. Rybina [Se encontraron publicaciones de la década de 1978 y 2009], "Novgorod's Amber Trade (Tenth-Fourteenth Centuries)" en Kaiser, op. cit., pp. 44-48.
} 
acusado de algún delito ${ }^{199}$. Es probable que en Novgorod los comerciantes estuvieran organizados en gremios. En otras ciudades como Smolensk, se repetía este mismo esquema pero no llegaron a ser tan poderosas como Novgorod. Sin embargo, los príncipes seguían participando en el comercio, por ejemplo en Vladimir, la más cercana competidora de Novgorod, su príncipe concentraba el poder político y económico.

Los principados y ciudades del sureste sufrían constantemente los ataques de los polovotsianos pueblos de la estepa criadores de ganado. Los principados de Chernigov y Peresyaslav eran los más afectados. Como suele ocurrir, no faltaron los príncipes de la Rus que se aliaron con los polovotsianos para atacar a sus enemigos. Las continuas correrías de este pueblo permitieron que poco a poco se extendiera hasta el norte del Mar Negro, al mismo tiempo que intervenía en las guerras entre los eslavos del este ${ }^{200}$. El cantar de la hueste de Igor narra la epopeya del enfrentamiento del príncipe de Novgorod, Igor Sviatoslavovich (1151-1202), aliado con su hermano el príncipe de Kiev, Vsevolod (11761212) y otros parientes en contra de los cumanos. El cantar narra la derrota de los eslavos del este y la captura de Igor. Ésta se interpreta como un castigo divino por el paganismo de Igor y por la desunión entre los rus ${ }^{201}$. A pesar de que los testimonios sobre la relación entre los rus y los polovotsianos apuntan hacia constantes enfrentamientos que las crónicas

\footnotetext{
199 “Medieval Sourcebook: Privileges Granted to German Merchants Novgorod, 1229”, selección de Paul Halsall, octubre de 1998 tomado de G. F. Sartorius, ed. Urkundliche Geschichte des Deutschen Hanse. J. Lappenberg, rev., (Hamburgo, 1830), vol. II, p. 29; reimpreso en Roy C. Cave y Herbert H. C. eds., A Source Book of Medieval Economic History, (Milwaukee; The Bruce Publishing Co., New York: Biblio and Tannen, 1965), pp. 225-231 en http://www.fordham.edu/Halsall/source/1229novgorod-germans.asp consultado 15 de noviembre de 2012; Halperin reseña de "Law in Medieval..., op. cit., p. 246; Los rutenos fueron un pueblo que pertenecieron a los eslavos del este, todavía sobrevivían como una entidad en el siglo XIX pero paulatinamente se diluyeron en otros pueblos eslavos como los rusos o los polacos.

200 The Chronicle of Novgorod... trad. Michel, op. cit., pp.4-49, Cross, The Russian..., op. cit., pp. 179-183; Encinas Moral, op. cit., pp. 8-10; Longworth, op. cit., p. 42.

${ }^{201}$ Cantar de la hueste de Ígor, op. cit., passim.
} 
interpretan como castigo divino, se mezclaron con los eslavos del este y seguramente dejaron su huella en los pueblos en los que más tarde habitaron la región.

A pesar de la realización de las cruzadas fomentadas por el Papa (1096-1261) los bizantinos intentaron influir en la política de los rus y, sobre todo, evitar que aprovecharan su debilidad para apoderarse del territorio que aún les quedaba. Sin embargo, tuvieron algunos roces con los rus a pesar de que éstos siempre reconocieron la primacía del emperador bizantino y no se sumaron a los cristianos latinos ${ }^{202}$.

Para complicar más la situación, los príncipes de la Rus sufrieron las consecuencias de la presencia de la Orden de Livonia entre los fineses del Báltico (1202-1236) y de los intentos de colonización de la Orden Teutónica (1190-1525) que apareció en la costa del Báltico en c. 1231. La Orden Teutónica tenía como objetivo convertir a los pueblos que habitaban a las orillas del Mar Báltico -y si era posible también a los eslavos del este- al cristianismo romano. Se establecieron en la costa y provocaron la migración de lituanos y letones hacia los principados de la Rus. Además, los polacos y los lituanos intentaron extenderse al oriente a costa de las principalidades de la Rus. La Crónica de Novgorod trata, entre otros temas, sobre las disputas entre los gobernantes de las diferentes ciudades, así como de las correrías de los polovtsianos, los lituanos, los fineses y algunos eslavos occidentales quienes quemaban poblados y atacaban hasta a los niños y a los clérigos. De acuerdo con la crónica, la Rus padecía un gran desorden interno, lo cual no impedía que

\footnotetext{
${ }^{202}$ Cross, The Russian..., op. cit., pp. 145,
} 
fueran fundados monasterios ${ }^{203}$. Hay que recordar que los monasterios solían tener grandes extensiones de tierra cultivable

A pesar de las luchas intestinas y los ataques del exterior, los campesinos continuaban con su labor pues en última instancia era la producción agrícola la que sostenía a las ciudades y a los príncipes y sus séquitos. No está por demás aclarar que las urbes tenían bajo su jurisdicción extensos territorios en los que había tierras de labor. Por ejemplo, Vladimir- Suzdal controlaba una región en la cual además de las tierras de cultivo también se encontraban las ciudades de Tver, Rostov, Yaroslav y Moscovia. Al parecer la organización en el campo casi no había cambiado, los esclavos continuaban como la principal fuerza de trabajo agrícola a los que se sumaban los campesinos libres y los peones. De cualquier manera, la guerra afectaba a los labradores aunque no siempre tuvieran que luchar por defenderse. La Primera Crónica cuenta que cuando en 1103 los príncipes Svyatopolk II (1050-1113) y Vladimir (m. 1151) se sentaron a discutir el momento para atacar a los polovtsianos, el séquito del primero señaló que no era conveniente iniciar operaciones en primavera para no afectar la siembra. Vladimir les preguntó ¿cuál era su preocupación, los campesinos en sí mismos o los caballos? ${ }^{204}$ Esto induce a suponer que aunque los campesinos no participaran directamente en las batallas, debían "prestar" sus caballos a los boyardos durante una campaña. Evidentemente, si no tenían animales de tiro, se hacía más difícil arar la tierra. A esta situación se añadían las inclemencias del clima sobre todo en la taiga donde provocaban periodos de hambruna, ésta era una peligro permanente para los labradores estuvieran bajo el dominio de un señor o

\footnotetext{
${ }^{203}$ The Novgorod Chronicle, Medieval Sourcebook..., op. cit., pp. 1-3; Hellmann, op. cit., pp. 47-64;

Vernadsky, op. cit., pp. 41-43, 51; Riasanovsky, op.cit., pp. 39- 54; Jacques Le Goff, op. cit., pp.40, 71; El tema de los monasterios será tratado con mayor detalle en el apartado 2.3.

${ }^{204}$ Cross, The Russian..., op. cit., p. 200.
} 
monasterio o bien fueran comunidades autónomas. Si los labradores no tenían qué comer tampoco había alimento para los caballos. La Crónica de Novgorod refiere, por ejemplo, que en 1128 hubo tal escasez de alimento que la gente emigraba o bien daba a sus hijos a los mercaderes porque no tenía qué darles de comer. En el otoño de 1145 llovió a raudales y no fue posible levantar la cosecha. Así, las calamidades afectaban constantemente a los $\operatorname{campesinos}^{205}$.

La disputa por el poder político no impidió que los rus compartieran prácticas culturales. El cristianismo siguió afianzándose como un elemento aglutinador. Poco después de la muerte de Yaroslav, San Antonio (983-1073) fundó el famoso Monasterio de las Cuevas en Kiev (1051) aunque ya llevaba algunos años como asceta en el lugar. Izyaslav le otorgó los terrenos de una colina al monje quien poco después se retiró a vivir solo en una de las cuevas. Los monjes labraron la iglesia y sus celdas en las cuevas de la colina. A San Antonio lo relevó como prior Barlaam (no se encontraron datos de este personaje) y más tarde San Toedosio de Kiev (1029-1074). Según la hagiografía escrita por el monje Néstor, Teodosio desde niño se entregó a Dios, cuando oyó hablar de San Antonio se presentó ante él pidiéndole que lo consagrara monje. Nikón, uno de los tantos monjes del monasterio, fue el encargado de hacerle la tonsura, más tarde se le ordenó sacerdote. Como abad, Teodosio encabezó la construcción formal del monasterio y solicitó a los monjes cenobitas de Constantinopla la Regla de San Teodoro el Estudita (759-826) 206 misma que establecía que todo monje debería de cultivar las virtudes de la castidad, la estabilidad y la caridad. San Toedosio impuso esta Regla en el monasterio de las Cuevas de Kiev. Por ello se le considera el fundador de los monasterios cenobitas en Rusia. Teodosio

\footnotetext{
205 The Novgorod Chronicle..., trad. Michel..., op. cit., p.11, 18.

${ }^{206}$ http://www.es.wikipedia.org/wiki/Teodoro_el_Estudita consultado 7 de agosto de 2013.
} 
fomentó la caridad hacia los pobres, el trabajo de los monjes como si fuesen esclavos, de manera que exigía humildad y obediencia. Teodosio tuvo una vida de mortificaciones y de lucha por su fe, su madre hizo lo indecible por impedir que se entregara a la vida religiosa y no conforme con ese sufrimiento, todavía usaba cadenas para lacerar su cuerpo ${ }^{207}$. También intervino en la política, cuando los hermanos de Izyaslav se levantaron en su contra, Teodosio le escribió una carta al príncipe Svyatoslav reprochándole haber asesinado a su hermano mayor, pero Svyatoslav no se atrevió a hacer nada en su contra ${ }^{208}$. El Monasterio de Las Cuevas de Kiev fue el modelo que adoptaron los monasterios fundados posteriormente, y San Antonio y San Teodosio los modelos de los monjes ascetas el primero y de los priores el segundo.

En cada principalidad adoraban sus propias advocaciones de la virgen o bien a sus santos locales, pero las creencias y los ritos litúrgicos practicados y propagados por la iglesia ortodoxa propiciaban un cierto grado de unidad religiosa. Por ejemplo, en Novgorod se adoraba el icono de Nuestra Señora de los Pecados ubicada en la Iglesia de Santiago. En el siglo XIII este icono fue trasladado a la Iglesia de El Salvador y empezó a adorarse como la protectora en la victoria de Novgorod en febrero de 1170 . La catedral de Santa Sofía en esa misma ciudad era considerada como su símbolo. El fervor de los novgorodianos y su poder político fueron tales que en 1156 instalaron su propio arzobispado. Pero no fueron los únicos, la difusión del cristianismo entre los rus había dado

\footnotetext{
207 "The Life of St. Theodosious" en Kaiser, op. cit., pp. 67-71; Monje Néstor "Life of Our Blessed Father Theodosius, Abbot of the Crypt Monastery" en Zenkovsky, op. cit., pp. 116- 134.

${ }^{208}$ Cross, The Russian..., op. cit., pp. 139-142, 156-164 en estas últimas páginas se encuentran relatos sobre la vida de Teodosio y de otros monjes del Monasterio de las Cuevas de Kiev.
} 
lugar a que en el siglo XIII existieran 16 diócesis ${ }^{209}$. Así pues, los motivos del culto podían cambiar pero lo importante era la fe en que vírgenes y santos velaban y protegían a los rus.

Asimismo, las prácticas bizantinas continuaron arraigando en los principados de los eslavos del este. Para empezar, las imágenes religiosas siguieron los patrones bizantinos pues los primeros artesanos llegaron de Bizancio y con ellos algunos abjasos ${ }^{210}$; pronto una escuela de pintura de iconos y de manufactura de mosaicos se desarrolló en las tierras de la Rus. Asimismo, la arquitectura en piedra, casi toda dirigida a levantar templos, adoptó los cánones bizantinos. Andrey Bogoliubskii, príncipe de Vladimir-Suzdal y Kiev, procuró ejercer el poder sobre sus dominios imitando a los emperadores bizantinos. Otra práctica que la dinastía de Vladimir- Suzdal tomó de Bizancio consistió en invocar a santos militares para que los protegieran en las batallas. Los príncipes erigieron iglesias en las que representaban a santos como Demetrio (c. 270-306) o Teodoro (m. en 306) -militares romanos originarios del oriente del imperio que murieron como mártires por practicar el cristianismo- con sus armas. Los príncipes de Valdimir-Suzdal incluso le atribuyeron a Boris y Gleb calidad de santos militares ${ }^{211}$, a pesar de que su santidad se debía a que se negaron a pelear en contra de su hermano. Esta práctica iniciada en Vladimir-Suzdal seguramente respondió a la guerra constante que los rus tenían entre sí y con pueblos vecinos. Estas adquisiciones culturales se sumaron a la continuidad de prácticas ancestrales

\footnotetext{
${ }^{209}$ Gail Lenhoff reseña del libro "Autour du mythe de la Sainte Russie: Christianisme, pouvoir et société chez les slaves orientaux (Xe-XVIIe siècles)" de Vladimir Vodoff en Slavic Review, 63:2, verano de 2004, pp. 399-400 en http://www.jstor.org/stable/3185753, consultado 2 de noviembre de 2012, p. 400; Riasanovsky, op. cit., p. 54, 79; Chronicle of Novgorod... trad. Michell..., op. cit., p XI.

${ }^{210}$ Monje Néstor, "Bishop Simon: the Coming of the Greek Iconographers from Constantinople to Abbot Nikon" en Zenkovsky, op. cit., pp. 138-140, no se encontraron datos sobre este Nikón quien parece ser el que tonsuró a Teodosio.

${ }^{211}$ Monica White [Actualmente profesora en la Universidad de Nottingham], "A Byzantine Tradition Transformed: Military Saints under the House of Suzdal"” en Russian Review, 63:3, Julio de 2004, pp. 493513 en http://www.jstor.org/stable/3664652 consultado 9 noviembre de 2012.
} 
eslavas, las bylinas son una muestra de ello aunque con el paso de los años hayan incluido algunos elementos cristianos. Sin embargo, no debe dudarse que la escritura de crónicas y sermones estuvo inspirada en la producción literaria bizantina. De igual manera, la mayoría de las construcciones se hacían en madera pues eran la materia prima que proporcionaba el bosque $^{212}$.

Es importante destacar que la escritura no se limitó a textos de carácter religioso. Se han encontrado algunas runas escandinavas, monedas con escritura y otras formas gráficas de comunicación $^{213}$. En excavaciones realizadas en la década de 1960 en Novgorod $^{214}$, se descubrieron conjuntos de tabletas de madera con salmos escritos en cirílico que datan de principio del siglo XI, hasta el momento se consideran los documentos escritos más antiguos de la Rus. Desde la segunda mitad del siglo XI, otras tabletas tienen mensajes cortos que se refieren a transacciones comerciales, esto es, las evidencias de escritura denotan que era utilizada por gente común que habitaba las ciudades. También se han hallado cilindros de madera que servían para cerrar los fardos con mercancías, algunos de ellos tienen inscripciones. Es decir, los mercaderes usaban la escritura para registrar sus operaciones. Pero no sólo ellos la utilizaban, se han encontrado firmas de los artesanos que participaron en la construcción de la catedral de Novgorod tanto en piedras como en los iconos. Asimismo se cuenta con cartas firmadas por soldados e incluso hay algunas redactadas por mujeres. En las nuevas ciudades del noreste también se han encontrado evidencias de escritura secular. Las tabletas de madera se localizan fundamentalmente en

\footnotetext{
${ }^{212}$ Longworth, op. cit., p. 44; Dukes, op. cit., pp. 24-25; Riasanovsky, op. cit., pp. 58-59; Moss, op. cit., pp. 47-52.

${ }^{213}$ Franklin, "Pre-Mongol ..., op. cit., p. 466.

214 "Birchbark Charters From Novogord (Twelfth Century)", "Graffiti from St. Sophia Cathedral, Kiev (Eleventh-Twelfth Centuries)"; Simon Franklin, "Literacy in Kievan Rus"”y "Evidence for Literacy: Novgorod Birchbark Charters (ca. 1220-30s)” en Kaiser, op. cit., pp. 71-78, 128-130.
} 
las ciudades del norte, pero esto no significa que no se hayan escrito en el sur. Otra evidencia de que había letrados en las ciudades que no eran religiosos son las inscripciones que se han descubierto en la catedral de Santa Sofía cuyo contenido se refiere a sucesos ocurridos en Kiev. La redacción de estos documentos pero sobre todo la escritura misma induce a suponer que no fueron escritos por escribanos profesionales. Ahora bien, gran parte de los documentos no están firmados y los que sí lo están no indican la profesión o el estrato social al que pertenecía el escritor, la mayoría no tienen carácter formal por lo que se cree que no fueron redactados por burócratas. Por último, conviene subrayar que también se han hallado algunas tabletas que muestran ejercicios de escritura de quienes estaban aprendiéndola. Estas evidencias se han fechado en las primeras décadas del siglo XIII, lo que parece indicar que para entonces los habitantes de las ciudades consideraban necesario que la población aprendiera a leer y escribir ${ }^{215}$.

\subsection{El noreste de la Rus}

Este último apartado trata específicamente del avance de los rus en dirección al noreste de los asentamientos de Novgorod en la taiga y en la tundra. Los datos no son muy abundantes pero si suficientes para mostrar cómo la paulatina transformación de la sociedad de los rus de jefaturas a pequeños Estados tuvo lugar de manera paralela a la expansión al noreste. Los habitantes de Novgorod fueron quienes se aventuraron en los bosques boreales situados al noreste de la ciudad. Uno de los motivos principales de este movimiento fue obtener pieles finas para venderlas a los bizantinos, a los musulmanes de la estepa y hasta a los europeos occidentales quienes les daban un uso suntuario. Es decir, la participación en las

\footnotetext{
${ }^{215}$ Eve Levin reseña de Simon Franklin, "Writing, Society and Culture in Early Rus, c. 950-1300” en Slavic Review, 62:4, invierno de 2003 , p. 874 en http://www.jstor.org/stable/31855709, consultada 2 de noviembre de 2012.
} 
rutas comerciales ofertando productos del bosque y cereales fue un elemento esencial para consolidar el poder político en las diferentes principalidades de la Rus que a su vez facilitara controlar territorios que proveyeran de recursos adicionales a estos Estados incipientes.

En un principio, las pieles que comerciaban los vikingos y eslavos antes y durante el esplendor de Kiev se obtenían de los bosques en la cuenca del Dniéper y el Voljov donde se ubicaban: Kiev, Gnezdovo, Novgorod y Staraya Ladoga. Pero los bosques del Dniéper y el Voljov fueron despareciendo, fue entonces cuando los bosques de la cuenca del Oka se convirtieron en cotos de caza. Esto explica en gran medida por qué Novgorod desplazó a Kiev como centro comercial. La región entre el Voljov y el Oka estaba habitaba por pueblos hablantes del lenguas de la familia fino-ungria cuando los eslavos del este llegaron. La Primera Crónica menciona a los meria primero como tributarios de los vikingos y más tarde combatiendo en las huestes de Oleg ${ }^{216}$. En aquel momento, siglo IX, tanto los eslavos del este que emigraron desde Novgorod hacia esta región como los pueblos ugro-fineses eran paganos y participaban en ceremonias conjuntas, por ejemplo de culto al oso. Es decir, se entablaron relaciones interculturales entre ambos. Hay que recordar que la región se ubica en el bosque boreal donde el oso es uno de los animales más fuertes que de vez en vez atacaba a las aldeas, así que el espíritu del oso era una de las deidades más importante para ellos. Los meria poco a poco dejaron de aparecer en las crónicas y desde el siglo XI ya no se mencionó miembro alguno de este pueblo. Esta situación indica que paulatinamente se fueron asimilando con los eslavos que colonizaron la región. La migración eslava cobró mayor intensidad cuando se estableció la ruta comercial por el Volga, de manera que los

\footnotetext{
${ }^{216}$ Cross, The Russian..., op. cit., pp. 55.
} 
eslavos no llegaron solos sino acompañados por escandinavos. Se fundaron las ciudades de Rostov, Beloozero, Vladimir y Suzdal tal vez en sitios en los que había aldeas de meria. Poco a poco se introdujo la agricultura y se impulsaron las manufacturas artesanales, para satisfacer las necesidades de quienes transitaban por la ruta comercial. La Primera Crónica consigna datos acerca de las actividades de los brujos, seguramente chamanes, que inducían a los nativos a matar a los colonizadores. Cuando los enviados del príncipe de Beloozero los capturaron y los interrogaron, los chamanes respondieron que los habían matado porque los difuntos tenían mucha riqueza y si se deshacían de ellos la abundancia regresaría a su pueblo. Este pasaje es más que elocuente, la presencia de los eslavos y escandinavos había trastocado la relación que los nativos ugro-fineses tenían con su ecosistema provocando necesidad entre estos últimos ${ }^{217}$.

Pero no todos los pueblos nativos de la región se fundieron con los eslavos y vikingos. Los mari lograron mantenerse como una comunidad distinta, conservaron su lengua y muchas de sus costumbres y hoy en día han logrado que se les reconozca como una de las múltiples etnias que forman parte de la Federación Rusa. Los mari estaban organizados en diferentes comunidades y tuvieron relaciones tanto con los eslavos del este como con otros pueblos como los bashikes. Cuando los mongoles sometieron algunos principados de la Rus, los mari se aliaron con uno u otro pueblo según su conveniencia, estrategia que les permitió mantenerse como un pueblo diferenciado. Esto no significa que los mari hayan permanecido con una cultura estática sino que ha ido cambiando como

\footnotetext{
${ }^{217}$ Cross, The Russian..., op. cit., pp. 150-154; I. V. Dubov [se encontraron obras publicadas por este autor en las décadas de 1980, 1990 y 2000], “The Ethnic History of Northeastern Rus', in the Ninth to Thirteenth Centuries” en Kaiser, op. cit., pp. 14-20.
} 
ocurre con todos los pueblos, pero han conservado su identidad ${ }^{218}$. Hasta ahora no se ha podido construir una explicación para comprender por qué los meria desaparecieron como un pueblo y los mari no, si ambos tuvieron una relación semejante con los colonizadores eslavos y escandinavos.

A la sombra de Novgorod, Smolensk (en el mapa 8 está de color durazno) también participaba en el tráfico comercial por el Volga. A medida que las presas disminuían y las tierras se dedicaban a la agricultura, los cazadores avanzaron en dirección al nordeste: primero a la parte alta del Volga, más tarde al Dvina septentrional hasta alcanzar el rio Péchora ubicado en la ladera oeste de los Montes Urales a esta región los novgorodianos la denominaron Zavolochye ${ }^{219}$. En breve, la gente de Novgorod incursionó al este de los Urales hasta el río Ob, territorio al que llamaron Yugra. Los pueblos que habitaban esta región eran cazadores y pescadores y vivían en pequeñas comunidades igualitarias, en Yugra no hubo asentamientos de los eslavos del este tan sólo exigían a algunos pueblos que pagaran tributo.

Para realizar las operaciones de exploración y cacería se requería de una fuerte inversión que sólo podían hacer los comerciantes adinerados o los terratenientes que se apoderaban o recibían de los príncipes las tierras desmontadas por los campesinos. Es decir, las avanzadas eran de pequeños grupos de personas que buscaban mejorar sus condiciones de vida, explotaban los recursos del bosque y, en breve, si era posible, lo desmontaban para cultivar. En la tundra practicar la agricultura no era posible, por ello los cazadores

\footnotetext{
${ }^{218}$ Ronald Wixman, reseña del libro Seppo Lallukka, "From Fugitive Peasants to Diaspora: the Eastern Mari in Tsarist and Federal Russia" en Slavic Review, vol. 63, no. 4, invierno de 2004, pp. 904-905 en http://www.jstor.org/stable/1520471 consultado 2 de noviembre de 2012.

${ }^{219}$ Significaba la tierra que está más allá de los lagos en la cuenca del Mar Blanco. Cross, The Russian..., op. cit., p. 271
} 
regresaban a los poblados ya fueran autónomos o insertos en los dominios de un señor y realizaban operaciones de intercambio. Los comerciantes acaudalados y los señores adquirían estas pieles preciosas y eran ellos quienes trataban o bien con los mercaderes de la Hansa en Novgorod u organizaban las flotas que navegaban por el Volga río abajo hasta alcanzar los centros comerciales de la estepa.

Estos comerciantes-cazadores tenían tres formas de obtener las pieles. Conseguían las presas por sí mismos, en el caso de los terratenientes dejaban parte del bosque sin desmontar y utilizaban trampas, los cazadores independientes también usaban trampas y armas. Otra manera, era estableciendo relaciones de intercambio con los nativos. En la región descrita vivían pueblos de habla ugro-finesa llamados komi y al este los péchora, más allá de los Urales los rus designaban a los habitantes como yugra. Puesto que habitaban en el Ártico vivían de la pesca y la caza de manera que estaban dispuestos a intercambiar pieles por cuchillos, espadas y hachas de metal. Hay que puntualizar que en la tundra los habitantes se vestían con pieles para soportar el frío pero sus atuendos estaban elaborados con cueros de reno o con intestinos de mamíferos marinos porque éstos últimos eran impermeables. La piel de marta cibelina o zorro plateado tan sólo se utilizaba en las capuchas. De manera que el uso de las pieles que hemos llamado finas no era tan frecuente como el de otro tipo de pieles. De ahí que estuvieran dispuestos a intercambiarlas por objetos que les proporcionaban una vida más confortable como un cuchillo de hierro en lugar de uno de piedra ${ }^{220}$.

Otra opción que tenían los rus consistía en exigir a los nativos que pagaran tributo. Al parecer los komi se sometieron fácilmente, no así los péchora ni los yugra que

\footnotetext{
${ }^{220}$ Ibidem, p. 184.
} 
esporádicamente mataban a los recolectores de tributo. Entonces los novgorodianos realizaban expediciones punitivas para someterlos de nuevo ${ }^{221}$.

De acuerdo con La Crónica de Novgorod, en 1187 los péchora mataron alrededor de 100 cobradores de tributo. En respuesta, seis años más tarde una expedición fue a Yugra y tomó por la fuerza dos aldeas. Los yugra les decían a los rus que no los arruinaran pues ellos les daban hierro (sin manufacturar) y pieles de marta cibelina. El relato termina con el regreso de la expedición a Novgorod ${ }^{222}$. Este pasaje muestra que las relaciones con los pueblos de la tundra eran violentas, lo que no impidió el intercambio de bienes e información entre los nativos y los rus de Novgorod.

Como se ha analizado en este capítulo, las posibilidades para el ulterior destino político de la Rus eran diversas. Si bien Kiev representaba la herencia de un poder que aspiraba a desempeñarse de manera centralizada, hubo otras regiones como Novgorod, que transitaron por otras experiencias. Autores como George Vernadsky ha calificado al gobierno de Novgorod como democrático aunque en la práctica era una democracia de notables $^{223}$. Pero existieron otros procesos sociales que tuvieron continuidad. En primer lugar el fenómeno de la migración hacia nuevos espacios ocupados por pueblos no eslavos en donde los rus pusieron en práctica sus conocimientos. Dicha migración fue favorecida por los enfrentamientos entre los príncipes de la Rus, es decir, por problemas políticos en los territorios que había pertenecido a la Rus de Kiev. Por el norte, los eslavos del este alcanzaron la tundra y llegaron al Mar Blanco, su experiencia en la cacería, pesca y navegación facilitó su permanencia en ese territorio pero todavía no se habían expandido

\footnotetext{
${ }^{221}$ Forsyth, op. cit., pp. 2-5; Fisher, op. cit., pp. 3-7

${ }^{222}$ Chronicle of Novgorod... trad. Michell..., op. cit., pp.33, 36-37.

${ }^{223}$ George Vernadsky, Kievan Russia. New Haven y Londres, 1976. 418 pp., mapas, p. 199.
} 
más allá de los Urales. Esta avanzada estaba en comunicación con otras regiones habitadas por los eslavos del este mediante los ríos que facilitaban el intercambio de todo tipo, así la tundra, la taiga y la estepa quedaron integradas en una red que a su vez se relacionaba con otras como en la que participaba la Hansa. Vale la pena subrayar que la incorporación del territorio del noreste de Europa a los dominios de Novgorod propiciaron que esta ciudad situada al noreste de Kiev quedara ubicada en el norte mientras que principados como Valdimir-Suzdal, Chernigov, Riazan (en el mapa 8 de verde claro) y Peresyaslav (en el mapa 8 de rosa fuerte, en el sur) en el este, el primero estaba ubicado al norte del resto pero al sur de los territorios novgorodianos.

En segundo lugar, la migración fue encabezada por sujetos que buscaban sitios para obtener bienes que no tenían en sus lugares de origen. Los campesinos así como los cazadores y mercaderes se aventuraban en nuevos espacios para desarrollar sus actividades con un beneficio mayor. Como resultado de migraciones y contactos, los eslavos del este vivían constantemente procesos de interculturalidad que marcaban diferencias entre ellos pero no lo suficientemente profundas como para que dejaran de considerase como miembros de un mismo pueblo. En este aspecto, la iglesia ortodoxa jugó un papel cada vez más importante tanto porque proporcionó las herramientas para que el idioma de los rus se escribiera facilitando la comunicación entre ellos, como porque aportó un sistema simbólico que los eslavos del este hicieron suyo.

Por fin un pueblo de la estepa consiguió someter a los principados de la Rus. En el siglo XIII, cuando florecían diversas ciudades comerciales y los boyardos -es decir, los grandes terratenientes- empezaban a someter al campesinado al régimen de servidumbre para garantizarse el acceso a la fuerza de trabajo, los mongoles, encabezados por Batu 
(1204-1255) los invadieron y conquistaron. En consecuencia se abrió un nuevo capítulo en la historia de la formación del Estado ruso. 


\section{CAPÍTULO III. LA RUS BAJO EL DOMINIO MONGOL $(c$. 1230-c.1300)}

\subsection{La Rus como parte del Janato Kipchak}

En el siglo XII, una la tribu de los kitues criadora de ganado (ovejas, cabras, vacas, camellos, pero sobre todo caballos) y guerrera que habitaba en la taiga al este del Lago Baikal inició la unificación de otras tribus vecinas que tenían las mismas características. En 1206, Temüjin, jan de su tribu, fue nombrado por el Juriltai (asamblea de jefes de clanes) como Gengis Jan. Bajo su mando se unieron todas las tribus conocidas en el futuro como mongolas $^{224}$ y nació con esta confederación el extraordinario ejército que creó, mediante la conquista, el imperio territorial más grande de la historia ${ }^{225}$.

La expansión de los mongoles fue vertiginosa gracias a la maestría con la que cabalgaban, la utilización del arco y la flecha y la estrategia de "pega y corre" para atacar a sus enemigos. A los ejércitos mongoles se integraron una gran cantidad de pueblos de habla turca que tenían costumbre similares pues eran también pueblos esteparios criadores de ganado con una organización tribal, todos ellos se mezclaron aunque el estrato social y político de jerarquía más alta era el de los mongoles, específicamente el linaje de Gengis Jan. Otro de los elementos que favorecieron el éxito de los mongoles fue el ejercicio del poder centralizado. Sobre Gengis Jan recaía toda la autoridad y sus decisiones eran

\footnotetext{
${ }^{224}$ http://www.es.wikipedia.org/wiki/Gengis_Kan consultado 28 de junio de 2014.

${ }^{225}$ Para una revisión sobre las características de los imperios nómadas como fue el caso del mongol vid. Nikolay N. Kradin (1962-) "Nomadism, Evolution and World-Systems: Pastoral Societies in Theories of Historical Development" en Journal of World-System Research, VIII, III, otoño de 2002, pp. 368-388 en http://intersci.ss.uci/wiki/ebooks/Articles/Nomadism\%20Kradin.pdf consultado 1 de diciembre de 2012 y del mismo autor "Cultural Complexity of Pastoral Nomads" 2006, 22 pp. en http://en.wikipedia.org/wiki/Nikolay_Kradin consultado 11 de diciembre de 2012, el autor denomina a estos imperios formados por sociedades pastoriles "jefaturas supercomplejas" concepto que se asume en esta tesis. Además postula que este tipo de imperios nómadas se formaron cuando el "tiempo eje" llegó a su fin en las sociedades preindustriales. Este último concepto acuñado por Karl Jaspers (1883-1969) en 1949.
} 
incuestionables, este atributo se extendió a su linaje. En ocasiones reunía una Gran Asamblea en la que participaban los jefes de los linajes aliados, quienes, si era necesario, designaban al Gran Jan. Asimismo había asambleas más pequeñas en las que el Gran Jan pedía consejo a sus parientes. Sin embargo, todos los pueblos conquistados debían rendir homenaje al linaje de Gengis $\operatorname{Jan}^{226}$.

De acuerdo con La historia secreta de los mongoles el intercambio de regalos era una expresión de la alianza entre jefes tribales. Temujin regaló a Ong Jan, quien había sido aliado de su padre, una capa de piel negra de marta cibelina, para sellar su alianza con él. Al parecer entre los pueblos pastores asiáticos de la estepa o de la taiga, se usaban capas y gorros de pieles finas para denotar un rango superior lo que indica que eran grupos socialmente jerarquizados. Los mongoles introdujeron esta costumbre en los pueblos que quedaron sujetos a ellos pues se ha encontrado entre los chinos, los pueblos de la estepa y en Rusia el uso de capas y gorros de piel$^{227}$.

Siguiendo las costumbres mongolas y de la ley $\operatorname{Yasak}^{228}$, Gengis Jan repartió el territorio de su imperio entre sus cuatro hijos. Yasak es la palabra que derivó de Yassa o Yasa un código que los mongoles decían había dictado Gengis Jan. No existe un documento completo de esta ley, sólo se cuenta con algunos fragmentos de los rollos y referencias en autores contemporáneos de la época. Los mongoles adoptaron el alfabeto uighur con el que fueron escritas tanto la Yasa como la Vida secreta de los mongoles. Diversos estudiosos

${ }^{226}$ The Secret..., vid. Introducción, pp. 1- 37; El libro..., vid., Introducción pp. 9-28. La asamblea donde fue elegido Gengis Jan se encuentra en las pp. 102-103, 190 de la versión en inglés y en las pp. 76-77, 152 de la versión en español; Stephen Kotkin (Phd 1988), "Defining Territories and Empires: from Mongol Ulus to Russian Siberia 1200-1800", Slavic Research Center, 1996 pdf en http://scholar.princeton.edu/kotkin/files/defining_territories_and_empires_from_mongol_ulus_to_russian_sibi r consultado 14 de diciembre de 2012, p. 3.

${ }^{227}$ The Secret..., op. cit., pp.79-80, 86, 122; El libro secreto..., op.cit., pp. 59, 63, 92.

${ }^{228}$ http://www.coldsiberia.org/webdoc9.htm=Its\%20message consultado 30 de diciembre de 2012; The Secret..., op. cit., pp. 3-4. 
han tratado de reconstruir las leyes que conformaban la Yasa. Lo que se ha podido establecer es que recogía tradiciones de los pueblos pastores que practicaban el chamanismo, características de las tribus mongolas.

Así, de acuerdo con la Yasak, la parte occidental fue la herencia de su hijo mayor Jochi (c. 1184-1227), a los hijos mayores se les asignaban los territorios más peligrosos que estaban en la frontera. Gengis Jan designó a su tercer hijo, Ogodei (c. 1186-1241), como su sucesor $^{229}$. Jochi murió antes que su padre, por tanto su hijo Batu, recibió el territorio al oeste del río Irtysh. En 1236, por órdenes de Gengis Jan, Batu emprendió la conquista de los búlgaros del Volga y de los eslavos del este. Estos territorios fueron sometidos cuando Ogodei era ya el Gran Jan pero Batu conservó su herencia ${ }^{230}$.

Para los mongoles el dominio se ejercía sobre los hombres más que sobre el territorio. Por ulus se entendía a todos los linajes que estaban aliados y sometidos a los descendientes de Genigs Jan. Problemas dinásticos llevaron a Batu y su $u l u s^{231}$ a participar mínimamente en la política del imperio, sin embargo, tanto él como sus sucesores reconocieron al Jan radicado en Mongolia. Este ulus fue conocido como el Janato Kipchak o de la Horda de Oro y abarcaba toda la ribera sur del río Don así como las partes media y sur del Volga, es decir, se localizaba prácticamente en la estepa ${ }^{232}$. El mapa 9 muestra la extensión del imperio mongol y en lila los territorios de la Rus que formaron parte de él.

\footnotetext{
${ }^{229}$ La historia secreta..., op. cit., pp.182-183, 196-202; The Secret..., op. cit., pp.224-225, 241-248.

${ }^{230}$ La historia secreta..., op. cit., pp. 206, 212- 213, 217; The Secret..., op. cit., pp. 253, 262-264.

${ }^{231}$ Kotkin, op. cit., p.3

232 Gavin Hambly (1934-2006), (comp.), Asia central. Trad. Maribel Carrillo, 2a ed., Madrid, Siglo XXI, 1973. 350 pp., mapas. (Historia Universal Siglo veintiuno, 16), pp. 89-93, 116-117. La información sobre la ley Yasak se encuentra en la p. 317; Vernadsky, op. cit.,pp. 59-60, 63.
} 


\section{Mapa 9. INVASIÓN MONGOLA A LA RUS}

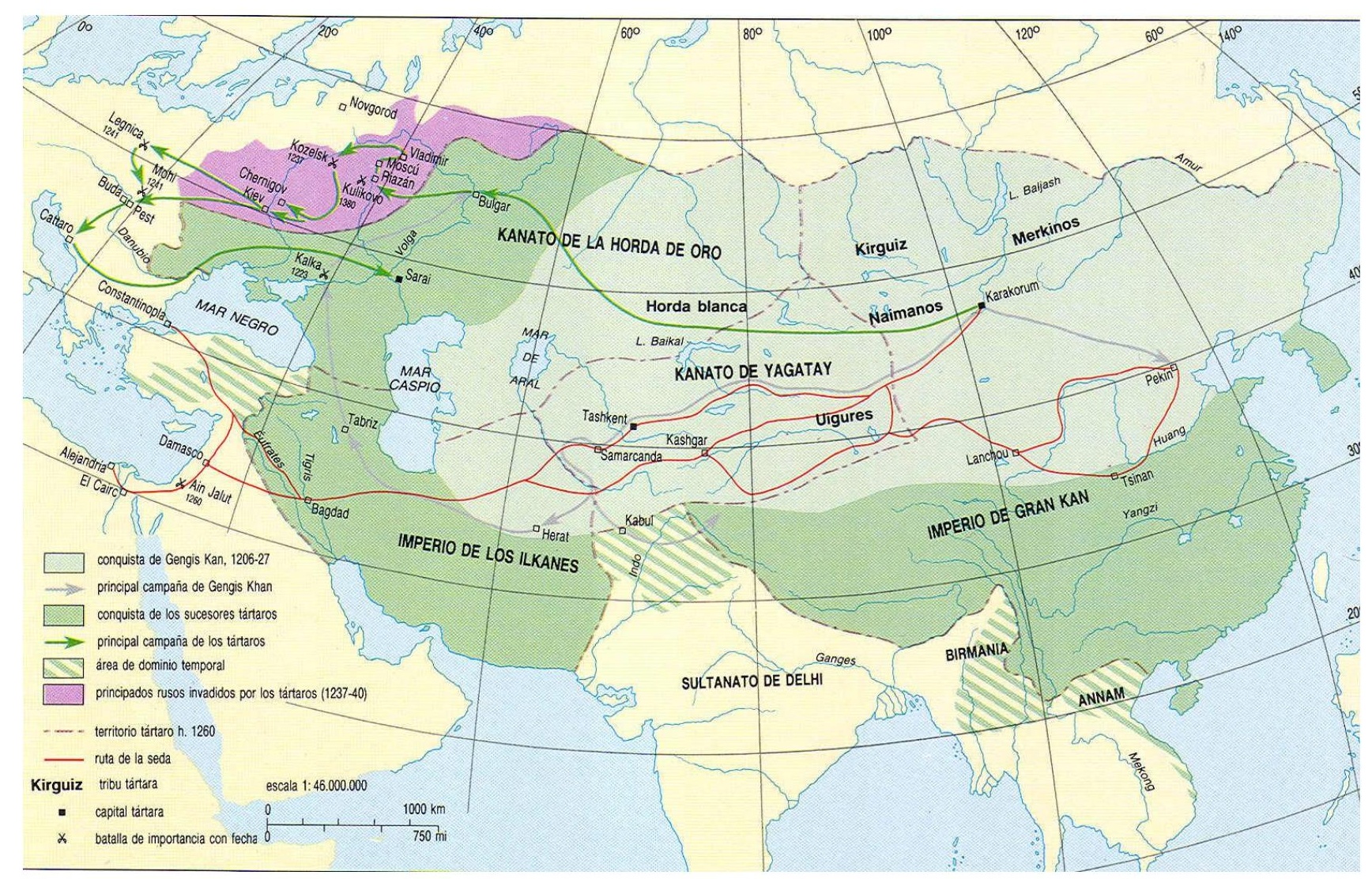

Fuente: Milner-Guland, op.cit., p. 50

La crónica de Novgorod que relata eventos hasta $1470^{233}$, informa que en 1224 se tuvo noticia sobre un pueblo desconocido al que le llamaban tártaro que había conquistado a los cumanos quienes habían solicitado ayuda a los príncipes de la Rus, éstos no la brindaron e incluso ignoraron las advertencias de que después los atacarían a ellos. En sus correrías hacia la Rus, los mongoles conquistaron algunas entidades como Vladimir. La misma crónica describe puntualmente cómo los mongoles tomaron la ciudad de Riazan y aniquilaron a hombres, mujeres, niños y clérigos y quemaron la ciudad. También se refiere a la conquista de las ciudades de Tver, Moscú, Suzdal y Rosotv.

${ }^{233}$ Véase la Introducción. 
En la Crónica, redactada por clérigos ortodoxos, se señala que la conquista mongola fue un castigo divino por los pecados cometidos por los rus. Es claro que el o los redactores, tuvieron que proporcionar una explicación que justificara la victoria de los paganos. En el Relato sobre la destrucción de Riazan ${ }^{234}$ también se atribuye la victoria de Batu a los pecados cometidos por los rus. Según esta fuente, el príncipe Yury Ingvarevich (muerto en 1237) solicitó primero la ayuda del Gran Príncipe de Vladimir quien no se la brindó porque decidió enfrentar a los mongoles sólo con sus fuerzas.

Según el relato ningún príncipe de la Rus apoyó a Riazan cuando el ataque era ya inminente. Yury envió a su hijo Fedor $(i-i)$ con regalos ante Batu, pero éste exigía que le entregaran a todas las mujeres nobles. El embajador de Riazan contestó a Batu que los cristianos no entregaban sus mujeres a los paganos. Esto le costó la vida. El autor anónimo describe cómo los mongoles invadieron el principado y descuartizaron a todas las familias boyardas, a los monjes y a la población en general, sin misericordia alguna, y quemaron la ciudad. Tan solo se salvó el hermano del príncipe Yury, Ingvar Ingvarevich (muerto en 1252) quien estaba en Chernigov cuando ocurrió la matanza y, más tarde, reconstruyó la ciudad de Riazan. En el documento no queda claro cómo negoció con Batu para recuperar el patrimonio de su familia ${ }^{235}$. Por otra parte, no debe olvidarse que el botín era uno de los frutos principales de la guerra.

\footnotetext{
234 "Tale of the Destruction of Riazan" en Zenkovsky, op. cit., doc. 36, pp.198-207.

${ }^{235}$ The Chronicle of ..., Trad. Michell, op. cit., p. 64; The Novgord Chronicle, op.cit., pp. 3-4; "Povest' o bitve na reke Kalke" [Narración sobre la batalla en el río Kalka] en Drevnerusskaya literatura [Literatura antigua rusa] en http://www.drevne.ru/lib/kalka.htm 3 pp., consultado 28 de septiembre de 2011, la traducción de los títulos es propia. En estas crónicas los rus llamaban tártaros a los mongoles. Éstos conquistaron a los tártaros desde la época de Gengis Jan y aquellos pasaron a formar parte de sus huestes. Cuando el imperio mongol se disolvió los rusos siguieron llamando tártaros a los pueblos esteparios vecinos. El libro secreto..., op. cit., pp.83, 101, The Secret..., op. cit., pp. 16,112, 133.
} 
Acerca de la crueldad en los ataques mongoles y la imagen que se ha difundido sobre su rapacidad y afán de destrucción, estudios contemporáneos sobre ellos han cuestionado esta aseveración ${ }^{236}$. Si bien los mongoles atacaban a aquellos que se les resistían u oponían, propiciaron el florecimiento de muchas otras regiones, por ello ahora se ha reconsiderado la interpretación de que impidieron el desarrollo económico de los pueblos conquistados, antes bien su legado ha sido cada vez más apreciado en el caso de Rusia. Por otra parte, el imperativo militar, esto es, la victoria, el botín, la sujeción de la fuerza de trabajo imponen actos de violencia y crueldad en cualquier guerra ${ }^{237}$.

Algunos principados lograron evitar que los mongoles tomaran sus ciudades. Así ocurrió con Smolensk cuya salvación dio pie a que surgiera la leyenda de San Mercurio, héroe al que se le atribuyó la defensa de la ciudad ${ }^{238}$. Otros príncipes prefirieron someterse a los mongoles antes que enfrentarse a ellos, tal fue el caso de Novgorod.

A pesar de que los boyardos no presentaron un frente unido en contra de la invasión mongola debido a sus guerras intestinas, aquellos eslavos que habían vivido bajo el dominio de Kiev compartían ya una lengua común cuya escritura compartían, un ritual religioso también común -el griego ortodoxo- y otros rasgos culturales como la arquitectura, elementos que los hacían reconocerse parte de un pueblo con un mismo pasado $^{239}$. La herencia cultural y política que dejó Kiev en la Rus fue fundamental para la

\footnotetext{
${ }^{236}$ Daniel C. Waugh, "The Pax Mongolica”, 2000, 5 pp. en http://www.sik-road.com/artl/paxmongolica.shtml consultado 13 de noviembre de 2012; Franklin, "Pre-mongol Rus...", op. cit., p. 469. Para una visión negativa sobre el impacto de la invasión mongola para la cultura rusa vid. A. M. Sakharov, "The Mongols and Cultural Change" en Kaiser y Marker, op. cit., pp. 137-140, según este autor la artesanía, la construcción, la literatura, en fin todas las expresiones de la cultura de los rus desaparecieron pero a partir de la segunda mitad del siglo XIV ésta renació, no queda claro cómo fue posible, mostrando una ínfima influencia mongola.

${ }^{237}$ Véase Sean McGlynn, A hierro y fuego. Las atrocidades de la guerra en la Edad Media. Trad. Tomás Fernández y Beatriz Eguibar. Barcelona, Crítica, [2009], 478 pp.

238 "The Heroic Deeds of Mercurius of Smolensk" en Zenkovsky, op. cit., doc. 37, pp. 208-211.

${ }^{239}$ Riasanovsky, op.cit., p.63, passim.
} 
formación posterior de un Estado ruso unificado. En el afán de preservar un grado de autonomía cultural, parte de la nobleza boyarda optó por someterse y aliarse a los mongoles.

Sin embargo, la disgregación del Estado de Kiev propició que otros Estados emergentes al occidente intentaran extenderse sobre el territorio que ocupaban los eslavos del este. La presencia mongola no amilanó ni a los suecos, ni a los polacos, ni a los lituanos y mucho menos a los Caballeros de la Orden Teutónica. Suecos y teutones intentaron apoderarse de Novgorod en tanto los principados del sur eran dominados por los mongoles. En 1225, los lituanos habían matado a varios comerciantes en una de las parcialidades de Novgorod, el príncipe Yaroslav II (1191-1246) los había repelido ${ }^{240}$. En las cronologías dinásticas rusas se establece una línea sucesoria desde Ryurik hasta Fiodor Ivanovich (1584-1598) en las que los gobernantes de distintos principados se muestran como descendientes del primero. Esta línea se establece a partir de que los padres dividían su patrimonio entre sus hijos de manera que los príncipes poderosos del momento de una u otra manera eran parientes y pertenecían a la dinastía de los Ryurikidas ${ }^{241}$.

Una vez que los mongoles habían conquistado gran parte de la Rus no estaban dispuestos a que los príncipes occidentales tomaran para sí a sus nuevos tributarios. Por ello apoyaron al príncipe de Novgorod, Alexander Nevsky (c. 1220-1263), en contra de los caballeros monjes teutones. Éstos tomaron Pskov, ciudad ubicada en los territorios de Novgorod, en 1240 de manera que parecían amenazar al resto del principado, Nevsky los

${ }^{240}$ Chronicle of Novgorod..., Trad. Michel..., op. cit., p.68.

${ }^{241}$ Vid. I. Solov'ev' [sin datos], Jronologiya po russkoi istorii. Jronologiya, rodoslovniya, vnutrennyaya i vnishnayaya diyatel'nost' gosudarei, parallel'niya sobitiya ebropeiskoi istrorii (Cronología sobre la historia rusa. Cronología, genealogía interna y externa de los hechos del Estado paralela a los acontecimientos de la historia europea), Odessa, Izdanie kniynago kagazina “Znanie”, 1912. 56 pp., traducción propia. 
derrotó el 5 de abril de 1242 en la batalla del Lago Peipus evitando que se extendieran al este.

La decisión de Nevsky puede entenderse si se considera que la orden teutónica intentaba incorporar a los pueblos que habitaban la costa del Báltico a la esfera de la iglesia romana, lo que hubiera significado perder su relativamente recién adquirida identidad religiosa ortodoxa, como de hecho les ocurrió a los fineses prusianos; en cambio, los mongoles, aunque se convirtieron al islam a fines del siglo XIII, bajo el janato de Uzbek (1282-1341), no interfirieron en las costumbres religiosas de los conquistados y tampoco en los asuntos internos de los pueblos dominados a menos que se resistieran a la conquista, se rebelaran o no pagaran los impuestos. Los mongoles adoptaron el Islam tras conquistar al califato abasí en 1256. Esta acción implicó que practicaran en islam de acuerdo con la interpretación que le dieron los persas. Es posible que algunos miembros de la burocracia persa islamizada sirvieran a los mongoles del Janato Kipchak ${ }^{242}$.

Por ello, el propio clero ortodoxo avaló la acción de Nevsky pues se conjuró el peligro de la imposición de la iglesia romana en la región. Por esa razón fue canonizado por la iglesia ortodoxa en 1547 . De hecho, Nevsky evitó la conquista de los suecos entonces adscritos a la iglesia romana y de los lituanos, tampoco aceptó la ayuda de la iglesia latina $^{243}$. Por otra parte, sus aliados mongoles lo ayudaron a dominar otros principados de la Rus que se habían resistido a ellos como fue el caso de Vladimir. Por lo pronto, este último quedó sometido a Novgorod y por encima de ella a los mongoles. El respaldo de los

\footnotetext{
${ }^{242}$ Kinder y Hilgemann, op. cit., pp. 143, 185; Sobre la orden teutónica y su presencia en el Báltico vid. Meyendorff, op. cit., pp. 53-55.

${ }^{243}$ Vid. Zenkovsky, op. cit., la historia de Nevsky se encuentra en el doc. 39, pp. 224- 236
} 
mongoles a la figura del príncipe de Novgorod empezó a minar poco a poco el poder de la veche $e^{244}$ como institución representativa.

El sometimiento a la pax mongolica (c. 1240-1480) significó que muchos miembros de la Rus fueran hechos prisioneros lo que equivalía a "ser esclavizados", pero la mayoría permanecieron en el mismo lugar y debían servir al jan o bien participar como efectivos militares en sus ejércitos o pagar tributo -en ocasiones muy alto. A cambio, los príncipes conservaron su autonomía cultural y hasta podían mantener su propio comercio con las ciudades de la Liga Hanseática que se había establecido principalmente en la cuenca del Mar Báltico $^{245}$. Sin embargo, esta autonomía no significó que los rus fueran indemnes a los procesos de interculturalidad y transculturación con los mongoles de Kipchak. A través del tiempo, de la estrecha convivencia con los mongoles y los cambios internos que vivieron cuando estuvieron sujetos a ellos, los rus se transformaron en rusos y se diferenciaron de otros pueblos que habían formado parte de los eslavos del este pero que al tener otras experiencias históricas dieron origen a otras naciones. En suma, la etnogénesis del pueblo ruso está vinculada a su relación de subordinación con un pueblo originario de Siberia oriental -los mongoles- mismo que se nutrió del bagaje cultural de otros pueblos sedentarios asiáticos como el chino y el persa y que a su vez legó esta síntesis cultural a los rusos.

Los príncipes de cada una de las parcialidades de la Rus, debían presentar sus respetos al jan, quien residía en la ciudad de Sarai, ubicada en la parte baja del río Volga.

\footnotetext{
${ }^{244}$ Chronicle of Novgorod..., trad. Michel... op. cit., pp. 84-87 entre los años de 1246 y 1250 , Nevsky se presentó ante los mongoles, pp. 92-93, desde estas páginas en adelante con frecuencia La crónica señala las visitas de los príncipes al jan así como la recaudación de impuestos. Hellmann, op. cit., pp. 65-67, 84-85; Riasanovsky, op. cit., pp. 79-81; Kotkin, op. cit., p. 3;

${ }^{245}$ Hambly, op.cit., pp. 118-119.
} 
En esa ocasión recibían su nombramiento (yarlak ${ }^{246}$ ) como gobernantes de sus dominios. Para controlarlos, el jan designaba a unos observadores (baskakes) que lo mantenían informado sobre sus acciones, pero también los príncipes debían visitar con frecuencia al jan de Kipchak e incluso dejar rehenes. A partir del siglo XIV, los mongoles, cambiaron su capital a la Nueva Sarai ubicada un poco más al norte de la primera.

Así pues, los gobernantes rusos continuaron al frente de sus pequeños Estados pero cuando surgía algún conflicto entre ellos, la justicia la impartía el jan quien actuaba como árbitro entre las partes. Por tanto, es evidente que los rusos reconocían como superior la autoridad del jan, a quien llamaban en los documentos zar. La palabra zar deriva de la palabra césar, es decir emperador. En 1204, los cruzados tomaron Constantinopla y fundaron el imperio latino (1204-1261). Para los ortodoxos esto significó que no hubiera un emperador legítimo. Al parecer, esta situación favoreció que los rusos identificaran al jan de Sarai como emperador respaldado por los designios divinos ${ }^{247}$. En general, los mongoles no fomentaron la rivalidad entre los príncipes rusos y evitaron aliarse con los poderosos del oeste, para eludir compromisos que debilitara su predominio.

Desde 1245, por órdenes del Gran Jan Ogodei, se levantó un censo con el fin de fijar el impuesto que cada uno de sus súbditos, terratenientes y campesinos, debían pagar. El tributo sobre la producción agrícola se tasó por cada arado y no por parcelas, lo que muestra que lo importante para ellos era la gente no el territorio. El pago del tributo era una de las obligaciones que incluía la ley Yasak. Los artesanos y mercaderes debían pagar un

\footnotetext{
${ }^{246}$ Significa "el documento" cfr. Hellmann, op. cit., p. 68.

${ }^{247}$ Apud. Charles J. Halperin, reseña del libro Gorskii, A. A. "Moskva i Orda" [Moscú y la horda]. Moscú, Nauka, 2000, 213 pp. en Russian Review, 61:1, enero de 2002, pp. 149-150 en http://www.jstor.org/stable/2679514 consultado 9 noviembre de 2012, p. 150; Meyendorff, op. cit., p.69; Kinder y, Hilgemann, op. cit., p. 215.
} 
impuesto sobre la renta denominado $\operatorname{tamga}^{248}$. Para asegurar el cobro, los mongoles colocaron destacamentos militares en puntos estratégicos; si alguna comunidad no cumplía con esta obligación sencillamente la sometían por la fuerza. El censo también permitió establecer con cuántos soldados debían contribuir los principados de la Rus para el ejército mongol. Se realizaron otros dos censos en 1257 y 1274 para ajustar el número de soldados que cada región rusa debía aportar. Los soldados rusos también recibían parte del botín que las tropas mongolas obtenían en sus ataques ${ }^{249}$.

La conquista de los mongoles devastó algunos territorios de la Rus. Las ciudades casi desaparecieron y con ellas la manufactura, pues los conquistadores se llevaron a la mayoría de los artesanos a Sarai; ya que los pueblos pastoriles producían pocas manufacturas las habilidades de los artesanos sedentarios fueron muy apreciadas. Por ello, el comercio de pieles finas continuó como la fuente más importante de ingresos para los príncipes eslavos pues en un principio no había mucho qué ofrecer en los mercados porque los mongoles dominaban casi toda la estepa; por tanto sólo los productos de la taiga resultaban atractivos para ellos. Gracias al vínculo con el imperio mongol las rutas comerciales del centro de Asia que cruzaban ese territorio no se cerraron para los rusos. Más aún, sus redes comerciales se ampliaron hacia el este al abrigo del dominio mongol.

En Sarai, los comerciantes rusos tenían su propio barrio. Más tarde, Astrakán, situada en el delta del río Volga, lugar en el que en este periodo se avecindaron los jázaros ya sometidos por los mongoles, se convirtió en el mercado principal en donde se podía

${ }^{248}$ Chronicle of Novgorod..., Trad. Michell..., op. cit., pp. 95-96, 121, passim, La Crónica menciona los pagos de Novgorod y desde el paulatino ascenso de Moscovia, también los de este principado.

${ }^{249}$ Hellmann, op.cit., pp. 65 passim; Kalisov, op.cit., p.52, passim; Dukes, op. cit., p. 29; Le Goff, op. cit., pp.222-223; Vernadsky, op.cit., pp.65-66, 69-71, Riasanovsky, op. cit., pp. 71-75; Longworth, op. cit., p. 49; Kotkin, op. cit., p. 4; Charles Halperin "Interpreting the Mongol Yoke: The Ideology of Silence" en Kaiser y Marker, op.cit., pp. 104-107. 
comerciar con los árabes, los persas, los armenios y hasta con indios y chinos. Tras la desintegración del imperio mongol, los comerciantes rusos lograron mantener el contacto con esos mercados, experiencia que también favoreció la expansión subsecuente en el noreste.

Por otra parte, el comercio con los europeos se redujo por el impacto de la expansión mongola. Aunque Novgorod mantuvo sus relaciones con la Hansa. Es más, al evitar el ataque de los mongoles, vivió su periodo de mayor florecimiento comercial pues también se benefició de la seguridad de las rutas controladas por ellos ${ }^{250}$.

\subsubsection{Viajeros y emisarios}

Respecto de la red de intercambio de información y bienes es importante recuperar los testimonios de viajeros quienes, procedentes de Europa occidental, transitaron por los caminos del imperio. Los viajeros dieron noticia sobre las costumbres de los mongoles y la organización del imperio. El francisano Jean de Plancarpin ((1182-1252) fue enviado por Inocencio IV (1185-1254) desde Lyon en Francia y comenzó su periplo en tierras mongolas en Kiev en febrero de 1246. Los propios mongoles le sirvieron de guías y lo condujeron hasta la tienda del Gran Jan. La convivencia con los guías le dio la oportunidad de observar y reportar las costumbres mongolas. En mayo de 1253 inició su viaje Guillaume de Rubruck (1215-1295) era miembro de la recién fundada orden frnciscana, enviado por San Luis rey de Francia (1214-1270) durante la Séptima Cruzada. Partió de Constantinopla y llegó hasta Mongolia siempre acompañado por guías e intérpretes, que a su juicio no

${ }^{250}$ Waugh, op. cit., pp. 3-4; Immanuel Wallerstein (1930-), El moderno sistema mundial. La agricultura capitalista y los orígenes de la economía -mundo europea en el siglo XVI. Trad. Antonio Resines, 5a ed., [México]. Siglo XXI, editores, 1989. 582 p., ils., (Historia), pp. 54, 208; Vernadsky, op. cit., pp. 61-62, 66; Hellmann, op. cit., p.76; http://astrakhan.name/index.php?razd=2 consultado 24 de mayo de 2011; Meyendorff, op. cit., p.69. 
estaban bien capacitados, pero lograron contactar con algunos europeos apresados por los mongoles quienes les facilitaron su comunicación con ellos. Ya que estos dos enviados eran frailes católico romanos, sus opiniones fueron un tanto prejuiciosas pues todo lo juzgaban en el marco del paganismo mongol, efectuaron el viaje siempre desconfiando de sus acompañantes pues daban por sentado que en cualquier momento podían agredirlos e incluso matarlos. En ambos casos tal vez lo que más les impresionó fue la inmensidad del territorio asiático así como la longitud y el caudal de los ríos. Rubruck dio cuenta de algunas costumbres de los pueblos que vivían en la tundra, aunque no viajó al norte, sus guías e informantes le hablaron de ellos. Ambos frailes también mencionan el rigorismo mongol en el ejercicio del poder. La propia convivencia, les hizo, sin embargo, apreciar que también encontraron personas amables, buenas y hasta con un comportamiento refinado ${ }^{251}$. No hay que olvidar el viaje muy prolongado que la familia Polo realizó (1271-1295) al imperio y a la corte de Kublai Jan (1225-1294), para entonces el Gran Jan ya residía en China. Desde el punto de vista de Marco Polo (1254-1324), los mongoles no eran bárbaros antes bien los janes eran hombres sabios y tolerantes. Si bien sólo Plancarpin visitó Kiev, para los europeos occidentales la sujeción de los príncipes rusos a los mongoles los hizo apreciarlos como rudos y bárbaros ${ }^{252}$.

Los mongoles afectaron principalmente el territorio del sur, lo que provocó que su población migrara hacia el suroeste y hacia el noreste. A pesar del reconocimiento del jan como autoridad suprema, en ocasiones los mongoles saquearon de nueva cuenta ese mismo territorio de manera que la emigración eslava no cesó. El fenómeno migratorio fue la razón

\footnotetext{
${ }^{251}$ Michel Mollat, Los exploradores del siglo XIII al XVI. Primeras miradas sobra nuevos mundos. Trad. Ligia Arjona Mijangos. México, Fondo de Cultura Económica, 1990. 216 pp. (Sección de obras de Historia), pp. 15-25, 104-124, 139, 141-143, 157-159, 171.

${ }^{252}$ Ibidem, pp. 181-183.
} 
principal por la que decayeron las ciudades pues ya no había la producción agrícola suficiente para sostenerlas. Quienes huyeron hacia el suroeste en seguida se vieron afectados por las guerras constantes con los vecinos occidentales que intentaban apoderarse de ese territorio.

En el caso del noreste, las ciudades y principados de Vladimir, Rostov y Tver, se vieron fortalecidos al aumentar la población y desde luego también su territorio pues tuvieron la posibilidad de extenderse hacia el este y el noreste. Por otra parte, y para equilibrar el poder entre los rusos, los mongoles organizaron tres ducados clientelares-Tver, Niyni Novgorod y Riazan ${ }^{253}$.

Bajo el dominio mongol, los príncipes de la Rus siguieron disputándose el dominio de unos sobre otros. Cuando los mongoles dejaron de cobrar el tributo directamente, el privilegio de alguno de los príncipes se hacía evidente cuando el jan le asignaba la tarea de recolectar el yasak entre sus pares. No se logró precisar en qué momento la voz Yasak pasó de denominar una serie de códigos y reglas que regían las relaciones entre los mongoles y los pueblos que tenían sometidos a designar exclusivamente el tributo. Es muy probable que esto sucediera cuando los mongoles se convirtieron al islam y la sociedad empezó a regirse por los preceptos musulmanes en lugar de la Yasak. El vocablo se utilizó entonces para designar tan sólo el tributo que los pueblos sometidos debían pagar a sus señores.

El príncipe encargado de recaudar el yasak contaba con la protección del jan de Kipchak y lograba el título de Gran Príncipe. A finales del siglo XIII el honor le fue concedido al príncipe de Vladimir. En 1328, Iván I (1288-1340), príncipe de Moscovia, con

\footnotetext{
${ }^{253}$ Hellmann, op. cit., p.79; B. H. Summer (1893-1951), Una retrohistoria de Rusia. Trad. Teodoro Ortiz. 2a ed. México, Fondo de Cultura Económica, 1985. 446 pp. (Sección de Obras de Historia), p. 34; Riasanovsky, op. cit., p. 93.
} 
la aquiescencia de los mongoles, se apoderó de todo el ducado de Vladimir y el gobernante de esa ciudad perdió el título de Gran Príncipe. En 1332, Uzbek (1313-1340) le concedió a Iván I el título de Gran Duque de Moscovia y le asignó la tarea de cobrar el yasak en su nombre ${ }^{254}$. A partir de ese momento, el príncipe de Moscovia fue sometiendo al resto de los principados aprovechando su deferencia.

\subsubsection{La frontera occidental}

Para el naciente Estado de Lituania la conquista territorial a costa de la Rus fue muy afortunada. Desde los primeros años del siglo XII, el ducado de Lituania avanzó al este apoderándose de ciudades como Minsk, Chernigov, Kiev. En la primera mitad del siglo XIV se anexaron Volynia, Kiev, Chernigov y en el siglo XV tenía en su poder gran parte de Smolensk. Los lituanos no obligaron a los boyardos a renegar de la fe ortodoxa y fueron frecuentes los matrimonios entre ambas noblezas. De manera que príncipes rus vecinos a Lituania también establecían alianzas con los gobernantes lituanos.

Por su parte, los polacos iniciaron una ofensiva en contra de otros pueblos en el este de Europa. Por convicción o por intereses expansionistas, el reino de Polonia se convirtió en el paladín del cristianismo católico romano en contra de los ortodoxos y los paganos lituanos desde el reinado de Casimiro el Grande (1333-1370). Con la unión de LituaniaPolonia (1389), la influencia polaca empezó a predominar sobre toda Lituania y, por tanto, en los territorios anexados habitados por rus ${ }^{255}$.

\footnotetext{
${ }^{254}$ Hambly, op. cit., p. 123; Longworth, op. cit., p. 49; Hellmann, op. cit., p. 68; Waugh, op. cit., p. 2.

${ }^{255}$ Chronicle of Novgorod..., trad. Michell... op. cit., p. 93 passim, la Crónica también consigna los ataques de los suecos y los polacos pero las agresiones de los lituanos eran más frecuentes; Riasanovsky, op. cit., pp. 132-135; Moss, op. cit., pp. 77-88; Meyendorff, op. cit., pp.61-67.
} 
Fue en este periodo de invasiones y guerras tanto por el este como por el oeste cuando los eslavos del este se diferenciaron en tres grupos: los grandes rusos quienes vivían en el noreste y quedaron sometidos a los mongoles, los pequeños rusos o ucranianos, ubicados en el curso medio del Dniéper y los rusos blancos o bielorrusos, localizados en la parte alta del Dniéper; el territorio de los dos últimos pueblos sufrió invasiones y guerras constantes en contra de Lituania y Polonia, esto los diferenció de los grandes rusos ${ }^{256}$.

Esta diferenciación fue el resultado de la convivencia de los habitantes de esta región de la antigua Rus con diferentes pueblos del oeste cuya influencia cultural tuvo distintas características. Los bielorrusos, por ejemplo, son un pueblo surgido del mestizaje entre eslavos del este, lituanos y polacos ${ }^{257}$. Los que se asumieron como rusos pudieron conservar en gran medida la cultura heredada de los eslavos del este al mismo tiempo que fueron integrándose con los pueblos ugro-fineses que habitaban la región.

En cambio, los ucranianos y los bielorrusos lidiaron con los polacos y los lituanos, principalmente, enfrentándose a la presión de sus vecinos occidentales para convertirlos al cristianismo romano y para adoptar sus costumbres. El asedio de los lituanos a las tierras de la Rus se inició antes de la conquista mongola, la presencia de éstos los azuzó todavía más. De hecho, lograron apoderarse de Kiev, el símbolo mismo de la Rus ${ }^{258}$. Incluso territorios que habían pertenecido a Kiev se perdieron definitivamente para el futuro imperio moscovita como ocurrió en el caso de Galitsiya y Volynia cuya población debió adoptar el catolicismo cuando quedaron anexados a Lituania en la segunda mitad del siglo XIII ${ }^{259}$.

\footnotetext{
${ }^{256}$ Riasanovsky, op.cit., pp. 65, 94, 138-139; Blum, op.cit., p. 59.

${ }^{257} \mathrm{http} / / /$ www.es.wikipedia.org/wiki/Historia_de_Bielorrusia consultado 12 de agosto de 2013.

${ }^{258}$ Hellmann, op. cit., pp. 80-81.

${ }^{259}$ The Novgorod Chronicle, op. cit., p.4; Blum, op. cit., p.59; Vernadsky, op. cit., p. 57.
} 


\subsection{El reacomodo socioeconómico}

Para cuando Moscovia se convirtió en Gran Ducado (1332), los rusos habían colonizado el territorio al este del Volga de donde obtenían pieles, colmillos de morsa, cera y caviar, es decir, por el norte siguieron extendiéndose en la taiga y la tundra. Así los rusos se interrelacionaron con otros pueblos como los maris y los mordavos que poco a poco se fueron mezclando biológica y culturalmente. No obstante, estos grupos han conservado su propia identidad. En el periodo de estudio, los maris en ocasiones apoyaban a los rusos y en otras se aliaban a los mongoles, según conviniera a sus intereses ${ }^{260}$.

La colonización fue el resultado de la migración de campesinos libres y emprendedores que huyeron de los territorios conquistados por los mongoles y buscaban nuevas tierras para el cultivo y la cría de ganado. Roturaban los bosques de la taiga y se avecindaban en esas tierras. Sus métodos de cultivo eran los mismos que en la etapa anterior: quemaban una parcela, la cultivaban con una rotación trienal hasta agotarla; cuando esto ocurría dejaban descansar la tierra y desmontaban otra porción. Los límites de cada fragmento roturado no estaban claramente establecidos lo cual no significaba un gran problema ya que los colonos vivían en comunidad. Estos campesinos se conocían como el "pueblo negro" que trabajaba tierras negras -las de la taiga- o bien como comunidad (volost). Existía una asamblea campesina que regulaba las relaciones entre las familias y el uso de las tierras cultivables así como la explotación del bosque. No está muy claro el régimen de propiedad de la tierra, si ésta era comunal o particular, lo cierto es que la

\footnotetext{
260 Mikhail Alexseev reseña del libro "From Fugitive Peasants to Diaspora: The Eastern Mari in Tsarist and Federal Russia by Seppo Lallukka" en Slavic Review, 63:4, invierno de 2004, pp. 904-905 en http://www.jstor.org/stable/1520471 consultado 2 noviembre 2012.
} 
asamblea disponía de las parcelas que estuviesen abandonadas y se encargaba de recolectar el tributo que debían pagar. Al frente de la comunidad estaba la figura del anciano (starosta) elegido por la asamblea y que hacía las veces de su representante frente a cualquier instancia fuera de ella. Era común que al poco tiempo, algún príncipe o un monasterio ofrecieran su protección a estos nuevos asentamientos, si la aceptaban los campesinos quedaban bajo su jurisdicción. Los colonos practicaban también la pesca, la caza y la recolección de miel, esto es, explotaban los productos del bosque boreal. Además eran artesanos pues producían por sí mismos la mayoría de las manufacturas que necesitaban ${ }^{261}$.

Las disputas entre los príncipes así como la costumbre de heredar el patrimonio a todos los hijos, propiciaron que la mayoría de sus dominios (udel, más tarde llamada votchina $^{262}$ ) fueran muy pequeños. La fuerza de trabajo campesina huyó como consecuencia de los asaltos de los mongoles, las guerras al occidente y las luchas intestinas entre los príncipes eslavos. Como resultado de la guerra que parecía no tener fin, muchas tierras en el corazón de la antigua Rus fueron abandonadas. Las calamidades no terminaban ahí, la hambruna y las epidemias también asolaron a la región. Estas dificultades propiciaron que los campesinos libres poco a poco aceptaran trabajar en las tierras de los señores. Los campesinos buscaban protección de las desgracias que padecían. Por ello, cuando sus tierras eran donadas por un príncipe a un boyardo o los nobles se las apropiaban, aceptaban pagar las rentas correspondientes. Bajo el dominio de los mongoles, pagaban el tributo a través de su señor. Los mongoles empleaban el tributo en trabajo de los

\footnotetext{
${ }^{261}$ Blum, op. cit., pp. 93-94.

${ }^{262}$ Udel significaba el patrimonio familiar que el propietario dividía entre sus herederos, votchina significaba la tierra heredada del padre, vid. Blum, op. cit., p.66, 74.
} 
labradores para utilizarlo en el correo, para mantener los caminos y para construir fortificaciones. El monto del tributo de los campesinos se fijaba en principio por los arados y también de acuerdo al tipo de tierra que ocupaban, al número de miembros de la familia y a la cantidad de animales que tenían. Fue en este periodo cuando los mongoles empezaron a llamar a los campesinos krest'ianin pues sólo los que no eran musulmanes pagaban el tributo sobre la tierra, en este caso los rusos cristianos, la mayoría de los cuales eran quienes trabajaban las parcelas. Es menester subrayar que los campesinos tenían la libertad de mudarse a otro sitio, ya fuera a las tierras de otro señor o bien a tierras nuevas que roturaban. Así fue como se colonizó paulatinamente el noreste. Cuando un señor o un monasterio se apoderaban de esas tierras o las recibían de su príncipe se convertían en su propiedad privada, el campesino mantenía la posesión de su parcela y podía transmitirla a sus descendientes, las únicas diferencias con su situación previa era que debía pagar una renta al señor o al monasterio y se desintegraba la asamblea comunal campesina. Los dueños de las tierras procuraban atraer trabajadores a sus dominios exentándolos durante algún tiempo del pago de las rentas, llegaban incluso a hacerles préstamos para que iniciaran las labores agrícolas ${ }^{263}$. Se puede decir que la escasez de fuerza de trabajo en el campo favoreció la situación de los campesinos libres pero también propició el aumento de la propiedad territorial en manos de los señores $y$, por tanto, que gran parte de los labradores estuvieran comprometidos a trabajar en esas tierras, es decir, el tránsito hacia la segunda servidumbre recibió un fuerte impulso ${ }^{264}$.

\footnotetext{
${ }^{263}$ Blum, op.cit., pp. 61, 105- 106; Hellmann, op. cit., pp.102-103.

${ }^{264}$ A. M. Sakharov, "The Mongol Yoke and Socioeconomic Change" en Kaiser y Marker, op. cit., pp.124126.
} 
Desde esta época, las rentas en especie o dinero individuales o colectivas recibieron el nombre de obrok y las rentas en trabajo barshchina, estas designaciones se conservaron hasta el colapso del imperio ruso siglos más tarde. En este periodo, los terratenientes obtuvieron inmunidad (kormlen'e) en el trato con sus dependientes, éste fue un primer paso para que la relación entre señores y campesinos iniciara su tránsito hacia la servidumbre. Esta situación puede explicarse a partir de que los mongoles no interfirieron en las relaciones sociales entre los rusos, mientras que los príncipes estaban más ocupados en defenderse unos de otros y de los invasores que en atender las necesidades de los campesinos, por tanto, era más sencillo dejar que cada quien se ocupara de impartir justicia entre sus renteros y esclavos aunque legalmente seguían bajo la autoridad del príncipe. Además la guerra exigía muchos recursos y los nobles dejaron de participar en el comercio de manera que los terratenientes solo podían ofrecer a los campesinos su protección. La inmunidad de los señores no implicó arbitrariedad en contra de los trabajadores del campo, sobre todo si los terratenientes debieron buscar formas de atraer a los labradores a sus dominios. Sin embargo, nada detenía a los campesinos que querían emigrar, por eso aumentaron las propiedades aloidales, es decir sin señor, en la frontera del noreste ${ }^{265}$.

Sin embargo, sobrevivía la fuerza de trabajo esclava, la cual no sufría abusos ni maltratos, debido precisamente a la baja densidad de población resultado de los infortunios a partir del siglo XIII. Incluso muchos señores liberaban a sus esclavos y los convertían en arrendatarios.

${ }^{265}$ Blum, op. cit., pp.73, 85-92; Hellmann, op. cit., pp. 91, 107; Riasanovsky, op. cit., p. 118; Dukes, op. cit., p. 35 . 
Respecto de los señores, durante el dominio mongol, la costumbre de dividir su patrimonio entre los herederos condujo a que algunos terratenientes tuvieran una porción de tierra tan reducida que debieron acogerse a la protección de príncipes más poderosos como el de Moscovia ${ }^{266}$. De manera que un gran señor, no solamente tenía dependientes porque les otorgara tierras sino también porque algunos de ellos pedían servirle a cambio de apoyo. Estos príncipes aceptaban que sus vasallos ofrecieran a los campesinos avecindados en sus posesiones que tampoco pagaran las cargas que debían dar al señor de su señor, valga la redundancia, pues la prioridad consistía en que se produjera riqueza, más tarde, cuando los trabajadores quedaran arraigados, podrían cobrarse las rentas. A pesar de todos los esfuerzos, había tierras que quedaban sin cultivarse. Este mecanismo dio por resultado que los boyardos tuvieran dominios cada vez más extensos pues las tierras de sus dependientes pasaban a formar parte de su patrimonio. De cualquier forma, los boyardos conservaron el privilegio de elegir a quién servían y de cambiarse de señor cuando lo desearan sin perder por ello sus tierras ${ }^{267}$.

\section{Monasterios}

Los mongoles no obstaculizaron la creación de monasterios, se fundaron un gran número como una reacción a la invasión. En efecto, la iglesia rusa facilitó mantener una cultura diferente a la de los mongoles al mismo tiempo que reforzó el poder de los príncipes. Hay que recordar que la base de las prácticas culturales cristianas estaba en la liturgia pues los monjes de la Rus no se distinguían por una sólida formación intelectual, pero alentaron las peregrinaciones a Tierra Santa lo que mantuvo a los rusos en relación con otros cristianos

\footnotetext{
${ }^{266}$ Blum, op.cit., p. 71.

${ }^{267}$ Kolistov, op. cit., p. 60; Blum, op.cit., pp.83-84; Riasanovsky, op. cit., pp. 116-117.
} 
ortodoxos. Los príncipes siempre iban acompañados por prelados, la mayoría bizantinos, para presentar sus respetos al jan. Además los clérigos hacían las veces de mediadores entre la nobleza. Los clérigos más cercanos al pueblo eran todavía más ignorantes, de manera que los campesinos cumplían con la liturgia pero en sus cantos no se ajustaban por completo a ella porque no recibían la instrucción necesaria, así que mantuvieron formas de cantar tradicionales.

Los monasterios fueron instituciones que ayudaron a organizar el espacio y a ordenar la colonización del noreste. Los monjes conseguían permiso de los señores para establecerse en las fronteras, reclutaban colonos y se dedicaban a la explotación sistemática de los bosques acumulando gran cantidad de dominio territorial. Los campesinos afectados conservaban su libertad de movimiento aunque debían pagar rentas a los monjes. Ya que estas instituciones y sus miembros se dedicaban a honrar a Dios estaban exentos de pagar yasak, de manera que pudieron acumular riquezas que registraban puntualmente. Para los mongoles, los monjes a pesar de su condición de terratenientes, no tenían que pagarlo porque eran hombres dedicados a practicar una de las religiones de El Libro que los musulmanes respetaban. De hecho, en la capital del janato Kipchak residía un obispo ortodoxo quien junto con el metropolitano de todas las Rusias propiciaron un acercamiento entre el emperador bizantino Miguel VIII Paleólogo (1259-1282) y el jan. Por tanto, las relaciones cordiales entre ambos protegieron a la iglesia rusa que acataba las disposiciones y acuerdos de los prelados bizantinos con los mongoles ya que el metropolitano dependía del patriarcado de Constantinopla ${ }^{268}$.

${ }^{268}$ Meyendorff, op. cit., pp.45-46, 70-72. 
Por ejemplo, alrededor de 1313 el jan Uzbek otorgó al metropolitano Pedro (13081326) inmunidad sobre todas sus posesiones. Ordenó que nadie le confiscara sus bienes muebles ni inmuebles, no se le exigiera tributo ni a él ni a su gente porque, decía, los negocios del metropolitano eran negocios de Dios. Ninguno de los habitantes de sus propiedades debía ir a la guerra, el único compromiso del metropolitano era rogar a Dios por la victoria de los mongoles. Enfatizaba que cualquiera que violara la propiedad de la iglesia estaba violando los intereses divinos ${ }^{269}$. Por supuesto en esta protección quedaron incluidos los monasterios.

Estos monasterios seguían la regla establecida por Sergio de Rodoney (1314-1392), por tanto, se apegaban al funcionamiento del monasterio de La Trinidad/San Sergio. Hasta el momento no se ha realizado una investigación puntual sobre el impacto que los monasterios de Simonov en Moscovia, de Trinidad/ Sergio Lavra, San Cirilo en Beloozero y el de San Eutimio en Suzdal tuvieron sobre el ascenso económico de Moscovia ${ }^{270}$. El apoyo a los monasterios muestra la política de tolerancia que los mongoles tuvieron hacia muchas prácticas culturales de los eslavos sometidos; mientras la iglesia ortodoxa contribuyera a mantener la paz, ellos no intentaron convertir a sus fieles ni apoderarse de su riqueza.

\footnotetext{
269 "Mongol Immunity Charter (Iarlyk) to Metropolitan Peter (ca. 1313)" en Kaiser y Marker, op. cit., pp.101102.

${ }^{270}$ Blum, op. cit., pp. 75-76; Vernadsky, op. cit., p.66; Longworth, op. cit., pp. 49-50; Hellmann, op. cit., pp. 87, 104-106; Simeonova, op. cit., passim; Maier, op.cit., p.167; Riasanovsky, op. cit., pp. 118-119, 121; Dukes, op. cit., pp. 38-40; Lenhoff, op. cit., p. 400. Desde 1970 fue diseñada una ruta turística conocida como "El anillo de oro" que recorre antiguas ciudades rusas en las que se localizan algunos de los monasterios mencionados. El recorrido parte de Moscú sigue con Serguiev Posad antes monasterio de La Trinidad-San Sergio, continúa con Pereslavl-Zalesski, Rostov el Grande, Yaroslav, Kostroma, Suzdal y Vladimir. Como puede apreciarse todos estos asentamientos fueron fundados en el periodo que abarca este estudio, es decir, la Edad Media rusa. http://www.latin.ru/es/anillo/anillo2.shtml consultado 5 de febrero de 2013.
} 
Cuando los mongoles se llevaron a los artesanos de las ciudades, la actividad artesanal recayó sobre los campesinos. Ellos también realizaban las labores de extracción de minerales. Estos trabajos les proporcionaban ingresos extras. De ahí que el comercio con el exterior fuera fundamentalmente de carácter suntuario. Los comerciantes avecindados en las ciudades casi siempre dependían del príncipe que las gobernaba ${ }^{271}$. Es importante subrayar que los príncipes y señores se concentraron en el campo como su fuente principal de riqueza. Al parecer, dejaron de participar personalmente en las flotillas y caravanas comerciales. Probablemente esto se debió a que la guerra requería de su atención casi todo el tiempo pues constantemente corrían el riesgo de perder sus dominios. Así que al igual que sus tierras eran administradas por servidores de su confianza, dejaron la concurrencia al mercado en manos de hombres libres que no pertenecían a la nobleza a quienes controlaban sencillamente porque ellos tenían a los soldados a su servicio.

Tal vez, los mercaderes preferían migrar a la frontera y emprender sus propios negocios para no compartir sus ganancias con los señores. Al parecer, esto también implicó un cambio en la forma del ejercicio del poder pues ahora quien lo detentaba basaba su riqueza primordialmente en la tierra ya fuera en la producción de las propias o en el tributo que cobraba; con esos bienes mantenía a un ejército de terratenientes que le guardaba lealtad porque defendía sus intereses. Es evidente que en gran parte este cambio fue catalizado por la presencia de los mongoles.

En cuanto a las mercancías para el comercio suntuario, los hombres de las comunas del noreste llevaban las pieles a ciudades como Novgorod o Pskov en donde las preparaban para venderlas. De manera simultánea llegaban los comerciantes que llevaban cereales y

\footnotetext{
${ }^{271}$ Hellmann, op. cit., pp. 92-96.
} 
otras artesanias a los mercados locales y europeos y vendían manufacturas que no se elaboraban en estos poblados de creación reciente. Este intercambio dio lugar al renacimiento de las ciudades comerciales ${ }^{272}$.

No todo el comercio se realizaba con pueblos del este. Novgorod se mantuvo como la ciudad comercial más importante con el oeste. De hecho, en 1323 la fundación de Oreshk dio lugar a que se definieran los territorios en poder de los suecos y de los novgorodianos. Los rusos llegaron hasta la desembocadura del rio Neva y comerciaban por el golfo de Finlandia. La Crónica de Novgorod menciona ataques de los lituanos a los mercaderes novgorodianos y la existencia del barrio de los comerciantes extranjeros en esa ciudad (nemtsy). Había embarcaciones procedentes de Novgorod que zarpaban de Staraia $\operatorname{Ladoga}^{273}$, navegaban por el Neva y llegaban hasta la península escandinava. En este intercambio también participaba la ciudad de Pskov. Al parecer la tradición de construcción de botes y barcos para navegar en aguas frías se originó en esta región bajo el dominio de Novogord y conjugaba tecnología propia con la aprendida de los escandinavos y de los fineses. Hasta el momento no se ha podido establecer una relación aceptable entre las representaciones de embarcaciones que se encuentran en miniaturas e iconos y los pocos restos arqueológicos que se han encontrado. La ruta marítima comercial por el noroeste se conservó hasta el siglo XV pero con enfrentamientos constantes entre las ciudades comerciales rusas y las de la costa del Mar Báltico por controlarla ${ }^{274}$.

\footnotetext{
${ }^{272}$ Kalistov, op. cit., pp. 60-62; Hellmann, op. cit., pp. 85-96; Longworth, op. cit., p. 48.

273 Sobre las rutas trazadas por los escandinavos vid. capítulo I.

${ }^{274}$ Sorokin, op. cit., pp.4-12.
} 
Algunas prácticas introducidas por los mongoles o tártaros ${ }^{275}$, se mantuvieron cuando se formó el imperio ruso. Los rusos empezaron a denominar a los mongoles, tártaros porque cuando los primeros se expandieron hacia el oeste llevaron entre sus tropas a diversos pueblos tanto de habla mongola como turca. Los tártaros eran un pueblo tungus de la estepa que hablaba una lengua turca. Aunque la élite que dominó en el imperio eran mongoles en Rusia estos pueblos poco a poco fueron mezclándose con los de habla turca y fueron imponiéndose esos idiomas, de ahí que los rusos los llamaran a todos tártaros.

Entre las prácticas que los rusos conservaron estuvieron: cobrar tributo y exigir servicio a toda la población sin importar el grupo social al que perteneciera así como registrar a los tributarios por familia, fue una de sus herencias. Asimismo, el aparato administrativo, la organización de las aduanas y el sistema de correo que facilitaban las comunicaciones que los mongoles aprendieron de los persas y los chinos también fueron heredados por Moscovia, desde luego mediante fenómenos de transculturación. El establecimiento del sistema postal está consignado en El libro secreto de los mongoles como una obra del Gran Jan Ogodei quien ordenó a Batu que enlazara su sistema de correo con el del resto del imperio mongol ${ }^{276}$. También se preservó el monopolio de la venta de bebidas como fuente de ingresos para el Estado. La formación de las tropas en cinco divisiones: una a la vanguardia, el cuerpo principal, un ala izquierda, otra derecha y la retaguardia también fue una herencia mongola. De igual manera, los rusos adoptaron la etiqueta diplomática. La interculturalidad entre ambos pueblos puede apreciarse en algunas palabras que pasaron a formar parte del ruso como la palabra dinero (dengi). Probablemente esto fue resultado de que algunos rusos hablaran mongol.

\footnotetext{
${ }^{275}$ Vernadsky, op.cit., p. 63; Kotkin, op. cit., pp.5-7.

${ }^{276}$ La historia secreta..., op.cit., p.225; The Secret..., op. cit., p.275.
} 
Dichas prácticas culturales contribuyeron a crear el Estado ruso encabezado por Moscovia. Es posible que los moscovitas adoptaran el concepto dinástico del Estado que prevaleció desde que consolidaron su poder hasta el fin del imperio, de los mongoles ${ }^{277}$. Por ello, los euroasianistas ${ }^{278}$ atribuyen a la herencia mongola un ejercicio del poder de "mano dura" que en la historia de Rusia se ejerció durante el gobierno autocrático de los zares, la etapa de la Unión de Repúblicas Socialistas Soviéticas y actualmente con los gobiernos de Vladimir Putin y Dmitri Medvedev. En esta tesis no se considera que esta forma del ejercicio del poder sea imputable por completo al dominio mongol ya que la herencia bizantina y la vikinga también fueron importantes. Los rusos de Moscovia, por ende, amalgamaron todas estas experincias con las propias.

Los mongoles no dejaron una herencia cultural más rica porque la barrera religiosa impidió un intercambio cultural más dinámico ya que los rusos eran cristianos ortodoxos y aquellos, primero fueron animistas y después se convirtieron al islam. Esta barrera puede explicarse a partir de uno de los elementos que Stuart Hall señala como constitutivos de la identidad: la posibilidad de excluir a los $\operatorname{otros}^{279}$. Los rusos excluyeron a los tártaros de su comunidad porque no eran cristianos ortodoxos ni hablaban ruso, por mencionar sólo algunas características, la misma situación operaba por parte de los tártaros. No obstante, hubo mestizaje entre tártaros y eslavos, muchos de ellos fueron trasladados a Sarai, princesas mongolas se casaron con príncipes de la Rus y, al debilitarse el imperio mongol, algunos tártaros emigraron a Moscovia. Familias que más tarde tuvieron una participación importante en la política rusa eran de origen tártaro convertidas al cristianismo, tal es el

\footnotetext{
277 Summer, op. cit., pp. 83-84; Vernadsky, op. cit., pp. 79-80; Longworth, op. cit., p. 47; Halperin, "Interpreting... en Kaiser y Marker, op. cit., pp.105-106.

${ }^{278}$ Waugh, op. cit., pp. 1-2; vid. Discusión en la Introducción.

${ }^{279}$ Hall, "Introduction... op. cit., pp. 4-5.
} 
caso de las familias Gudonov y Saburov. La experiencia con los mongoles preparó a los rusos para convivir con pueblos que practicaran religiones diferentes a la suya, especialmente con los musulmanes ${ }^{280}$.

Tal vez, la herencia más importante que los mongoles dejaron en los rusos fue su interés por extenderse en el continente asiático. La experiencia histórica de formar parte de un imperio euroasiático sembró la intención de realizar la misma acción nada más que en sentido contrario, es decir, desde el oeste hacia el este. En un principio, la Rus de Kiev no rebasó el territorio europeo aunque participara en redes de intercambio que la unían a Asia. Los rusos apreciaron al territorio asiático como una continuación hacia el este del que ellos ocupaban gracias su incorporación en el gran Estado multicultural y territorial que fue el imperio mongol.

Todos estos elementos de origen mongol cristalizaron en la construcción y consolidadción del Estado ruso a partir del creciente predominio de Moscovia sobre los rusos y otros pueblos como los propios tártaros y aquéllos con los que se encontraron cuando iniciaron la expansión transurálica.

\footnotetext{
${ }^{280}$ Fernand Braudel (1902-1985), Las civilizaciones actuales. Estudio de historia económica y social. Trad. J. Gómez y Gonzalo Anes. México, Rei, 1991. 500 pp., cuads. Y mapas, p. 465; Mehrdad Haghayeghi reseña del libro "Islam in Russia: The Politics of Identity and Security by Shireen T. Hunter, Jeffrey L. Thomas y Alexander Melikishvili" en Slavic Review, 64:4, invierno de 2005, pp. $921-922$ en http://www.jstor.org/stable/3649960 consultado 2 de noviembre de 2012.
} 


\section{CAPÍTULO IV. DEL ASCENSO DE MOSCOVIA A LA} TERCERA ROMA (c.1300-1584)

\subsection{Moscovia: la ofensiva contra los mongoles y los principados}

rusos.

En este capítulo se analiza cómo la dinastía moscovita fue configurando un proyecto de Estado centralizando paulatinamente el poder pero al mismo tiempo apoyando a aquellos sectores sociales cuya actividad favorecía el fortalecimiento del mismo. Esto implicó que otros grupos sociales quedaran subordinados por completo a los beneficiados. La construcción de este Estado implicó la expansión y anexión de territorios desde los aledaños a Moscovia hasta los de la costa del Pacífico. En otras palabras, el predominio paulatino del principado de Moscovia significó tanto la unificación de los principados y ciudades rusos bajo una sola autoridad como el desarrollo de un fenómeno de expansión hacia el este todavía más dinámico ${ }^{281}$.

Moscovia fue fundada en fecha incierta en la primera mitad del siglo XII por el príncipe de Vladimir-Suzdal. Poco se sabe sobre sus primeros gobernantes, al parecer en la segunda mitad del siglo XIII bajo el gobierno de Daniel (1261-1325), hijo menor de Aleksandr Nevsky, Moscovia tuvo su propia dinastía. En 1317 o 1318, Yuri Danilovich (1281-1325), príncipe de Moscovia, contrajo nupcias con la hermana del jan quien fue bautizada antes del matrimonio. El gobernante de Tver, que ostentaba el título de Gran Príncipe, atacó Moscovia, tomó prisionera a la hermana del jan y la mató. La reacción del

\footnotetext{
${ }^{281}$ Ver apartado 4.3 de este capítulo y capítulo VI.
} 
jan fue inmediata, con la ayuda de Yuri asesinó al príncipe de Tver y designó a su yerno como el Gran Príncipe (Veliki Knyaz). Yuri contribuyó con el jan de Kipchak a terminar con la rebelión de Tver, aunque todavía tuvieron lugar más asesinatos de príncipes. En $c$. 1325 Iván I Kalita (1288-1340), hermano de Yuri, heredó el principado y la alianza con los $\operatorname{tártaros}^{282}$.

Iván cultivó buenas relaciones con los mongoles gracias a las cuáles le otorgaron el título de Gran Duque en 1332 y años más tarde el de Gran Príncipe. Además de cobrar el yasak a sus pares se apoderó de algunos principados por la fuerza o comprándolos con su fortuna personal; para poblarlos rescató prisioneros rusos en manos de los mongoles. De esta manera amplió sus dominios. Además practicó la política de alentar enlaces matrimoniales con las familias más poderosas para así ganar su lealtad. Iván Kalita convenció al metropolitano de trasladar su residencia de Vladimir a Moscú en 1325. Esto le dio a Moscovia un mayor prestigio ante el resto de los principados rusos. Para protegerse a sí mismo y al metropolitano, fortificó el kremlin en donde también mandó construir una catedral $^{283}$. Todas las ciudades medievales de la Rus tenían un kremlin, ahí residían los poderes gubernamentales y eclesiásticos. En Novgorod, por ejemplo, en el kremlin se reunía la veche, se alojaba el príncipe y vivía el obispo. Alrededor del kremlin se establecían los vecinos de la ciudad.

${ }^{282}$ The Chronicle..., Trad. Michell, op. cit., pp. 123-124. Kalita, al parecer, significaba "bolsa de dinero", ahora es una palabra en desuso; Charles J. Halperin reseña del libro "Vsego esi ispolnena zemlia russkaia...": Lichnosti I mental'nost' russkogo srednevekov'ia: Ocherki [Interpretación general de la tierra rusa... Personalidad y mentalidad en la Edad Media rusa: ensayos] de Anton Anatol'evich Gorskii en Russian Review, 61:4, octubre de 2002, pp. 641-643 en http://www.jstopr.org/stable/3664762 consultado 9 de noviembre de 2012, traducción propia; Dukes, op. cit., p.31.

${ }^{283}$ The Chronicle ..., trad. Michell, op. cit., p.124 passim, la crónica menciona cada vez que los príncipes de Moscovia cobraban el tributo a Novgorod; Hellmann, op. cit., p. 74; Riasanovsky, op. cit., pp. 97-99, 112; Longworth, op. cit., pp. 54-55. 
A Kalita le sucedió su hijo Simeón Ivanovich el Orgulloso (1316-1353) en 1341, éste continuó añadiendo territorios a su principado. Su hermano y heredero Iván II el Sumiso (1326-1359) dejó la dirección del principado en manos del metropolitano Aleksei (1354-1378) quien además era su embajador ante los tártaros. El nombramiento de Aleksei como metropolitano por el patriarca de Constantinopla fue excepcional. En Constantinopla preferían nombrar clérigos bizantinos para mantener a la iglesia rusa bajo su control. Sin embargo, Aleksei había recibido el apoyo de su antecesor y el de Iván Kalita. Por única ocasión el patriarca accedió a nombrar metropolitano a un ruso ${ }^{284}$. Ambos gobernantes detentaron el título de Gran Príncipe.

Dmitri (1350-1389) era menor de edad cuando su padre Iván murió. Su tío, príncipe de Suzdal, reclamó Moscovia para sí. El metropolitano Aleksei, regente en ese momento, supo cómo apoyarse en los moscovitas para defender la herencia de Dmitri más tarde apodado Donskoi quien, finalmente, se erigió como príncipe de Moscovia ${ }^{285}$.

En el siglo XIV, el imperio mongol empezó a decaer, en el caso del janato Kipchak las disputas internas debilitaron el control sobre los principados rusos. Esta situación incitó a los estados al oeste de la Rus a intentar una vez más anexarse el territorio de los rusos ortodoxos. El duque de Lituania fue el primero en atacar y entre 1362 y 1363 se apoderó de la región del río Don hasta el oeste del Dniéper. En 1372, el Gran Príncipe Dmitri Donskoi -quien por cierto también había recibido el título de príncipe de Vladimir gracias a la intercesión de la jerarquía eclesiástica-, atacó a los búlgaros del Volga, ahora agrupados en Kazan, tributarios de los mongoles. Esto provocó un enfrentamiento con uno de los

\footnotetext{
${ }^{284}$ Meyendorff, op.cit., p. 89.

${ }^{285}$ The Chronicle..., Trad. Michell, op. cit., p. 148; Riasanovsky, op. cit., pp. 99-100.
} 
opositores al jan de Kipchak quien sufrió dos derrotas (1378 y 1380) ante Dmitri Donskoi; la segunda es la más famosa y tuvo lugar en Kulikovo a orillas del Don. El gran príncipe de Moscovia tuvo que sostener dos frentes pues en 1375 luchó en contra de la alianza de Lituania y el principado de Tver, que competía con Moscovia por someter al resto de las principalidades rusas. Sin embargo, Moscovia venció y Tver debió aceptar su dominio. A finales de su mandato, el territorio de Vladimir-Suzdal era considerado patrimonio de los príncipes de Moscovia. A pesar de que los mongoles recuperaron su relación de vasallaje sobre Moscovia en 1382, esas victorias habían mostrado que ya no eran invencibles ${ }^{286}$. Así que los príncipes de Moscovia sólo esperaron el momento propicio para dejar de pagar tributo a los mongoles y apoderarse de territorios bajo su domino mientras éstos recelaban cada vez más del principado que habían respaldado.

La victoria de Dmitri Donskoi fue celebrada en todos los principados rusos, no sólo en Moscovia ${ }^{287}$. Sofonii de Riazan escribió un poema épico conocido como Zadonshshina (Relato de los eventos más allá del Don) en el que enaltece a los príncipes de Moscovia y aboga por la unidad de los rusos. En el poema se habla de defender la tierra rusa en donde habitan los descendientes de Vladimir de Kiev, del musulmán Mamai (muerto en 1380)288. Según el poema, cuando los moscovitas despedazaban a los tártaros, éstos prometieron no atacar nunca más a Rusia ni exigirle tributo. El poema también se refiere al gran botín que se obtuvo en esta batalla. Cuando se enumera a los boyardos caídos, muchos de ellos

${ }^{286}$ The Chronicle..., Trad. Michell, op. cit., p.154, 156-159; Hambly, op. cit., p. 123; Hellmann, op. cit., p. 96; Riasanosvsky, op. cit., pp. 99-101; Vernadsky, op. cit., pp. 71-74.

${ }^{287}$ A. A. Gorskii postula la tesis de que la interpretación de estas victorias como el primer paso para la liberación de los rusos del dominio tártaro ocurrió hasta el siglo XVII pues en el periodo en el que tuvieron lugar los acontecimientos narrados, los documentos rusos no muestran que los moscovitas cuestionaran la primacía de los tártaros, vid. Halperin, Gorskii, "Moskva i Orda", op. cit., p. 150.

${ }^{288}$ Sobre Mamai vid. infra. 
pertenecían a otras ciudades y principados de Rusia ${ }^{289}$. En la Plegaria sobre la vida y muerte del Gran Príncipe Dmitri Ivanovich [Donskoi], se exaltan las virtudes y la gran fe del moscovita contraponiéndolas a los defectos del pérfido pagano Mamai ${ }^{290}$. Otro manuscrito que ejemplifica cómo fue aclamada esta victoria es el Relato sobre la temeridad de Mamai, que inicia con la decisión de éste de atacar a Dmitri (Donskoi) de Moscovia para apoderarse de las riquezas rusas. Lo interesante de esta narración son los discursos que se elaboraron para mostrar el llamado del Gran Príncipe al resto de los príncipes reiterando que la batalla se presentaría para defender a la cristiandad rusa y a su tierra de los paganos. Cuando Dmitri pidió la bendición del famoso monje San Sergio de Rodoney los discursos aluden a la protección divina y de los santos Boris y Gleb ${ }^{291}$. Se incluye la pieza que recrea la carta que San Sergio envió al Gran Príncipe cuando estaba por iniciar la batalla. En ella, Sergio de Rodoney le expresaba que Dios estaba de su lado porque su causa era justa pues Mamai había orquestado el enfrentamiento y estaba defendiendo a la cristiandad rusa. Al final, el relato describe al infiel como un cobarde que huyó al verse derrotado abandonado a sus aliados: el príncipe de Riazan y el Duque de Lituania. Esta acción lo condenó a vivir aislado en la estepa pues ningún jan tártaro deseaba aliarse con un traidor ${ }^{292}$. Esta pieza es una muestra del discurso religioso sobre la protección de Dios a los príncipes de Moscovia y de la decisión de éstos de defender a la cristiandad ortodoxa.

\section{El papel de la iglesia ortodoxa}

\footnotetext{
289 "Sofony of Riazan: Zadonshchina" en Zenkovsky, op. cit., doc. 38, pp. 211-223.

290 Aunque hay que notar que Mamai era infiel, porque practicaba el islam, no pagano pero en las crónicas rusas con frecuencia llaman a los mongoles paganos, tal vez porque en un principio lo fueron. "Orison on the Life and Death of Grand Prince Dmity Ivanovich” en Zenkovsky, op. cit., doc. 49, pp. 315-322.

${ }^{291}$ Mártires en la Rus de Kiev quienes más tarde fueron canonizados. Véase Capítulo II.

292 Skazanie o Mamaevom poboishche [Relato sobre la batalla de Mamai] en Obrazovatel'ny portal "Drebnerysskaya literatura" [Portal de estudios "Literatura antigua"], 2002-2011, 20 pp. en http://www.drevne.ru/lib/mamay.htm consultado 28 de noviembre de 2011
} 
Es necesario subrayar el papel que jugó la iglesia bajo los mongoles; se le toleró, situación que aprovechó para evangelizar a los campesinos. Pero un hecho definitivo fue que Sergio de Radoney, fundador del monasterio de la Santa Trinidad, hubiera bendecido a Dmitri Donskoi cuando venció a los tártaros ${ }^{293}$. Los rusos empezaron a catalogarlo como un "santo", gracias a la victoria en la batalla y a su trabajo en el monasterio, más tarde fue canonizado. Su nombre original era Bartolomeo, de origen noble, su padre había perdido su patrimonio debido a la invasión mongola y a que el príncipe de Moscovia se había apoderado de la ciudad de Rostov, su lugar de origen. Así que la familia había emigrado a Radoney. Según la hagiografía escrita por Epifanio El Sabio (muerto en 1420) ${ }^{294}$ en un principio, se había ido de ermitaño siguiendo el llamado de Dios. En su sitio de residencia construyó una capilla dedicada a la Santísima Trinidad durante el gobierno de Simeón. Cuando se convirtió en monje, tomó el nombre de Sergio. Era tal su benevolencia que algunos se acercaron para convivir con él, pero Sergio se resistía a fundar un monasterio pues prefería vivir en la soledad. Sin embargo, no pudo evitar que lo siguieran. Sergio cultivaba lo que comía y ayudó a sus seguidores a construir sus celdas. Sus discípulos lo conminaron a fundar un monasterio y aceptó. Sólo la influencia del obispo de Peresyaslav logró que aceptara el cargo de abad, él mismo lo invistió. En ese cargo estableció las reglas del funcionamiento del monasterio. En principio todos los bienes pertenecían a la comunidad, los monjes debían dedicarse a la oración y debían trabajar para sostener a la comunidad y satisfacer todas las necesidades que tuvieran. Los monjes deberían practicar el

\footnotetext{
${ }^{293}$ Vernadsky, op. cit., pp. 71-74; The Novgorod Chronicle, op. cit., p.5.

294 "Epiphanius the Wise: The Life, Acts, and Miracles of Our Blessed and Holy Father Sergius of Rodonezh" en Zenkovsky, op. cit., doc. 45, pp. 262- 290. Epifanio el Sabio escribió la vida de San Sergio y de San Estaban a finales del siglo XIV y principios del XV. Su hagiografías tenían más el objetivo de definir cuáles deberían ser las características de un santo, vid. Ibid., p.259; Este documento también puede consultarse en http://www.dur.ac.uk/a.k.harrington/sergrado.html consultado 29 de septiembre de 2011; Meyendorff, op. cit., pp. 134-136.
} 
temor a Dios, la humildad, la sumisión y la obediencia. Sergio diseñó la disposición arquitectónica del monasterio con todos los recintos que debía tener. La fama de Sergio cundió y muchas personas decidieron avecindarse cerca del monasterio pues creían que ahí tendrían mejores oportunidades de sobrevivencia sin la presión de los señores y protegidos por un hombre benevolente. Los campesinos desmontaron el bosque, construyeron casas y al fin fundaron una pequeña aldea. Su autoridad espiritual llevó a los propios príncipes a recurrir a él para dirimir sus controversias. Por ello, Dmitri Donskoii, había acudido a pedirle consejo sobre si debía enfrentarse a los mongoles, Sergio lo animó asegurándole que Dios estaba de su lado. Este monje siempre reconoció la autoridad del metropolitano y del patriarcado de Constantinopla y apoyó políticamente a los príncipes de Moscovia para someter al resto de los principados rusos. Sergio de Rodoney fue canonizado por el patriarcado de Constantinopla en 1422.

Su discípulo Esteban de Perm evangelizó a los fineses. Tradujo a su idioma las Sagradas Escrituras ya que la iglesia ortodoxa no tenía una lengua oficial y sagrada. Así, poco a poco, el cristianismo ruso empezó a contar con santos propios lo que reafirmó la fe del pueblo y reforzó su identidad frente a otros grupos eslavos. De hecho, el monasterio de La Trinidad/San Sergio se convirtió en uno de los sitios religiosos más significativo para los rusos. Pero el movimiento más importante que derivó de su fundación fue el impulso de colonización de nuevos territorios al noreste bajo el amparo de los príncipes de Moscovia. De esta manera el dominio territorial aumentaba tal y como puede apreciarse en el mapa 10. Los monasterios que se establecieron posteriormente siguieron las normas dictadas por Sergio de Rodoney. A los monasterios se sumaban no sólo monjes sino también colonos 
seculares que deseaban trabajar bajo su protección y guía, siguiendo, por supuesto, las enseñanzas de San Sergio ${ }^{295}$.

${ }^{295}$ Epifanio el Sabio, "Panegiric to St. Setephen of Perm" en Zenkovsky, op. cit., doc. 44, pp. 260-262; Riasanovsky, op. cit., pp. 112, 121-122; Longworth, op. cit., pp.59-61; vid. supra apartado 3.2. 


\section{Mapa 10. MONASTERIOS RUSOS ORTODOXOS}

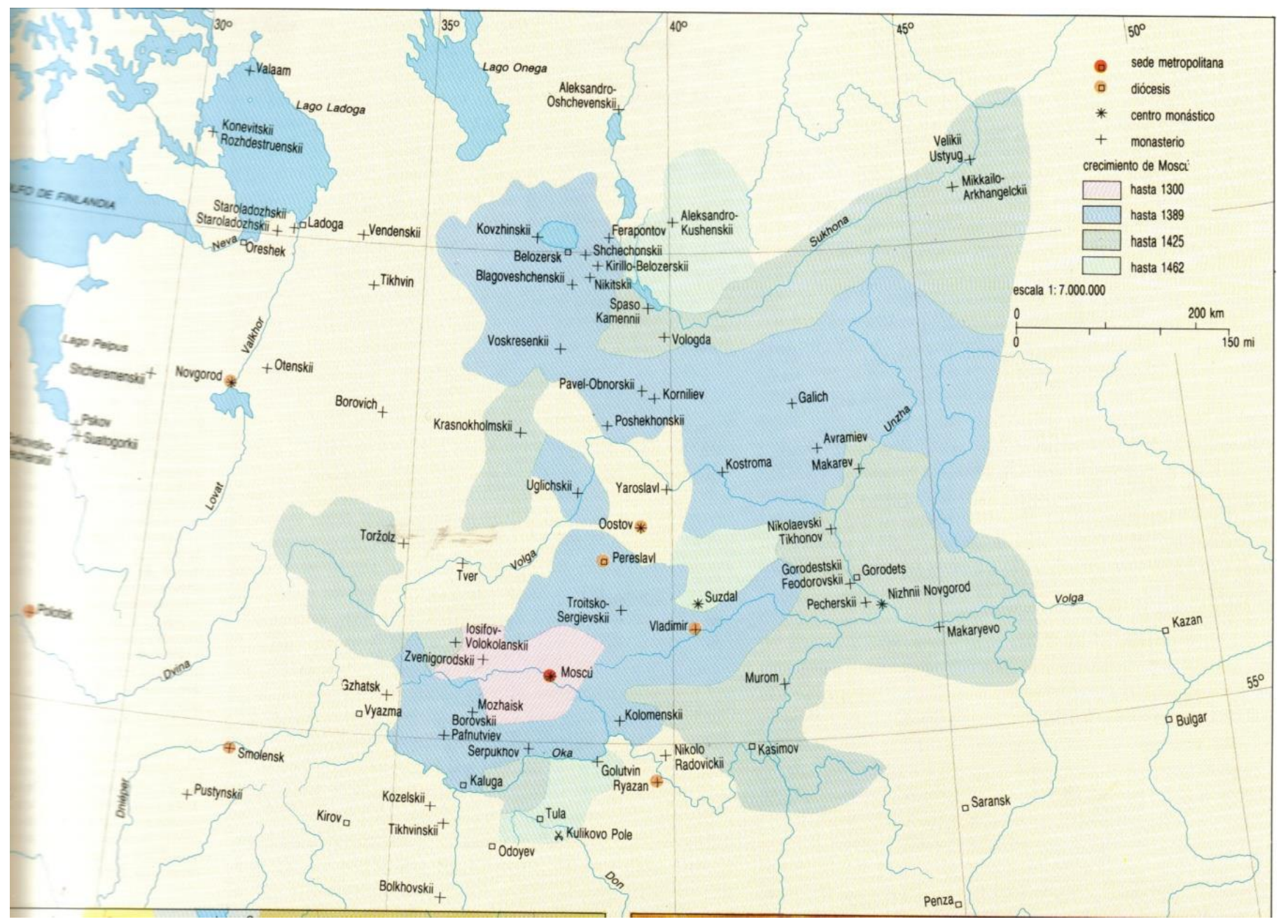

Fuente: Donald Mathew, Europa medieval. Raíces de la cultura moderna. Barcelona, Ediciones Culturales Internacionales, 2002. 240 pp., (Atlas culturales del mundo), p.195

En cuanto al gobierno de Dmitri Donskoi es necesario analizar dos prácticas que paulatinamente fueron desarrollándose al interior del Estado moscovita. Al parecer, los príncipes pedían consejo a algunos de los señores bajo su autoridad. Este grupo selecto constituía una especie de duma, es decir de consejo. No se ha podido precisar con certidumbre si algunos boyardos desempeñaban esta función por derecho o porque el 
príncipe los designaba, ni tampoco las cualidades que debían tener para estar cerca de él. Una de las hipótesis que más aceptación ha tenido es que estos boyardos tenían lazos de parentesco con el príncipe mas no puede comprobarse porque hubo parientes que no participaban en este consejo. Al parecer no era una duma institucionalizada porque tampoco ha podido elucidarse cuándo se reunía ni si opinaba en todo tipo de asuntos de gobierno. Tan sólo se sabe ${ }^{296}$ que existía y que el príncipe escuchaba sus consejos, esto hace suponer que, en parte, las decisiones del gobernante estaban consensadas.

Otra de las prácticas la encontramos en el testamento de Dmitri Donskoi. En éste puede apreciarse cómo el príncipe heredó su patrimonio entre sus hijos y su esposa, práctica que no desapareció con la consolidación del Estado. La mayor parte de sus tierras las heredó a su primer hijo el príncipe Vasili. A los otros tres hijos y a su esposa les dejó porciones mucho más pequeñas de su territorio. La viuda tendría el derecho de transmitir su herencia a cualquiera de sus hijos. Señaló que en caso de que Vasili muriera, su patrimonio pasaría a su segundo hijo, el príncipe Yuri. Asimismo especificaba que sus hijos no debían pagar tributo a los tártaros sino que el que recogieran en las tierras heredadas sería suyo. Por último, les recomendaba que cuidaran a los boyardos que le habían servido como si fueran un solo hombre ${ }^{297}$. El concepto patrimonialista daba al príncipe el derecho de disponer de sus riquezas y de los plebeyos como está expresado con toda claridad en este

\footnotetext{
${ }^{296}$ Nancy Shields Kollman reseña de "The Sovereign and His Counsellors: Ritualised Consultations in Muscovite Political Culture, 1350s-1570s" de Sergei Bogatyrev en Salvic Review, 60:3, otoño de 2001, pp. 645-646 en http://www.jastor.org/stable/2696859 consultado 3 noviembre de 2012; Russell E. Martin reseña de "The Sovereign and His Counsellors: Ritualised Consultations in Muscovite Political Culture, 1350s1570s" de Sergei Bogatyrev en Russian Review, 61:2, abril de 2002, pp. 301-302 en http://www.jstor.org/stable/3664288 consultado 9 de noviembre de 2012.

297 "Northeast Rus': The Second Testament of Moscow Grand Prince Dmitrii Donskoi (1389)" en Kaiser y Marker, op. cit., pp. 87-90.
} 
testamento. También cabe subrayar la importancia que les dio a los boyardos que le servían, después de todo, la expansión de sus dominios la debía a quienes habían peleado a su lado.

Para fortuna de los rusos, en 1395, Tamerlán (c. 1336-1405) atacó al janato de Kipchak. Esta acción prácticamente lo liquidó, se formaron janatos independientes en el territorio que había ocupado: Kazán, Astrakán, Crimea y, por último, Sibir. Los mongoles sobrevivientes de Kipchak se congregaron en el janato de la Crimea y a partir de entonces se mezclaron con los habitantes locales. Una vez más tuvo lugar la génesis de un pueblo que resulta de la integración cultural de dos antecesores, semejantes pero no iguales ya que la península y sus alrededores habían Estado en poder de los pechengos y todos practicaron el islam.

El ulus de Batu desapareció y los janatos que surgieron de su desintegración peleaban entre sí constantemente. Esta situación favoreció que al iniciar el siglo XV, los moscovitas se apoderaran del territorio en el que se encontraban los búlgaros del Volga quienes emigraron también al sureste de Europa ${ }^{298}$.

Al mismo tiempo que el príncipe de Moscovia intentaba liberarse de las pretensiones de los nuevos janatos por cobrarle tributo, en alianza con el reino de LituaniaPolonia derrotaron definitivamente a la orden teutónica (1410). Esta alianza de ninguna manera implicó que la lucha entre ellos cesara, de hecho, en 1404, Lituania se apoderó de Smolensk. Vasili I (1389-1425) compensó esta pérdida apoderándose de Niyni Novgorod. Durante la lucha en contra de los tártaros, su sucesor, el príncipe Vasili II (1425-1462) fue hecho prisionero por el jan Ulug-Mehmet (muerto en 1445) quien lo dejó en libertad a cambio de un rescate y de que se comprometiera a pagarle tributo. En consecuencia, ${ }^{298}$ Hambly, op. cit., pp. 125-126. 
regresó a Moscovia y pagó tributo a los tártaros. Al mismo tiempo, Vasili II intentaba conservar el poder que su tío, el príncipe Yuri, le disputaba, es decir, todavía no se instauraba la línea sucesoria de padre a hijo. Además Dmitri Donskoi había especificado en su testamento que a la muerte de su primer hijo heredaría el segundo de manera que los hermanos de los príncipes y aun los hijos de éstos, se sentían con derecho a heredar ese patrimonio. Esta indefinición suscitaba guerras continuas entre la elite gobernante. Cuando Vasili II regresó a Moscovia venció a su primo quien a la muerte de su padre reclamaba la sucesión. Obtuvo esta victoria -no sin muchos sinsabores, ya que sus enemigos lo cegarongracias al apoyo de los nobles terratenientes de Moscovia quienes lo reconocieron como el soberano legítimo porque descendía supuestamente en línea directa de la dinastía de los Ryuríkidas, mientras que el tío representaba una rama colateral. Seguramente también influyó el hecho de que Vasili I intentara, antes de morir, que los boyardos reconocieran a su hijo como sucesor ${ }^{299}$. Este reconocimiento muestra el aumento del principio autoritario personalista al grado de que se imponía poco a poco la sucesión de padres a hijos.

A partir de la consolidación de poder de Vasili II, Moscovia se fortaleció. Podría decirse que el principado inició su expansión sometiendo a otras parcialidades rusas. En 1456 el autócrata atacó Novgorod y aunque no lo conquistó, el principado norteño ya no pudo sustraerse a su influencia.

\footnotetext{
299 The Novgorod Chronicle, op.cit., p.5; The Chronicle..., Trad. Michell, op. cit., p. 176-177, 189 passim, La Crónica de Novgorod termina en 1446 cuando tenía lugar esta guerra intestina, enfrentamientos con otros principados, con los tártaros y problemas con el metropolitano. El año de 1471 fue añadido por órdenes de Iván IV para dar cuenta de la conquista de Novgorod por su padre, vid., p.205 nota1;Vernardsky, op.cit., pp. 74-78; Hellmann, op. cit., pp. 99-101; Summer, op.cit., p.34; Kalistov, op. cit., pp. 66-67; Riasanovsky, op. cit., p. 102; Longworth, op. cit., p. 65.
} 
Una muestra de la influencia moscovita en Novogord es la biografía de $\underline{\text { San Mijail, }}$ $\underline{\text { un fanático de Dios }}^{300}$ quien predicaba a favor de la incorporación de la principalidad a Moscovia. Vivió en el monasterio de la Santa Trinidad en Klopsko cerca de Novgorod. En una ocasión el jefe de la veche de Novgorod le comentó a Mijail que recibiría la ayuda del príncipe de Lituania para enfrentar al príncipe de Moscovia. De acuerdo con el relato, Mijail le sentenció al gobernante que mejor se presentara ante el príncipe de Moscovia, hiciera las paces con él y pagara tributo porque de otra manera Dios lo abandonaría, además el príncipe de Lituania no se aliaría con él. Este relato es una clara muestra de cómo los príncipes de Moscovia supieron utilizar las profecías generadas en el seno de la iglesia ortodoxa para engrandecerse e intentar unificar a todos los rusos bajo su poder.

Acto seguido, Vasili II conquistó las ciudades de Pskov, Tver y Riazan. Vasili II estableció un consejo o duma constituido por cinco o seis boyardos y amplió a la burocracia que paulatinamente se iba creando para controlar y administrar los territorios anexados al principado. El poder del gran príncipe de Moscovia se fortaleció aún más cuando en 1452 -justo mientras Constantinopla estaba a punto de sucumbir ante los turcos otomanosKasim, el jan de Kasimov en el janato de Kazan, aceptó prestarle obediencia. A la muerte de Vasili II, Iván III (1462-1505) heredó el principado ${ }^{301}$.

El panorama político favoreció a Moscovia cuando en 1441 los obispos de los principados rusos se negaron a aceptar la unión de la iglesia ortodoxa con la católica. Al parecer, el metropolitano Isidoro (1385-1463) asistió al Concilio de Florencia (1439) y regresó al este con la novedad de que había reconocido la supremacía de la iglesia romana y

\footnotetext{
300 "The Life of St. Michael, a Fool in Christ" en Zenkovsky, op. cit., doc. 47, pp. 300-310.

${ }^{301}$ Longworth, op. cit., pp. 65-66.
} 
por lo tanto desde ese momento se adoptaría el rito católico romano ${ }^{302}$. Esto dio ocasión para que los obispos rusos, en 1448, eligieran de entre ellos al primer metropolitano de una iglesia independiente. Con ello cobraron fuerza las leyendas y las vidas de los santos nativos, también se redactaron gran parte de las crónicas, como La Crónica de Sofía $(\text { Sophiiskaya Lyetopis) })^{303}$.

En resumen, desde finales del siglo XIV la economía de los principados de la Rus se recuperó. Los artesanos de los dominios de los señores y de los monasterios recibieron el apoyo necesario para elaborar manufacturas que los terratenientes estaban interesados en comercializar. Las rutas del Volga hacia el Mar Negro y el Mar Caspio fueron retomadas por los rusos sin las restricciones que los mongoles les habían impuesto. A su vez, mercaderes de Génova entraron en contacto con Rusia en el puerto de Tana ubicado en la desembocadura del Don así como en Sudak localizado en Crimea.

Bajo estos buenos augurios inició una nueva etapa en la formación del Estado ruso.

\subsection{La unificación de todas las Rusias.}

\subsubsection{La política y el gobierno}

302 The Novgorod Chronicle, op. cit., p. 5; Riasanovsky, op. cit., p. 103; Vernadsky, op. cit., p. 82; Kinder y Hilgemann, op. cit., p. 215 ..

303 Véase la Introducción; Maier, op. cit., p.168; Vernadsky, op. cit., pp. 83-84; http://www.referencebooks.brillonline.com/entries/encyclopedia-of-the-medieval-chronicle 18 de diciembre de 2012 . 
Cuando en 1472, el príncipe de Moscú se casó con Sofía Paleólogo (1455-1503) -cuya familia residía en Roma tras la caída de Constantinopla ${ }^{304}$ - añadió al escudo de su casa, el águila bicéfala bizantina y adoptó la parafernalia imperial para su coronación presentándose como sucesor del emperador del imperio romano oriental que había sucumbido ante los otomanos en 1453. A partir de ese momento se constituyó en el primer soberano ruso: Iván III o El Grande. Éste se apoderó de Iaroslav en 1463, de Novgorod en 1478 y en 1485 sometió a Tver, derrotó a los tártaros en 1480 y recuperó la soberanía para su Estado. En 1493 se proclamó a sí mismo Soberano de todas las Rusias y autócrata (samoderyets ${ }^{305}$ ) reclamando autoridad sobre todo el territorio que alguna vez había reconocido la primacía de Kiev y mucho más. Al mismo tiempo, el resto de las ciudades y parcialidades rusas fueron anexadas al imperio en formación so pretexto de protegerlas de los tártaros y de otros pueblos trashumantes de la estepa. Para ello, Iván III siguió la política de concederles tierras a los tártaros que reconocían su autoridad, asimilarlos a los boyardos y encomendarles la protección de su frontera. En este sentido, Iván III practicó la tolerancia religiosa que los mongoles habían observado hacia los rusos y permitió la convivencia multicultural e intercultural que los eslavos habían tenido con los pueblos fineses y bálticos, con los janatos de Jazaria y de los búlgaros del Volga, así como con los vikingos. De esta manera, el recién creado Estado ruso fue aumentando su extensión territorial hacia el sur y el este, básicamente en zonas habitadas por ucranianos, la estepa volvió a unirse a la taiga $^{306}$.

\footnotetext{
${ }^{304}$ http://www.en.wikipedia.org/wiki/Sophia_Palaiologina consultado 6 de agosto de 2014.

${ }^{305}$ Palabra forma de por sam ' mismo y deryat' tener, mantener que significa mantenerse o sostenerse a sí mismo o sea autócrata, Preobrazhensky, op. cit., pp. 181, 248

${ }^{306}$ Blum, op. cit., p. 95 passim; Hellmann, op. cit., pp., 108, 113; Summer, op.cit., p.35; Riasanovsky, op. cit., pp. 89-91, 103-107; J. R. Hale, La Europa del Renacimiento 1480-1520. Trad. Ramón García Cotacelo. $7^{\text {a }}$ ed. en castellano. Madrid, Siglo XXI editores, 1986. 410 pp., (Historia de Europa Siglo XXI), pp. 60, 65, 100;
} 
En el occidente, Iván III se enfrentó al ducado de Lituania en varias ocasiones: entre 1492 y 1494 la guerra no proporcionó ganancias territoriales a ninguno de los contendientes. En el conflicto entre 1500 y 1503, Iván el Grande arrancó a Lituania el territorio ubicado entre la cuenca superior del Dniéper al oeste, el Oka al este y el Desna al sur en donde se localiza Chernigov, la mayoría de los boyardos de la región rompieron su alianza con el duque de Lituania y reconocieron la autoridad del príncipe de Moscovia (1503). Una nueva disputa militar entre 1507 y 1508 tampoco reportó ganancias territoriales ni a Moscovia ni a Lituania. En cambio, la guerra de 1512 a 1522 le dio a Moscovia Smolensk y se fijó la frontera entre ambos Estados en el río Dniéper. Sin embargo, Iván el Grande ya no pudo recuperar los territorios de Volinya, en poder de Lituania, y Galitzia, incorporada al reino de Polonia. No obstante, estas victorias señalaron a Moscovia y a su gobernante como herederos del desaparecido imperio bizantino y de Kiev y constituyeron los fundamentos de la legitimidad del poder centralizador de los príncipes $^{307}$.

La expansión del Principado de Moscovia requirió la formación paulatina de un ejército profesional cada vez más efectivo y, principalmente, leal al autócrata para que no dependiera del parecer de los boyardos. La nobleza de servicio engrosó las filas del mismo pero también era necesario equiparlo cada vez mejor. Iván III contrató armeros alemanes

Austin Jersil reseña del libro "Russia and Islam: A Historical Survey por Galina M. Yemelianova" en Slavic Review, 62:4, invierno de 2003, pp. 849-850 en http://www.jstor.org/stable/3185687 consultado 2 de noviembre de 2012; Llama la atención que haya estudiosos que consideren que la aceptación del servicio de los musulmanes es un evidencia de que los príncipes moscovitas antepusieron un proyecto imperial al mandato del "nacionalismo étnico" vid. Nicholas V. Riasanovsky reseña de "Russia and the Russians: A History" por Geoffrey Hosking en Slavic Review, 62:2, verano de 2002, p. 400 en http://www.jstor.org/stable/269154 consultado 2 de noviembre de 2012. En esta investigación se considera que no existía ninguna razón histórica para que los príncipes de Moscovia optaran por el "nacionalismo étnico" que no conocían, como se demostró en los capítulos anteriores, los rusos difícilmente podían conceptualizar un principio que históricamente les era ajeno.

307 http://www.es.wikipedia.org/wiki/Historia_de_Lituania consultado 12 de agosto de 2013; Longworth, op. cit., pp.69-70; Dukes, op. cit., pp.69-70. 
para establecer fábricas de armas de fuego y conseguir, a mediano plazo, cesar de importar este tipo de armas. Asimismo la artillería adquirió mayor importancia a medida que era necesario quebrantar la resistencia de las ciudades, como ocurrió con la toma de Nogrvorod, por ejemplo. La innovación en las tácticas militares incluyó la utilización de perros adiestrados para el ataque. Desde luego, el aumento de las fuerzas militares y las guerras de expansión requirieron la creación de una infraestructura que facilitara la movilización y el abastecimiento de las tropas ${ }^{308}$.

Para fomentar la unidad de sus territorios, Iván el Grande promulgó un código de justicia que recogía la tradición moscovita y la de Pskov. Pero el autócrata no descuidó su relación con su base de apoyo: los boyardos moscovitas. Cuando decidió casar a su hijo, corregente y sucesor Vasili Ivanovich (1479-1533) se instauró el smort (exhibición de princesas, potenciales esposas de los príncipes herederos, 1505). Las familias de boyardos se examinaban unas a otras para preseleccionar a la futura esposa del príncipe, la elección se hacía con base en los vínculos políticos que el enlace matrimonial podía aportar, desde esta perspectiva se prefería una mujer moscovita e indudablemente ortodoxa. De entre este grupo, el contrayente podía elegir a su esposa ${ }^{309}$.

Así pues la política de los Grandes Príncipes de Moscovia que podría resultar a primera vista contradictoria no lo era pues su objetivo consistía en cohesionar y disciplinar a la nobleza lo cual era indispensable para consolidar su poder. Al mismo tiempo, era necesario asegurarse la lealtad y la coincidencia de intereses con los boyardos más cercanos, pues la política centralizadora de Iván III generó oposición entre la nobleza.

\footnotetext{
${ }^{308}$ Longworth, op. cit., pp. 78, 81.

${ }^{309}$ Martin, op. cit., pp. 418-42; Alan Earl, Breve historia de Rusia. Trad. J. Ferrer Alen. Barcelona, Rotativa, [1973]. 188 pp., mapas, p. 40.
} 
En cuanto a su relación con otros Estados europeos, Iván III recibió a un embajador de Maximiliano de Habsburgo (1459-1519), emperador del Sacro Imperio Rromano, quien tenía la intención de contar con su apoyo en caso de que los otomanos atacaran su imperio; Maximiliano le ofreció investirlo como rey. Por supuesto Iván contestó que no requería de investidura alguna, tampoco le convenía tener problemas con los otomanos con los cuales prefería que sus mercaderes comerciaran. Pero Iván no menospreciaba la ventaja que pudiera obtener al mantener relaciones con el occidente. Ésa fue una de las razones por las que invadió una porción del territorio habitado por pueblos fineses y se apoderó de Novgorod y su comercio ${ }^{310}$.

Su hijo y sucesor Vasili III recuperó el principado de Pskov en 1510 aboliéndole su autonomía, el de Riazan en 1521 al sur y Rostov y Yaroslav al norte, todos habitados por rusos. De hecho, el nuevo zar desplegó una política de continuidad. Además de emprender guerras de expansión, se esforzó por obtener el reconocimiento de otros gobernantes, estableció relaciones diplomáticas con el sacro imperio romano, con el imperio otomano, el papado y el imperio mogol, recién fundado por Babur (1483-1530) en el norte de la India $(1527)^{311}$. Estas relaciones hablan de la realidad euroasiática que Moscovia había heredado del pasado inmediato. En efecto, parece que la dominación mongola le brindó este carácter.

Durante su régimen, fue enviado por el emperador germano a Moscú, Sigismund von Herberstein (1486-1566) en 1517 y 1526. Uno de los objetivos de sus viajes era explorar las posibilidades de retomar las relaciones comerciales entre Rusia y las ciudades de La Hansa. Para los Estados europeos del oeste, el principado de Moscovia, libre de los

\footnotetext{
${ }^{310}$ George Clark, La Europa moderna. 1450 -1720. Trad. Francisco González Arámburu. 4a. reimp. México, Fondo de Cultura Económica, 1986. 224 pp., mapa (Breviarios, 169), p. 47.

${ }^{311}$ Riasanovsky, op. cit., p. 108; Sixsmith, op. cit., p. 41.
} 
tártaros, aparecía como un aliado potencial. Por lo pronto, los comerciantes germanos perdieron la oportunidad de llegar a la región porque Iván III abolió los acuerdos mercantiles con la Hansa. El comercio por el Mar Negro tampoco era una opción pues los otomanos estaban instalados ahí y no permitían la llegada de los europeos a Estambul, incluso había confiscado los pequeños enclaves venecianos ${ }^{312}$. De hecho, en 1520 Paolo Centurione (c. 1480-¿), enviado por el Papa León X (1475-1521) presentó al zar un proyecto para establecer una ruta comercial por el Mar Blanco rodeando la península de Escandinavia, Vasili III no aceptó. Herberstein, por su parte, visitó la costa del Ártico y observó atentamente a la sociedad que visitó y el espacio en que habitaban, los describió en su libro Rerum moscoviticarum commentarii (Comentario sobre Moscovia) impreso en 1549 que tuvo una gran difusión ${ }^{313}$. Una de las experiencias que narró fueron los interrogatorios pormenorizados a que eran sometidos los extranjeros antes presentarse al soberano.

Vasili III murió cuando su sucesor Iván (1530-1584) era menor de edad, por ello las familias más poderosas se enfrentaron para ejercer la regencia, por fin Andrei Shuiskii (i1543) ocupó el cargo. Éste fue apresado por los servidores de Iván cuando contaba con 13 años de edad retomando la tradición bizantina de la edad mínima en que el heredero podía coronarse emperador. Iván IV (1533-1584) planeó con todo cuidado su coronación como zar con el fin de demostrar a propios y extraños el poder político que asumía ${ }^{314}$. Iván Grozny, es decir "El Terrible" aunque también puede traducirse como "El Sombrío",

\footnotetext{
${ }^{312}$ Kinder y Hilgemann, op. cit., p. 217.

${ }^{313}$ Mollat, op. cit., pp. 78-82, 139-140; http://www.es.wikipedia.org/wiki/Sigismund_Herberstein consultado 26 abril de 2013; http://www.treccani.it/enciclopedia/paolo-cantelli-centurione (Dizionario-Biografico)/ consultado 26 de abril de 2013.

314 Crummey, op. cit., p. 475; Riasanovsky, op. cit., pp. 143-145; http://genealogy.euweb.cz/russia/rurik13.html consultado 2 de enero de 2013.
} 
mantuvo en un principio una política similar a la de su padre, pero la rudeza que utilizó en lo que la historiografía sobre el tema considera la segunda parte de su mandato condujo a Moscovia a una crisis de la que emergió propiamente el imperio ruso ${ }^{315}$.

Iván IV realizó una reforma en el ejército pues su proyecto estaba encaminado a la expansión territorial. Por tanto, era necesario modernizar al ejército la artillería y la caballería fueron reorganizadas y estableció una línea defensiva para proteger la frontera del sur. Favoreció el reclutamiento de expertos germanos y escoceses, entre otros, en tecnología militar y en 1550 creó seis compañías de mosqueteros conocidas como strel'tsy $y^{316}$

Gracias a esta reorganización, en 1552 Iván IV sometió al janato de Kazán y cuatro años después el de Astrakán. El zar comprendía la importancia de la ruta comercial del Volga en la estepa y la fertilidad de sus tierras. La integración de estos territorios al Estado moscovita evidenció el proceso de la formación de un Estado multicultural donde, en principio, una vez sometidos los pueblos portadores de una cultura distinta a la rusa, el Estado toleraba sus prácticas culturales en tanto no pusiera en peligro su control. Aunque a nivel local los rusos interactuaron de diferente forma con los diversos pueblos que quedaron bajo su dominio ${ }^{317}$. A los ojos de otros Estados europeos Moscovia fue apreciada como la defensora de la cristiandad, ortodoxa y católica, ante los embates musulmanes por

\footnotetext{
${ }^{315}$ Para una evaluación sintética del gobierno de Iván IV con base en investigaciones recientes véase Robert O. Crummney, "Ivan IV: Reformer or Tyrant?" en http://www.stetson.edu/psteeves/classes/crummey.html, 5 pp. consultado 11 de enero de 2013; Kollman, op. cit., pp. 440-442; Longworth, op. cit., pp. 87,90.

${ }^{316}$ Riasanovsky, op. cit., p. 146; Longworth, op. cit., p.90.

${ }^{317}$ Crummey, "The Latest..., op. cit., apud. Andreas Kappeler, Russlands erste Nationalitäten: Das Zarevich und die Völker der Mittleren Wolga vom 16. Bis 19. Jahrhundert (Cologne, 1982); Russland als Vielvölkerreich: Entstehung. Geschichte. Zerfall (Munich, 1993), pp.483-484.
} 
el este ${ }^{318}$. Percepción benéfica para Moscovia que se entendía a sí misma como el paladín de la verdadera cristiandad, la ortodoxa.

Las conquistas de Kazan y Astrakán llevaron la frontera del naciente imperio a la región del Cáucaso, aunque por el momento Iván IV se abstuvo de intentar extenderse sobre ese territorio, sus súbditos pronto establecieron contacto con los pueblos que lo habitaban. En 1555 envió tropas a petición del propio jefe de Circasia para ayudar a los circasianos en contra del jan de Crimea. Así se originó la relación de Moscú con el Cáucaso. En esta región, como más tarde en Siberia, el zar construyó fortificaciones a fin de defenderse de posibles ataques de los musulmanes y mantener el territorio bajo su $\operatorname{control}^{319}$.

Entre 1534 y 1537, en un enfrentamiento en contra de Lituania, Iván IV ganó Veliy y Sebey. En 1570, Iván IV obtuvo el acceso al Mar Báltico en la batalla de Narva. Pero las victorias cesaron cuando el zar intentó apoderarse también del janato de Crimea, empresa en la que fracasó.

Cuando emprendió una nueva guerra en contra de Livonia con el objetivo de apoderarse de las costas del Mar Báltico, los tártaros de Crimea, aprovechando su ausencia, atacaron y saquearon Moscú. El naciente imperio estaba rodeado de enemigos. La guerra fallida en el Báltico obligó a Iván IV a firmar tratados desventajosos con Polonia (1582) y

\footnotetext{
318 Euan Cameron [Ph. D. 1982] (ed.), El siglo XVI. Trad. Teófilo de Lozoya y Juan Rabasseda-Gascón. Barcelona, Crítica, 2006. (Historia de Europa Oxford), p. 199.

319 http:/www/.es.wikipedia.org/wiki/Circasia consultado 23 de abril de 2014; Clark, op. cit., p.142; Longworth, op. cit., pp.92-94.
} 
Suecia (1583) en los que perdió la salida al mar. La derrota en el noroeste y en el sur produjo un desastre económico que fue evidente a la muerte del $\operatorname{zar}^{320}$.

\subsubsection{Una iglesia ruso-ortodoxa}

La iglesia de todas las Rusias fue el pilar de la concepción que paulatinamente se desarrolló en torno al príncipe respecto de su legitimidad, de sus obligaciones y derechos. Poco antes de la caída de Constantinopla en manos de los otomanos, los obispos y arzobispos de la tierra rusa, reunidos en un concilio en Moscú (1448), decidieron que sus prelados no requerían de la sanción del patriarca de Constantinopla, como se le llamaba aunque los otomanos hubieran cambiado el nombre de la ciudad, que estaba en territorio de infieles. Como la iglesia ortodoxa siempre había reconocido la primacía del Estado sobre ella, desde 1459 el "príncipe de todas las Rusias", quien se casó con la sobrina del último emperador bizantino, se convirtió en la máxima autoridad religiosa. Esta situación le brindó un halo de sacralidad al gobernante. En su carácter de jefe de la iglesia, Iván III confiscó las tierras de los monasterios localizados en el territorio que había controlado Novgorod, los monjes se sometieron a sus disposiciones. Treinta años después, el metropolitano de Moscovia, clérigo superior en la iglesia rusa, se elevó a la dignidad de patriarca.

La propia iglesia desarrolló el postulado de que el gobernante de Moscovia era quien encabezaba a la iglesia ortodoxa rusa así como el emperador lo había hecho en el imperio bizantino. Además el resto de las iglesias ortodoxas estaban en territorio dominado por los otomanos de manera que solo el gobernante moscovita era soberano. Así lo interpretaron el metropolitano Zosima (1490-1494) y Iosaf Sanin (1440-1515) abad del

\footnotetext{
${ }^{320}$ Hellmann, op. cit., pp.110-111, 114, 126; Hambly, op. cit., p 126; Riasanovsky, op. cit., p. 152; Sixsmith, op. cit., p. 46; http://www.es.wiki/Guerras_moscovita-lituanas consultado 12 de agosto de 2013.
} 
monasterio de Volokolamsk. La unión del Estado y de la iglesia debía ser absoluta, principio sancionado por el concilio de 1503 y defendido por el abad de Volokolamsk ${ }^{321}$. A partir de estos principios Filoteo de Pskov (1460-1542) en una carta dirigida a Vasili III (fechada en 1524) le hacía ver que el príncipe de Moscú era el sucesor del emperador bizantino y su capital la Tercera Roma, es decir, la encargada de la salvación eterna pues todos los reinos cristianos estaban bajo su gobierno ${ }^{322}$. Así, Iván III fue llamado autócrata pero Iván IV fue coronado como zar por el metropolitano Macario (1542-1563) y por tanto cabeza de la iglesia ortodoxa. En seguida se habló de la Santa Rusia ${ }^{323}$.

La organización de la iglesia rusa se definió durante los concilios de 1547, 1549, 1551y 1554. El de 1551, el Sínodo de los Cien Capítulos, realizado bajo el mandato de Iván IV, fue encabezado por el patriarca Macario y tuvo como misión establecer con claridad las relaciones entre el Estado y la iglesia. Reglamentó la adquisición de tierras de los monasterios. Pero Iván IV deseaba disponer de la riqueza de la iglesia que controlaba gran parte de las tierras cultivables, este interés creó una tensión permanente entre el zar y los altos jerarcas de la iglesia rusa. Fue hasta 1580 que los abades de los monasterios

\footnotetext{
${ }^{321}$ Pedro Bádenas de la Peña, Antonio Bravo García, Inmaculada Pérez Martín (eds.), El cielo en la tierra. Estudios sobre el Monasterio Bizantino. [España], Consejo Superior de Investigaciones Científicas, 1997. 352 pp. (Nueva Roma, 3), p. 226.

322 Filofei, "Moscow the Third Rome (excerpts)" en http://www.dur.ac.uk/a.k.harrington/3rdrome.html consultado 28 de noviembre de 2011. En estudios recientes se ha postulado que la iglesia y el Estado ruso más que considerar a Moscú como la Tercera Roma, lo conceptualizaban como la Nueva Jerusalén pues lo ortodoxos se consideraban a sí mismos como los practicantes del cristianismo original, Crummey, op. cit., p. 479; http://www.orthodoxwiki.org/Philoteus_of_Pskov consultado 11 abril 2013; http://www.saints.sqpn.com/saintjb3.htm consultado 11 abril 2013, al decir que todos los reinos cristianos estaban bajo su dominio aludían a que los ortodoxos consideraban al patriarca por encima del papa romano.

${ }^{323}$ Hellmann, op. cit., p. 114, 116-118; Maier, op. cit., pp. 168-169; Blum, op.cit., p.136; Riasanovsky, op. cit., pp. 123-124; Hale, op. cit., p. 259.
} 
accedieron a que se registrara toda la tierra que poseían a cambio de que no se les confiscara ni un pedazo ${ }^{324}$.

Una de las cuestiones que requiere de mayor investigación consiste en explicar cómo fue que la gente común, el pueblo ruso, hizo suyas estas interpretaciones acerca del poder sacralizado de los zares ${ }^{325}$. Probablemente los ritos de coronación, los matrimonios y todos los eventos en los que participaba la iglesia utilizaba símbolos para reforzar la figura del zar y para que fueran presenciados al menos por un segmento de la población de manera que el mensaje también fue difundido entre ellos. Otra de las vías por las que la población pudo haber aceptado este vínculo entre la iglesia y el Estado fue el adoctrinamiento de la propia iglesia, es decir, al inculcar la fe también se fomentó una inclinación política. Si el zar era la cabeza de la iglesia y Dios estaba con él y al mismo tiempo era el defensor de la verdadera fe; según los altos jerarcas de la iglesia rusa, estos principios tuvieron que ser transmitidos por los monjes quienes tenían una relación directa con el pueblo. Además, la iglesia sancionaba el orden social que existía en Rusia y por tanto debía realizar la labor necesaria para lograr que las capas menos favorecidas de la población aceptaran la situación como un mandato divino.

Tal vez también tuvo una influencia determinante que durante el gobierno de Iván IV, la iglesia ortodoxa rusa canonizara alrededor de 39 nuevos santos. Además, los estandartes que llevaba el ejército del zar tenían imágenes de Jesucristo, de santos como

\footnotetext{
${ }^{324}$ Riasanovsky, op. cit., p. 146, 197-198; Longworth, op. cit., pp.99-101; Bánedas, op. cit., p.266; Donald Ostrowksi (actualmente profesor en la Universidad de Harvard) y Marshall T. Poe, Portraits of Old Russia. Imagined Lives of Ordinary People, 1300-1725. Nueva York y Londres, M. E. Sharpe, 2011. 324/XXVIII pp., ils., p. XVI.

${ }^{325}$ Zoe Knox reseña del libro "Political Symbols in Russian History: Church, State, and the Quest for Order and Justice" de Lee Trepanier en Slavic Review, 67:4, invierno de 2008, pp. 1021-1022 en http://www.jstor.org/stable/27653064 consultado 2 de noviembre de 2012.
} 
Dmitri y frases que aludían a que las guerras tenían como objetivo principal defender a la ortodoxia cristiana. Iván IV también estimuló que los nuevos territorios añadidos a su imperio se convirtieran al cristianismo ortodoxo cuando sus habitantes profesaban otra religión o eran paganos. En el caso de Kazan fomentó la inmigración de rusos y pronto se estableció un arzobispado en la ciudad que tuvo por objeto realizar una labor de conversión de los tártaros ${ }^{326}$.

Los clérigos eran quienes predominaban en la escritura del ruso, traducían textos religiosos principalmente -ya fuera del búlgaro o del griego- pero también producían documentos de carácter moral y político. Los nobles y sectores de los mandos bajos de la burocracia consumían también literatura llegada del oeste europeo. Durante el régimen de Iván IV se instaló la primera imprenta que adaptó los tipos a las letras rusas ${ }^{327}$, lo que facilitó la difusión de las obras escritas en ruso. El arte de la manufactura de iconos también se concentraban en temas religiosos y la arquitectura más importante fue asimismo religiosa, como fue el caso de la catedral de San Basilio construida entre 1555-1560, durante el gobierno de Iván IV ${ }^{328}$.

Pero para la mayoría de la población, es decir, los campesinos y, en general, los aldeanos, los skomoroji -quienes cantaban las bylnias, hacían actos con animales domesticados, bailaban y en fin con sus presentaciones entretenían al pueblo - eran los

\footnotetext{
${ }^{326}$ Longworth, op. cit., pp. 90-92.

${ }^{327}$ Ibidem, p. 87.

${ }^{328}$ Riasanovsky, op. cit., p. 203-201.
} 
difusores más importantes de la cultura rusa a pesar de que la nobleza y la iglesia reprobaban sus espectáculos ${ }^{329}$.

\subsubsection{La burocracia}

La extensión de los dominios de Moscovia implicó la creación de un aparato burocrático particular para administrarlos. Así, resultaron muy útiles funcionarios y clérigos que emigraron a Moscovia tras la conquista de Constantinopla. Ellos proporcionaron una experiencia administrativa, militar y diplomática que los moscovitas no tenían, sus enseñanzas proporcionaron una base sólida para la administración del imperio en ciernes ${ }^{330}$.

Los antiguos principados se transformaron en provincias. Se crearon oficinas o prikaz para resolver asuntos de orden militar, de abastecimiento, de relaciones con otros Estados y cobrar impuestos. Las competencias de cada prikaz no quedaron claramente establecidas. En parte la infraestructura y la recaudación de ingresos para el Estado fue heredada de los mongoles pero ahora eran los miembros de la nobleza o los ricos mercaderes quienes cobraban los impuestos. Asimismo aparecieron órganos de gobierno: la druyina se transformó en la duma, aunque nadie sabía con exactitud cuáles eran sus funciones. Al parecer era básicamente un cuerpo de consejeros que sólo en casos extremos tomaba decisiones de gobierno si el zar se ausentaba. Todos recibían un salario en metálico lo que le dio una gran autonomía al gobierno ${ }^{331}$.

Una experiencia muy importante que los inmigrantes bizantinos proporcionaron al Principado de Moscovia fue la diplomática. Los griegos enseñaron a los rusos el protocolo

\footnotetext{
329 “Minstrels in Rus': An Immunity Charter (1470)" y Russell Zguta, "Russian Minstrelos: a Modern View” en Kaiser y Marker, op. cit., pp. 131-137.

${ }^{330}$ Longworth, op. cit., p. 68; Dukes, op. cit., p. 68.

${ }^{331}$ Sobre la moneda se tratará en el apartado 4.2.2.
} 
que debía emplearse en las misiones enviadas a otros Estados y la que se debía al Príncipe cuando recibía embajadas. Asimismo adiestraron a los rusos para crear un cuerpo de traductores tanto para realizar su labor oralmente como con documentos.

Paralelamente a la labor diplomática también fueron formados expertos en lo que hoy denominamos un sistema de inteligencia que mantuviera informado al Príncipe sobre la política desplegada por aquellos Estados con los que mantenían contactos. Así poco a poco fue acumulándose información sobre la situación socioeconómica y política de los Estados adversarios de Rusia de manera que cada vez se tenía más información para tratar y negociar con ellos. El segmento burocrático adiestrado en las relaciones con el exterior constituyó un cuerpo fundamental en el proceso de expansión de Moscovia y más tarde del naciente imperio ruso ${ }^{332}$.

\subsubsection{Codificación jurídica}

Para unificar el orden judicial, en 1497 Iván III elaboró un nuevo código o Sudebnik ${ }^{333}$. Iván IV emprendió reformas cuyo fin era consolidar el poder del Estado lo que a su vez sería la base de su expansión territorial. En primer lugar se rodeó de ministros con quienes discutía asuntos relacionados con la iglesia, el ejército y las relaciones con otros Estados. Convocó a una asamblea de la tierra (zemskii sabor) en 1549 que tenía la función de brindarle consejo, en ella podían participar boyardos, hombres de la iglesia y plebeyos, comerciantes o artesanos. Al parecer quedaron excluidos los campesinos quienes poco a poco quedaron bajo el dominio de la nobleza. Esta asamblea expresaba el parecer de todos quienes prestaban servicio al zar. El número de sus integrantes también variaba de acuerdo

\footnotetext{
${ }^{332}$ Longworth, op. cit., pp. 74-78, 87, 105.

${ }^{333}$ Hellmann, op. cit., pp.121-122; Riasanovsky, op. cit., p. 189. 191-192, 206-207.
} 
con la convocatoria del zar, al menos reunía a 200 personas. Tampoco queda claro cómo eran elegidos los participantes. Como resultado de la primera reunión de la zemskii sobor, Iván Grozny puso en marcha reformas de gobierno. Un año más tarde promulgó un nuevo código (Sudebnik) que buscaba limitar el poder de los funcionarios con el establecimiento de asambleas ( $g u b a)$ en las comunidades campesinas y en las ciudades, sus miembros eran elegidos entre los habitantes, casi siempre la encabezaba la nobleza de servicio, y tenían autonomía administrativa. Pero a finales de su gobierno las funciones administrativas y militares recayeron sobre el voyevoda ${ }^{334}$ que ejercía su mandato sobre una provincia por un lapso de tres o cuatro años. Como era de esperarse, los funcionarios públicos debían cuando menos saber leer y escribir. La mayoría de la población recibía su educación en los monasterios $^{335}$.

En resumen, las características que Iván III, Vasili III e Iván IV le imprimieron al Estado ruso, incluyendo la participación de la nobleza en la elección de la esposa, permanecieron por lo menos hasta principio del siglo $\mathrm{XIX}^{336}$. Los príncipes de Moscú lograron constituirse en la fuente suprema del poder y hacerse obedecer mediante el aparato administrativo y, desde luego, su ejército consolidando así al Estado encabezado por un autócrata.

\subsubsection{Las transformaciones socioeconómicas}

\footnotetext{
${ }^{334}$ Durante los siglos XVI al XVIII la palabra significaba gobernador provincial el cual también desempañaba funciones de jefe militar. Actualmente el término ha caído en desuso, vid., Nogueira, op.cit., p.83.

${ }^{335}$ Maier, op. cit., p. 169; Hellmann, op. cit., pp. 135-137; Riasanovsky, op. cit., p. 146, 189; Longworth, op. cit., p. 91; Perry Anderson, El Estado absolutista, Trad, Santos Juliá. 2a ed. México, Siglo XXI, 1980. 594 pp. (Historia), pp. 335-340.

${ }^{336}$ Kollman, op. cit., pp. 441-446.
} 
La consolidación del poder de Moscovia sobre parte del territorio de la antigua Rus se debió en gran medida a la producción agrícola que cubrió las necesidades alimenticias del ejército y la burocracia. La agricultura tuvo periodos de buenas cosechas y periodos de hambruna. Por ejemplo La Crónica de Novgorod señala que en 1445 no había comida en la ciudad, la gente se desesperaba, lloraba y moría de hambre. Algunos llegaron a venderse a sí mismos a cambio de un mendrugo de pan. Lo que ocurrió fue que la población creció con mayor rapidez que la producción. Sin embargo, había tierras sin cultivar porque la migración al noreste no podía detenerse. En el corazón de las tierras rusas unificadas por Moscovia, los privilegios que los señores concedían a los labradores en el siglo XV dio lugar a que aparecieran dos tipos de campesinos: los llamados straojil'tsy quienes llevaban generaciones en el dominio y los novoprijodsty o sea, los recién llegados que por algún tiempo gozaban de exenciones en el pago de contribuciones al boyardo. Existían además los polovnik que realizaba un acuerdo con el propietario de la tierra para rentarla por un tiempo determinado y pagaban una parte proporcional de su cosecha también acordada previamente. La competencia entre los terratenientes por la fuerza de trabajo los llevó, tanto a laicos como a clérigos, a presionar para que se limitara el derecho del campesinado libre a cambiar de señor cuando quisiera. En 1497, el código emitido por Iván III establecía que los campesinos sólo podían cambiar de residencia una semana antes y una después del día de San Jorge (23 de abril) siempre y cuando saldaran todas sus deudas con el señor e incluso le dieran un pequeño rescate. La temporada para salir de los dominios coincidía con el inicio de la primavera. El pago de la barchina, es decir el trabajo en las tierras del señor, y el obrok, el pago en especie, se extendió aún más a medida que las comunidades campesinas se incorporaban a los dominios de los boyardos. Al mismo tiempo, los terratenientes procuraban aumentar las cargas de los campesinos especialmente la barchina, 
que empezaron a demandar en metálico. El centeno y la avena eran los cereales que en mayor cantidad se entregaban como obrok. Los campesinos también se distinguían entre bol'shie y prejodsty, los primeros tenían animales de tiro y los segundos no, pero todos pagaban sus cargas tanto al boyardo como al zar y recibían el apelativo genérico de serebrennik $^{337}$. Es decir, existían jerarquías entre los propios campesinos. Las parcelas asignadas a una familia tenían el nombre de vyt, cada vyt tenía una extensión de aproximadamente 147 chetverti o 4000 hectáreas ${ }^{338}$ entre tierras fértiles, no muy fértiles, yermas, bosque y pajar. Pero poco a poco la extensión efectiva fue reduciéndose no sólo por la presión de los boyardos sino porque los campesinos abandonaban parte de sus tierras para así evadir las cargas y los impuestos, por eso la inmensa mayoría vivían en una situación tan precaria que una mala cosecha o una requisa significaban su ruina completa, la solución para no endeudarse o morir era huir a la estepa o al noreste ${ }^{339}$.

Iván IV intentó ordenar el pago de impuestos sobre la tierra. Se estableció que cada año se actualizaría el registro catastral pero los agrimensores en realidad no sabían medir ni tampoco dominaban la aritmética, de manera que recurrían a los propios campesinos quienes tenían muy claro la extensión de tierra que debían trabajar y más o menos cuánto producían. Sobre esos datos se elaboraba el catastro que tenía inconsistencias. Lo que los inspectores consignaban mejor era el número de familias campesinas, el bosque, las

\footnotetext{
${ }^{337}$ Sustantivo que deriva de la palabra serebo que significa plata. Así pues serebrennik era el que daba la riqueza que podía convertirse en plata, vid. Blum, op. cit., p.116, 236-239

3381 chertvert equivalía a 27.31 hectáreas aproximadamente. Blum, op. cit., p.237; http://www.encyclopedia2.thefreedictionary.com/chetvert consultado 23 de diciembre de 2012; Longworth, op. cit., p.53.

${ }^{339}$ Cameron, op. cit., p.113; El fenómeno del aumento de cargas a los campesinos no ocurrió exclusivamente en Moscovia sino en toda Europa y fue parte del costo social de la formación del Estado moderno. Sin embargo, en Moscovia el empobrecimiento de los campesinos fue mayor que en otros lugares, ello explica la huida hacia la estepa cosaca o hacia Siberia y, desde luego, las rebeliones campesinas sobre las que trataremos en el siguiente capítulo, vid. Richard van Dulmen, Los inicios de la Europa moderna (1550-1648). Trad. Ma. Luisa Delgado y José Luis Martínez. 3a ed. México, Siglo XXI, 1986. 470 pp., (Historia universal siglo XXI, 24), pp.106-107.
} 
huertas, los pastizales y las pescaderías que había en cada votchina, estos factores también se tomaban en cuanta para tasar los impuestos. Las viudas y los campesinos muy pobres estaban exentos de pagar impuestos. Durante el gobierno de Iván IV las contribuciones exigidas tanto a los terratenientes nobles como al resto de la población aumentaron tanto que muchos se desplazaron hacia el noreste ${ }^{340}$.

En cuanto a la mano de obra esclava aunque todavía existía, los señores preferían emplearla en labores artesanales, domésticas o de administración y, cuando era posible, transformarlos en renteros. De esta manera fueron desapareciendo poco a poco del trabajo en el campo. Desde luego hay que señalar que además los renteros tenían que pagar para recibir autorización para casarse, para vender por su cuenta en el mercado y además de cuando en cuando el señor les pedía "préstamos" forzosos, que no les pagaba, de esta manera se apoderaba de una parte adicional de la producción agrícola. La servidumbre, institución aparecida en Europa occidental y central, se instauró paulatinamente en las tierras de los boyardos y fue la columna vertebral del imperio ruso, esta institución, copiada de Europa muestra que Rusia también participó de esta tradición ${ }^{341}$.

Por otra parte, los boyardos, sobre todo aquellos que tenían dominios pequeños, consideraron ventajoso continuar acogiéndose a la protección del poderoso príncipe moscovita. Pero el príncipe no confiaba por completo en su lealtad. Vasili I estableció que si alguno de sus boyardos los traicionaba podía confiscarle sus tierras, pero a partir de Vasili III el boyardo que solicitaba su protección debía firmar un contrato por el que renunciaba a su derecho de cambiar de residencia y se obligaba a prestarle servicio y

\footnotetext{
${ }^{340}$ Blum, op. cit., p.231-232.

${ }^{341}$ The Novgorod Chronicle, op. cit., pp. 5-6; Hellman, op. cit., pp. 124-125; Kolistov, op. cit., p. 60; Blum, op. cit., p. 6, 98-103, 111, 116, 220-221; van Dulmen, op. cit., p.33
} 
lealtad, éste fue el origen de la nobleza de servicio. La votchina poco a poco dio paso a la aparición de la pomestye, es decir, la garantía de la posesión de la tierra estaba en función del servicio que el terrateniente (pomeshchnik) proporcionara al príncipe. Cuando Iván III conquistó Novgorod, utilizó por vez primera este tipo de concesión de tierras. Inspirado en el sistema de tenencia de la tierra que los emperadores bizantinos utilizaron para asegurarse la lealtad y el servicio entregando tierras a sus servidores (pronoia) ${ }^{342}$, Iván III distribuyó tierras de la principalidad de Novgorod entre los vecinos que lo habían apoyado y los moscovitas. Los beneficiados recibían una porción de tierra, pomestye, a cambio de servir al Príncipe como soldados. Si quien recibía estas tierras cumplía cabalmente su compromiso, su hijo podía heredarlas y estaba obligado a continuar sirviendo al príncipe. De lo contrario, el autócrata recuperaba la tierra concedida. De esta manera, Iván III aseguró los territorios de Novgorod para Moscovia. El sistema pomestye obligó a levantar mapas de las regiones en las que se otorgaban de tal manera que se controlara a los beneficiarios para que realizaran el servicio correspondiente en función del tipo y cantidad de tierras que habían recibido. Para el efecto, se creó una oficina encargada de llamar al servicio a los pomeshchniki ${ }^{343}$.

El servicio más importante era el militar, después de todo Moscovia estaba en franco proceso de expansión, aunque también participaban en la burocracia. Durante el gobierno de Iván IV la pomestye se extendió a tal punto que gran parte de las tierras de las comunidades campesinas libres quedaron sujetas a ella, incluso los renteros al interior de los señoríos debían prestarle servicio al zar por encima de los derechos del señor.

\footnotetext{
${ }^{342}$ Kinder y Hilgemann, op. cit., p. 181.

${ }^{343}$ Longworth. op. cit., p. 73.
} 
El rango de los boyardos se definía en función del servicio que él y sus ancestros hubiesen prestado al príncipe de Moscovia, para ello existía el sistema de mestnichestvo mediante el cual se estudiaba el pasado de la familia extensa y se asignaba el rango del boyardo, de esta manera se determinaba cuáles cargos debía ocupar. En otras palabras, el autócrata impidió que la nobleza presentara un frente unido pues aquél establecía su rango y por tanto sus tierras y el cargo que ocupaba. La nobleza más antigua (knyazya) tenía asignados los mejores puestos, pero si algún boyardo intentaba dejar de prestar su servicio al zar se le acusaba de traición y se le confiscaba su patrimonio. Así, poco a poco la antigua nobleza ya no pudo disponer de sus tierras a su arbitrio exclusivo. Al parecer, los linajes arraigados en los territorios que se convirtieron en provincias del Estado moscovita procuraron ocupar los puestos de jefes de asambleas o voyevodas en su región ${ }^{344}$.

Para obligar a los boyardos que se resistían a sujetarse a la pomestye, Iván IV se apoyó en los militares de a pie armados con mosquetes o strel'tsy, reclutados entre los plebeyos, sin importar su ocupación, quienes recibían un salario por sus servicios. Los regimientos de strel'sty además proporcionaban una protección directa al zar y a Moscú. Esta reforma condujo a una reorganización de la prestación del servicio militar por parte de los señores. Por el decreto (ukaz) del 20 de septiembre de 1556 se estableció cuántos hombres armados debería enviar un boyardo al ejército del zar de acuerdo a la extensión de su patrimonio. De no cumplir cabalmente sus obligaciones su dominio o parte de él le sería confiscado y éste sería otorgado a quien si estuviera dispuesto a servirle. Así surgieron los

\footnotetext{
${ }^{344}$ Blum, op. cit., pp. 81, 84-85, 137-140; Hellmann, op. cit., pp. 118-121; Crummey, "The Lastest..., op. cit.,
} p. 476. 
militares plebeyos que dieron origen a la oprichina ${ }^{345}$ diez años después. En un principio éste era un territorio en el que se ubicaban terratenientes en su mayoría de origen plebeyo (oprichnik) que recibían sus tierras del zar y, por eso estaban obligados a prestarle servicio. Eran muy leales a él y contribuyeron a combatir a los boyardos de abolengo. El resto del territorio se denominaba zemshchina (el país). Los boyardos descendientes de los príncipes, knyazya, fueron trasladados a nuevas pomestye, lejos de su lugar de origen y la mayoría de tierras fueron entregadas a la oprichina.

Ni las aldeas campesinas se salvaron de la confiscación. De igual manera los territorios ubicados al norte y noreste que habían Estado bajo el dominio de Novgorod arrasada por Iván IV en 1570 acusada de planear una rebelión en contubernio con los polacos- fueron cedidos a los miembros de la oprichina por lo que los monasterios ya no se establecieron ahí. Iván IV se adjudicó alrededor de la cuarta parte de todas las tierras confiscadas que se convirtieron en propiedad del Estado. Dos años más tarde la oprichina cayó en desgracia porque el zar desconfió de ella y la eliminó.

La política de Iván IV de someter a los boyardos a su autoridad estuvo acompañada de decretos que obligaban a los campesinos avecindados en los territorios de los boyardos a permanecer en el dominio de su señor, hasta que en 1580 quedaron adscritos a la tierra, aunque el cambio tardó en arraigarse. Éstos podían conservar la propiedad sobre sus animales. Por otra parte, en las tierras del Estado los campesinos quedaron sujetos directamente a él. El Estado también tenía trabajadores que no eran labradores. Estos plebeyos se dedicaban al comercio y a la manufactura. A pesar de los privilegios otorgados,

\footnotetext{
${ }^{345}$ La raíz es oprich', término caído en desuso que significaba provecho, Preobrazhensky, op. cit., p. 324. La
} oprichina no era exactamente un feudo porque no estaba garantizado el derecho de heredarlo a los hijos. 
rancias familias de boyardos (knyazya) siguieron oponiéndose a la consolidación de la autocracia moscovita, pero la reforma de Iván IV había dado un enorme paso para su consolidación $^{346}$.

En cuanto a aquellos que recibieron pomestye en realidad tuvieron pocos beneficios pues la extensión de sus tierras era pequeña y como no tenían riquezas previas era muy difícil sufragar los gastos para armarse como militares. Así que en la práctica muchos de ellos terminaron abandonando su concesión y mudándose a las fronteras con los cosacos o al este. Otros pedían préstamos a los monasterios que después no podían pagar así que de todas formas perdían su concesión, los intereses que cobraban eran muy altos por ello Iván IV ordenó que el deudor empezara a pagarlos después de cinco años de contraído el préstamo. Si los señores intentaban aumentar las cargas a los campesinos éstos huían así que no faltó el pomeshchik que trabajara él mismo su tierras, claro mientras no estaba en $\operatorname{servicio}^{347}$

Recapitulando: la política agraria desplegada por los príncipes de Moscovia y el zar disciplinó a los boyardos y los sometió a su autoridad. La pequeña nobleza que impulsaron sirvió para golpear a la knyazya, pero algunas familias sobrevivieron a las desgracias y pocos miembros de la pequeña nobleza se consolidaron como terratenientes. Para este estudio lo más importante fue que las unidades agrarias a pesar de las dificultades para arraigar a la fuerza de trabajo campesina, tarea en la que el Estado las apoyó, produjeron los suficientes cereales como para que una parte de la producción fuera conducida por los comerciantes al norte de Asia. Sin este abastecimiento la ocupación rusa del noreste del

\footnotetext{
346 Kalistov, op. cit., p.75-79; Hellmann, op. cit., pp. 136-137, 141; Blum, op. cit., pp. 136, 141-147; Riasanovsky, op. cit., pp. 148-151; Earl, op. cit., pp. 44-46; Cameron, op. cit., p. 98.

${ }^{347}$ Blum, op. cit., pp. 201- 207.
} 
imperio no hubiera sido posible pues los recursos que ofrecían el norte de la taiga y la tundra no eran suficientes para sostener una población migrante distinta a la que por siglos había sobrevivido en aquella región pescando y cazando. No obstante, no debe perderse de vista que esta sociedad agraria estaba expuesta a la hambruna pues un invierno largo, así como un deshielo rápido que causara inundaciones podía provocar la pérdida de las cosechas.

La rudeza con la que Iván IV realizó la transformación en la tenencia de la tierra implicó en términos políticos ataques, confiscaciones y hasta la pena de muerte para muchos boyardos así como para miembros de la oprichina. La situación de violencia y represión se dirigió hacia nobles y plebeyos pero el zar supo maniobrar de tal manera que logró vencer cualquier resistencia. Debido a la crudeza y la verticalidad con la que aplicó su política recibió el sobrenombre de groznyi. La transformación en la tenencia de la tierra estuvo encaminada a fortalecer el poder político de la autocracia con la consecuente pérdida del poder político de la nobleza, sin que por ello perdiera su calidad de estamento privilegiado. Asimismo tuvo el objetivo de ampliar su base fiscal a fin de sostener a la burocracia pero, sobre todo, para contar con los recursos suficientes para las guerras de expansión $^{348}$. A pesar de la violencia, cuando Iván IV abandonó el Kremlin en un gesto que significaba que sin la obediencia de todos sus súbitos los dejaría solos, la sociedad rusa le solicitó su regreso porque argumentaban que sin la guía del zar estaban perdidos, esta maniobra facilitó sus ataques hacia los nobles. La política de Iván IV fue apreciada por la mayoría de sus súbditos como necesaria para fortalecer al Estado del cual dependían para sobrevivir. Tal vez esta percepción fue el resultado de la historia vivida con anterioridad

\footnotetext{
${ }^{348}$ Longworth, op. cit., p. 99; Van Dulmen, op. cit., pp.121-122, 124,131, 160-170.
} 
cuando la falta de unidad entre los nobles había provocado la fragmentación. La política de unificación y centralización exigió el sacrificio de los intereses individuales en favor de los colectivos expresados en el fortalecimiento del Estado justamente lo que proporcionó la instauración de la autocracia ${ }^{349}$.

Andrei Kurbsky (1528-1583) fue uno de los boyardos que en un principio estuvieron cerca de Iván IV pero cuando éste inició su régimen de terror huyó a Lituania. Desde ahí le envió cartas al zar en las que criticaba su manera de actuar en contra de la nobleza $^{350}$. En su primera carta le decía que los boyardos que, como él, habían sido tratados injustamente y vivían en el exilio, clamaban venganza a dios. Atribuía estos abusos a que el zar se había dejado seducir por la aprobación de sus cómplices. A su vez, Iván Grozny le respondió ${ }^{351}$ llamándolo traidor pues se rehusó a servirlo y al despertar su enojo había provocado que dios lo desprotegiera a él, a sus ancestros y a sus descendientes. Iván invocó a Vladimir, Vladimir Monómaco, Aleksandr Nievsky, Dmitri Donskoi, Iván III y a su propio padre, Vasili III, como los constructores de su poder y por tanto los hechos de sus ancestros legitimaban sus decisiones.

Le recordó que cuando fue niño ningún boyardo defendió sus derechos como zar ni veló por los intereses de su Estado, antes bien atacaron a sus funcionarios y se apoderaron de su tesoro. Peor aún, los boyardos, incluido Kurbsky, habían desacreditado a su familia acusando a su abuela materna de extraer corazones humanos y de haber incendiado Moscú. La turba instigada por estas difamaciones había matado a su abuelo materno y habían

\footnotetext{
${ }^{349}$ Earl, op. cit., p.46; Sixsmith, op. cit., pp.46-50

350 "Prince Andrew Kurbsky: First Epistle Written to the Tsar and Grand Prince of Moscow in Consequence of His Fierce Persecution" en Zenkovsky, op. cit., doc. 55, pp.366-370.

351 "Ivan IV: Epistle of the Tsar and Sovereign to All His Russian Tsardom Against Those Who Have Broken The Pledge of Allegiance, Against Prince Andrew Kurbsky and His Comrades, Concerning Their Treacheries en Ibid., doc. 54, pp. 370-376.
} 
intentado matar a su madre, a sus hermanos y a él. Por traidor, en ese momento se encontraba bajo la protección del príncipe de Lituania de manera que no había perdón divino para él. El análisis de esta correspondencia muestra cómo Iván IV estaba completamente convencido de que las medidas que había tomado en contra de la knyazya para sujetarla al poder del Estado en las últimas décadas de su gobierno no sólo eran acertadas sino también legítimas.

Una de las razones del fortalecimiento de la economía moscovita en el siglo XVI fue el crecimiento de la población. Durante los gobiernos de Iván III, Vasili III y los primeros años de Iván IV las tierras laborables del imperio en formación volvieron a ocuparse, gracias también a la política apoyada por los autócratas de exentar por un tiempo del pago de las cargas a los campesinos. Al aumentar la población, el mercado interno creció pues las ciudades requerían de bienes agropecuarios, mientras que la producción manufacturera se incrementó. Gran parte de estos artesanos y trabajadores no eran libres sino que el Estado disponía de ellos. Pequeñas aldeas se convirtieron en ciudades sobre todo en la región fronteriza pero la artesanía rural no desapareció. Mercaderes y artesanos residían en las ciudades, todas ellas fortificadas. Algunas se especializaron en determinado tipo de productos: Moscú, por ejemplo, fabricaba armas y ropa de lana. Novgorod y Pskov producían hierro y plata. De hecho, Iván III El Grande contrató mineros germanos para buscar plata y cobre en la ribera del río Péchora que desde los Urales fluía al Mar del Norte.

Además, Iván III reorganizó el sistema monetario en sus dominios, cuando tomó el poder, una grivenka, que no era otra cosa que una barra de plata de 200 gramos, se dividía en 48 zolotniki, pero la barra se cortaba en pedazos equivalentes. La acción de cortar (rubit) dio origen a la palabra rublo. La moneda fraccionaria del zolotnik era el dengi. Iván III hizo 
de la acuñación un monopolio del Estado para que todos utilizaran la misma moneda y estableció que el rublo, 200 gramos plata, era igual a 100 kopecks o dengi, también de plata. La moneda común tenía su efigie y prohibió a los señores acuñar sus propias monedas como había sucedido hasta entonces. ${ }^{352}$.

Novogord se mantuvo como una de las productoras de pieles curtidas más importantes pero las ciudades de Kazan y Serpyjov, localizadas al este se sumaron a ella. De acuerdo con La Crónica de Novgorod, alrededor de 1420, esta ciudad empezó a realizar transacciones comerciales con monedas de plata y daba a los germanos monedas de cobre, esta noticia nos habla del fortalecimiento comercial ruso. Novgorod y Pskov, mantuvieron el intercambio con las ciudades de la Hansa y fueron los centros comerciales más importantes hasta que quedaron sometidas a Moscovia. Entonces Moscú emergió como el centro comercial y político por excelencia. Iván III prohibió el comercio con la Hansa y también combatió a los Caballeros de Livonia para evitar que jugaran el papel de intermediaros comerciales entre el principado de Moscovia y los centros comerciales del resto de Europa. Los extranjeros no se limitaron a participar en el comercio, también invirtieron en la producción de mercancías. Algunos ejercieron profesiones como médicos o asesores militares ${ }^{353}$.

Los monasterios impulsaron la organización de ferias que por lo común se realizaban en el día en que se celebraba al santo patrono. Como ocurría en muchas otras partes del mundo, los monjes eran muy buenos empresarios pues producían en los monasterios casi todo lo que vendían de manera que sus ganancias eran jugosas. En muchas

352 Dukes, op. cit., p. 37; Blum, op. cit., pp. 117-119, 131. Un zolotnik pesaba 4.26 gramos de plata; http://www.rusopedia.rt.com/economia/issue 21.html consultado 6 de agosto de 2014.

${ }^{353}$ Riasanovsky, op. cit., p. 148. 
ciudades se instalaba un mercado cada semana (posad). El gran problema era el transporte de mercancías, las distancias eran largas y la opción de hacerlo por tierra o por río dependía de la estación ${ }^{354}$.

\section{Mapa 11. RUTAS COMERCIALES RUSAS EN EL SIGLO XV}

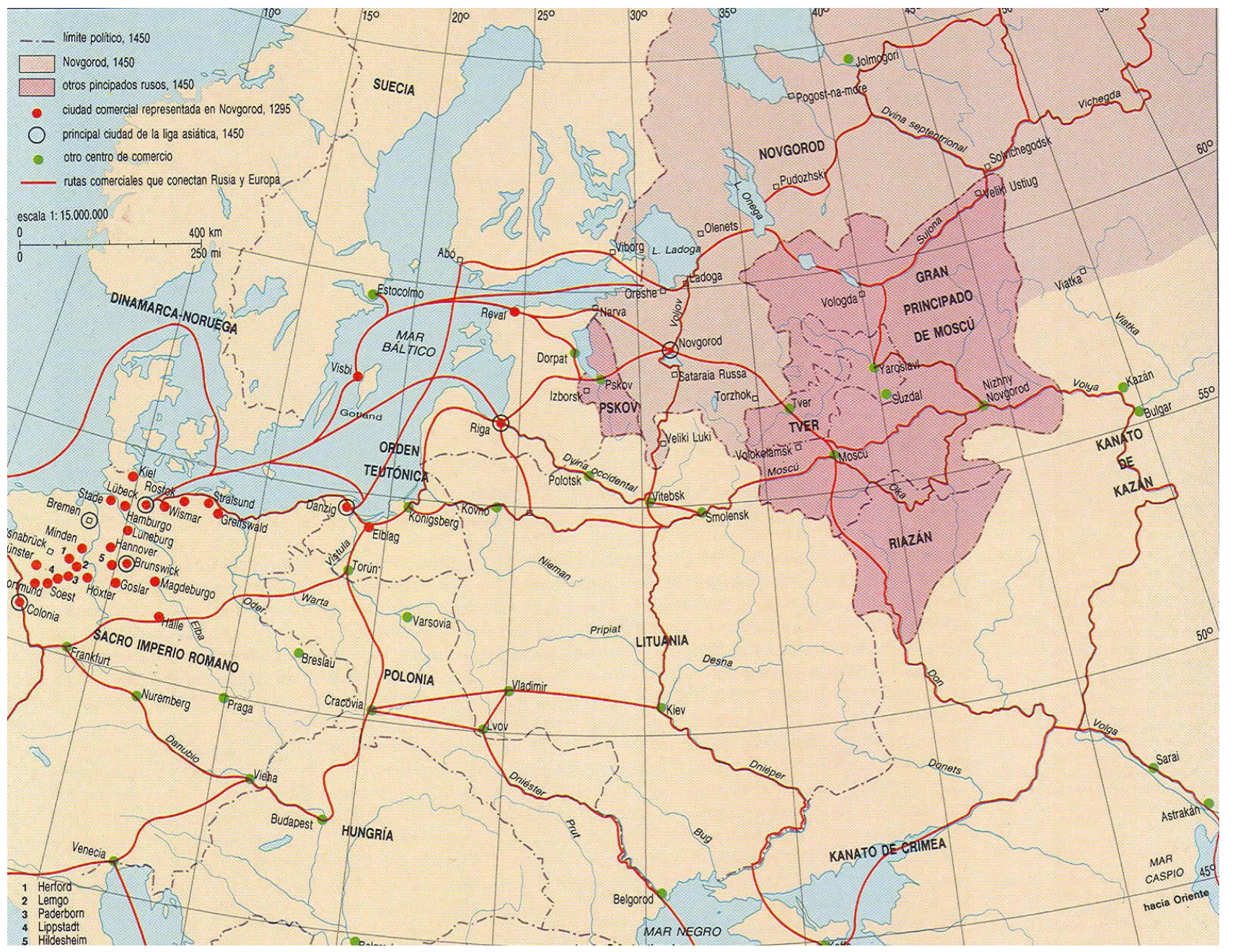

Fuente: Milner-Guiland, op. cit., p. 60

${ }^{354}$ The Novgorod Chronicle, op.cit., p.189; Blum, op. cit., pp. 122-127, 130; Kolistov, op. cit., pp.61-62, 80; Hale, op. cit., p. 222; Longworth, op. cit., pp.80-81 ; Riasanovsky, op. cit., p. 108. Sobre el comercio por el Mar Blanco hablaremos en el apartado siguiente. 
El intercambio más importante para Moscovia era el que mantenía en las rutas de Asia. Muchos mercaderes actuaban a su vez como enviados del zar ante las cortes de los janatos de Asia central y Persia sometida al imperio otomano en el siglo XV. Éstos eran comerciantes adinerados y poderosos conocidos como gosti ${ }^{355}$. Desde Moscovia se llevaban armaduras, armas y manufacturas de metal y piel así como textiles. Moscovia compraba artículos suntuarios -gran parte de las cuales reexportaba a Europa occidental- algodón pero, sobre todo, borregos y caballos. Los miembros de cualquier estamento podía dedicarse al comercio, de hecho el mercader más importante y poderoso era el zar. Su ventaja consistía en que monopolizaba la venta de productos tales como las pieles finas, las bebidas alcohólicas, los cereales, el caviar, entre algunos más; recuérdese que la existencia de monopolios del Estado fue una herencia de los mongoles. Por añadidura podía elevar los precios a su conveniencia, forzar a los comerciantes a comprarle primero a él antes que a nadie más o al revés a venderle primero los productos traídos del exterior. Pero hasta los siervos podían concurrir al mercado y vender parte de su cosecha o sus artesanías ${ }^{356}$.

Consciente de la importancia de los mercados, Vasili III prohibió a los comerciantes rusos asistir a la feria de Kazan. En su lugar promovió la realización de una feria en su territorio, fundó un fuerte cerca de aquella ciudad al que nombró Vasilievskaia. Muchos comerciantes que antes iban a Kazan se dirigieron al fuerte; poco después, y dada la importancia de los monjes como comerciantes, impulsó la feria en Niyni Novgorod ubicada en las cercanías del Monasterio de San Macario en la cuenca del Volga ${ }^{357}$.

\footnotetext{
${ }^{355}$ Moss, op. cit., pp. 134, 187.

${ }^{356}$ Blum, op. cit., pp. 128-130; Hellmann, op. cit., pp. 123-124.

${ }^{357}$ Riasanovsky, op. cit., p.108; Longworth, op. cit., p. 84.
} 
Cuando Iván IV aplicó su política para someter a los boyardos la economía se desplomó. Los plebeyos -labradores, artesanos y hasta algunos comerciantes- vivían en la zozobra al mismo tiempo que su condición cambiaba de hombres libres a siervos, por ello gran número de ellos huyeron hacia el noreste.

\subsubsection{Los cosacos}

La conquista de los mongoles y las guerras con los reinos del oeste dieron lugar a la paulatina diferenciación de los eslavos del este en rusos, ucranianos y bielorrusos. Gran parte del territorio que había integrado el Estado de Kiev logró evadir el domino de Polonia-Lituania. La estepa al norte del Mar Negro quedó como una tierra de nadie en donde habitaban los ucranianos, quienes seguramente eran descendientes de los eslavos del este y los pechenegos a quienes se unieron rusos, polacos y hasta lituanos. En la región habitaban también tártaros que no se integraron a los nuevos janatos y que habían contribuido a expulsar a los polacos. Esta población fue designada genéricamente como cosacos. En el siglo XV, los cosacos estaban agrupados en comunidades autónomas a las que se unieron desarraigados, vagabundos o campesinos que huían del régimen de servidumbre que empezaba a imponerse en los Estados aledaños. 


\section{Mapa 12. TERRITORIO APROXIMADO OCUPADO POR LOS COSACOS EN EL}

SIGLO XVI.

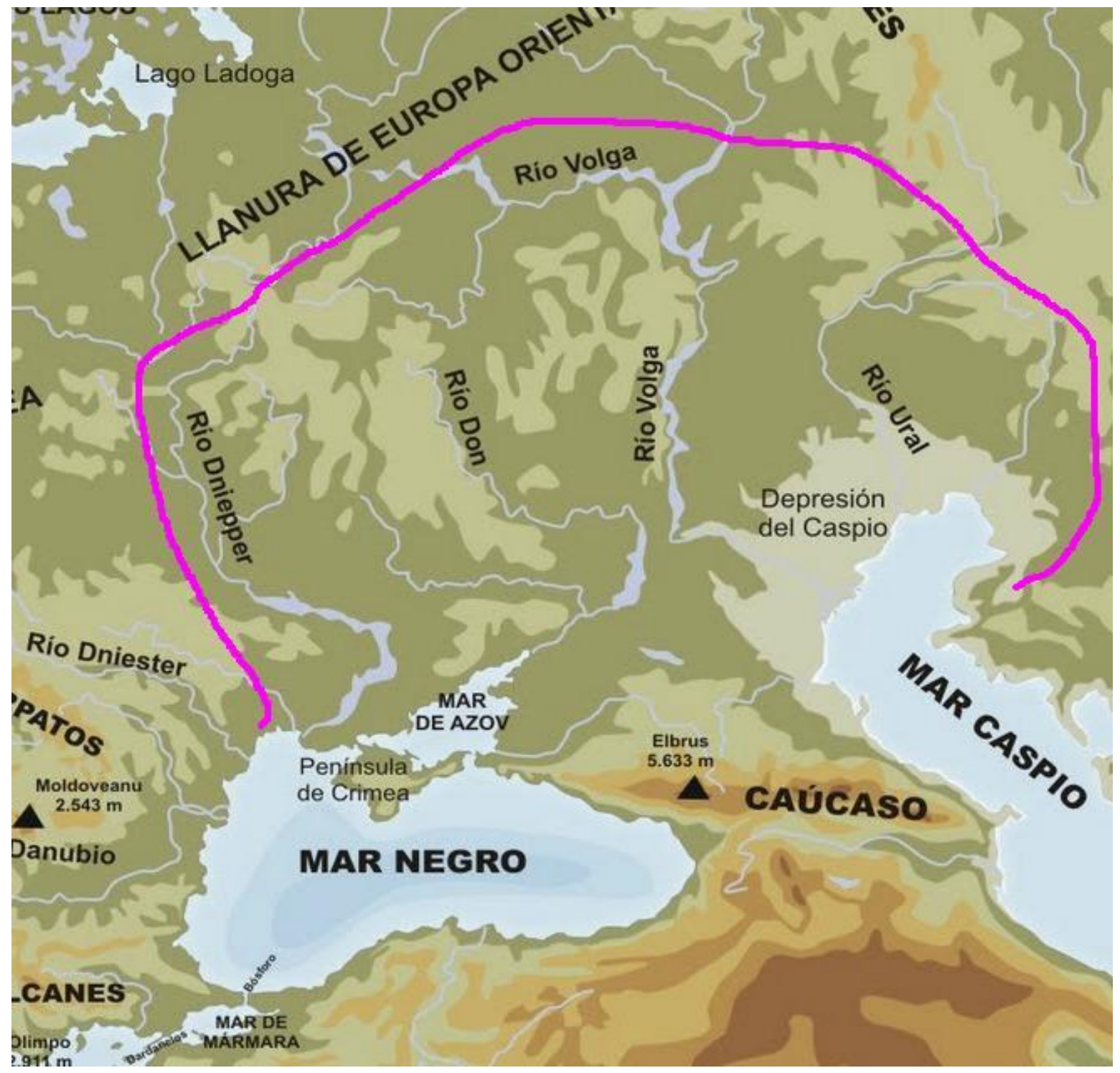

La línea rosa marca la frontera aproximada. Elaboración propia.

Una vez más, la convivencia dio origen a un pueblo que desempeñó un papel de suma importancia en la consolidación y expansión del Estado ruso que se puede caracterizar como una entidad multicultural en el marco de la cual tuvieron lugar procesos de interculturalidad. Los cosacos eran considerados hombres libres -en turco kazak 
significaba "hombre libre" 358 - que podían mudarse sin restricciones. Este privilegio, se debía a que vivían en la frontera sur entre Moscovia y el ducado de Lituania. Los cosacos no practicaban la agricultura sino que vivían de criar ganado, la caza, la pesca y el botín, así sus costumbres eran muy semejantes a las de los pueblos de la estepa. En este periodo la propiedad territorial era comunal y siguió siéndolo cuando, años más tarde, empezaron a practicar la agricultura. Una de sus ocupaciones principales era participar en la guerra como tropas mercenarias.

Los cosacos tenían una organización militar. De hecho, su jefe -aclamado por la misma comunidad en asamblea-, los dirigía en todas las batallas o escaramuzas en las que participaban. La asamblea de los cosacos también dirimía conflictos y sancionaba a los infractores de sus costumbres. Todos ellos eran cristianos ortodoxos. Como habitantes de la frontera no sujetos al poder de Moscovia, buscaban botín no sólo entre los pueblos agricultores sino también entre los cazadores víctimas más propicias porque éstos no tenían armas de fuego y además asaltaban a las caravanas de comerciantes. Por eso, muchos cosacos se aventuraron a adentrarse en el nordeste de Moscovia y fueron pioneros en explorarlo.

Existían tres comunidades de cosacos bien diferenciadas. Los cosacos del bajo Dniéper (zaporoyie) también llamados cosacos de Ucrania cuyo jefe recibía el nombre de hetman, los del Don ubicados en la rivera de dicho río -su jefe recibía el nombramiento de ataman-, y los cosacos del Volga que se extendían hasta el rio Ural. En el mapa 12 está señalado el territorio aproximado que ocupaban. Su ubicación cercana a los ríos los protegía de los asaltos de otros pueblos de la estepa. A partir del colapso del janato Kipchak

\footnotetext{
${ }^{358}$ Preobrazhensky, op. cit., pp. 281-282.
} 
y hasta mediados del siglo XVII los cosacos mantuvieron su autonomía, aunque desde el ascenso de Moscovia se alquilaban como tropas mercenarias al Estado ruso. Durante el gobierno de Iván IV los cosacos del Dniéper se aliaron al zar aunque el vínculo fue muy inestable. Los cosacos del Don también buscaron la protección del zar. Estas relaciones permitieron que el gobierno de Moscú también tuviera injerencia con los cosacos del Volga.

De estas comunidades salieron pequeños grupos de cosacos que juraban su lealtad al zar besando una cruz. Ellos se convirtieron en los "cosacos de servicio", abandonaban a su comunidad e iban a avecindarse en las fronteras moscovitas. Actuaban como milicias defensivas a cambio de parcelas para el cultivo en caso de que desearon transformarse en agricultores, pero podían dedicarse a otra actividad. En cualquier caso el gobierno ruso los abastecía de armas y municiones, de comida y vestido como forma de pago. Así fue como al nordeste llegaron muchos cosacos de servicio que desempeñaban la tarea de cobrar los impuestos a los habitantes de la región fueran nativos o de origen ruso y también constituían fuerzas militares fronterizas al servicio del zar ${ }^{359}$.

Desde 1576, el rey de Polonia quiso organizar a los cosacos como una milicia a su servicio a cambio de un salario y de abastecerlos de todo lo que necesitaran. Sin embargo los cosacos del oeste rechazaron tal ofrecimiento pues no quisieron que ningún gobierno interviniera en su territorio. En 1569 Polonia se anexó la parte occidental del territorio conocido como Ucrania. El pueblo plebeyo formado en su mayoría por los cosacos zaporoyie exigió formar parte de la asamblea polaca en la que sólo participaba la nobleza.

\footnotetext{
${ }^{359}$ Vernadsky, op. cit., pp. 85-86, 95-97, 105, 120-121, 124-128; Hellmann, op.cit., pp. 144- 145, 149; Forsyth, op.cit., p. 29; Blum, op. cit., p. 520; Longworth, op. cit., p. 78, 94-95; Summer, op. cit., pp. 44-45. En Tarás Bulba Nicolai Gogol describió la aparición de los cosacos como una manifestación del potencial del pueblo ruso en épocas de desasosiego. Nicolás Gogol (1809-1852), Tarás Bulba. Sin trad. [Barcelona], Ediciones Orbis, s.d. 128 pp., ils. (Las grandes novelas de aventuras, 48), pp.10-11.
} 
Su demanda fue ignorada y para agudizar el rechazo, los polacos iniciaron el reparto sistemático de las tierras de Ucrania a la nobleza y la sujeción de los cosacos a la servidumbre. En consecuencia, los cosacos pidieron la protección de la iglesia ortodoxa rusa, ya que tampoco querían convertirse al catolicismo. Es posible que la pérdida de su territorio indujera a muchos cosacos a dirigirse al norte de Asia buscando nuevas oportunidades antes que quedar sujetos a los señores. Al final de su gobierno, Iván IV arremetió en contra de los reinos de Polonia-Lituania y Suecia en la guerra de Livonia. Su derrota cerró las puertas del Báltico para Rusia durante todo el siglo XVII, la crisis económica que la guerra dejó, así como la minoría de edad del heredero de Iván IV, sumió al Estado moscovita en una guerra interna de la que emergió el imperio ruso.

\subsection{Incursiones allende los Urales y la conquista de janato de Sibir}

Ya que los mongoles no invadieron a las principalidades del norte de la Rus -Novgorod optó por reconocer su autoridad -los negocios comerciales continuaron desarrollándose tanto con La Hansa como en la frontera del noreste. Su papel como el centro comercial más importante de la Rus se mantuvo durante el periodo del dominio mongol. Gracias a la presencia de los mongoles, los novgorodianos apreciaron más la zona de Zavalochye o Yugra, como denominaron al territorio al oeste de los Montes Urales. 


\section{Mapa 13. EUROPA ORIENTAL EN EL SIGLO XV.}

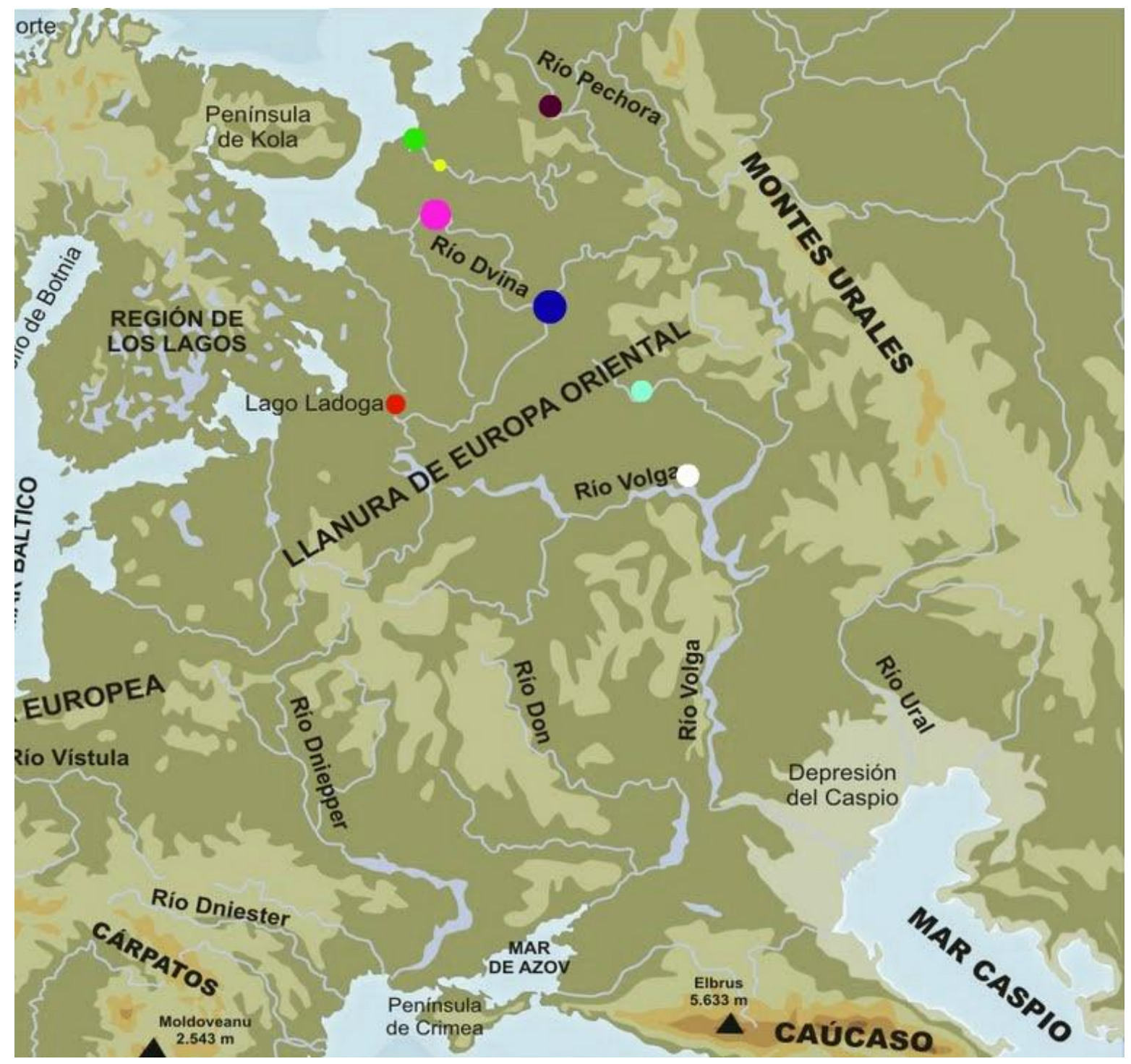

Rosa-Jolgomory, azul-Ustyug, rojo-Vologda, amarillo-Lampoynia, verde-Mezen, turquesaViatka, blanco-Kazan y guinda-Pustozersk. Elaboración propia

En efecto, el norte de Asia, al menos hasta la zona de la taiga, fue conquistado por los mongoles en dirección este-oeste. Ellos pidieron yasak en pieles de reno y caballos a los habitantes de la región. Pronto también solicitaron como tributo las pieles finas. Las pieles de ardilla primero y más tarde las de marta cibelina, castor y zorro plateado se incorporaron como mercancías suntuarias. Al parecer, el intercambio de estos bienes por artículos 
provenientes del sur como armas de metal y artesanías propiciaron que los pueblos de la taiga dejaran de elaborar muchas de sus manufacturas e incluso abandonaran la incipiente agricultura que practicaban para satisfacer la demanda de pieles finas, de cueros de reno y caballos que solicitaban los mongoles.

Cuando Gengis Jan repartió su imperio, los territorios aledaños a los Urales se integraron al ulus de Jochi, es decir estuvieron bajo el dominio del janato Kipchak. Por su parte, el principado de Novgorod continuó beneficiándose de las pieles y la sal que podían conseguirse más allá de los Urales ${ }^{360}$.

Los productos que los mercaderes novgorodianos llevaban desde Yugra eran muy valiosos, por ello en 1322 los pueblos de Ustyug, los péchora y los yugra ${ }^{361}$, resentidos con ellos porque los obtenían como tributo, los asaltaron y les quitaron toda la mercancía que transportaban. Tal afrenta motivó al año siguiente una expedición punitiva y fueron obligados a firmar un tratado de paz en "los viejos términos" es decir, de sujeción a Novgorod. De cualquier manera los habitantes del noreste al oeste de los Urales atacaban con frecuencia a los novgorodianos pues no aceptaban con agrado su dominio ${ }^{362}$.

Los príncipes de Moscovia comprendieron la importancia del tráfico de pieles en la economía de Novgorod, así que intentaron beneficiarse de él. Iván I Kalita enviaba cada año por mar a una partida de cazadores a la desembocadura del río Péchora con la intención de que los novgorodianos le reconocieran derechos sobre la zona. En 1366, el Gran Príncipe Dmitri Ivanovich amenazó con atacar Novogord porque, según él, sus mercaderes

\footnotetext{
${ }^{360}$ Igor V. Naumov [Actualmente profesor de la Universidad Técnica Estatal de Irkutks], David N. Collins (ed.), The History of Siberia. Londres y Nueva York, Routledge, Taylor and Francis Group, 2006. 242 pp., ils. y mapas, pp. 44-46.

${ }^{361}$ Estos pueblos eran comunidades jantys y mansis que se describirán líneas abajo.

362 The Chronicle..., trad. Michell, op. cit., p. 123, 125; Riasanovsky, op. cit., p.84-87.
} 
habían sido capturados en el Volga, los novgorodianos se vieron obligados a firmar un tratado de paz y a resarcirlo con 8000 rublos $^{363}$. Es probable que tal tratado haya implicado la participación de los moscovitas en la red de intercambio de Novgorod con Yugra y La Hansa.

Cuando Vasili I heredó el ducado de Moscovia, los novgorodianos ratificaron la paz. Sin embargo, en 1393 el Gran Duque atacó Novgorod y se apoderó de algunos distritos del norte, los habitantes de Novgorod pidieron la paz. No satisfecho con lo obtenido, en 1397, Vasili I envió a sus hombres a proponerles a los jefes de los poblados de la cuenca del Dvina que prestaran juramento al Gran Duque de Moscovia a cambio de su protección en contra de Novgorod. Los jefes aceptaron así que los novgorodianos enviaron una embajada ante Vasili I exhortándolo a respetar su territorio. Como Vasili I no les regresó sus tierras, atacaron la región de Beloozero a fin de recuperar sus territorios en la cuenca del Dvina y lo consiguieron. Castigaron con dureza a los pueblos de Yugra y cobraron 300 rublos a cada uno de los mercaderes moscovitas, el Gran Duque tuvo que firmar la paz y congraciarse con los novgorodianos. Vasili I volvió a atacar los territorios de la cuenca del Dvina en 1401, pero se conformó con saquearlos. En 1425, una vez más los pueblos de Ustyug se rebelaron en contra de Novgorod ${ }^{364}$.

Lo anterior, constata las intenciones moscovitas de participar en el comercio de pieles finas como se habían evidenciado desde el siglo XIV pero la empresa no fue sencilla. Por lo pronto, gracias a los esfuerzos de Esteban Jarp santificado como Esteban de Perm, las comunidades komi habían recibido el bautismo. Gracias a la conquista geoestratégica de

\footnotetext{
${ }^{363}$ The Chronicle..., trad. Michell, op. cit., pp. 150-151, 161, 169-173; Lydia T. Black (1925-2007), Russians in Alaska 1732-1867. Fairbanks, Alaska, University of Alaska Press, 2004. 328 pp., ils., y mapas, p. 15. ${ }^{364}$ The Chronicle..., trad. Michell, op. cit., pp. 165-166, 175, 192; Ostrosky, op. cit., pp.XII-XIII.
} 
Novgorod por Iván III el Grande por fin pudieron apoderarse de este tráfico. Según la Crónica de Novgorod, los habitantes de la cuenca del Dvina, es decir los komi, se sumaron a la causa de Iván III en contra de la ciudad. Iván III empleó como estrategia primero entrar en contacto con los pueblos de Yugra, que no pudo someter, y dirigirse después a la ribera de Dvina para atacar al último el centro de la principalidad de Novgorod. Más tarde, Iván IV confiscó extensos territorios en Novgorod pero esta política fue inaugurada por Iván III quien obligó a algunas familias poderosas de la región a emigrar a Moscovia y las reemplazó con gente moscovita ${ }^{365}$.

Al parecer los llamados campesinos negros, que recibían el adjetivo porque desmontaban tierras negras (chernozem) de la taiga, que se mudaron a la costa del Mar Blanco adquirieron un nivel de vida desahogado porque complementaban la agricultura con la pesca, la caza, la explotación del bosque y el mar, la fabricación de manufacturas y hasta el comercio local. Hacían cuantiosas donaciones a los monasterios de la región a cambio de que rezaran por la salvación de sus almas o bien por caridad. Las familias vivían en casas que tenían graneros y pequeñas porciones de tierra. Por lo común, a la familia nuclear se añadían los abuelos y los hermanos solteros. Los habitantes se congregaban en aldeas pequeñas. Gran parte de estas familias no hablaban ruso o bien porque sus ancestros no lo hablaban pues descendían de la población local komi que había quedado bajo el dominio de los rusos o se habían integrado a las aldeas fundadas por ellos o porque lo inmigrantes lo habían ido perdiendo al convivir con los pueblos que habitaban ahí.

\footnotetext{
${ }^{365}$ The Chronicle..., trad. Michell, op. cit., pp. 218-219, este fragmento implicaría que los habitantes de la región ya estaban parcialmente cristianizados, para ese momento había algunos monasterios pero lo más seguro es que los cristianos ortodoxos fueran los inmigrantes más que los pueblos originarios pues los únicos bautizados eran los komi, lo que no implica que hubieran abandonado sus creencias previas. Fisher, op. cit., pp. 9-10; Forsyth, op. cit., pp. 5, 50.
} 
Cuando estas comunidades quedaron sujetas al Estado en la época de Iván III empezaron a pagar tributo y si, para su desgracia, quedaron adjudicadas a algún monasterio entonces su buena fortuna se vio seriamente disminuida pues también debieron pagar las cargas a los monjes. Era probable que en poco tiempo las tierras en las que sus antepasados habían obtenido su riqueza pasaran a formar parte del monasterio y tarde o temprano los residentes se convirtieran en sus trabajadores. Los funcionarios que recaudaban los impuestos les llamaban karelian porque hablaban básicamente idiomas del tronco lingüístico finés salpicado de ruso en un territorio llamado Carelia al noreste del Lago Ladoga. Los monjes intentaban evangelizarlos aunque no visitaban las aldeas con regularidad pero casi todos recibían el bautismo, aprendían oraciones y tenían una sepultura cristiana. Esta gente navegaba en las costas del Mar Blanco y también en los ríos que desembocaban en él, su experiencia y trabajo fueron fundamentales para que años más tarde se abriera el comercio de Moscovia con Europa central y occidental trajinando por las gélidas aguas de los mares de Barents y Noruego ${ }^{366}$.

En el siglo XV existían algunas ciudades pequeñas que habían crecido al amparo del intercambio y el pago de tributo a Novgorod. En el mapa 13 se puede visualizar su ubicación aproximada. Jolmogory (en rosa) se localizaba en el norte del rio Dvina, Ustyug (en azul) en donde se unen los ríos Iug y Sujona, ambos afluentes del Dvina, era el centro en el que se reunía la mayor cantidad de pieles del noreste europeo. Al oeste de Ustyug sobre el río Sujona se encontraba Vologda (en rojo). En las cercanías del rio Mezen, localizado entre los grandes ríos Dvina y Péchora se fundaron Lampoynia (en amarillo) y

\footnotetext{
366 Esta breve descripción de la integración de los habitantes del noreste de la tundra europea al Estado moscovita es una recreación elaborada por Jennifer B. Spock con base en los documentos del monasterio de Solovki. Jenifer B. Spock [PhD 1999], “The Parfiev Family Northern Free Peasants” en Ostrowski, op. cit., pp.233-242.
} 
Mezen (en verde). En la primera se realizaban dos ferias al año en la que se reunían tártaros, rusos y pueblos samoyedos ${ }^{367}$. Al sur, en la estepa, se encontraban las ciudades de Viatka (en azul turquesa) a donde llegaban pieles provenientes de la costa del Mar Blanco que los tártaros llevaban. Después Kazan (en blanco) se incorporó como otro centro importante para intercambiar pieles por manufacturas. Para apoyar el tráfico de pieles se fundó Pustozersk (en guinda) en el río Péchora ${ }^{368}$.

En suma, la principalidad de Nogvorod sentó las bases para la expansión rusa sobre el norte de Asia pues había incursionado en la taiga y la tundra de Europa; para entrar a la parte asiática tan sólo había que cruzar los montes Urales. Pero los príncipes de Moscovia no contaban con los recursos financieros ni humanos para promover la exploración y el avance sobre el noreste. Tal vez por ello no obstaculizaron a los emprendedores que habían extendido sus dominios más allá de los Urales y les permitieron llegar tan al este como pudieron tanto por tierra como por mar, siempre que reconocieran su soberanía sobre ellos.

La incorporación del noreste de Europa al Estado moscovita implicó cambios importantes en el tráfico de pieles. En primera instancia éste aumentó, por eso los rusos avanzaron hacia la zona del Mezen y el Péchora. Las rutas para comunicar el este con el oeste se ampliaron, ahora también llegaron hasta Moscú. Había una ruta que corría por la cuenca del Dvina y sus afluentes que conectaba con el Volga, a ella se unió el río Mezen. La otra ruta implicaba navegar por el Mar Blanco desde la desembocadura del Dvina hasta el Péchora. Se tocaban los centros de intercambio ya mencionados. Asimismo, Moscú se

\footnotetext{
${ }^{367}$ Los rusos llamaban samoyedos a pueblos diferentes con idiomas semejantes que pertenecen al tronco urálico: enets, nenets, dolgan, nganasan, selkup y kama, ya desaparecido. Los samoyedos se localizan en la tundra desde la costa del Mar Blanco hasta la península de Tamir. Todos ellos son criadores de reno, pescadores y cazadores. Vid., http://www.es.wikipedia.org/wiki/Lenguas samoyedas consultado 5 de mayo de 2014, Fisher, op. cit., pp. 11-12; Naumov, op. cit., p. 48.

${ }^{368}$ Fisher, op. cit., p. 12.
} 
desarrolló como exportador de pieles finas mientras Novgorod se fue a pique. Gran parte de las pieles se obtenían porque los propios rusos atrapaban o cazaban a las presas o porque mantenían relaciones de intercambio con los nativos. A ello se añadió el pago de tributo que impuso el Príncipe de Moscovia. Así los mercaderes del oeste: polacos, lituanos, del sacro imperio romano y de la península itálica llegaron a Moscú. Este florecimiento en el tráfico de pieles obtenidas en el extremo nororiental de Europa pronto generó la necesidad de avanzar al este atravesando los Urales ${ }^{369}$.

Una de las familias más importantes al este de los Urales era la de los Stroganov avecindada en Perm, región que tuvieron bajo su custodia durante 20 años. Su patriarca Anika Fiodorovich Stroganov (1498-1570) tenía una votchina muy extensa en donde extraía sal, hierro, plata y tal vez pieles. Desde 1560, los Stroganov enviaron avanzadas al este de los Urales buscando minerales y sal y aprovecharon para recolectar pieles que enviaban a Moscú. Como las ganancias para el zar fueron importantes, en 1574 Iván IV les concedió el privilegio de colonizar al este de los Urales. La familia fundó algunos poblados fortificados y para 1622 había alrededor de 23000 colonos en esas tierras ${ }^{370}$. Por tanto, no fue casual que promovieran la destrucción de janato de Sibir que ya resultaba limitante para sus operaciones pues los asaltos de los tártaros a sus tierras le provocaban pérdidas.

El janato de Sibir fue fundado en algún momento entre 1405 y 1428 como consecuencia del debilitamiento del janato Kipchak, su capital era Chimgi-Tura y sus habitantes eran musulmanes. Estos tártaros tenían bajo su dominio a los samoyedos la mayoría de los cuales estaban organizados en familias extensas y vivían en aldeas pequeñas

\footnotetext{
${ }^{369}$ Fisher, op. cit., pp. 12-16, 24.

${ }^{370}$ Geoffrey Parker, Europa en crisis 1598 -1648. Trad. Alberto Jiménez. 2a ed. en esp. [España], Siglo XXI, 1981. 466 pp., cuads., mapa, (Historia de Europa Siglo XXI), p. 125; Al parecer muchos de estos trabajadores eran komis, Forsyth, op. cit., p. 29.
} 
dedicadas a la cacería y a la pesca. Estos pueblos pagaban tributo en pieles finas a los janes de Sibir. Cuando Iván IV tomó Kazan, el jan de Sibir envió embajadores para reconocerse como pueblo tributario del zar pero en 1573 el nuevo jan decidió no pagar más tributo. De ahí que la petición de los Stroganov al zar para destruir al janato de Sibir, prosperara ${ }^{371}$. Semion Anikeyevich Stroganov (i-1609) contrató al cosaco Yermak Timofievich (1532/1542-1584) -quien tenía la distinción de ataman y pertenecía a los cosacos del Donpara que incursionara al este de los Urales y conquistara el janato de Sibir. Yermak y sus hombres lograron tomar la capital de Sibir en 1581, el cosaco le envió ricos presentes al zar quien se mostró complacido. Pero una cosa era tomar la capital y otra someter a los tártaros, así que el territorio estaba lejos de la paz. El zar decidió enviar una fuerza militar para que apoyara la conquista pero como el cosaco murió emboscado por los tártaros, los Stroganov aceptaron la ayuda al zar para acabar por completo con la resistencia de los janes de Sibir y con ello perdieron sus privilegios exclusivos ${ }^{372}$.

Los rusos lograron someter a los nganasan, los enets y los nenents - de la familia lingüística urálica- y con ellos empezaron a interactuar los rusos y cosacos. Con base en el derecho de conquista, les exigieron el pago de yasak; de hecho, con la conquista, estos pueblos llamados samoyedos sólo cambiaron de conquistador al que pagaron el yasak. Cuando Iván IV murió, los rusos no habían logrado aniquilar la resistencia de los tártaros pero ya se beneficiaban de la riqueza de su territorio. A partir del sometimiento del janato de Sibir, el noreste quedó abierto a todos los que quisieran aventurarse pues el Estado los

\footnotetext{
${ }^{371}$ http://en.wikipedia.org/wiki/Khanate_of_Sibir consultado 14 de diciembre de 2012; Naumov, op. cit., pp. 46-47; van Dulmen, op. cit., p. 81. Sibir fue la traducción que los rusos hicieron del nombre de un pueblo transurálico. La raíz de esta palabra significa difícil, trabajoso, que hace daño vid. Preobrazensky, op. cit., pp.282-283. Por extensión, los rusos llamaron al norte de Asia Siberia con el que se conoce comúnmente.

372 Kotkin, op. cit., pp. 8-9; Hambly, op. cit., p. 126; Summer, op. cit., p. 27; Riasanovsky, op. cit., pp. 152153; Fisher, op. cit., pp. 23-27; Naumov, op. cit., pp. 55- 59.
} 
respaldaba. Al igual que el resto de los samoyedos, los pueblos sometidos estaban organizados en tribus y los miembros de los clanes que las integraban no se casaban entre sí. No tenían liderazgos permanentes, tan solo había jefes cuando guerreaban contra otro pueblo. El único personaje que se distinguía del resto era el chaman pero sin que tuviera privilegios especiales. Se dedicaban a la pesca y la caza de mamíferos marinos. Asimismo eran criadores de reno cuya piel les servía para vestirse. Vivían en tiendas cónicas que cubrían con pieles de reno. Se ayudaban de los perros samoyedos para cuidar el ganado. Tenían lugares sagrados donde colocaban representaciones de sus dioses y enterraban a sus muertos en cajas de madera ${ }^{373}$.

Al sur, en la taiga se encontraban pueblos de habla ugro-finesa, los jantys y los mansis, llamados por los rusos voglus y ostiaks respectivamente. Estaban organizados en clanes agrupados en dos grandes linajes. Eran seminómadas que vivían de la pesca y la caza, aunque algunas comunidades al norte aprendieron de los samoyedos a criar renos y en el sur algunos grupos mansis cultivaban cebada y criaban reses y caballos. Pero la gran mayoría, tal vez sumaban alrededor de 16000 personas antes de la llegada de los rusos, comían pescado y carne que ahumaban o salaban. Consumían también la grasa de los animales algunos la comían cruda otros la guisaban pero todos tomaban la sangre fresca. Los cueros les servían de vestido y, a veces, utilizaban el cáñamo, asimismo se tatuaban. Tenían un religión animista y por ello reverenciaban a la naturaleza, de hecho tenían tótems para identificar a sus clanes. El animal más venerado era el oso pardo, si llegaban a cazarlo realizaban un rito muy especial. Enterraban a los muertos y si eran cazadores les ponían sus armas. Además hacían composiciones poéticas y tenían instrumentos musicales. Al parecer,

\footnotetext{
${ }^{373}$ Forsyth, op. cit., pp. 18-19; M. A. Czaplicka, Samanism, ceremonii si ritualuri arhaice. Traducere bin
} limba engñleza Marilena Constantinescu. Bucaresti, Editura Herald, [2014]. 256 pp., ils. 
los jantys reconocían su territorio con base en los lugares sagrados en donde realizaban sus ritos casi todos ellos vinculados con sus prácticas de sobrevivencia ${ }^{374}$. Tanto los jantys como los mansis abandonaron al jan de Sibir y ofrecieron sus servicio a los rusos. Se les impuso el pago de $y a s a k^{375}$ y fueron incorporados a las huestes rusas como "tártaros de servicio", de manera que contribuyeron a someter a otros pueblos del norte de Asia ${ }^{376}$. Por lo común, las comunidades que colaboraban con los rusos se asumían como aliados. Ése fue el caso de los komis, de los jantys, situación que se repitió durante el proceso de conquista del norte de Asia.

La población nativa no era muy numerosa y estaba dispersa, los rusos eran una minoría que se establecía en pequeños poblados (zimov' $\left.e^{377}\right)$ en donde se reunía el producto del tributo así como lo que obtenían los propios cazadores rusos, que no era un monto pequeño. Ya que había pocos militares, una parte de las pieles finas que los rusos obtenían de los samoyedos las conseguían por medio del intercambio comercial o de intercambio de regalos, pero cuando podían recurrían al pillaje. Ni los exploradores ni los administradores nombrados por el zar tenían escrúpulos para abusar de los pueblos de Siberia $^{378}$.

No está por demás señalar que a finales del siglo XV el territorio de Rusia alcanzaba el mar Ártico por el norte, llegaba al río Seim al sur y desde el golfo de Finlandia al oeste hasta el río Ob al este, atravesando por los montes Urales; en esta expansión habían

\footnotetext{
${ }^{374}$ Gail Fondahl reseña del libro de Peter Jordan, "Material Culture and Sacred Landscape: The Anthropology of the Siberia Khanty" en Slavic Review, vol. 64, no. 1, primavera de 2005, pp. 217-218 en http://www.jstor.org/stable/3650115 consultado 2 de noviembre de 2012.

${ }^{375}$ Yasak significaba ya en ese momento "lo que entrega un pueblo no ruso" vid. Preobrazhnensky, op. cit., p. 140, en el contexto de la expansión en Siberia significaba el tributo que los pueblos no rusos integrados al imperio entregaban al zar. Forsyth, op.cit., p.33; Hellmann, op. cit., p. 128.

${ }^{376}$ Forsyth, op. cit., pp.11-15; Kotkin, op. cit., pp. 9-10; Naumov, op. cit., p.48; en el imperio español a los pueblos del septentrión que colaboraban con los conquistdores se les llamaba "indios auxiliaries" o "indios amigos".

${ }^{377}$ Esta palabra designa el campamento para pasar el invierno, no era un puesto militar.

${ }^{378}$ Forsyth, op. cit., pp. 33-35.
} 
participado los comerciantes, los cazadores $^{379}$, los campesinos -libres o del Estado- y el Estado pues en el norte y en el este no había grandes terratenientes ni nobleza de servicio, los boyardos de abolengo no recibieron donaciones ahí.

Es necesario subrayar la importancia de la navegación por los ríos que permitía salir al Mar Ártico y llegar al puerto de Arcángel, localizado en la costa europea. En 1533, comerciantes ingleses, comandados por Richard Chancellor (1521-1556), buscando un paso por el norte en dirección a América, aparecieron en las costas del Mar Blanco ${ }^{380}$. La dificultad para continuar con la navegación y la buena disposición de los rusos para comerciar dio lugar a la fundación de la Compañía Moscovita (Muscovy Trading Company) en Londres en 1555. Ésta fue la primera sociedad anónima creada en Inglaterra y sentó el precedente para que más tarde su fundaran otras compañías por acciones. Ante la oportunidad que se presentaba, Iván IV envió en 1556 mercaderes con productos rusos para establecer un intercambio permanente con aquel reino, la Compañía Moscovita detentó el monopolio comercial inglés con Rusia pero Iván IV no les concedió el monopolio del comercio ruso con Europa occidental. Este comercio dio lugar a que en 1584 fuese fundado el puerto de Arcángel. Éste, a su vez, fue el punto de partida de comerciantes y cazadores para delinear la ruta comercial hacia el este, misma que facilitaba trasladar las pieles y otros productos como el marfil, el aceite de ballena, la cera y la resina, madera, lino y cáñamo

\footnotetext{
${ }^{379}$ Los comerciantes y cazadores fueron llamados promyshlennik. En ruso promyshlennik es un sustantivo que significa industrial. En el contexto del proceso de expansión en Siberia, promyshlennik se refiere a aquel que organizaba a las partidas de cazadores y conseguía o aportaba el capital inicial para una expedición. Ahora bien, el sustantivo promysel de donde deriva la primera palabra, significa oficio, ocupación o industria. Los promyshlenniki, en plural, en Siberia se dedicaba a la industria del tráfico de pieles que implica desde preparar a las partidas de cazadores, fueran de nativos o rusos, hasta introducir las pieles en los mercados de Europa y Asia vid. Nogueira, op. cit., p. 612; Slovar' ispansko-russkii russko-ispanskii. Dopushcheno Ministerstvom Obrazovaniya Ukrainy kak posobie dliya obshcheobrazobatel'nij shkol i vysshij uchebnyj zavedenii. Kiiv, Irpin', 1996. 536 pp., p. 461

${ }^{380}$ Dukes, op. cit., p. 61.
} 
para venderlos a los ingleses. También se comerciaban mercancías provenientes de la Rusia europea como carne salada y cereales y algunas mercancías asiáticas, chinas y persas principalmente. La Compañía Moscovita vendía tejidos de lana, algunos de ellos incluso llegaron a Persia. El comercio con los ingleses favoreció el aumento del tráfico de pieles en la región de Mangazeia, localizada al este de la parte norte del río Ob a la que los rusos acababan de llegar (véase el mapa 14). Al parecer la demanda de pieles finas en Europa se disparó en el siglo XVI. En ese siglo las pieles eran adquiridas no sólo por la nobleza, sino también por los ricos mercaderes y a veces no tan ricos ${ }^{381}$. Las pieles de marta cibelina, castor y zorro se convirtieron también en Europa occidental en un símbolo de status social y económico.

Algunos de estos productos también se destinaban al consumo local como el aceite de ballena, el marfil y los tendones de morsa que se usaban en lugar de cuerdas pues en la tundra no hay material para hacerlas, en fin, bienes que necesitaban para sobrevivir en la región. De manera que los comerciantes-cazadores promyshlenniki impulsaron la exploración de los ríos, todos ellos navegables, remontando hasta la desembocadura de los mismos, las mercancías podrían trasladarse por el Mar Ártico hasta Arcángel y de ahí a Europa occidental. La red comercial y de comunicación que se creó en la costa de la tundra asiática fue fundamentalmente fluvial pero estaba estrechamente ligada a los caminos terrestres. Los primeros rusos que crearon una tradición en los métodos de navegación por la costa se establecieron en la isla Novaia Zemlia, (véase el mapa14), y fueron conocidos

\footnotetext{
${ }^{381}$ Hellman, op.cit., pp. 140, 144-145; Cameron, op. cit., pp. 41, 60 y 67. En este periodo todavía el comercio exterior estaba en manos de extranjeros. Primero los jázaros, búlgaros y varegos lo monopolizaron, después las ciudades rusas dependieron de los transportes de la Hansa y para el siglo XVI los ingleses controlaban la ruta comercial y los barcos que la transitaban por el Mar Blanco; http://www.es.wikipedia.org/wiki/Compañía de Moscovia consultada 13 de enero de 2013; Vernadsky, op.cit., p.85-86; Summer, op. cit., p.24; Willets, op. cit., p. 408; Riasanovsky, op. cit., p. 148; Blum, op. cit., p.128; Fisher, op. cit., p. 17-23.
} 
como pomor'ie porque transitaban por las costas del mar Ártico hasta la desembocadura del río Yenisey ${ }^{382}$. Sus métodos fueron fundamentales en la expansión por el norte de Asia. Estos rusos de inmediato adoptaron aquellas costumbres y artefactos que los nativos de la región utilizaban para cazar, pescar y navegar; los productos que obtenían eran colmillos de morsa y pieles de marta cibelina. El intercambio y la síntesis cultural que dio origen a los pomor'ie fue resultado del mestizaje entre los eslavos que llegaron del suroeste y los pueblos de habla ugro-finesa y urálica ${ }^{383}$. Es decir, la interculturalidad que tuvo lugar entre los pueblos que se encontraron en la tundra europea y en el noroccidente de Asia dio origen a los "rusos" pomor'ie quienes también participaron en la expansión sobre Siberia. En el mapa 14 están señalados los pueblos asiáticos con quienes los rusos y cosacos se fueron encontrando en su expansión en el norte de Asia y con las cuales se mezclaron.

\footnotetext{
382 Pomor'ie es la palabra que designa a la costa norte de Rusia. Nogueira, op.cit., p.557

${ }^{383}$ Black, op. cit., pp. 3-5; Kalistov, op.cit., p.80.
} 


\section{Mapa 14. PUEBLOS NATIVOS DE SIBERIA CLASIFICADOS CON BASE EN EL TRONCO LINGÜÍSTICO}

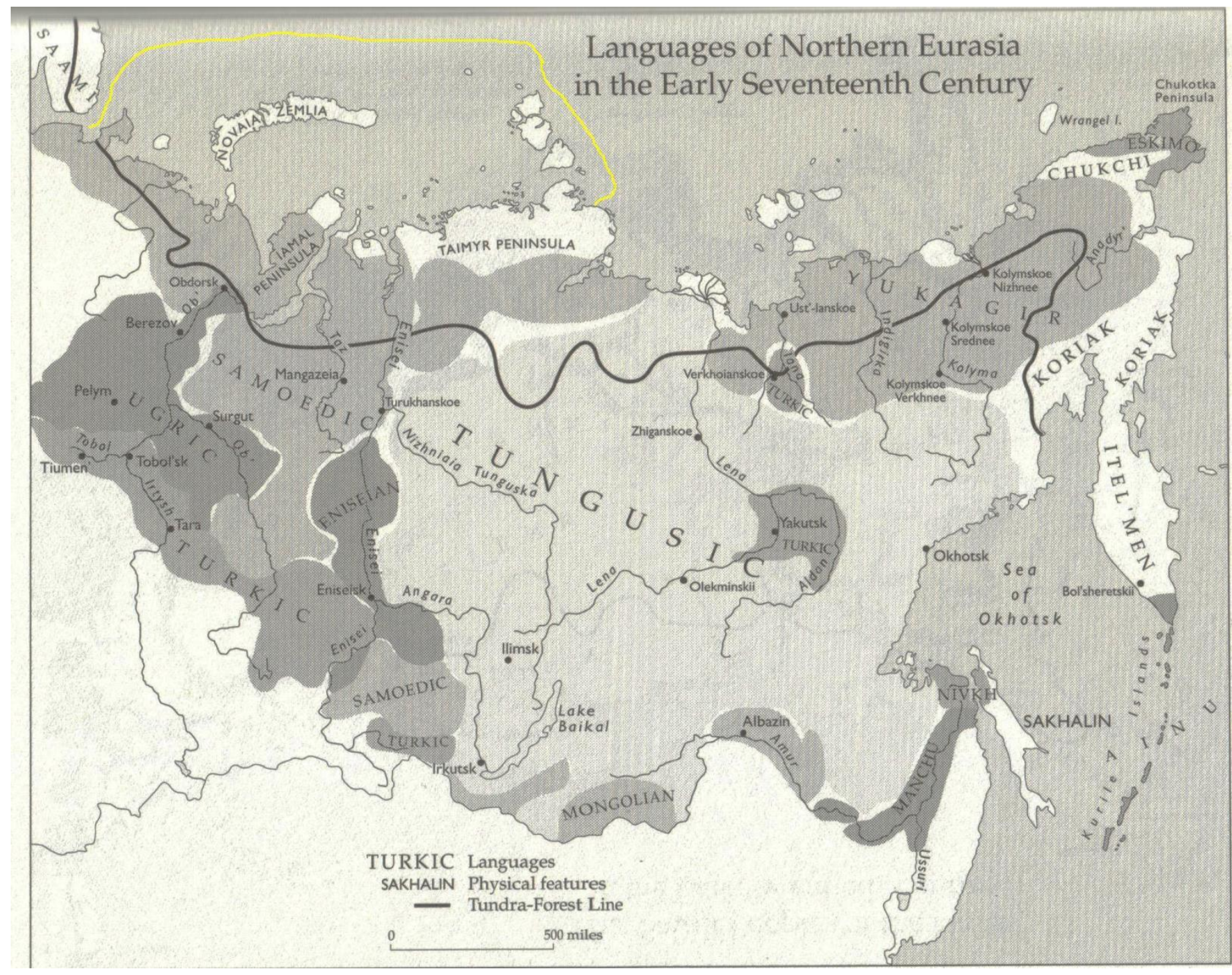

Fuente: Sleznike, op. cit., p. XV, la línea amarilla marca el territorio aproximado de los promor'ie

El territorio del noreste proporcionó una cantidad enorme de presas, principalmente de martas cibelinas. Aquí los rusos encontraron muchos otros recursos naturales como las minas de sal, hierro, oro y plata. Los Stroganov hicieron su fortuna gracias a la explotación de salinas y también invirtieron en el tráfico de pieles finas que introdujeron en el mercado inglés exportándolas por el puerto de Arcángel, eran pues gosti. Esta familia de 
emprendedores fue el prototipo de los pomyshlennik, pero tenían una base agrícola, casi la mitad de las tierras que poseían las dedicaba a la producción para su propio consumo y comercialización, no tenían campesinos sujetos a pago de rentas señoriales ${ }^{384}$.

El Estado ruso no delineó ningún proyecto específico para la colonización del noreste, por tal razón las instancias para gobernar esas tierras fueron conformándose sobre la marcha. Sin embargo, el Estado apoyó el avance de los promyshlenniki enviando tropas y administradores en virtud de que los pueblos sometidos le pagaban el yasak, los cazadores, comerciantes y campesinos también pagaban impuestos y al mismo tiempo se ampliaba sus dominios. En primer lugar, se fundaron $\operatorname{los}$ ostrogi $^{385}$ que eran pequeñas guarniciones militares en donde se almacenaba el yasak para enviarlo después a Moscú. Se designó un voyevoda, encargado de la administración de la nueva provincia que se creó más allá de los Urales y que también desempeñaba funciones militares. Asimismo fue nombrado un recolector de impuestos quien cobraba su salario de lo mismo que recaudaba, el resto lo enviaba a Moscú. En este periodo la oficina que atendía las cuestiones de Siberia era la de Asuntos Extranjeros (Posol'skii prikaz), lo que muestra que todavía el gobierno moscovita no lo concebía como su territorio ${ }^{386}$.

La ocupación permanente del territorio fue posible porque los eslavos introdujeron una economía que combinaba la explotación del bosque con la agricultura de quema y roza

\footnotetext{
${ }^{384}$ Blum, op. cit., p. 209; Hellmann, op.cit., p. 158; Kalistov, op.cit., p. 80; vid. supra al inicio de este apartado.

${ }^{385}$ En singular ostrog. Estos puestos militares, pequeños fuertes, similares a los presidios de la frontera del virreinato de la Nueva España, funcionaron durante los siglos XVI Y XVII. Actualmente esta palabra se utiliza para nombrar a las prisiones o presidios, igual que como ocurrió en el caso español. Preobrazhensky, op. cit., p.666; http://www.es.wikipedia.org/wiki/Ostrog 16 de febrero de 2014. Es importante llamar la atención sobre el hecho de que tanto el imperio español como el ruso en procesos de expansión territorial en direcciones opuestas durante el siglo XVI hayan utilizado instituciones similares para controlar los espacios que iban incorporando, vid. Clark, op. cit., p.142

${ }^{386}$ Blum, op. cit., p. 143; Black, op. cit., p. 6.
} 
que habían desarrollado a lo largo de su historia ${ }^{387}$. Tras los cazadores y comerciantes de pieles y de otros productos del bosque, se avecindaban los campesinos quienes se desempeñaban como líneas de abastecimiento para las avanzadas de los primeros. Así la población local o bien se mudaba al este o bien se mezclaba con los inmigrantes dando lugar al mestizaje étnico y cultural. Por otra parte, la llegada de los rusos a esta región también fue producto de la política reformista de Iván IV quien sometió a la población a una exacción tal que ésta prefirió huir a la frontera del noreste. Se calcula que la mayor parte de las tierras laborables del centro del territorio unificado por Moscovia quedaron desocupadas $^{388}$.

Así el territorio más allá de los Urales fue visto por los rusos como un lugar al que podían emigrar para explotarlo en su propio beneficio ${ }^{389}$. Es importante considerar que las etnias con quienes los rusos debieron convivir mostraron resistencia. En ocasiones atacaban a los recién llegados pero también huían de ellos o desplegaban estrategias para no entregar el tributo ${ }^{390}$. La rápida expansión sobre la taiga y la tundra asiáticas -en 1581 pasaron los Urales y en 1644 ya habían alcanzado la región del río Amur- convirtió a Rusia en el Estado más extenso del periodo. Además, la conquista del territorio oriental le dio al Estado su condición de imperio tanto por el sometimiento de nuevos pueblos al poder del zar como por la gran cantidad de riqueza que este territorio le aportó ${ }^{391}$.

\footnotetext{
${ }^{387}$ Summer, op. cit., p. 19.

${ }^{388}$ Hellmann, op. cit., pp. 138-139; Blum, op. cit., p. 152.

${ }^{389}$ Kotkin, op. cit., p.1.

${ }^{390}$ Hay autores que consideran que para el Estado moscovita y más tarde para el imperio, avanzar la frontera hacia el este no presentó dificultades ni preocupaciones. Si bien no implicó tanta inversión militar como la del oeste o la del sur no se debe subestimar a los pueblos que habitaban en norte de Asia y considerar que someterlos no representó dificultades. Vid. Henry Willets, "Los países eslavos. Polonia y la evolución de Rusia” en Tablot Rice, op. cit., p. 406.

391 Van Dulmen, op. cit., p. 81.
} 


\section{CAPÍTULO V. LA INSTAURACIÓN DE LA DINASTÍA ROMANOV (1584-1676)}

\subsection{La época de las tribulaciones}

\subsubsection{Crisis dinástica}

Iván Grozny, coronado zar de Rusia, murió dejando como heredero a su hijo Fiodor I (1584-1598) un hombre enfermizo y poco interesado en el ejercicio del poder. Boris Godunov (c. 1551-1605) quien fue un boyardo cercano a Iván, ocupó la regencia. Godunov supo realizar su tarea adecuadamente. En 1587, emitió el ukaz que prohibió definitivamente a los campesinos cambiar de señor, ratificando así las medidas decretadas por Iván IV. Además fomentó la educación de las elites pues contrató maestros de Europa central y occidental al mismo tiempo que permitió salir a los jóvenes para estudiar en el extranjero. Para congraciarse con la rancia nobleza, cerró el acceso de las capas bajas de la sociedad a la nobleza de servicio. Abolió los privilegios fiscales para los acreedores del gobierno al mismo tiempo de que apoyó a los artesanos y comerciantes que habitaban en los suburbios exentándolos de pagar impuestos. Boris Godunov contó con la colaboración de otros boyardos quienes ocuparon los ministerios de Política Exterior, el de los strel'tsy, el del Tesoro y los Departamentos en contra de la Delincuencia y de Servicios del Estado, de manera que se velaba por la seguridad del Estado. Bajo la regencia de Godunov se estableció el patriarcado de Rusia (1589).

En cuanto a la política exterior, se firmó la paz con Polonia en 1587 y en 1595, tras una guerra con Suecia, fueron recuperados algunos territorios aledaños al golfo de Finlandia. En 1586, el rey de Georgia se convirtió en vasallo del zar a cambio de obtener su ayuda en contra de los tártaros, así la fe ortodoxa llegó al Cáucaso. Por otra parte, los 
tártaros de Crimea no perdían oportunidad de atacar Rusia y saquear la región, por ello Godunov inició la construcción de ciudades fortificadas para proteger la frontera: se fundaron Samara en 1585, Varoney al año siguiente, Tsaristryn en 1588, Saratov en 1590 y Elets en 1592. Asimismo se establecieron poblados en Siberia, por ejemplo Pelym $(1587)^{392}$.

Además del zar Fiodor I, a Iván le sobrevivió otro hijo, Dmitri (1581-1591) quien no tenía derecho al trono porque nació de su último matrimonio y la iglesia ortodoxa no reconocía este enlace. El niño murió violentamente y su familia materna, los Nogois, esparció el rumor de que Godunov había ordenado asesinarlo. Este dato es importante por los sucesos que se desarrollaron algunos años más tarde. A la muerte de Fiodor I, la familia Ryuríkida se extinguió.

Como no existían reglas claras para la sucesión, casi enseguida la zemskii sobor designó a Godunov como zar, esto significó que la asamblea creada por Iván IV adquirió una función para la que no había sido establecida: la de elegir al zar. Esta situación desencadenó la lucha por el poder de familias prominentes como los Nagois en contra de los Godunovs (smutnoe vremia). En 1601 salieron a la luz las maniobras de los Romanovs en contra del nuevo zar. Fedor Romanov (c. 1553-1633) fue obligado a tomar los hábitos con el nombre de Filaret, su familia fue deportada y sus bienes confiscados ${ }^{393}$.

Pese a las intrigas políticas, Boris Godunov continuó siendo un gobernante atento a las necesidades que tenía el Estado. Estableció relaciones con el imperio otomano de manera que la situación en la frontera del sur era menos inquietante. Asimismo reguló sus

\footnotetext{
${ }^{392}$ Parker, op. cit., pp. 124-125; Longworth, op. cit., pp.109-111, 113-114.

${ }^{393}$ Hellmann, op. cit., p.133; Riasanovsky, op. cit., pp. 155-157; Parker, op. cit., p.125. Smuta significa enturbiar, la expresión por tanto significa textualmente tiempos enturbiados Preobrazhensky, op. cit., p. 340.
} 
relaciones comerciales con Francia y las Provincias Unidas. Pero su gobierno se vio envuelto en serios problemas internos y externos. Uno de los sucesos más graves fue la hambruna resultado de una alteración climática que provocó inviernos crudos y largos; aunque el gobierno intentó paliarla no contó con los recursos suficientes para abastecer a la población. Al parecer, tan sólo en Moscú perecieron alrededor de 100000 personas. Los campesinos abandonaron sus tierras y muchos de ellos fueron a las ciudades buscando comida. Esta situación agravó la crisis de producción de alimentos y dio lugar al bandolerismo. Entre 1601 y 1603 los campesinos se rebelaron porque el hambre se había extendido por toda Rusia y consideraban que nadie les prestaba ayuda.

En ese contexto, apareció un personaje que decía ser Dmitri ${ }^{394}$, el hijo de Iván IV y reclamaba su derecho al trono que, en términos estrictos, no tenía. Sin embargo, el falso Dmitri obtuvo una gran aceptación del pueblo que atribuía sus desventuras a que Boris Godunov había usurpado el trono, ellos no entendían las maniobras de la zemskii sobor ni los abusos de los boyardos que se quedaban con la mayor parte de sus cosechas. Estudios recientes señalan que Dmitri fue apoyado por familias boyardas, al parecer Adam Wisniowiecki (c. 1566-1622) quien tenía sus tierras en el suroeste de Rusia, financió a Dmitri pues puso a su disposición algunos contingentes de cosacos a la vez que le consiguió la ayuda de los gobernantes de Lituania-Polonia ${ }^{395}$ quienes respaldaron al pretendiente al trono para así apoderarse de Moscovia. Un gran contingente de polacos y

\footnotetext{
${ }^{394}$ En esta Época de las tribulaciones aparecieron personajes de quienes se sabe muy poco sobre sus orígenes. Ellos formaban parte de los grupos sociales que pagaban impuestos y cargas o bien que eran esclavos. El desorden les facilitó tener una participación destacada en un contexto en el que las elites luchaban entre sí por el poder. El primer falso Dmitri fue uno de ellos. No ha sido posible saber quién era ni los motivos por los que se declaró a sí mismo hijo de Iván IV, pero lo cierto es que la madre del difunto Dmitri lo reconoció como su hijo, cuando perdió el poder tampoco se registró su biografía.

${ }^{395}$ En 1596 tuvo lugar la unificación constitucional del Ducado de Lituania con el reino de Polonia de manera que las tropas polacas contaban en sus filas con soldados lituanos, vid., Clark, op. cit., pp. 143-144.
} 
cosacos encabezados por el falso Dmitri invadió el sur de Rusia. A pesar de las derrotas, Dmitri volvía a levantar sus tropas pues tenía ascendiente sobre los cosacos.

Mientras tenía lugar esta lucha sobrevino la muerte de Boris Godunov. Su vástago fue coronado como Fiodor II (1589-1605), pero la familia de los Godunovs tenía muchos enemigos. De inmediato Fiodor II fue depuesto y asesinado. El falso Dmitri fue coronado zar en junio de 1605. Sin embargo, cometió el error de mostrarse muy afín a los polacos que lo habían apoyado al grado de casarse con una polaca católica, aunque no obligó a sus súbditos a convertirse al catolicismo. Sus consejeros eran polacos y germanos, no se ayudó de la iglesia ortodoxa sino de los jesuitas, alentó que los jóvenes fueran a educarse al extranjero y no alivió las cargas sobre los siervos. Para los rusos, estos actos así como el desprecio con que eran tratados por los polacos constituyeron una afrenta, así que algunos boyardos encabezados por Vasili Shuiskii (1552-1612) y el pueblo de Moscú se levantaron en su contra. Fue echado del poder en mayo de $1607^{396}$.

Estos problemas políticos expresaban el reacomodo social que la política de Iván IV había provocado. En efecto, quienes ocuparon el poder reclutaron nuevos miembros para la nobleza de servicio. Los pomestniki a su vez trataban de obtener el mayor beneficio de su posición a costa de los campesinos. La producción cayó y la hambruna llevó a la población a la desesperación. Esta caótica situación impulsó a los campesinos a huir hacia las fronteras tanto a la estepa como a la taiga y la tundra ${ }^{397}$.

${ }^{396}$ http://www.es.wikipedia.org/wiki/Borís_Godunov consultado 1 de febrero de 2013; Hellmann, op. cit., p.
$129 ;$ http://www.en.wikipedia.org/wiki/False_Dmity_I consultado 7 de marzo de 2013; Riasanovsky, op. cit.,
pp. $160-163$; Anderson, op. cit., pp. 340-341; Longworth, op. cit., pp. 115-121; Parker, op. cit., pp. 126-127
http://www.es.wikipedia.org/wiki/Adam_Wisniowiescki consultado 24 de abril de 2014.
397 Riasanovsky, op. cit., pp. 158-160; en el marco general de la historia europea, el periodo de la
Tribulaciones ocurrió en una época de rebeliones, guerras, caída demográfica y dificultades económicas en 
Tras el levantamiento, Shuiskii se coronó zar como Vasili IV. Era descendiente de una rama colateral de los Ryuríkidas pero como no fue nombrado por la zemskii sobor -que se arrogó la facultar de designar al zar al desaparecer el tronco principal de la familia- no tenía ninguna legitimidad. Para intentar afianzar su poder y como era noble, declaró que nadie sería ejecutado si antes no lo autorizaba una duma integrada por boyardos. Cualquier acusación sería investigada antes de condenar al presunto culpable y en caso de que la denuncia resultara falsa el delator sería castigado. También prometió que los parientes de un acusado no sufrirían persecuciones ni castigos por culpa del probable infractor. Al parecer, deseaba garantizarle a sus pares que no padecerían los excesos vividos en tiempo de Iván IV y de Boris Godunov.

De inmediato los campesinos de la región del Volga y de Astrakán se levantaron en armas. El desorden cundió y algunos nobles del sur desconocieron su gobierno. En ese momento destacó la figura de Iván Bolotnikov (c. 1565-1608) ${ }^{398}$, rebelde apoyado por esclavos, siervos, desheredados fugitivos, vagabundos y miembros de la nueva nobleza. Surgió un segundo falso Dmitri (muerto en diciembre de 1610) a quien Shuiskii no supo enfrentar. Con el respaldo de cosacos, gente común y pomeshchniki, el segundo falso Dmitri estableció su corte en Tushino, cerca de Moscú. Otorgaba tierras, ejercía justicia y cobraba impuestos, incluso algunos príncipes del norte lo reconocieron como gobernante. Al parecer, Dmitri también recibía ayuda de los polacos. Sin embargo, ante la falta de recursos pronto dejó sus tropas sin abastecimiento. El patriarca Germogen (c. 1530-1612) convocó a la sociedad rusa para oponerse a los polacos. Tal iniciativa se debió a que los

todo el continente, vid. Joseph Bergin, El siglo XVII. Europa 1598-1715. Trad. Antonio Desmonts. Barcelona, Crítica, 2002. (Historia de Europa Oxford), pp. 10-11.

${ }^{398}$ Esta rebelión se tratará con detalle más adelante. 
jerarcas de la iglesia ortodoxa rusa no querían correr el riesgo de que los católicos se impusieran en Rusia. Es importante señalar que Germogen era de ascendencia tártara, de hecho antes de ocupar el cargo de patriarca, para el que fue designado en 1606, hizo su carrera en la iglesia de San Nicolás en Kazan donde fue nombrado metropolitano. Dedicaba su vida al estudio de las sagradas escrituras, tradujo algunas de ellas del griego al ruso, y a predicar entre los tártaros, muchos de los cuales adoptaron el cristianismo ortodoxo. Germogen es un ejemplo de cómo se consideraba ruso a aquel que hablara el idioma, fuera cristiano ortodoxo y defendiera al Estado con sede en Moscú. De hecho, el patriarca envió dos cartas a Tushino en las que expresaba que los seguidores del segundo falso Dmitri estaban traicionando a la Rusia ortodoxa, también traicionaban a sus hermanos y a su fe, por tanto, los exhortaba a que abandonaran el lugar y regresaran a la senda correcta ${ }^{399}$.

Para controlar a sus enemigos internos, Vasili IV solicitó el respaldo del rey de Suecia. Mijail Skopin Shuiskii (1586-1610), primo del "zar" acompañado por tropas suecas, logró tomar Tushino derrotando al segundo falso Dmitri ${ }^{400}$. Pero el rey de Polonia Segismundo III (1566-1632), no aceptó esta alianza y envió sus ejércitos a Rusia. Se mostró dispuesto a que su hijo Ladislao (1595-1648) fuera coronado zar retirando su apoyo al segundo falso Dmitri, según lo sugerían algunos boyardos enemigos de Shuiskii. Vasili IV saboreó por breve tiempo la miel de la victoria pues su primo fue asesinado casi enseguida. Se reunió una duma integrada por nobles, plebeyos notables y clérigos que resolvió deponerlo. El trono quedó vacante desde julio de 1610 hasta 1613. La duma ofreció la corona a Ladislao con la condición de que adoptara el cristianismo ortodoxo pero el rey

399 http://www.tradizione.oodegr.com/tradiziones_index/vitesanti/hermogen.htm consultado 8 de marzo de 2013, Willets, op. cit., pp. 377-378, 410; Parker, op. cit., pp. 128-129.

400 http://www.en.wikipedia.org/wiki/False_Dmity_II consultado 7 de marzo de 2013; http://www.encyclopedia2.thefreedictionay.com/mikhail+skopinshuiskii consultado 8 de marzo de 2013. 
Segismundo III quiso coronarse zar en lugar de su hijo, lo que hubiese implicado que Rusia y Polonia quedarían unificadas bajo una sola corona católica. Esto desagradó a los rusos nobles, clérigos y plebeyos quienes lucharon hasta derrotar el rey de Polonia. Los rusos organizaron un ejército que fue encabezado por Procopius Liapunov (muerto en1611) quien al mismo tiempo tomó todas las decisiones de gobierno. El enfrentamiento en Moscú terminó con la defección de los cosacos del Don encabezados por el ataman Iván Zarutsky (muerto en 1614), éstos consideraron que los boyardos estaban atacando sus intereses y los de los campesinos y mataron a Liapunov ${ }^{401}$.

Las tropas extranjeras ganaron ciudades importantes: los suecos, quienes apoyaron a los rusos en contra de los polacos, se apoderaron de Novgorod y los polacos de Smolensk. Simultáneamente reapareció el segundo falso Dmitri pues la situación parecía propicia para coronarse zar. Una vez más, el patriarca Germogen llamó a la resistencia. Los polacos lo apresaron y lo recluyeron en el monasterio del Arcángel Miguel en el Kremlin. En Niynii Novgorod, Kuzma Minin (muerto en 1616) fue elegido por sus paisanos como administrador de los recursos que aportaron para formar un nuevo ejército. El mando del mismo quedó en manos de knyaz Dmitri Payarsky (1578-1642) y Dmitri Trubetzkoy (muerto en 1625) a quienes se unieron a los sobrevivientes del ejército anterior. Payarsky, Trubetzkoy y Minin organizaron un gobierno provisional en Yaroslav y prometieron que convocarían una zemskii sobor para designar a un nuevo zar. El abad de La Trinidad/San Sergio, Dionisio (no se encontraron sus fechas), también se sumó a la causa seguido de

\footnotetext{
${ }^{401}$ Vernadsky, op. cit., p. 120; Hellmann, op. cit., pp. 129-131; Riasanovsky, op. cit., pp.164-170; Longworth, op. cit., pp.121-123; Parker, op. cit., pp. 129-131; El cosaco Zarutsky había participado en la rebelión dirigida por Bolotnikov, después se unió a este ejército y dirigió un atentado en contra de Liapunov, como fracasó, huyó. Más tarde se casó con la viuda del segundo falso Dmitri, intentó que su hijastro fuera reconocido zar. Cuando falló regresó a Astrakán en donde su propia gente se rebeló en su contra y fue asesinado, véase http://www.es.wikipedia.org/wiki/Iván_Zarutski consultado 8 de marzo de 2013
} 
30000 hombres y apuró al príncipe para atacar Moscú. Al parecer, gran parte de las tropas rusas estaban conformadas por gente de servicio que fue convocada por los Departamentos de Finanzas y de Servicios al Estado ${ }^{402}$, quienes se sumaran a la causa serían recompensados, quienes no respondieran al llamado sufrirían las consecuencias, hasta los tártaros que habitaban el imperio fueron movilizados. La iglesia, por su parte, aportó, además de los discursos a favor de la defensa del cristianismo ortodoxo, recursos pecuniarios para financiar al ejército. Entretanto, los polacos quisieron obligar a Germogen a disuadir al ejército ruso de atacarlos pero el patriarca se negó. Lo dejaron encerrado y murió el 7 de febrero de 1612. Por fin, el ejército atacó Moscú y expulsaron a los polacos $^{403}$. Tras la derrota de las fuerzas polacas, los tres líderes reunieron a la zemskii sobor para elegir un nuevo zar. En esta asamblea participaron todos los estamentos sociales de Rusia incluidos los campesinos, al parecer fueron nombrados alrededor de 500 miembros ${ }^{404}$.

El 7 de febrero de 1613 fue elegido Mijail Fedorovich Romanov, miembro de la familia de la primera esposa de Iván IV y por tanto su pariente. Aunque la familia había participado en las intrigas en contra de los Godunovs, al parecer, su riqueza compró voluntades y así la balanza se inclinó a su favor. Una vez que fue electo Mijail, la zemskii sobor se autodisolvió $(1622)^{405}$, es decir, los representantes de la sociedad rusa que la integraban reconocieron al nuevo zar como un autócrata pues gobernaría el patrimonio que

\footnotetext{
402 A pesar de las dificultades políticas todo parece indicar que al menos parte de la burocracia seguía trabajando.

${ }^{403}$ Riasanovsky, op. cit., pp. 170-171, 189-190; Longworth, op. cit., pp. 125-127; Vernadsky, op. cit., p. 120; http://www.en.wikipedia.org/wiki/Trubetskoy_family\#Time_of_Troubles consultado 8 de marzo de 2013; http://www.es.wikipedia.org/wiki//Kuzmá_Minin consultado 8 de marzo de 2013; http://www.lavra.ru/palomnikam/istoriya-monastyrya consultado 8 de marzo de 2013.

404 Moss, op. cit., p. 157.

${ }^{405}$ Hellmann, op. cit., p. 131; Longworth, op. cit., p. 126.
} 
se había puesto en sus manos sin la participación en la toma de decisiones de ningún otro órgano de gobierno. De esta manera, el poder del Estado se reestableció y consolidó cuando terminó el periodo de las tribulaciones, pues sobre el autócrata recaería la capacidad de legislar, su decisiones no podrían apelarse y tendría la capacidad de imponer sanciones a todo aquel súbdito que no acatara sus disposiciones. Los plebeyos, especialmente los campesinos, lo aceptaron porque esperaban que el zar recién nombrado contuviera la expoliación de los señores, esperanza que no se cumplión ${ }^{406}$.

El zar otorgó el perdón a todos aquellos que habían participado en las luchas intestinas, medida indispensable para recuperar la paz. A los cosacos del Don que permanecieron en Rusia los enroló en el ejército. Fueron enviados embajadores a distintos reinos para anunciar el ascenso al trono del nuevo zar. Además negoció la paz con Suecia en 1617 con la que recuperó Novgorod aunque dejó Carelia e Ingra en manos suecas lo que le bloqueó la salida al Báltico. El zar también tuvo que dar una compensación en metálico al rey de Suecia. Al año siguiente firmó la paz con Polonia y se intercambiaron prisioneros. Más tarde, entre 1632 y 1634, Mijail I emprendió la guerra en contra de Polonia. Primero se alió con Suecia pero cuando el rey sueco murió, el pacto se rompió. El zar firmó la paz pero Smolensk permaneció con Polonia y la indemnizó con 20000 rublos a cambio de que el nuevo rey polaco renunciara a todas sus pretensiones de ceñir la corona rusa ${ }^{407}$.

A partir de la llegada de la dinastía Romanov, los elementos que habían surgido en el principado de Moscovia para legitimar el poder del príncipe primero y del zar después, se

\footnotetext{
${ }^{406}$ Hellmann, op.cit., p. 135; Riasanovsky, op. cit., p. 171; vid. Morton H. Fried, "Estado como institución" David L. Sills (dir), Enciclopedia internacional de las ciencias sociales. 11 vols. $1^{\text {a }}$ reimp. España, Aguilar, 1979, t. IV, pp.459- 465

${ }^{407}$ Hellmann, op. cit., p. 131, 148; Riasanovsky, op. cit., pp. 172-177; Clark, op. cit., p.145; Parker, op. cit., pp. 134, 278; el reino de Polonia se extendió fundamentalmente sobre las tierras de Ucrania, vid. Bergin, op. cit., pp. 121-122.
} 
reforzaron. La concepción de Moscú como la Tercera Roma, además de validar el ejercicio del poder del autócrata, ya que el zar se presentaba como heredero de las tradiciones romanas y bizantinas, también le asignaba una autoridad sagrada. El zar se erigió como el defensor de la verdadera fe cristiana, la ortodoxa. Para fortalecer esta imagen el zar casi nunca salía del Kremlin y cuando lo hacía generalmente era como peregrino para visitar algún monasterio. Así aunque el vínculo entre el zar y la iglesia era estrecho ésta no compitió con el Estado por ejercer el poder temporal sólo lo apuntaló y lo compartió.

El Estado ruso enfocó sus funciones a mantener la paz y a defender la fe ortodoxa de sus súbditos, a cambio esperaba servicio, si eran nobles, recursos pecuniarios si eran trabajadores de cualquier tipo y lealtad de todos. Esta situación provocó que el Estado no participara directamente en movilizar a la sociedad para desarrollar la productividad, en el mejor de los casos no la obstruía pero el control sobre la población ${ }^{408}$, sobre todo en la Rusia europea, coartaba casi todas las iniciativas. De ahí que el norte de Asia se convirtió en la tierra de los emprendedores. La burocracia estatal fue reorganizada para dirigir todos los recursos humanos y naturales en beneficio de la autocracia y para consolidar su organización en función del servicio que la nobleza debía prestar al zar. Los voyevody concentraron el poder regional en nombre del zar, esto contribuyó a la centralización del poder. Mijail también contó con un consejo que lo acompañó durante todo su gobierno ${ }^{409}$. A pesar de que Rusia ya tenía un gobierno bien establecido la inquietud en la población no desapareció y el peligro de nuevas revueltas se mantuvo latente durante todo el reinado del primer Romanov.

\footnotetext{
${ }^{408}$ La burocracia controlaba a la nobleza porque consignaba el servicio prestado al zar y así asignaba el rango, la mayoría de los campesinos estaban adscritos a su señor y a través de él pagaban sus impuestos al Estado. Además la mayoría de la población de las ciudades eran siervos del Estado. De esta manera, el Estado controlaba a la población.

${ }^{409}$ Raef, op. cit., pp. 4-9; Riasanovsky, op. cit., p. 192; Willets, op. cit., p. 411; Bergin, op. cit., pp. 123-124.
} 
Entre los siglos XV al XVII a los cosacos que se aliaban con algún príncipe se les llamaba "cosacos de servicio", una vez terminado el compromiso militar, recuperaban su autonomía. Sólo que cuando intentaban regresar a su territorio se encontraban con que algún señor, polaco o ruso, se había apoderado de él ${ }^{410}$. Los cosacos se encontraban en las tierras fértiles de la estepa por ello los nobles las ambicionaban. Los cosacos sirvieron no sólo al zar, también se aliaron con el rey de Polonia y eran constantemente asediados por los tártaros de Crimea. A finales del gobierno de Mijail I, los cosacos zaporoye, también llamados de Ucrania, solicitaron la protección del zar pues los nobles polacos continuaban repartiéndose sus tierras e intentaban someterlos al régimen de servidumbre, éste los aceptó. Los cosacos prestaron juramento durante el gobierno de su sucesor $(1654)^{411}$.

El zar Aleksei Mijailovich ascendió al trono en 1645, cuando tenía 16 años, y murió en 1676. En este periodo la dinastía Romanov se consolidó en el poder. En los primeros años de su gobierno tuvo como colaborador cercano a B. I. Morozov (1590-1661) ${ }^{412}$, quien, a decir de algunos, era el poder detrás del trono. Sus abusos provocaron la animadversión de los strel'ltsy y la burocracia, así como el disgusto de la nobleza porque no se le restituían debidamente los campesinos prófugos. La gota que derramó el vaso fue la imposición del impuesto sobre la sal, por cierto con la cual comerciaba Morozov. La revuelta estalló en Moscú en junio de 1648, el propio zar tuvo que intervenir, destituyó a Morozov y repartió compensaciones a los inconformes. Otra de las medidas de Aleksei fue convocar a la zemskii sobor para que redactara un código que estableciera el orden legal que regiría al

\footnotetext{
${ }^{410}$ Hellmann, op.cit., p. 145

411 Willets, op. cit., pp. 378-380; para ahondar en la relaciones de los cosacos con los polacos vid. Ambroise Jobert, Breve historia de Polonia. Trad. Sara E. Billino. Buenos Aires, "El Ateneo", 1966. 160 pp., ils. y mapas, pp. 34-36.

412 Se tratará sobre sus negocios más adelante.
} 
imperio, el resultado fue el Uloyenie (código) de $1649^{413}$. De acuerdo con él, todos los campesinos quedaron adscritos a la tierra a perpetuidad y debían pagar las cargas a sus señores e impuestos al zar. Los habitantes de las ciudades, por su parte, fueron organizados en corporaciones bajo el control del zar. También debían pagar sus impuestos. Fue ratificado el servicio que los nobles debían prestar al Estado así como la asignación del rango de acuerdo con éste y la mestnichestvo ${ }^{414}$.

Pero las protestas urbanas volvieron a presentarse debido a problemas de abastecimiento y los altos impuestos que debía pagarse. El Estado imperial requería cada vez de mayores ingresos para sostener su aparato burocrático y al ejército. En Pskov y Novgorod la población se levantó en demanda de alimentos, el zar prometió amnistía para todos y reunir a la zemskii sobor para buscar soluciones al problema. En 1653, se emitió un decreto que estableció el monto de los derechos aduanales que debían pagarse en las ciudades. El descontento estalló cuando el gobierno acuñó monedas de cobre en sustitución de las de plata con la intención de hacerse de recursos para financiar la guerra en contra de Polonia (1658-1663). Los precios de los alimentos básicos aumentaron, las poblaciones de Psokv y Novgorod mostraron su descontento, pero en Moscú los habitantes se rebelaron en 1662. La nobleza de servicio contribuyó a reprimir de forma sangrienta la revuelta aunque para restañar las heridas, en 1663 se volvió a acuñar la moneda de plata. A fin de evitar estos sinsabores una vez más se reordenaron los derechos aduanales en las ciudades en $1667^{415}$. A estos disturbios se sumó el movimiento de los "Viejos creyentes" que se opuso a

\footnotetext{
${ }^{413}$ Moss, op. cit., pp. 164, 184 passim.

${ }^{414}$ Dukes, op. cit., pp. 74-75; Bergin, op.cit., pp. 60-70, 72-73, 124.

415 Dukes, op. cit., pp.75-76; Longworth, op. cit., pp. 143-144; Moss, op. cit., p. 164.
} 
la reforma litúrgica ${ }^{416}$. Pero la rebelión más violenta y extendida fue la encabezada por el cosaco del Don, Stenka Razin en la segunda mitad de la década de $1660^{417}$.

Aleksei tuvo que proteger su frontera occidental contra las pretensiones expansionisras del reino de Polonia. En la guerra de 1654 la victoria rusa dio por resultado la reincorporación de Smolensk al imperio ${ }^{418}$, cuyo creciente poderío aunado a los intentos de la nobleza polaca de someter a los cosacos zaparoyie a la servidumbre e imponerles el cristianismo romano, llevó al hetman Jmelnytsky, jefe de los cosacos del Dniéper o de Ucrania, a solicitar la protección del zar. La mayoría de los cosacos de Ucrania expresaron su lucha en términos religiosos pero a su oposición a la servidumbre también se sumaba el deseo de recuperar su soberanía. Por fin, Aleksei los acogió en 1653, después de tres años en los que la asamblea del pueblo (zemskii sobor) debatió si convenía o no aliarse con ellos. En enero del siguiente año los cosacos prestaron juramento de fidelidad en Pereyaslav, besando la cruz. Así, 60000 cosacos zaporoyie fueron registrados como cosacos de servicio. Pocos años más tarde se desencadenó la rebelión de los cosacos del Don ${ }^{419}$.

El gobierno ruso también tuvo conflictos bélicos con el reino de Suecia que, en el siglo XVII luchaba por imponer su hegemonía política y militar en la región del Báltico. Entre 1610 y 1617 durante la smuta, aprovechó la oportunidad para apropiarse del territorio al oeste y al norte del lago Ladoga. Durante el gobierno de Aleksei tuvo lugar un nuevo enfrentamiento entre 1656 y 1658 para evitar perder las zonas cercanas al Báltico. Los

\footnotetext{
${ }^{416}$ Este movimiento será explicado párrafos más adelante.

${ }^{417}$ Esta rebelión se tratará en el apartado 5.2

${ }^{418} \mathrm{http} / / /$ www.es.wikipedia.org/wiki/principado_de Smolensk consultado 12 de agosto de 2013.

${ }^{419}$ Shane O'Rourke reseña del libro "The Cossacks and Religion in Early Modern Ukraine" de Serhii Plokhy en Slavic Review, vol. 62, no. 4, invierno de 2003, pp.844-845 en http://www.jstor.org/stable/3185683 consultado 2 de noviembre de 2012; http://www.es.wikipedia.org/wiki/Ucrania\#Edad de_oro_de_Kiev consultado 12 de agosto de 2013; Bergin, op. cit., p. 122; Hellmann, op. cit., p. 149; Longworth, op. cit., pp.138-141; Vernadsky, op. cit., p. 128.
} 
reveses militares sufridos por Rusia durante la smuta llevaron al gobierno a emprender una nueva reforma militar. Fueron contratados oficiales mercenarios extranjeros quienes se encargaron de adiestrar a la nobleza de servicio, a los cosacos y a algunos siervos. En 1660, los ejércitos rusos estaban organizados en regimientos disciplinados, en su mayoría la tropa era de cosacos y campesinos, y se adquirió armamento moderno -armas de fuego y cañones- en Europa occidental. Patrick Gordon (1635-1699), de origen escocés, fue el artífice de la reorganización del ejército, para ello echó mano de mercenarios no sólo como asesores sino también para formar regimientos ${ }^{420}$. Asimismo fueron contratados especialistas en fabricación de armas de fuego y pólvora quienes se encargaron de echar a andar la industria armamentista en Rusia pues no sólo organizaron las fábricas sino que capacitaron a los artesanos rusos. Andrei Vinius (1641-1717) fue el organizador de esta industria $^{421}$. Para abastecerla de materia prima, fueron contratados expertos en búsqueda y explotación de minerales ${ }^{422}$.

Ya que no todos los cosacos estuvieron de acuerdo con la alianza con Rusia, en 1658 un nuevo hetman la rompió y se unió a Polonia en el marco de la guerra con Suecia. Los cosacos zaporoyie estaban divididos y mientras unos querían la protección rusa otros buscaban ayuda con los polacos o con los tártaros de Crimea. Por fin en 1663, se llegó a un acuerdo, Ucrania quedó dividida entre Polonia y Rusia. Esta última ganó la porción oriental con Kiev incluido. Es decir, parte del antiguo territorio de la Rus de Kiev (véanse los mapas 7 y 15) fue integrado al imperio ruso ${ }^{423}$.

\footnotetext{
${ }^{420}$ Longworth, op. cit., pp. 136-138

${ }^{421}$ Moss, op. cit., pp.188, 195

422 Bergin, op. cit., p. 124; Dukes, op. cit., pp. 79-80.

${ }^{423}$ Hellmann, op. cit., p. 149; Longworth, op. cit., pp. 141-145; Willets, op. cit., p. 381.
} 
La extraordinaria expansión territorial del imperio ruso bajo la dinastía Romanov implicó que la burocracia también aumentara. Este fenómeno fue consecuencia de la necesidad de administrar hombres y recursos naturales a favor del Estado. Las oficinas tomaron el control del gobierno y el zar dejó de convocar a la asamblea del pueblo, mientras que la duma de boyardos, que alguna vez había dado consejo al príncipe, ya no tenía función alguna. Se instituyeron oficinas regionales, que debían responder a las centrales, al frente de las cuales quedaron los vayevody (gobernadores) quienes en la práctica gozaban de una gran autonomía pues también detentaban el poder militar. Por otra parte, la destreza de los representantes rusos en la diplomacia mostró ser efectiva durante el gobierno de Aleksei, lo que aunado al exitoso desempeño militar dio lugar a que el imperio empezara a percibirse como un Estado fuerte en el resto de Europa ${ }^{424}$. El mapa 15 muestra la extensión territorial de la Rusia europea durante el reinado de Aleksei.

${ }^{424}$ Dukes, op. cit., pp. 76-77; Hellmann, op. cit., pp.157-158; Longworth, op. cit., p. 145-146. 
Mapa 15. RUSIA EUROPEA DURANTE EL GOBIERNO DE ALEKSEI

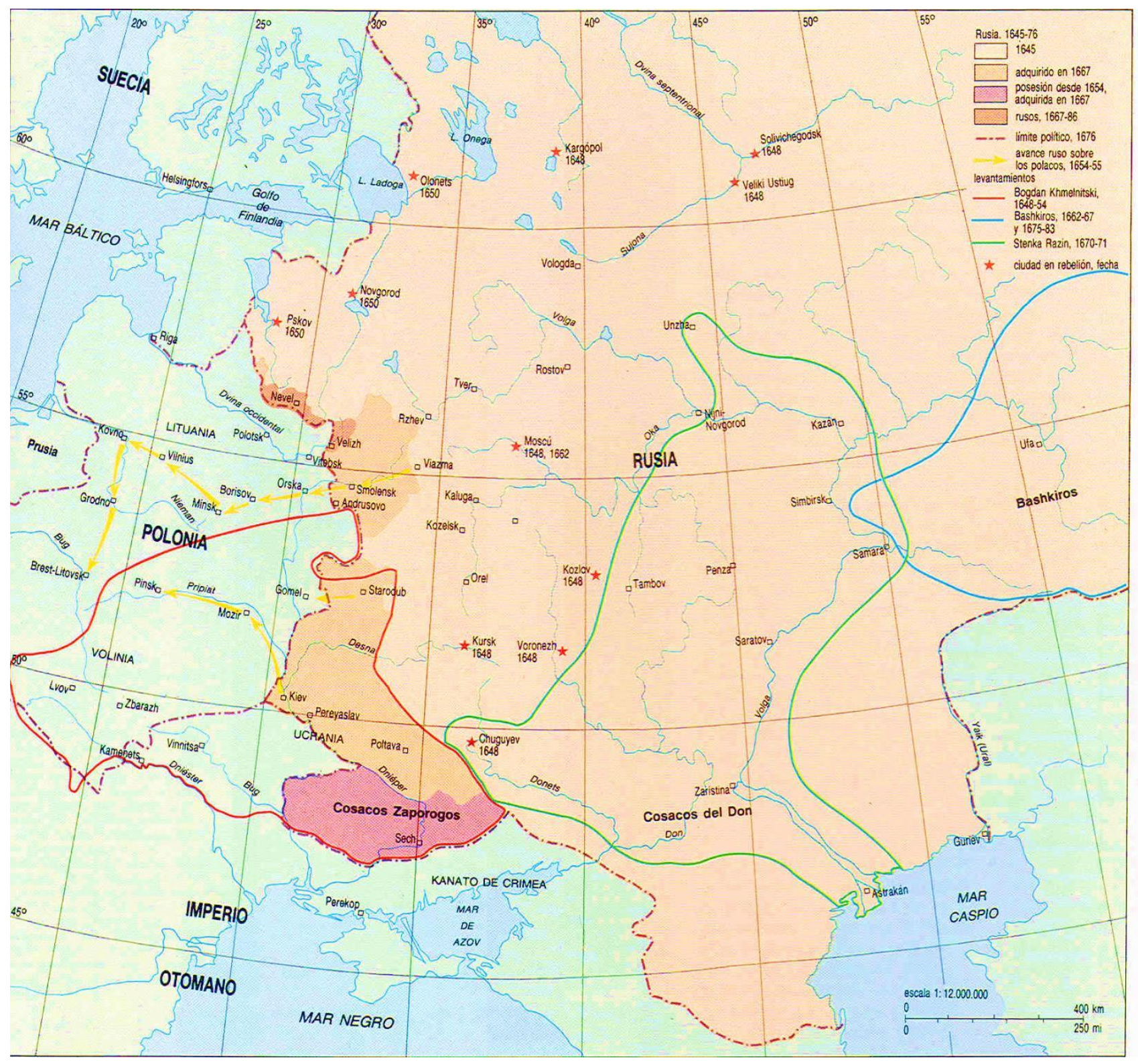

Fuente: Milner-Gulland, op. cit., p. 79

La reforma de la iglesia que el zar puso en manos del patriarca Nikón (1605-1681), nombrado en 1653, dio lugar a un cisma (Raskoi). La intención de la reforma era unificar el rito y reforzar la tarea pastoral. Ello implicaba retomar la tradición bizantina en el sentido 
de que los clérigos debían conocer las escrituras y adentrarse en la teología. En 1650 los eruditos que residían en Kiev fueron llevados a Moscú para revisar los textos sagrados y fijar de manera definitiva los textos y la ortografía en ruso. Así los clérigos se dedicaron a estudiar la literatura religiosa griega y latina, lo que a su vez facilitó que los miembros de la nobleza también accedieran a este tipo de conocimiento. Éste fue el germen de los intelectuales rusos, ya en este siglo hubo nobles que tenían voluminosas bibliotecas.

Sin embargo, los ortodoxos conservadores, encabezados por el arcipreste Avvakum Petrovich (1620-1682), rechazaron las reformas. Así nació el movimiento de los "Viejos creyentes", muchos de ellos emigraron a Siberia para continuar practicando su fe a la vieja usanza ya que Nikón exilió a Avvakum a ese territorio ${ }^{425}$. Pero Nikón cometió el error de intentar acrecentar el poder político del patriarca frente al zar considerando que era el ministro más importante de la Tercera Roma. También pretendía erigirse en el jefe principal de toda la iglesia ortodoxa, por lo que en 1666 fue destituido y recluido en un monasterio. Con estas medidas apoyadas por los propios obispos -reunidos en un sínodo al que se sumaron los patriarcas de Antioquia y Alejandría- y por la mayoría de la sociedad s aumentó la subordinación de la iglesia al poder del zar. Gran parte de los clérigos rusos seguían adscritos a un monasterio cuyas tierras eran otorgadas por el zar ${ }^{426}$.

La cultura y la tecnología desarrolladas en Europa occidental tuvieron una influencia creciente en Rusia desde fines del siglo XVI y a lo largo del siglo XVII. Así como fueron contratados especialistas para reformar al ejército, también llegaron personas dedicadas a la construcción, a la explotación de minerales e inversionistas. Al mismo

\footnotetext{
${ }^{425}$ Vid., apartado 5.2 sobre la vida de Avvakum en Siberia

${ }_{426}$ Bádenas, et al., op.cit., pp.267-268; Begin, op. cit., pp. 124-125; Clark, op. cit., pp. 204-205; Dukes, op. cit., pp. 85-86; Hellmann, op. cit., pp. 160-161; Van Dulmen, op. cit., p. 250.
} 
tiempo, algunos miembros de la elite fueron enviados a estudiar al occidente. En 1634, se imprimió la primera gramática rusa para apoyar la educación elemental, es decir, que el alumno aprendiera a leer y escribir. La reforma de la iglesia dio lugar a que se formara un grupo de traductores que sirvieron al Estado para allegarle información sobre lo que ocurría al oeste. Así, la educación, al menos de la nobleza, ya no recayó exclusivamente en la iglesia ortodoxa. De hecho, parte de la elite nobiliaria contrataba tutores privados para educar a sus hijos. Estos instructores salían de la Academia de Kiev dedicada al estudio de las sagradas escrituras, en 1666 fue fundada otra academia similar en Moscú. La diferencia entre ellas consistía en que la de Kiev se centraba más sobre las escrituras latinas y la de Moscú sobre las griegas ${ }^{427}$. La influencia de Europa occidental fue favorecida por la ocupación de la costa oeste de Ucrania, procesos que coincidieron con la expansión en el norte de Asia, ambos fenómenos reforzaron al imperio como un Estado euroasiático.

\subsubsection{La agricultura}

A los problemas políticos se sumó una crisis económica severa. Los cambios en la tenencia de la tierra realizados bajo Iván IV provocaron una caída en la producción debido fundamentalmente a la huida de los labradores. Los boyardos no tuvieron la fuerza económica para oponerse al ejercicio del poder de Godunov pero los campesinos, exhaustos por las contribuciones que tenían que pagar si se rebelaron. Pese a las hambrunas debidas a alteraciones climáticas y al proceso de reacomodo que tuvo el campo en su conjunto, la nobleza de servicio no fue abrogada. Cuando Mijail Romanov fue coronado zar, el cambio se había consolidado. Todo terrateniente debía prestarle servicio y los campesinos libres prácticamente habían desaparecido, adscritos a la tierra debían pagar las cargas a su señor y

${ }^{427}$ Vernadsky, op. cit., pp. 143-146; Dukes, op. cit., p. 65, 88. 
al zar. La nueva aristocracia terrateniente, producto de la oprichina, consiguió imponerse a la knyazya por lo que los cargos a los nobles fueron asignados con base en el servicio prestado al zar y no del historial de su linaje.

En 1628, el zar emitió un $u k a z$ en el que ofrecía a nobles y plebeyos la venta de tierras del Estado que se encontraban en la región aledaña a Moscú. La pequeña nobleza respondió a la iniciativa de la autocracia y así poco a poco la producción agrícola se recuperó durante el siglo XVII. Al mismo tiempo, el zar hizo concesiones a familias cercanas a la suya. Se puede considerar que las familias poderosas del siglo XVII no habían pertenecido a la knyazya de manera que debían su posición a las concesiones de los zares. Al mismo tiempo, sobrevivieron terratenientes cuyos dominios no eran extensos y que trabajaban ellos mismos con algunos otros labradores. Comunidades campesinas que habían huido del corazón de Rusia regresaron a sus antiguas aldeas ahora todas sujetas a alguna pomestye o votchina. Las tierras de cultivo de la Rusia europea fueron trabajadas de nuevo. Sin embargo, la fuerza de trabajo no logró ser muy abundante. En 1670, en la región de Moscú había sólo tres habitantes por kilómetro cuadrado y debido a que se localiza en la taiga sólo podía cultivarse durante cinco meses del año. Al norte la situación era más difícil, en las tierras de Novogord el trabajo agrícola podía realizarse sólo durante cuatro meses del año ${ }^{428}$, la productividad del campo ruso en la taiga era muy baja.

La población creció tanto por la expansión territorial como porque el clima mejoró de manera que se produjeron los cereales necesarios para alimentarla. Además, el gobierno siguió la política de reubicar familias campesinas para fomentar la agricultura en las regiones que no se practicaba, como en Siberia, o bien para trasladar artesanos

${ }^{428}$ Parker, op. cit., p.402-403 
especializados y distintos tipos de profesionales desde los territorios conquistados al oeste hacia Rusia, muchos de ellos fueron enviados al norte de Asia. Sin embargo, el aumento demográfico no fue extraordinario pues las hambrunas y las epidemias (1602-1606 y16541657) cobraron muchas vidas ${ }^{429}$.

Sin contar con registros precisos se ha podido determinar que el monto de las cargas a los siervos aumentaron en el siglo XVII, a pesar de que en un principio el zar Mijail tuvo que exentar de impuestos a muchas comunidades para facilitar que se recobraran. El pago se exigía con mayor frecuencia en metálico pero como los campesinos difícilmente podían cumplir con este requerimiento, el obrok siguió recibiéndose en especie y era el señor el que lo vendía en el mercado. En virtud de que los campesinos propietarios de sus tierras fueron desapareciendo, la exigencia de la barchina aumentó. Ahora los labradores debían realizar obras de construcción y mantenimiento de la infraestructura para los señores y para el Estado. Al parecer, los campesinos debían trabajar de dos a tres días para el señor. A estas cargas debemos añadir los impuestos que se le pagaban al zar que fijaban los agrimensores a quienes Mijail I puso a trabajar poco después de ascender al trono.

En el siglo XVII, todos los pretendientes al trono durante la época de las tribulaciones exigían los impuestos para sufragar los gastos de guerra. Cuando los Romanov llegaron al poder, los boyardos acostumbraban quedarse con una parte de estos impuestos como compensación por su servicio. De cualquier manera, los conflictos del periodo provocaron que muchos de los registros sobre el pago de impuestos fueran destruidos de manera que las contribuciones se tasaron de acuerdo con los nuevos reportes de los inspectores, pero muchas parcelas habían sido abandonadas. Sin embargo, en el

${ }^{429}$ Moss, op. cit., pp. 191-194. 
corazón del imperio ruso el tamaño de las parcelas de las familias campesinas no aumentó e, incluso, los hijos se quedaron con los padres pues mudarse podía significar conseguir tierras con cargas más altas. En cambio, las tierras que la nobleza con recursos escasos trabajaba directamente porque no tenían siervos estaban exentas de impuestos. Además, una gran porción de la población que había huido al sur, al este y al noreste no regresó.

Aunque al instaurarse la nueva dinastía la población aumentó poco a poco, los impuestos que el gobierno recaudaba no aumentaron gran cosa pues gran parte de la población se incorporó al ejército. No obstante, gracias a la migración, tierras muy fértiles de la estepa incrementaron la producción agrícola de Rusia. Es decir, el aumento se debió a la práctica de la agricultura extensiva con limitadas mejoras tecnológicas. Con los cambios en el régimen de tenencia de la tierra, de la relación de los campesinos con los terratenientes, la imposición de impuestos y la emigración, la antigua comuna campesina había quedado destruida, reorganizar el campo requirió de mucho tiempo y sólo se consiguió hasta el gobierno del zar Pedro I (1689-1725) ${ }^{430}$.

El camino hacia la servidumbre siguió adelante. Desde el periodo de Iván IV el número de jornaleros, en teoría libres, que se endeudaban con los señores había aumentado. En efecto, al celebrar el contrato, muchos debían solicitar un préstamo para empezar a cultivar. Las condiciones de los préstamos eran tales que el deudor prácticamente no saldaba su deuda en toda su vida. Había contratos que se celebrara con el padre y el hijo o con la familia entera de manera que todos debían trabajar para pagar el préstamo y la deuda se heredaba de padres a hijos. De acuerdo con el código (Sudebnik) establecido por Iván IV, los deudores sólo quedaban libres si su acreedor moría porque no se podía heredar el

${ }^{430}$ Blum, op. cit., pp. 147-154, 165, 221, 234-235; Dukes, op. cit., p. 81; Longworth , op. cit., pp. 128-129. 
cobro de deudas $^{431}$. Desde luego el nuevo señor inmediatamente buscaba la manera de conservar a estos labradores con nuevos préstamos. Así, paulatinamente, los jornaleros se convirtieron en siervos. Otro elemento que favoreció de forma determinante la aparición de la servidumbre fue la limitación que se impuso a los campesinos para salir del dominio de su señor. Desde el siglo XVI quien quería mudarse debía avisarle al señor con anticipación, éste fijaba la cuota de compensación para que el campesino pudiera salir de sus tierras. Si alguien se iba sin avisar o sin pagar su cuota se le consideraba fugitivo y de encontrársele debía regresar al señorío. Por otra parte, nadie podía mudarse si estaba en deuda con el señor. Para aumentar las dificultades, hay que recordar que el terrateniente tenía inmunidad sobre sus trabajadores de manera que si cometía alguna arbitrariedad para impedir que lo abandonaran, el campesino no tenía a quién recurrir para que se respetara su derecho a irse.

A pesar del crecimiento de la población, las tierras cultivables del centro de la Rusia europea quedaban yermas debido a la emigración de los campesinos, por ello había señores dispuestos a pagar las deudas de los colonos con tal que se fueran con ellos. El acreedor muchas veces aceptaba el pago a sabiendas de que perdería brazos en el campo pero para el campesino la mudanza no siempre resultaba ventajosa. Sin embargo, con la instauración de la oprichina y más tarde con la guerra dinástica era muy común que los señores pagaran las deudas de los campesinos o más aún que se los "robaran” a su antiguo señor. Esto ocurría sobre todo con los terratenientes que recibían tierras en la estepa y no tenían labradores. En este último caso si las autoridades del zar los localizaban los regresaban con su antiguo señor. Para evitar la pérdida de fuerza de trabajo, en 1580 Iván IV prohibió por un año que los campesinos pudieran mudarse (zapovednye gody). Al parecer, Iván Grozny repitió esta

${ }^{431}$ Blum, op. cit., pp. 245-246. 
prohibición varias veces pero desde 1603 cada año fue zapovednye gody hasta que se abolió la servidumbre en 1861. En 1597, fue promulgado un $u k a z$ que obligaba a los terratenientes que habían recibido fugitivos a regresárselos a su anterior señor pero como los tiempos eran turbulentos no siempre podía saberse cuáles eran campesinos fugitivos y cuáles no. Mijail I también promulgó un decreto semejante para que los labradores regresaran con sus antiguos señores. Estas medidas estaban dirigidas sobre todo a proteger a los pomeshchniki, o sea la nobleza que creó Iván IV al otorgarles una pomestye, quienes con dificultades tenían trabajadores en sus dominios y los grandes terratenientes se los quitaban pagando las deudas o "robándoselos".

La creciente presión sobre los campesinos explica la violenta participación que tuvieron durante la guerra dinástica y las rebeliones siguientes. Entre 1606 y 1607, Iván Bolotnikov, quien había sido esclavo, al mando de un gran contingente de cosacos, campesinos, fugitivos de las ciudades y todo tipo de marginados y hasta algunos boyardos enemigos de Shuiskii, logró durante unos meses controlar un territorio en el que repartió las tierras de los boyardos entre los campesinos. Él y sus seguidores cuestionaron la autoridad de la nobleza y su derecho a detentar la propiedad de la tierra que aquéllos trabajaban. Bolotnikov prometió a sus seguidores una transformación de la sociedad en la que el zar obligaría a los nobles a producir sólo lo que requerían para vivir y reduciría los impuestos, de esta manera los campesinos podrían disponer del sobrante de la producción para su consumo y vender el resto en el mercado, tal como ocurría en el pasado. En breve, la nobleza que lo seguía lo abandonó y junto con sus correligionarios lo combatieron y al año 
siguiente, tras un largo sitio en Tula, Bolotnikov se entregó pero negoció que dejaran libres a sus seguidores. Poco después Vasili IV ordenó su ejecución ${ }^{432}$.

Tampoco tuvieron suerte los campesinos que apoyaron al segundo falso Dmitri. Cuando Mijail Romanov ascendió al trono los siervos, krepostnoi chelovek estaban ya adscritos a la tierra. Sin embargo, como el señor ejercía la justicia sobre ellos, en la práctica los nobles transladaban a los siervos de un parcela a otra o incluso podían correrlos de su dominio y dejarlos sin tierra de labranza. En ocasiones, los señores vendían a los siervos enmascarándolo en formas de compensación que el comprador otorgaba primero. Sin embargo, los siervos tenían personalidad jurídica y el señor no tenía derecho de vida o muerte sobre ellos, podían disponer de algunos de sus bienes pero debían pagar sus cargas y sus impuestos. Conservaron el derecho a mudarse, pero en la práctica se hacían contratos que comprometían a los campesinos a no abandonar a su señor hasta que éste muriera y, en caso contrario, debían pagar un rescate tan oneroso que nadie podía sufragarlo. Además el Estado suspendía cada año el derecho de mudanza ${ }^{433}$. Por fin, en 1649 el Uloyenie declaró siervos a todos los campesinos. Un señor podía recuperar a sus trabajadores sin límite de tiempo y respondía por ellos ante el Estado en términos fiscales y civiles, También se sancionó que el señor podría administrar justicia en delitos locales y menores ${ }^{434}$. Por fin, la servidumbre se había instaurado en la Rusia europea y el imperio contó con una base económica más o menos estable.

Este proceso no estuvo exento de manifestaciones de resistencia por parte de la población. Las revueltas ocurrieron tanto en el campo como en la ciudad. El zar Aleksei

\footnotetext{
432 http://www.answers.com/topíc/ivan-bolotnikov consultado 7 de marzo de 2013; Willets, op. cit., p.410; Van Dulmen, op. cit., pp.169-170, 353-354.

${ }^{433}$ Blum, op. cit., pp. 7-8, 242- 260; Hellmann, op.cit., pp. 142-144; Riasanovsky, op. cit., pp. 165-166.

${ }^{434}$ Hellmann, op. cit., p. 152
} 
debió sofocar rebeliones sucesivas. Se puede considerar que los levantamientos de los cosacos en contra del gobierno polaco también fueron rebeliones en contra de la imposición de la servidumbre. Cuando se acogieron a la protección del gobierno ruso lo que ocurrió fue que los señores polacos fueron reemplazados por cosacos cercanos al zar que sometieron a sus antiguos correligionarios y a los campesinos de Ucrania a la servidumbre, siempre que no estuvieran enlistados como "cosacos de servicio". Esta jerarquización entre los cosacos también se debió a que con la imposición de la servidumbre llegaron nuevos prófugos a sus territorios, especialmente a la región del Don. Los recién llegados querían dedicarse a la agricultura pero los viejos cosacos temían que al extenderse las tierras de cultivo también se difundiera la servidumbre. Así que los nuevos cosacos no tuvieron más remedio que dedicarse al pillaje. Al mando del cosaco del Don, Stenka Razin (1630-1671), realizaron una exitosa expedición de saqueo en Persia. Esta aventura, dio lugar a la gran rebelión cosaca entre 1670 y 1671. Al parecer, Razin cobijó a muchos campesinos y habitantes de las ciudades que huyeron como consecuencia de las guerras en contra de Polonia y Suecia, no sólo por la devastación que provocaban sino por el aumento de cargas e impuestos que el gobierno exigió para enfrentar los gastos militares. Asimismo, se sumaron a la rebelión miembros de los pueblos sometidos recientemente como maris y mordavos. En 1670, Razin proclamó el establecimiento de la República Cosaca en la que no habría esclavitud, ni privilegios, todos serían iguales. Sin embargo, la lucha de Razin no se dirigía en contra del zar sino de los nobles quienes, según su percepción, eran los que oprimían a los plebeyos sin la venia de aquel ${ }^{435}$. Atacó Astrakán y otras ciudades comerciales en el curso del Volga a las que saqueaba. Los señores de la estepa hacia quienes se dirigía la revuelta, se organizaron para combatirlo. Hubo varios enfrentamientos pero la mejor organización

\footnotetext{
${ }^{435}$ http://www.es.wikipedia.org/wiki/Stenka_Razin consultado 29 de abril de 2014.
} 
militar de los boyardos así como que el patriarca de Moscú condenara a los rebeldes provocó que Razin sufriera varios reveses y perdiera apoyo de gran parte de sus seguidores. En 1671 fue capturado y torturado hasta morir. El zar Aleksei reprimió con la misma crudeza a muchos de sus seguidores ${ }^{436}$.

En el siglo XVII, todavía había fuerza de trabajo esclava (cholop). De hecho, en las tierras fronterizas, en la parte baja del río Oka y el curso medio del Volga, es decir la estepa, en donde había pomestye, los dueños podían hacer rentables sus dominios con esclavos pues ellos no debían pagar impuestos al zar. Pero con la institucionalización de la servidumbre los esclavos tendieron a desaparecer y a convertirse en siervos. Tan sólo quedaban campesinos libres, los llamados "negros", en la costa del Mar Blanco, en las cuencas de los ríos Dvina y Kama y más allá de los Urales. Estos agricultores debían pagar sus contribuciones, por ello, la burocracia levantaba catastros en estas regiones. Como ahí las tierras no eran fértiles la mayoría de los terratenientes eran los monjes, el zar les otorgaba tierras "negras" y los labradores tenían que pagar cargas e impuestos. De cualquier manera, la mayor porción de los labradores se encontraban en el centro de la Rusia europea y en algunas porciones de la estepa, casi todos ellos eran siervos. Por último conviene recordar que las labores del campo se realizaban con instrumentos de madera, solo en la región del río Don se utilizaban arados de rueda y había muy pocos molinos para moler el grano pues en el bosque las aspas podían atorarse y los ríos, aunque caudalosos no tenían las caídas necesarias para mover un molino. No obstante, gracias a la implantación paulatina del régimen de servidumbre, durante la Guerra de las Treinta Años (1618-1648),

\footnotetext{
${ }^{436}$ Vernadsky, op. cit., pp. 134-135; Van Dulmen, op. cit., p. 356; Willets, op. cit., p.410; Moss, op. cit., pp. 165-166.
} 
en la que el imperio ruso no participó militarmente, vendió grandes cantidades de cereales a Suecia entre 1630 y $1635^{437}$.

La descripción de la economía agraria permite reafirmar que uno de los pilares fundamentales de la capacidad de expansión de Rusia fue el establecimiento de la servidumbre pues, en primer lugar, proporcionó las alimentos necesarios, especialmente trigo $^{438}$, para sostener al ejército y a la población del norte de la taiga y de la tundra la cual no cultivaba ni podía hacerlo sino que se dedicaba a la explotación de los recursos del bosque boreal, del Mar Ártico y al comercio. En segundo lugar, la explotación servil indujo a gran parte de la población plebeya, que aumentó desde el siglo XVI a pesar de todos los problemas políticos, a buscar otras opciones de sobrevivencia que no restringieran su libertad de movimiento ni apagaran su iniciativa emprendedora. Una de las regiones más atractiva fue el norte de Asia en donde el control del gobierno se debilitaba y los aventureros y empresarios podían desplegar más ampliamente su ingenio y sus empresas económicas.

En la época de las tribulaciones, las pomestye se hicieron heredables, los hombres podían prestar servicio al Estado y por tanto administrar sus tierras desde los 15 años. En caso de que no hubiese heredero, la pomestye podía pasar a una persona ajena a la familia pero tenía que mantener a la viuda y a las hijas hasta que se murieran o se casaran. Votchina y pomestye se asemejaron desde que las primeras implicaron prestar servicio al zar y las segundas fueron heredables. En el siglo XVII, la pomestye era ya una propiedad privada que podía venderse o hipotecarse, así que poco a poco el término desapareció y los

${ }^{437}$ Blum, op. cit., pp.268-273; Dukes, op. cit., p. 81; Parker, op. cit., pp.407-408, 411; Henry Kamen, La sociedad europea, 1500 -1700. Trad. Ma. Luisa Balseiro. Madrid, Alianza Editorial, 1986. 352 pp. (Alianza Universidad, historia, 475), pp. 201-203.

${ }^{438}$ Hellmann, op. cit., p. 151 
dominios de los terratenientes volvieron a designarse con el término de votchina pero, hay que insistir, a diferencia de las etapas anteriores, ahora la votchina conllevaba prestar servicio al zar y el señor ya no podía elegir servir a nadie más porque en ese caso era acusado de traición y sus tierras le eran confiscadas. En 1620, Mijail reordenó la tributación de la votchina y las contribuciones se fijaron en función del número de siervos y no de la extensión del patrimonio. Además fue vedada la posibilidad de enajenar el núcleo de la herencia y sólo podían venderse territorios que se hubieran obtenido por compra o pago de préstamos. El cambio en el régimen de tenencia de la tierra iniciado con Iván III así como el fin de las guerras internas y la promulgación de la Uloyenie favorecieron que en el siglo XVII los nobles se ocuparan directamente de la administración de sus tierras, incluso que participaran directamente en la supervisión de las siembra y la cosecha, esto fue posible porque el servicio debía prestarlo algún miembro de la familia ya fuera el padre o el hijo ${ }^{439}$.

Los monasterios eran también grandes propietarios. En el siglo XVII había alrededor de 300 monasterios, el más importante de los cuales era el de Trinidad/ San Sergio, los rusos no olvidaban la bendición que su fundador había dado a Dmitri Donskoi $^{440}$. Durante la reforma de Iván IV algunos nobles le habían donado sus tierras a algún monasterio a cambio de recibir una renta vitalicia. Le seguía en importancia San Cirilo ubicado en Beloozero y San Saviour/San Joaquín. Pero quien más tierra donó a los monasterios fue el propio Iván IV, actitud francamente contradictoria con la intención de debilitar a la iglesia para que se sometiera a sus decisiones. La mayor parte de la producción de los monasterios se vendía en el exterior, así que también tenían una participación importante en el comercio. La riqueza de la iglesia era tal que en 1584, año en

\footnotetext{
${ }^{439}$ Blum, op. cit., pp. 185-187, 210.

440 Véase apartado 4.1.
} 
el que murió el zar Iván IV, los monasterios empezaron a pagar impuestos sobre la tierra. Tal vez por esta razón a partir del siglo XVII la acumulación de tierras por los monasterios empezó a decaer, el Estado logró impedir en muchos casos que los nobles les donaran sus tierras $^{441}$.

Los cultivos fundamentales continuaban siendo el centeno, el trigo, la avena, la cebada y el mijo. Las técnicas no se modificaron. A la guerra interna y externa se sumaron la falta de innovación tecnológica y las cargas cada vez más onerosas que los campesinos debían pagar como factores que provocaron una caída de la producción de cereales en la Rusia europea. Si el campo ruso no colapsó se debió a la instauración de la servidumbre y a la apertura de nuevas tierras de cultivo. El mercado interno de cereales creció gracias a la demanda del Estado para abastecer al ejército y a la población que migró más allá de Siberia occidental donde no se practicaba la agricultura. También se criaba ganado pero esta actividad estaba por debajo de la agricultura ${ }^{442}$.

Las prácticas culturales de los campesinos y los desposeídos en general, también se modificaron. Los relatos y cantos empezaron a ocuparse de ellos mismos ${ }^{443}$. Por ejemplo, Stenka Razin se convirtió en un protagonista de sus historias. Existe una canción tradicional que se refiere a sus andanzas por el Volga ${ }^{444}$. Desde el siglo XIX y en el XX se compusieron poemas sinfónicos en su honor ${ }^{445}$.

\subsubsection{Manufactura y comercio}

\footnotetext{
${ }^{441}$ Kamen, op. cit., p. 173; Blum, op. cit., pp.189-198; Riasanovsky, op. cit., p. 159; Hellman, op. cit., p. 151.

442 Blum, op. cit., pp. 165-167; Immanuel Wallerstein, El moderno sistema mundial II. El mercantilismo y la consolidación de la economía mundo europea, 1600-1750. Trad. Pilar López Máñez. $2^{\text {a }}$ ed. México, Siglo XXI, 1984. 526 pp. (Historia), p. 182

${ }^{443}$ Dukes, op. cit., p.88.

${ }^{444} \mathrm{http}: / / \mathrm{www}$.accordeonworld.weebly.com/stenka-razin-lyrucs.html consultado 8 de agosto de 2014.

${ }^{445}$ Sixsmith, op. cit., p. 70 reproduce el poema de Yevgeny Yevtushenko musicalizado por Dmitri Shostakovich.
} 
En la sociedad rusa todos los súbditos debían prestarle servicio al zar, dependiendo del estamento al que pertenecieran éste se prestaba de manera diferente. Los boyardos cercanos al zar desempañaban altos cargos militares o burocráticos. El siguiente segmento de la nobleza ocupaba los mandos medios. Por último, la nobleza provincial estaba obligada a servir en el ejército. La riqueza entre ellos estaba distribuida desigualmente, mientras que un boyardo poseía tierras con más de 10000 siervos, miembros de la nobleza provincial no tenían siervos. El siguiente estamento estaba conformado por los hombres de servicio que no tenían tierras y por tanto servían como mosqueteros y por lo común vivían en las ciudades; los cosacos de servicio pertenecían a este estamento. Por debajo de ellos se encontraban los campesinos en condición de servidumbre. El estamento más bajo era el de los esclavos que tras la instauración de la servidumbre desapareció paulatinamente. Además al Estado no le redituaba la existencia de esclavos ya que no pagaban impuestos. De hecho, la Uloyenie prohibió que los hombres libres se vendieran a sí mismos como esclavos ${ }^{446}$.

Así pues, los habitantes de las ciudades que eran plebeyos y se dedicaban por lo común a la artesanía o eran pequeños comerciantes, también perdieron la libertad de mudarse a su antojo. Por el $u k a z$ de 1613, la posadskie liudi que pagaba impuestos fue obligada a regresar a Moscú, poco después tal exigencia se decretó para otras ciudades ${ }^{447}$. Es decir, para fijar las tasas y cobrar los impuestos, el zar y sus consejeros consideraron que la medida más efectiva consistía en exigirle a la gente libre una residencia fija que sólo podrían cambiar con permiso del gobierno. Durante el gobierno de Aleksei los habitantes de la cuidad fueron organizados en corporaciones controladas por el régimen.

\footnotetext{
${ }^{446}$ Moss, op. cit., pp. 192-194.

${ }^{447}$ Blum, op. cit., p. 270
} 
Las ciudades con un desarrollo comercial mayor fueron Moscú, donde residía el comerciante más importante, el zar, y la ciudad de Tula en la que se establecieron fábricas de armamento, pues lo modernización del ejército incluyó que el Estado ruso se aventurara a producir sus propias armas. Tula fue la región donde se crearon las armerías porque ahí se fundía el hierro que se producía en el imperio. Más tarde, también empezó a producirse hierro en los Urales. Puesto que en Rusia no había un sector importante de empresarios que contaran con capital para fundar una fábrica, la mayoría pertenecían a extranjeros, entre los empresarios más destacados se encontraba Pieter Marcelis (1602-1672) originario de los Países Bajos ${ }^{448}$.

Todas las rutas comerciales llegaba a Moscú, por ello el barrio de los extranjeros, nemets, más importante estaba ahí. Podían encontrarse europeos occidentales lo mismo que asiáticos como los mordavos o los tártaros. Poco a poco Novgorod, Pskov y Smolensk transformaron su economía. Ya que la explotación de pieles se había recorrido al este de los Urales, estas regiones se dedicaron a sembrar cáñamo y a producir lino y cueros. Smolensk se convirtió en la ciudad comercial más próspera en el oeste después de Moscú. La ruta pluvial hacia el puerto de Arcángel era el rio Dvina. Se exportaban grandes cantidades de cereales, pieles, madera, cueros, potasa y ropa y se importaban joyas de oro y plata, diamantes, pero también papel, agujas para coser, vino y armas, entre otros artículos. Hacia el noreste, la cuenca del Volga era la que comunicaba a Niyni Novgorod con Kazan, Astrakán y Siberia. En Niyni Novgorod se realizaba una de las ferias comerciales más lucrativas de Rusia ${ }^{449}$.

\footnotetext{
${ }^{448}$ Hellmann, op. cit., pp. 153-154; Dukes, op. cit., p. 82; Kamen, op. cit., p. 94; http://www.ilibrariana.wordpress.com/.../de-familie-marcelis-in-r... consultado 1 de mayo de 2014 ${ }^{449}$ Dukes, op. cit., pp. 60, 82-83
} 
El intercambio comercial no se detuvo a pesar de los problemas políticos. Cuando Boris Gudonov fue zar se desarrollaron las relaciones comerciales con Inglaterra. Arcángel se consolidó como el puerto en donde se realizaba el embarque y desembarque de las mercancías que se llevaban o traían de Europa occidental. El predominio de los ingleses decayó y, poco después, los holandeses también participaron en esta ruta ${ }^{450}$. La participación holandesa en el comercio con Rusia alcanzó tal magnitud que las letras de cambio expedidas en el naciente imperio sólo podían cambiarse en Amsterdam. Sin embargo, el reino de Suecia intentó convertirse en el intermediario entre los Países Bajos y Rusia, de manera que en las guerras del siglo XVII no sólo buscaba la expansión territorial sino también el control del comercio por el Báltico. Gran parte de los artículos adquiridos en Rusia, fueran rusos o bien de otras regiones asiáticas, eran pagados con plata ${ }^{451}$.

Así las rutas comerciales que antaño trazaron los vikingos se fueron ampliando e incorporaron nuevos territorios. Si bien las redes comerciales euroasiáticas no tenían el mismo grado de consolidación, la expansión territorial de Rusia retomó los vínculos con la estepa asiática y estableció la red que incorporó al norte de Asia y China con el este de Europa en dirección oeste-este, combinando rutas terrestres con fluviales, y por segmentos por el Ártico.

Ya que las tierras de los alrededores de Moscú no eran tan fértiles como las de la estepa, los campesinos tenían tiempo para dedicarse a producir manufacturas en sus propias casas para después concurrir al mercado a venderlas. Sin embargo, la industria artesanal y el comercio no brindaban oportunidades de movilidad social ya que un campesino por muy próspero que fuera al dedicarse al comercio, seguía dependiendo de su señor. Tal vez por

\footnotetext{
${ }^{450}$ Blum, op. cit., p. 128; Riasanovksy, op. cit., p. 160; Wallerstein, t.II, op. cit., p. 270.
}

${ }^{451}$ Ibidem, t. II, op. cit., pp. 80, 138, 148, 150, 297, 303. 
eso era socialmente aceptado que la nobleza y hasta el propio zar tuvieran negocios comerciales pues su condición estamentaria no variaba en función de la riqueza ni de la ocupación que tuvieran sino por el servicio que prestaban al zar. Un ejemplo paradigmático del boyardo, burócrata y empresario fue Boris I. Morozov quien estuvo al frente de las oficinas (prikazi) de Strel'tsy, Farmacia y Finanzas durante el gobierno del zar Aleksei. Comerciaba cereales, en sus minas extraía potasa y hierro y tenía una planta metalúrgica, además era dueño de molinos, destilerías y contaba alrededor de 55000 siervos. Fue quien tuvo la idea de imponer un impuesto a la sal que provocó la Rebelión de la sal en 1648. Pero este magnate debía su buena fortuna a que era concuño del zar. Esta situación explica por qué la industria artesanal de los plebeyos y el mercado no se expandieron gran cosa y la mayoría de la población trataba de huir para liberarse de los impuestos que debía pagar al Estado. Por añadidura, el gobierno creó más monopolios de manera que resultaba sumamente difícil competir con él y sus protegidos. Así pues, las ciudades no crecieron debido al desarrollo de la economía urbana sino porque fueron los lugares de residencia de los burócratas y los militares ${ }^{452}$.

Los ricos comerciantes amparados por el gobierno, gosti, continuaron acrecentando sus riquezas. Algunos gozaron del privilegio de comerciar en el exterior. Estos mercaderes recibían beneficios del Estado pero también le prestaban servicios. Tal vez el gost más importante en el siglo XVII fue G. L. Nikitinov [no se encontraron datos] quien tenía una flotilla que navegaba por el Volga y vendía ropa de lana, pescado y sal. Las Nuevas Reglas Comerciales decretadas en $1667^{453}$ estaban dirigidas a proteger a los súbditos del imperio

\footnotetext{
${ }^{452}$ Hellmann, op. cit., pp. 155-157; Kamen, op. cit., p.111, 151; http://www.es.wikipedia.org/wiki/Borís_Morózov consultado 1 de mayo de 2014

${ }^{453}$ Dukes, op. cit., pp.83-84; Moss, op. cit., pp. 188-189.
} 
pues prohibían que los comerciantes extranjeros participaran en el comercio al menudeo e imponían impuestos elevados a las mercancías del exterior.

En síntesis, después de las tribulaciones sufridas al iniciar el siglo XVII, la Rusia europea fue recuperándose, debido, en gran medida, a la expansión encabezada por una porción de sus súbditos en el norte de Asia. 


\section{CAPÍTULO VI. LA EXPANSIÓN HACIA EL ESTE POR EL}

\section{NORTE DE ASIA}

\subsection{Exploración y explotación}

\subsubsection{Instancias administrativas}

Fue durante la crisis dinástica cuando paradójicamente, la expansión sobre el norte de Asia fue vertiginosa. El propio Boris Gudonov la apuntaló al fundar el fuerte de Tiumen en 1586 y al año siguiente Tobolsk (véase el mapa 16). Asimismo creó un oficina encargada de administrar el territorio de Siberia (Sibirskii stol) ${ }^{454}$. Durante la smuta a pesar de que el gobierno de Moscú no podía prestarles ayuda, los rusos empezaron a someter a los janatos vecinos, cuando avanzaron hacia la estepa y la taiga en dirección al este, a todos los pueblos se les impuso el pago del yasak como otrora lo habían pagado ellos a los mongoles. Sin embargo, como los habitantes de Siberia -como se le llamó al norte de Asia tras la conquista del janato de Sibir $^{455}$-, en su mayoría, no eran agricultores el yasak lo pagaban en pieles las cuales comercializaba el Estado. A las comunidades que aportaban este tributo se les llamaba pueblos de yasak. Ahora bien, desde que inició la expansión sobre Siberia, los pueblos que ahí habitaban eran considerados como forasteros (inozemtsy), es decir, no se les consideraba rusos y seguramente por ello este territorio fue controlado por la Oficina de Asuntos Exteriores (Posolskii priksaz) hasta 1594, debido a que ésta regulaba las relaciones

\footnotetext{
${ }^{454}$ Hambly, op. cit., p. 127; Black, op. cit., p. 7.

455 No se tiene la certeza del origen del nombre de Siberia que los rusos le asignaron al norte de Asia. Es probable que los mongoles designaran como "sibir" a un pueblo que habitaba en el valle del río Irtish y después se utilizara el término para nombrar al territorio que habitaban. En cualquier caso, los rusos adoptaron este nombre para referirse a la tundra y la taiga asiáticas. Kotkin, op. cit., p. 14.
} 
con el janato de Sibir antes de que fuera conquistado. Aunque después se crearon oficinas especiales, durante todo el siglo XVII los nativos conservaron el status de forasteros ${ }^{456}$.

En principio, el territorio del noreste de derecho formaba parte de Rusia porque los súbditos del zar lo habían conquistado, por eso se gobernaba desde Moscú pero de hecho había un vacío del poder del autócrata ya que las instituciones fueron creándose poco a poco. La burocracia que administraba Siberia se encontraba tanto en Moscú como en el norte de Asia. En efecto, las oficinas que tomaban las decisiones y contabilizaban el yasak estaban en la capital y la burocracia provincial era la que mantenía sujetos a los nativos y también a los rusos y cosacos súbditos del zar. Al principio, el propio zar no tenía claro en calidad de qué debía gobernar Siberia pues ni siquiera se conocía cabalmente su extensión. Entre 1595 y 1599 la Oficina de Novgorod (Novgorodskii prikaz) se encargó de los territorios al este de los Urales. A partir del gobierno de Boris Godunov Siberia quedó a cargo de la Sibirskii stol. Durante el reinado de Mijail I los boyardos que integraban la duma aconsejaban al zar sobre cómo administrar el territorio que se iba integrando al imperio. También contribuía el Tribunal de Kazan (Kazanskii dvorets) que tenía jurisdicción sobre los valles del Volga, el Kama y Siberia occidental. Todos los acuerdos se ejecutaban a través de la Oficina de Siberia ${ }^{457}$.

Con el fin de reordenar la administración de Siberia, en 1637 el zar Aleksei creó una oficina de más alto nivel para encargarse del territorio (Sibirskii prikaz). Al frente de esta

\footnotetext{
${ }^{456}$ John King Fairbank (1907-1991), East Asia: the Modern Transformation. Edwin O. Reischauer and Albert M. Craig. Boston, Houghton Mifflin, 1965. 955 p., ils. (Reischauer, E.O., A History of East Asian Civilization, 21), p.45; Yuri Slezkine [no se encontraron datos], Arctic Mirrors Russia and the Small Peoples of the North. Ithaca and London, Cornell University Press, 1994. 456 pp., pp. 11, 40; Kalisov, op.cit., pp.63 passim; Basil Dmytryshyn [actualmente professor emérito de la Universidad de Portland, Oregon, Canadá], "The Administrative Apparatus of the Russian Colony in Siberia and Northern Asia, 1581-1700" en Wood, op. cit., pp.17-36, p. 19.

${ }^{457}$ Dmytryshyn, Loc. cit.
} 
Oficina se encontraban un boyardo y dos clérigos ayudados por un sinnúmero de mandos bajos y escribanos quienes redactaban los documentos y hacían los trámites para que se ejecutaran las órdenes. La oficina se dividía en "escritorios o mesas" (stoly) que resolvían asuntos específicos, cada uno tenía un jefe (golova). Entre las más destacadas estaban la Razryadny stol encargada de las cuestiones militares o la Gasudareva kazna que recibía, tasaba y vendía las pieles finas. En la Oficina de Siberia se establecía el monto del tributo que los nativos debían pagar así como la carga de impuestos que los emprendedores rusos y cosacos debían al zar y se ocupaban de diseñar planes para usufructuar el territorio del norte de Asia, entre otros asuntos más. Por otra parte, estaba vinculada con otras oficinas que la apoyaban en cumplir sus tareas, por ejemplo la Razryadnyi prikaz (Oficina de Asuntos Militares) recomendaba a quienes se nombraba gobernadores y enviaba tropas, no muy numerosas, por cierto. La Yamskii prikaz (Oficina de correo) contribuía a controlar las comunicaciones con Siberia. El territorio de Siberia fue dividido en voevodstvo (provincias administrativas) encabezadas por un voyevoda. A su vez la provincia estaba dividida en distritos $(u e z d)^{458}$.

En el código decretado en 1649 (Uloyenie) por el zar Aleksei ${ }^{459}$, todas las oficinas de gobierno quedaron bajo el mando de la Cámara de Adjudicación (Raspraynaya palata), de manera que toda la burocracia fue centralizada. Esta institución tomaría, en última instancia, cualquier decisión sobre la administración de Siberia. Sin embargo, no consiguieron vigilar por completo a los administradores de Siberia. Como el Estado no contaba con los recursos suficientes para entregarles a los funcionarios su salario, permitió que se cobraran de las ganancias que se obtenían en la propia Siberia y el resto de la riqueza

\footnotetext{
${ }^{458}$ Dmytryshyn, op. cit., pp. 20-21, 25.

${ }^{459}$ Ibidem, pp. 26-27.
} 
que pertenecía al zar se enviara a Moscú. Los burócratas de alto rango eran enviados desde Moscú: el gobernador y el escribano (poddyachie s pripisyu), responsable de todas las cuentas y de informar a la Oficina de Siberia en Moscú sobre lo que ocurría en la región. El resto de los funcionarios eran reclutados por los voyevody de entre los comerciantes, los prisioneros europeos enviados al exilio y los cazadores, muchos de ellos cosacos de servicio, que seguramente participaban en sus negocios.

Los funcionarios menores eran los que establecían relaciones con los nativos, les cobraran el tributo, intercambiaban regalos, recibían a los rehenes, les vendían alimentos que antes no consumían como el pan y se encargaban de conducir los abastecimientos necesarios para alimentar a los rusos. Todos aquellos que tenían autoridad, incluyendo a los mandos inferiores, les cobraban cuotas a los nativos de manera que debían pagar varias veces el monto del tributo. La situación se agravaba porque el yasak debía entregarse entre diciembre y enero, si los nativos no reunían lo que debían pagar, podían completarlo en junio. En la práctica los burócratas les adelantaban parte del pago por las pieles que les compraban y después las valuaban a precios muy bajos de forma que quedaban endeudados porque no saldaban ni el pago adelantado ni el yasak ${ }^{460}$.

Ya que el voyevoda desempeñaba funciones militares tenía bajo su mando a diferentes tipos de soldados. En primer lugar estaban los strel'tsy o mosqueteros de caballería o infantería. Les seguían en jerarquía los cosacos de servicio. Por debajo de ellos estaban las milicias formadas por los rusos campesinos, artesanos o pequeños comerciantes. El siguiente cuerpo era el de los promyshlenniki quienes siempre estaban armados para enfrentar cualquier contingencia que se presentara con los nativos. El siguiente grupo se

\footnotetext{
${ }^{460}$ Black, op. cit., p. 7; Longworth, op. cit., pp. 133-134; Forsyth, op. cit., p. 42; Gibson, op. cit., pp. 82-83.
} 
formaba con los exiliados políticos y los prisioneros de guerra y por último, en el rango más bajo se encontraban las tropas auxiliares de nativos ${ }^{461}$.

A pesar de los esfuerzos de la burocracia moscovita, los gobernadores de Siberia hacían sus propios negocios de manera que, aunque gran cantidad de las pieles recolectadas llegaban a Moscú, muchas de ellas se quedaban en sus manos y las vendían por su cuenta, sumando sus ganancias al salario asignado de 250 rublos al año ${ }^{462}$. El cargo de gobernador o voyevoda se asignaba a miembros de la nobleza no sólo porque debían prestar servicio al zar sino también porque significaba la oportunidad de acrecentar su fortuna. Por ejemplo Dmitri Trubetzkoy, quien había participado en la batalla de 1612, fue nombrado voyevoda en Siberia. En muchos casos, los nobles compraban el cargo de gobernador con la expectativa de recuperar con creces su inversión ${ }^{463}$. En muchos casos, quienes ocupaban estos cargos pertenecían a los sectores medio y bajo de la nobleza, la oportunidad los transformaba en familias poderosas en Siberia. Así poco a poco, en Siberia apareció una nobleza formada por rusos y cosacos que también se mezclaban con los naturales que se ponían al servicio del zar. La familia Remezov es un ejemplo de este proceso. Moisei Remezov llegó a Tobolosk en 1625 y sus descendientes fueron servidores del zar en Siberia occidental ${ }^{464}$.

Pero, el gobernador también tenía problemas pues para cobrar el tributo era su deber registrar a los sujetos, tarea difícil de cumplir con pueblos nómadas ya que era fortuito que

\footnotetext{
${ }^{461}$ Dmytryshyn, op. cit., p. 28

${ }^{462}$ Forsyth, op.cit., p.41; Robert Joseph Kerner (1887-1956), "The Russian Eastward Movement: Some Observations on its Historical Significance" in Morgan B. Sherwood (Ed), Alaska and its History. Seattle, University of Washington Press, 1967. 475 pp., fotografías, pp.3-8; Gibson, op. cit., pp. 78-79; Parker, op. cit., pp. 124-125; Riasanovsky, op. cit., pp.194-195; Summer, op.cit., pp. 15-16, 28.

${ }_{463} \mathrm{http}$ ://www.en.wikipedia.org/wiki/Trubetskoy family\#Time of Troubles consultado 8 de marzo de 2013

${ }^{464}$ Christoph Witzenrath, "S. U. Remezov, Cossack Adventurer, and the Opening of Siberia" en Ostroski y Poe, op. cit., pp. 209-221.
} 
se presentaran las mismas personas, de manera que los censos eran inútiles. Así que para reunir las pieles que debía enviar a Moscú -conservar el puesto dependía de la cantidad de pieles que remitía- el gobernador exigía regalos de los nativos (pominki) que solo recibía en ocasiones a pesar de los castigos que recibían quienes no los daban. Cuando algún tributario registrado moría trataba de que sus parientes pagaran lo que le correspondía al difunto. El asunto se dificultaba más porque para borrar un registro se debía realizar un trámite que concluía con un ukaz que permitía eliminar al finado de la lista de tributarios. El envío de pieles también era un riesgo pues si el voyevoda pagaba por una piel un precio mayor del que le asignaban los burócratas de Moscú, él debía absorber la diferencia, el Estado siempre tenía ganancias. Además, de los recursos que se gastaban en la región, el gobernador debía pagar los abastecimientos para la tropa y los nativos aliados, si los había, y sufragar los gastos de las contiendas en contra de los grupos no sujetos a yasak. A los aliados podía compensarlos con el botín pero también debía pagarles por la ayuda para levantar las construcciones y por servir de guías y de traductores ${ }^{465}$. En efecto, con todo y la certeza de que los nativos eran inferiores, los conquistadores no podían prescindir ni de sus saberes, ni de su experiencia, ni de su ayuda.

\subsubsection{Exploración y establecimientos rusos}

A pesar de que la autocracia no parece haber elaborado un proyecto para la expansión sobre Siberia y la incorporación de este territorio a su patrimonio, tampoco podemos suponer que simplemente permitió que los exploradores y cazadores hicieran todo el trabajo. La riqueza que el bosque boreal podía proporcionar al Estado era conocida de tiempo atrás. Por tanto, las expediciones efectuadas por los emprendedores no eran ajenas a sus intereses. Por eso

${ }^{465}$ Slezkine, op. cit., pp. 21-23; Dmytryshyn, op. cit., p.26. 
las alentó, las apoyó y, en ocasiones las promovió. Fuera cual fuere el caso, en cuanto un nuevo territorio era explorado el zar enviaba a sus representantes y tropas para proteger a sus súbditos ${ }^{466}$.

La ruta por la taiga permitió que los promyshlenniki fundaran los ostrogi ${ }^{467}$ de Berezov y Pelym en 1593 y Mangazeia en 1601 en la ribera del río Yenisei, ésta se convirtió en el centro más importante de acopio de bienes y tributo y fue la base para la expansión sobre el resto de Siberia. Al sur de la taiga, en la cuenca del río Ob fundaron Sugut en 1594, Verjoturie y Narym cuatro años después y Tomsk en $1604^{468}$. En 1618 fundaron Kuznetsk en el sur de la taiga. Los rusos siguieron por Siberia central. En general, los exploradores conservaron la toponimia de los accidentes geográficos que los habitantes locales les daban, si hubo cambios se debieron a que no comprendían cabalmente los fonemas ${ }^{469}$. En 1607 ya habían explorado la cuenca del Yenisei y en 1619 fundaron el otrog de Yeniseisk, el cual fue la base de operaciones para explorar Siberia oriental. Se puede considerar que al terminar la segunda década del siglo XVII, unos cuantos años después del ascenso de los Romanov al poder, Siberia occidental estaba bajo el control de Rusia.

En 1633, Piotr Beketov (1600-17661) fundó el ostrog de Yakutsk que se convirtió en uno de los centros comerciales más importantes del noreste. Éste se encuentra sobre la parte alta del rio Lena y se convirtió en el sitio desde el cual salieron las expediciones que

\footnotetext{
${ }^{466}$ David N. Collins "Subjugation and Settlement in Seventeenth end Eighteen-century Siberia" en Wood, op. cit., pp. 37-56, p. 38

${ }^{467}$ La palabra española que mejor traduce el término ostrog (en singular) es presidio, es decir aquellos sitios localizados en la frontera del imperio español que tenían guarniciones para proteger a los colonos de los habitantes de los territorios recién colonizados, especialmente si los pueblos eran de cazadores-recolectores.

${ }^{468}$ Kotkin, op.cit., p. 10; Naumov, op. cit., p. 60.

${ }^{469}$ Kotkin, op. cit., p. 14.
} 
exploraron la costa asiática del Pacífico. Iván Perfilev (¿?) alcanzó la desembocadura del río Lena en 1633. Por este río regresaron a la costa en la tundra. Siguiendo por el sur, en 1639 Iván Moskvitin (i-c. 1647) llegó hasta las costas del Mar de Ojotsk pero los exploradores no desistieron de la ruta por el mar. A mediados del siglo XVII exploraron el extremo nororiental de Asia y bajaron hasta el Mar de Ojotsk. Es decir, llegaron a dicho mar siguiendo dos rutas: una al norte de la tundra navegando algunos tramos por los mares de Kara y Lapitev y por el sur siguiendo las cuencas de los ríos Ob, Yenisei, Lena y Kolyma. Por el sur de la taiga, Kurbat Ivanov (¿-1666) descubrió el Lago Baikal y Vasili Poiarkov (¿?) el río Amur en 1645. En esta región se fundaron los ostrogi de Albazin en 1651, Nerchinsk en 1654 e Irkutsk en $1661^{470}$. En el mapa 16 se pueden localizar las rutas de exploración y los fuertes más importantes fundados en Siberia.

${ }^{470}$ Naumov, op. cit., pp. 60-61; Forsyth, op. cit., pp. 38; Summer, op. cit., p. 27. 


\section{Mapa 16. RUSIA ASIÁTICA: SIBERIA EN EL SIGLO XVII}
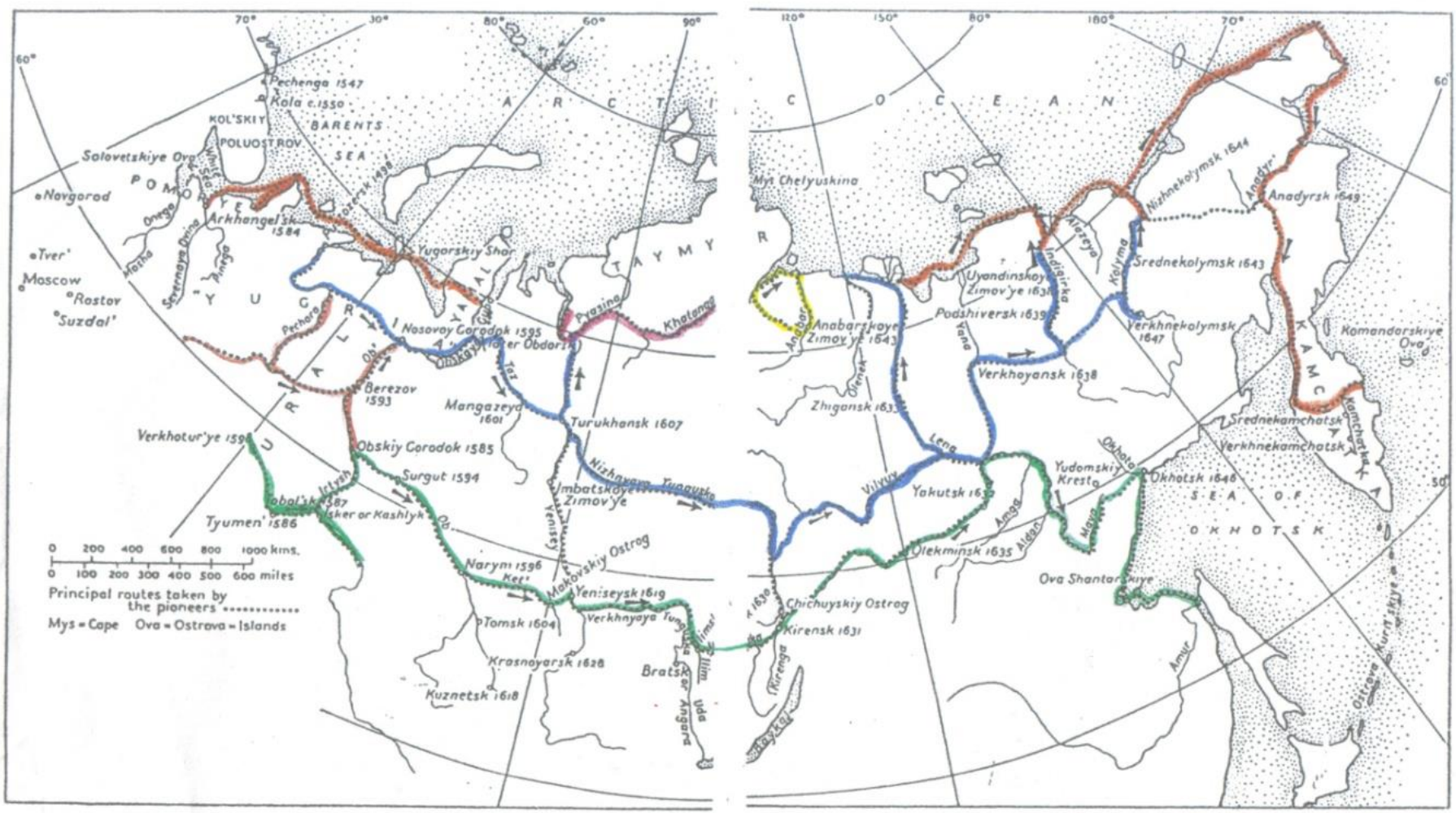

Map 2.I The Russian advance across Siberia in the sixteenth and seventeenth centuries

Source: Terence Armstrong. Russian Settlement in the North. Cambridge University Press, Cambridge. 1965, p. 12. (with permission)

Fuente: Basil Dmytryshyn, "The Administrative Apparatus of the Russian Colony in Siberia and Northern Asia, 1581-1700 en Alan Wood (ed.), The History of Siberia. From Russian Conquest to Revolution. Londres, Routledge, 1991, pp.17-36, p. 32. Los colores tienen como objetivo destacar las rutas.

No todos los asentamientos rusos alcanzaban el rango de ostrog, había guarniciones más pequeñas denominadas ostroyki y los pequeños campamentos de invierno llamados zimov'e donde los exploradores y cazadores rusos y cosacos se refugiaban. Estos sitios estaban acondicionados para que los rusos pudieran escapar en caso de un ataque 
sorpresivo de los nativos. Ahí se reunía el yasak y mantenían cautivos a los rehenes. Con el tiempo algunos se convirtieron en pueblos importantes pues los comerciantes solían refugiarse en ellos al igual que algunos artesanos. Además, usualmente tenían una iglesia y ahí se establecían los monjes. Así, estos fuertes fueron el origen de poblados y hasta ciudades en las que conquistadores y colonizadores convivían con los nativos ${ }^{471}$.

En el caso de Irkutsk, por ejemplo, en 1652 se estableció un zimov'e para recolectar yasak entre los buriatos y los tunguses. Tuvo un buen inicio y en 1661 fue reconstruido como ostrog. Alrededor de 20 años más tarde el asentamiento fue elevado al rango de ciudad en donde residía el voyevoda que controlaba toda la región de Siberia oriental ${ }^{472}$.

Hay que insistir sobre la expansión vía marítima. Los samoyedos que vivían en la costa fueron de los primeros pueblos que entraron en contacto con los rusos. Gran parte de las pieles de ardilla, zorro, marta cibelina y castor las conseguían los pomor'ie intercambiando artículos de metal y algunas chucherías con los nativos. Así fundaron Mangazeia y llegaron a la desembocadura del Yenisey. En la parte norte de Siberia central no navegaron pues los hielos del Ártico eran más densos. Retomaron la exploración de la costa en la desembocadura del río Komi hasta el río Oleniok. Pero casi en seguida hallaron la desembocadura del Lena, así que en el territorio anterior no fundaron ninguna aldea. Fue a partir del Lena que retomaron la navegación costera en dirección al este hasta que lograron rodear la península Chukchi y bajaron a la desembocadura del río Anadyr. Hay que subrayar que la exploración de Siberia se realizó en la costa por navegantes que siempre iban acompañados por cosacos de servicio y por promyshlenniki quienes usaban los ríos pero también los trineos para viajar por tierra.

\footnotetext{
${ }^{471}$ Dmytyshyn, op. cit., p. 24, 29-31.

${ }^{472}$ Collins, op. cit., p. 39
} 
El gobierno ruso fue muy cuidadoso en evitar que sus descubrimientos fueran conocidos en el exterior $y$, sobre todo, realizó esfuerzos para impedir que barcos extranjeros surcaran el Ártico. Por ello alrededor de 1600 fue prohibido el arribo de buques no rusos al puerto de Mangazeia ${ }^{473}$. Conforme los cazadores y exploradores rusos y cosacos avanzaron hacia el este el hermetismo del gobierno imperial fue mayor pues no deseaba que otros Estados europeos llegaran a China por el mar Ártico, de hecho Richard Chancellor había llegado a Rusia cuando buscaba una ruta para llegar a China y comerciar con ella ${ }^{474}$. Por otra parte, rusos y cosacos no tomaban posesión del territorio en nombre del zar sino que buscaban aquello que le diera riqueza esto es, seres humanos que pagaran tributo ${ }^{475}$, así que era determinante impedir que otros europeos lograran someterlos. Por tanto, para la autocracia rusa la expansión en Siberia implicaba también un asunto de seguridad, estaba dispuesta a impedir que cualquier otro Estado europeo pudiera amenazarla por el este ${ }^{476}$.

La exploración de la costa fue posible gracias a que desde el siglo XV los marinos desarrollaron la tecnología naval que les permitió construir embarcaciones llamadas koch que surcaban aguas muy frías y podrían resistir chocar con bloques de hielo. Cuando llegaron a la desembocadura del rio Kolyma, los emprendedores se convencieron de que era posible alcanzar el extremo nororiental de Asia navegando en dirección al este. Los promyshlenniki estaban muy interesados porque desde el ascenso de los Romanov al poder, el Estado les otorgaba licencias para efectuar expediciones tanto con fines comerciales como para explorar nuevos territorios, en este último caso cobraban sus servicios con las pieles que conseguían. Por lo tanto, a partir del segundo tercio del siglo XVII, la expansión

\footnotetext{
${ }^{473}$ Witzenrath, op. cit., p. 211.

${ }^{474}$ Dukes, op. cit., p. 51

475 Slezkine, op. cit., pp. 37-39.

476 Sixsmith, op. cit., p. 62.
} 
en el noreste estaba más o menos controlada por el gobierno para no perder el tributo y los impuestos de la décima parte de las ganancias de los particulares e impedir que se divulgaran los resultados de las nuevas exploraciones. Así, cuando se otorgaba una licencia para explorar, un funcionario acompañaba al grupo a fin de reportar puntualmente los resultados del viaje y cobrar la décima parte de las ganancias obtenidas por los comerciantes y los cazadores $^{477}$.

Gran parte de los cazadores que se aventuraron a explorar Siberia eran gente que buscaba hacer fortuna porque muchos pertenecían a los estamentos más bajos de la sociedad rusa. La mayoría eran iletrados que no tenían otra opción para mejorar sus condiciones de vida. Algunos eran fugitivos de la justicia que huían para evitar el castigo. Les siguieron otros fugitivos que escapaban de la servidumbre y tenían la intención de establecerse en un lugar que les ofreciera mejores condiciones de vida. Ellos constituyeron la mayor parte de la población migrante que ganó Siberia para el zar ruso.

\subsubsection{Emprendedores y campesinos}

El avance hacia el noreste fue facilitado en gran medida porque desde la Rusia europea hasta el este de Asia existe una gran planicie, además el clima de la tundra y de la taiga no les exigió a los promyshlenniki un esfuerzo especial de adaptación: navegaban, cazaban, pescaban y comerciaban mientras avanzaban al este. Esto implicó que el naciente imperio tuvo una frontera abierta hacia el noreste, en tanto que parecía no tener límite, y como la densidad de población de la región era muy baja se facilitó la emigración desde el oeste ${ }^{478}$.

\footnotetext{
477 Black; op.cit., pp. 15-16.

${ }^{478}$ Riasanovsky, op. cit., pp. 9-10; Summer, op. cit., pp. 26-27.
} 
A partir de la caída del janato de Sibir, el Estado fue estableciendo una red de fortificaciones (ostrog) para garantizar la seguridad de sus súbditos y mantenerlos en contacto con la Rusia europea. En los ostrogi había guarniciones militares y colonos, pues los habitantes de Siberia opusieron resistencia a la llegada de los rusos. Cuando fue necesario, los conquistadores sometieron a sangre y fuego a quienes se levantaron en su contra. Las fortificaciones se fundaban en las rutas de comunicación terrestres, fluviales y marítimas trazadas por los emprendedores cosacos y cazadores. Su ubicación estratégica los convirtió en los lugares de residencia del voyevoda y sus ayudantes de manera que los rusos debían pagar ahí sus impuestos y los nativos entregar el tributo. También se convirtieron en centros de intercambio entre los mismos rusos y con los naturales de Siberia. Los habitantes de los ostrogi también cultivaban durante los cinco meses que el clima lo permitía, pescaban y explotaban otros recursos del bosque boreal como la madera, la miel y la $\operatorname{cera}^{479}$

Por su parte, los inversionistas y cazadores estaban muy estimulados por las jugosas ganancias que podían obtener a pesar de los impuestos que pagaban al zar. Aunque hay que aclarar que no todos los exploradores cazadores amasaron fortunas porque vendían sus pieles a los comerciantes, es más, muchos de ellos ni siquiera obtuvieron el salario que el Estado debía pagarles. Los que incrementaron su riqueza fueron fundamentalmente los gosti ya que eran ellos quienes financiaban las expediciones y por ello, les correspondía la mayor tajada de las ganancias después de que el Estado cobraba las suyas. Por otra parte, los mercaderes se enriquecían no sólo porque vendían las pieles finas en otros mercados sino también porque ellos mismos llevaban cereales y otros productos agropecuarios a los

\footnotetext{
${ }^{479}$ Fairbank, op. cit., p. 45; Black, op. cit., pp. 15-16.
} 
cosacos y rusos que habitaban entre los pueblos del norte de Asia quienes sólo se dedicaban a cazar y no practicaban la agricultura ${ }^{480}$.

En 1626, el zar ordenó levantar el primer mapa oficial de Siberia ${ }^{481}$, quería saber cuáles eran los pueblos incorporados al imperio, los impuestos que podía recaudar, las riquezas minerales que se encontraban en su territorio y las rutas de comunicación marítimas y terrestres con la Rusia europea. Tal medida era indispensable para procurar ejercer su poder con base en la información sobre las costumbres de los pueblos con los que se habían topado los cazadores y exploradores y la riqueza natural de que disponían. Al reunir la información se realizó una primera clasificación de los pueblos que habitaban el norte de Asia: sedentarios (sidiache) y nómadas (kochevye o kochevnye). Estos últimos se distinguían en: pastores (skotnye), agricultores (pashennye), pedestres (peshie), jinetes de caballos (konnye) y jinetes de reno (olennye). Sin embargo, los exploradores cosacos casi nunca presentaban informes bien estructurados sino que recopilaban datos de forma fragmentaria y siempre enfocados a los obstáculos que podrían presentarse para extraer tributo de los pueblos con los que entraban en contacto ${ }^{482}$.

En Siberia había rusos que sabían leer y escribir. Semen Ulianovich Remezov (1642- $c$. 1720) nacido en Tobolsk era miembro de una familia de la pequeña nobleza radicada en Tobolsk. Su tarea principal consistía en elaborar mapas de Siberia. Los primeros los realizó según había aprendido en su ciudad natal pero más tarde recibió educación en Moscú. En sus mapas ubicaba los asentamientos rusos así como los territorios en los que vivían los nativos. Añadía la información recopilada de los informes redactados

\footnotetext{
${ }^{480}$ Wallerstein I, op.cit., p.435; Longworth, op. cit., pp. 131-132.

${ }^{481}$ Black, op.cit., pp. 15, 30, la autora señala que no hay certeza sobre si el mapa de 1667 fue resultado del trabajo que ordenó el zar Mijail.

${ }^{482}$ Slezkine, op. cit, pp. 38-39; Longworth, op. cit., p 133; Parker, op. cit., p.134.
} 
por los expedicionarios rusos y cosacos y también relatos que los nativos compartían con él. Después de muchas indagaciones se produjo el primer atlas que daba cuenta de los pueblos y los recursos que se encontraban en Siberia, pero fue hasta 1667 que se dibujó el primer mapa de la región y se cumplió la orden del zar. Por su parte, Remezov publicó su atlas de Siberia en $1701^{483}$.

Tal vez para afianzar el dominio ruso sobre el territorio siberiano, el mismo zar ordenó en 1630 que fueran reubicados vecinos de pequeñas ciudades como Ustyug, Vologda, Tot'ma y Sol'vychegodsk en el asentamiento de Tobolsk fundado en 1587 en la parte alta del río Ob y que según su parecer no contaba con suficientes habitantes rusos. Además, la intención del gobierno fue estimular el desarrollo de la agricultura en Siberia occidental la cual fue fundamental para el avance sobre el resto de la llanura siberiana. Quienes se convertían en labradores en Siberia no siempre eran campesinos que habían escapado de sus señores, en muchos casos eran siervos del Estado, nobles caídos en desgracia y nativos forzados a aprender las labores del campo. El gobierno de Moscú promovía su mudanza a Siberia para que cosecharan los cereales para el consumo de las líneas de avanzada. Por tanto, aunque la servidumbre no se extendió al norte de Asia, los campesinos tampoco vivieron al margen de la administración estatal, ya fueran siervos del Estado o independientes, tarde o temprano todos pagaban impuestos ${ }^{484}$.

Algunos territorios del este de los Urales fueron cedidos a los monasterios y sólo en ellos existió la servidumbre pero la mayoría de los colonos eran "gente negra", o sea plebeyos dueños de sus tierras pudieran o no cultivar en ellas. Los cosacos y rusos

\footnotetext{
${ }^{483}$ Witzenrath, op. cit., passim. El mapa completo de Remezov no se encuentra pero fragmentos de su obra pueden consultarse en http://mmedia.nsu.ru/remezov/vbook/obj8/title.htm consultado 12 de agosto de 2014. ${ }^{484}$ Black, op. cit., p.7; Longworth, op. cit., p. 131; Slezkine, op. cit., p. 25.; Collins, op. cit., p. 40
} 
avanzaron más rápidamente que la iglesia porque no pudo fundar monasterios más allá de Siberia occidental pues era sumamente difícil cultivar y el zar tampoco les concedió tierras. La mayoría de los labradores inmigrantes se organizaron en aldeas campesinas, como grupo pagaban los impuestos, hacían labores administrativas, decidían cómo se repartían las parcelas y mantenían a los fuereños lejos de las tierras que consideraba de su propiedad comunal. En estas comunidades, que reproducían a la antigua aldea campesina, cada familia tenía su propia parcela y la cultivaba por su cuenta y riesgo pero los miembros de la comuna le prestaban ayuda si no levantaba buenas cosechas. En los siglos XVI y XVII las comunas se apoderaban de territorios extensos y a cada familia le tocaba una porción grande de tierra ${ }^{485}$. A pesar de que no era sencillo cultivar porque cuando las cosechas se perdían las semillas tardaban en llegar y los nativos se resistían a la aceptar a los agricultores, en 1662 los campesinos rusos habían logrado convertir a la región de Tobolsk en la productora principal de cereales en Siberia occidental ${ }^{486}$.

En el norte de Asia no se impuso el sistema pomestye sencillamente porque sólo en pequeñas zonas podía cultivarse, de manera que era el lugar ideal para huir de las cargas impuestas por los terratenientes y el Estado. La época de la smuta favoreció la inmigración de emprendedores pero también la de bandas de asaltantes que asolaban la costa del Mar Blanco. Sin embargo, algunos lograron obtener buenas ganancias con la agricultura. Ése fue el caso de Yerofei Pavlovich Jabarov (¿-1671) quien nació en el seno de una familia campesina en Veliki Ustiug. En 1628, decidió avecindarse en la región del río Lena, distrito

\footnotetext{
${ }^{485}$ Blum, op. cit., p. 157, 162-164, 521; Dukes, op. cit., p. 79; James R. Gibson [actualmente profesor emérito en la Universidad de York, Toronto, Canadá],"Paradoxical Perceptions of Siberia: Patrician and Plebeian Images up to the Mid-1990s" en Galya Dimet (PhD 1987) y Yuri Slezkine (Eds.), Between Heaven and Hell. The Myth of Siberia in Russian Culture. Nueva York. St. Martin's Press, 1993. 278 pp., pp. 67-89, pp., pp. 83-85.

${ }^{486}$ Kotkin, op. cit., pp. 15-16
} 
de Yakustk. Recibió tierras del gobierno local que dedicó al cultivo y en las que explotó la sal. Su prosperidad le permitió construir un molino, pero, al parecer, cometía abusos en contra de sus trabajadores, seguramente nativos, y los precios de sus productos eran altos. Lo cierto es que el voyevoda le confiscó todas sus propiedades y lo encarceló en 1642. Cuando salió libre tres años después, se dirigió a la región del Amur. Emprendió una campaña entre 1650 y 1652, se apoderó del fuerte de Albazin donde sometió por la fuerza a la población local. El cultivo de sus tierras fue tan exitoso que proveía a toda la región con pan. No obstante, en 1654 le confiscaron nuevamente sus propiedades pues fue acusado ante el voyevoda de crueldad y abusos extremos en contra de la población. Fue enviado a Moscú en donde en lugar de un castigo recibió el título de boyardo pues el zar consideró que sus servicios le fueron muy útiles, también lo recompensó nombrándolo administrador de Ust-Kut ubicada en Siberia occidental, en donde murió. En su honor este poblado recibió el nombre de Jabarovsk ${ }^{487}$.

Pero no todos eran tan afortunados, hubo cazadores y exploradores que vivían en la penuria y campesinos que tampoco solucionaron su pobreza. Algunos quedaron sumidos en la miseria y si eran nativos forzados a labrar el campo, vivían como esclavos o siervos. De igual manera, las mujeres que llegaron del occidente sufrieron abusos por parte de cosacos y rusos, si quedaban viudas o eran solteras los hombres con poder las obligaban a cohabitar con ellos ${ }^{488}$.

El zar mantuvo el monopolio de la venta de las pieles finas, fruto del yasak, en los mercados de Asia y Europa occidental lo que le brindó grandes ganancias. Las pieles siberianas se introducían en el mercado europeo y también las compraban gobernantes

\footnotetext{
487 Naumov, op. cit., p.62.

${ }^{488}$ Forsyth, op. cit., p. 67-68
} 
asiáticos que las utilizaban como símbolo de prestigio. Pero Siberia proporcionaba otros productos: los halcones utilizados en la cacería también podían capturarse en Siberia. La grasa de las focas, los bigotes de las morsas y el marfil de los colmillos de los mamíferos marinos eran asimismo demandados en el exterior. Minerales como el hierro o el oro se extraían fundamentalmente para el consumo local pero también se exportaban en pequeñas cantidades. El ámbar del bosque boreal también era sumamente apreciado ${ }^{489}$.

Recapitulando: la población que se encontraba en Siberia alrededor de 1670 estaba integrada por los pueblos nativos y los conquistadores y colonizadores oriundos de la Rusia europea. Estos últimos eran los promyshlenniki-emprendedores, cazadores y comercianteslas personas que huyeron, la mayoría campesinos, los hombres de servicio enviados por el Estado ya fuera para colonizar o administrar (monjes, siervos del Estado y cosacos de servicio), los funcionarios de alto rango y, por último, los enemigos del Estado (políticos, religiosos y prisioneros de guerra $)^{490}$. El número de migrantes desde la Rusia europea a Siberia es incierto. Para el año de 1662 algunos cálculos arrojan 70000 inmigrantes esparcidos por todo el territorio y otros suman alrededor de 150 000. En cualquier caso la cifra fue impactante para una población nativa que se calcula entre alrededor de 200000 a 288000 habitantes ${ }^{491}$.

En el siguiente apartado analizaremos los vínculos que se establecieron entre los inmigrantes llegados de la Rusia europea y los nativos de Siberia, proceso que refrendó las características multiétnicas y multiculturales del Estado que tuvo sus antecedentes en la Rus

\footnotetext{
${ }^{489}$ Longworth, op. cit., p. 133.

${ }^{490}$ Dmytryshyn, op. cit., p. 22.

${ }^{491}$ Moss, op. cit., pp. 178-179; Krotkin, op. cit., p. p. 15.
} 
de Kiev, nació en el ducado de Moscovia y se convirtió en imperio cuando fue coronado el primer zar.

\subsection{Interrelaciones con los pueblos del norte de Asia}

\subsubsection{Los habitantes de Siberia}

Cuando los rusos incursionaron en el noreste los pueblos que ahí habitaban eran nómadas o trashumantes si consideramos a los que tenían rebaños de renos ${ }^{492}$. La mayoría cazaban y recolectaban frutos del bosque boreal, pero también había comunidades dedicadas al pastoreo del reno y a la cría de caballos. Dada la hidrografía del norte de Asia muchos pueblos vivían de la pesca, en la tundra donde prácticamente no había vegetales cazaban mamíferos marinos en el Mar Ártico. Asimismo tenían perros.

Sólo algunos pueblos del sur, cercanos a la estepa, practicaban la agricultura aunque no dependían de ella, por ello, no prescindían de la cacería, la pesca o el pastoreo. Estos pueblos estaban organizados en bandas o tribus, según el caso de manera que no había una autoridad permanente al interior del grupo porque eran sociedades igualitarias. Muy pocas comunidades podrían considerarse jefaturas. Las familias estaban agrupadas en clanes exogámicos y mediante el parentesco se creaban vínculos de solidaridad entre ellos. El trabajo se realizaba de acuerdo con la edad y el sexo, por lo común los hombres proveían la comida y las mujeres se encargaban de satisfacer el resto de las necesidades del grupo como el transporte o la confección de ropa. Ya que eran sociedades igualitarias, la redistribución de bienes se hacía por medio de la dote para la novia, el trueque y el intercambio de regalos. Tenían una religión animista por lo que mostraban un gran respeto

${ }^{492}$ Forsyth, op. cit., p.10 passim; Sleznike, op. cit., pp. 3-7, 39, Moss, op. cit., p. 178. 
a la naturaleza. El personaje que ponía a la comunidad en contacto con los espíritus y por lo común guiaba los ritos era el chamán ${ }^{493}$. Aunque compartían rasgos culturales semejantes, los pueblos del norte de Asia hablaban una enorme variedad de idiomas, lo que indica entre otros elementos- una diversidad cultural muy compleja. Había pueblos de troncos lingüísticos ugro-finés, urálico y turco. La ubicación aproximada de los pueblos se muestra en los mapas 14 y 17.

\section{Mapa 17. PUEBLOS DE SIBERIA AL INICIAR EL SIGLO XVII}

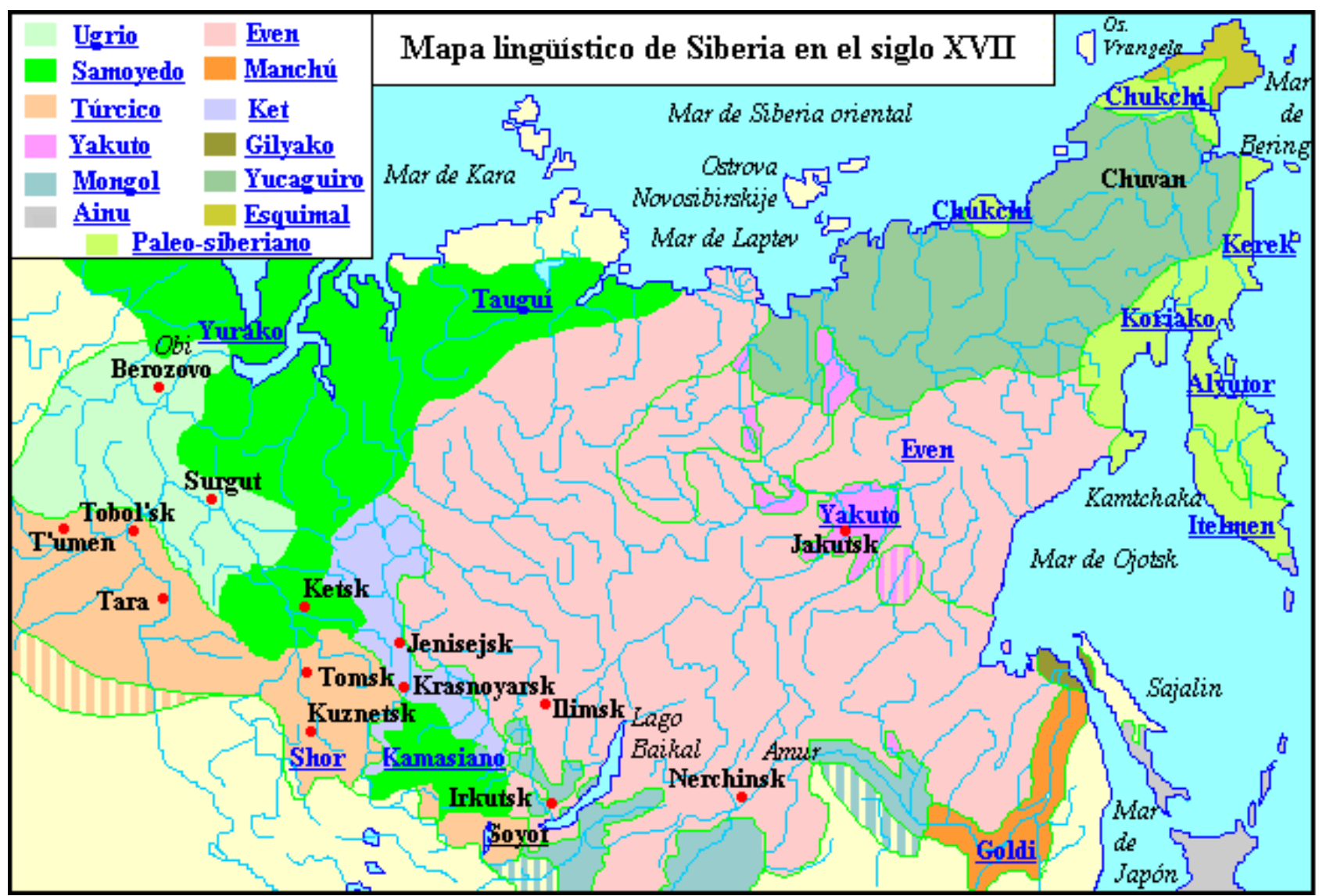

Fuente: http://www.proel.org/indexphp?pagina=mundo/paleosibe consultado $12 \mathrm{de}$ agosto de 2014

\footnotetext{
${ }^{493}$ El texto clásico que caracterizó sistemáticamente la práctica de los chamanes en Asia es el de María A. Czaplicka, op. cit., publicado por primera vez en 1914.
} 
Entre los ríos Ob y Yenisey habitaban los selkup que los rusos llamaron samoyedos ostyak, según algunos cálculos en el siglo XVII sumaban alrededor de 3200 personas. Cercanos al río Yenisey se encontraban los kets cuyo idioma no ha podido relacionarse con ningún tronco linguiístico. Sumaban alrededor de 2000 personas. Vivían de la pesca, caza y recolección, pero aquellos que se encontraban al norte también criaban renos. Ambos pueblos navegaban con destreza por los ríos. Los kets que se localizaban al sur conocían el cultivo y tenían hatos de caballos y reses, asimismo trabajaban el hierro. A pesar de algunas diferencias entre ellos, se mezclaban entre sí y también con los eslavos. Al sur, en los linderos entre la taiga y la estepa, se encontraban los kirguises quienes hablaban un idioma de la familia lingüística turca. Se calcula que 8000 individuos eran kirguises. Formaron parte del imperio mongol. Eran criadores de ganado aunque algunas tribus cultivaban y cazaban pero todos eran trashumantes. Comerciaban con los chinos y los persas pues además de producir artículos de cuero, fabricaban armas de hierro y ofrecían pieles finas así que los rusos se beneficiaron de estas redes de intercambio. Algunas tribus kirguises practicaban el budismo. Los que se encontraban al oeste se integraron a los janatos de Kazan y Sibir y adoptaron el islam. Cuando fue destruido el janato de Kazan, de los tártaros se desprendieron los bashkires. Había alrededor de 25000 tártaros de Siberia Ya que los kirguises y los tártaros eran los pueblos mejor organizados, en gran medida gracias a la herencia mongola, antes de la expansión rusa ellos cobraban tributo tanto a los kets como a los samoyedos pero no consiguieron islamizarlos. Pese a la fundación de los ostrogi de Tomsk y Kuznets la mayoría de estos tártaros y kirguises conservaron su autonomía durante el siglo XVII. De hecho, estos últimos asentamientos eran pequeños enclaves habitados por rusos y tártaros de servicio que competían día con día con los nómadas por 
explotar los lugares de caza, las pescaderías y cobrarles, a quienes se dejaran, algo de tributo $^{494}$.

Entre los tártaros y los kirguises, habitaban pueblos que se clasifican como turcos de Altai. Los teleut formaban parte de estos últimos. Criaban ganado vacuno y equino, cazaban, pescaban y recolectaban, en el siglo XVII sumaban alrededor de 5000 personas. Las rutas por las que transitaban con su ganado los pusieron en contacto con los rusos de Tomsk. En el siglo XVII, establecieron una alianza con el voyevoda que residía ahí. Aceptaron dar regalos (pominki) al zar pero solamente cuando ellos así lo desearan, por lo tanto no estaban sujetos al pago de yasak. Ya que acordaron una alianza militar en 1609, entregaban rehenes a los rusos. En la práctica los teleut no estaban sujetos a los rusos antes bien se creó una relación de dependencia mutua. Los teleut compraban productos agrícolas y hierro a los rusos y éstos adquirían caballos, reses, cueros y mujeres. Sin embargo, sus relaciones no siempre fueron cordiales pues los teleuts y los rusos competían por cobrarles tributo a los pueblos vecinos ${ }^{495}$.

En la costa norte de Siberia occidental, había aldeas de jantys que no eran nómadas porque no tenían a dónde ir pero que sabían explotar muy bien los recursos marinos. El este del Yenisey se encontraron con los pueblos tunguses quienes se extendían desde la tundra hasta la taiga y sumaban aproximadamente 36000 habitantes $^{496}$. Estos pueblos hablan una lengua que algunos estudiosos consideran derivó del tronco lingüístico altaico, pero no existe consenso pues otros consideran que pertenece al tronco de los idiomas túrquicos y otros más piensan que pertenece a la familia mongola. Comprenden diferentes pueblos:

\footnotetext{
${ }^{494}$ Naumov, op. cit., p. 48; Forsyth, op. cit., pp. 19-26, 37, 95; Kotkin, op. cit., p. 10; Geniya Derevyannykh "Bashkirs" en http://www.russiasperiphery.blogs.wm.edu/russias.../bashkirs/ consultado 6 de mayo de 2014 ${ }^{495}$ Collins, op. cit., pp. 49-50

${ }^{496}$ http://www.es.wikipedia.org/wiki/Pueblos_tunguses consultado 6 de mayo de 2014.
} 
evenki, evens, yurchen, negidal, nanai, orok y ulchs que vivían en Siberia, también hay pueblos tunguses en China. Todo ellos eran pueblos de criadores de venados y renos. El rebaño pertenecía a la comunidad y estos animales no eran sacrificados pero a los renos no domesticados sí los cazaban. Usaban las pieles de venados y renos para vestirse, los ordeñaban y los montaban. Durante el invierno se dispersaban en pequeñas bandas pero en el verano formaban campamentos hasta de 12 tiendas cónicas cubiertas de cuero de reno en las que habitaba una familia. También cazaban y obtenían otros recursos del bosque y aunque cada clan reconocía un territorio en el cual se movía, en épocas de escasez lo compartía con otros parientes pero consideraban negativo tomar de la naturaleza más de lo que necesitaban para vivir. Los padres arreglaban el matrimonio de los hijos y el novio debía trabajar una temporada para la familia de la novia antes de casarse. Tenían una religión animista y un chamán que realizaba los ritos de comunicación con los espíritus. Tenían una gran veneración al oso pardo. No enterraban a los muertos, solo los colocaban sobre la tierra o sobre los árboles con sus armas. Los tunguses que vivían en la costa ártica habían aprendido de los samoyedos a cazar mamíferos marinos y a pescar. Los tunguses vecinos de los mongoles se asemejaban a éstos, vivían en yurtas y criaban ganado vacuno y caballar $^{497}$.

Los tunguses del este compartían su territorio con los yakutos que constituían una población de 30000 personas y al sur, en la zona del lago Baikal con los buriatos que eran alrededor de $25000^{498}$. Los primeros hablaban un idioma de la familia túrquica mientras que los buriatos uno del tronco mongólico. Los yakutos se llamaban a sí mismos saja.

\footnotetext{
${ }^{497}$ Forsyth, op. cit., pp. 36-37, 48-55; http://www.es.wikipedia.org/wiki/Lenguas tunguses consultado 6 de mayo de 2014.

498 Naumov, op. cit., p. 48.
} 
Criaban ganado vacuno y caballar. Durante el verano vivían en yurtas y consumían leche de vaca y de yegua así como carne de caballo. En el invierno vivían en cabañas comunales en las que había lugar para el hogar que les proporcionaba calor y luz. Sabían trabajar el hierro. Para cazar, usaban cascos además del arco y la flecha. Estaban organizados en jefaturas, el jefe recibía el nombre de toyon. La jefatura era electiva aunque también podía heredarse, el chamán realizaba el rito de investidura del jefe. Estaban divididos en 80 tribus cuyos clanes eran endogámicos. Eran animistas y los espíritus más venerados eran el oso, el cuervo y el águila. Antes de la llegada de los rusos estaban en franco proceso de expansión hacia el oeste, el norte y el este. Los yakutos protagonizaron rebeliones en contra de los rusos en 1634, 1638 y 1648. En su territorio fue fundado el ostrog de Yakutsk ${ }^{499}$.

Los buriatos tenían una cultura ecuestre porque eran mongoles. Habían formado parte del imperio mongol construido por Gengis Jan, se rebelaron y derrotados fueron diezmados. Cuando los rusos y cosacos aparecieron en la región, los buriatos practicaban el budismo. Aunque criaban caballos, muchas jefaturas eran sedentarias porque cultivaban cebada, heno y trigo negro, complementaban la dieta con la caza. Los jefes, llamados janes o taishis, tenían poder en tiempo de guerra y les correspondía mayor parte del botín. Por ello había algunos jefes que poseían hatos numerosos sobre todo en las comunidades del este, éstos se denominaban noyon. En esta sociedad jerarquizada, los chamanes gozaban de gran prestigio. Había chamanes de varias generaciones que estaban por encima de los chamanes de primera generación. También se distinguían en chamanes blancos, si servían a los espíritus del cielo y chamanes negros si se comunicaban con los espíritus

\footnotetext{
${ }^{499}$ Forsyth, op. cit., pp. 55-57; http://www.es.wikipedia.org/wiki/Yakutos consultada 9 de agosto de 2014.
} 
subterráneos $^{500}$. Tenían un panteón muy grande en el que también incluían a algunos ancestros. Los buriatos que vivían al este conservaron la escritura aprendida bajo el dominio del imperio mongol ${ }^{501} \mathrm{y}$, a pesar de los rusos, conservaron su escritura y su literatura. Comerciaban con los tunguses y los chinos. Gracias a su herencia mongola, tenían una organización militar eficiente que les permitía guerrear en contra de otros pueblos para obligarlos a entregarles tributo, pero los propios buriatos eran tributarios de los mongoles. Desde 1625, los rusos y cosacos aparecieron en su territorio y se inició la guerra entre ellos ya que los rusos intentaron obligarlos a pagar yasak mientras que los buriatos, a su vez, querían seguir cobrando tributo a los kets y los samoyedos. En algunos casos, los rusos tuvieron éxito pero en este periodo no consiguieron someter a todas las jefaturas. Por eso se fundaron varios ostrogi en el norte de la estepa a fin de vencer la resistencia de los buriatos y de evitar que asaltaran y cobraran tributo a los pueblos que los rusos ya habían sometido al pago del yasak. Un duro golpe para el intercambio de los buriatos fue el acuerdo entre los mongoles y el zar para comerciar. Sin embargo, el territorio que los mongoles ocupaban colindante con el de los buriatos fue zona de conflicto para los rusos en el siglo XVII ${ }^{502}$.

Al este del territorio de los mongoles se localiza la cuenca del río Amur, región propicia para el cultivo. En el siglo XVII, tras la instauración de la dinastía manchú en 1644, el imperio chino empezó a colonizar esta región ubicada en su frontera nororiental. Desde 1652, los rusos y cosacos intentaron establecerse en la zona. Atacaron a los daures pueblos criadores de ganado que vivían ahí y tributaban al imperio chino. En consecuencia,

\footnotetext{
${ }^{500}$ Czaplicka, op. cit., pp. 67-68

501 Véase apartado 3.1 de esta tesis.

502 http://www.centrodeartigos.com/artículos-enciclopédicos/article_88121.html consultado 6 de mayo de 2014; Forsyth, op. cit., pp.84-94, 96-98; véase mapa 17.
} 
los chinos de inmediato se dieron a la tarea de repeler a los rusos. Aunque no lograron apoderarse de manera permanente de ninguna porción del territorio, los promyshlenniki realizaban incursiones para conseguir cereales y en ocasiones hasta llevaban campesinos para obtener sus propias cosechas. Más tarde, esta situación propició un conflicto fronterizo entre China y Rusia ${ }^{503}$.

En el extremo oriental de Siberia localizado en la tundra, los exploradores y cazadores conocieron a los chukchis, los esquimales llamados yuipik en Siberia, los yukaghirs y los koriacos, estos últimos también habitaban en la península de Kamchatka junto con los itelmenos. Todos los pueblos mencionados ocupaban la zona desde la desembocadura del rio Kolyma hasta la costa del Pacífico y la península de Kamchatka como puede verse en el mapa 17. Compartían muchos rasgos culturales, se considera que todos ellos vivían en la etapa del paleolítico superior pues en esa zona es imposible cultivar. Con excepción de los itelmenos, había comunidades que vivían cerca de las costas y otros que vivían en el interior, dependiendo de su ubicación sus medios principales de subsistencia cambiaban. Aunque hablaban lenguas distintas, todos tenían rasgos semejantes y practicaban el trueque unos con otros.

La economía de los esquimales de Siberia estaba volcada hacia el mar. A los mamíferos marinos que otros pueblos cazaban en la costa del Ártico, ellos sumaban la cacería de ballena. Estos animales les proporcionaban todas las materias primas que necesitaban para vivir, tenían tiendas de verano cubiertas de piel de foca o reno, trabajaban el marfil, la ropa impermeable que usaban cuando salían en sus embarcaciones a cazar ballenas, la fabricaban con los intestinos de los mamíferos. La ropa diaria era de piel de

\footnotetext{
${ }^{503}$ Forsyth, op. cit., pp. 103-105, Fairbank, op. cit., p. 45; Naumov, op. cit., pp. 48, 65; Kinder y Hilgemann, op. cit., p. 299.
} 
foca. Usaban la grasa como combustible para encender lámparas y también les servía de alimento. En el invierno habitaban en casas comunales semisubterráneas. Se tatuaban el rostro, el antebrazo y las manos y se insertaban huesos en los labios. Estaban organizados en bandas relacionadas por lazos de parentesco, lo que fortificaba la solidaridad entre ellas necesaria para cazar de manera conjunta las ballenas y repartir todo lo que obtenían de ellas. Por esta razón, hacían ritos especiales cuando iniciaba la cacería de la ballena. La hospitalidad sexual era otra forma de establecer lazos de solidaridad entre las diferentes bandas. El único miembro que gozaba de cierto prestigio social era el chamán, aunque no tenía ninguna autoridad sobre el grupo ${ }^{504}$.

Los chukchis se localizaban en el extremo nororiental de Asia, si vivían en la costa su economía era similar a la de los esquimales, juntos sumaban alrededor de 7000 personas. Las bandas que estaban en el interior pastoreaban manadas de renos ayudados por los perros hausky. Hablaban una lengua de la familia chukota-kamchatka que está considerada una de las más antiguas del continente. El chukchi es un idioma que se habla distinto según el género. Se autodenominan luoraverlan que significa "hombres honrados". Su religión era animista, creían que el cuervo había creado el mundo. Esculpían en madera y piedra las imágenes de los espíritus que veneraban y sacrificaban en su honor renos o perros. El chamán encabezaba todos los ritos y cumplían, como es usual, con la tarea de comunicarse con los espíritus para aliviar la enfermedad. Durante el verano, los hombres estaban completamente desnudos y las mujeres, por su parte, descubrían su torso y sus brazos, es decir, estaban acostumbrados a soportar temperaturas muy bajas. En el invierno sus vestidos eran de piel de reno. Estaban organizados en bandas endogámicas, practicaban

\footnotetext{
${ }^{504}$ Forsyth, op. cit., pp.70-71; http://www.taringa.net/posts/info/16821812/Origen-de-los-Esquimales.html consultado 10 de agosto de 2014.
} 
la poligamia, es decir, un hombre podía tener varias esposas a la vez y las mujeres podían cambiar de marido. Asimismo, acostumbraban la hospitalidad sexual, esto es, al recibir a un forastero, éste pasaba la primera noche con la esposa del huésped; con ello se establecían lazos de solidaridad. Cuando algún miembro de la comunidad estaba irremediablemente enfermo y era viejo solicitaba a alguno de sus parientes que lo matara ya fuera estrangulándolo o disparándole un dardo. Eran muy buenos guerreros, por eso en el siglo XVII los rusos no lograron imponerles el pago de tributo ${ }^{505}$.

Los koriacos se localizaban al norte de la península de Kamchatka y también había comunidades al interior de ésta. Ellos se nombraban a sí mismos chauchu'si o chauchen si pastoreaban reno y nemelan si eran pescadores. Existían alrededor de 10000 individuos que hablaban siete variantes del idioma koriaco perteneciente a la familia chukotakamchatka. Su cultura era sumamente parecida a la de los chukchi. Tenían hatos de renos, hacían mantequilla y queso con la leche y los montaban. Consumían salmón que pescaban en los ríos. Usaban trineos y raquetas para caminar en la nieve. En su religión animista también veneraban al Gran Cuervo que era el protagonista de su mito de origen ${ }^{506}$.

En las costas de Kamchatka rodeando a los koriacos vivían las comunidades de itelmenos. Ellos fueron llamados por los rusos kamchadales. Su lengua pertenecía a la familia chukota-kamchatka. Eran pescadores y cazadores. Construían canoas de un solo tronco a diferencia de sus vecinos que usaban botes hechos de piel de foca. También utilizaban trineos y domesticaron al perro para que tirara de ellos. Pescaban con redes,

\footnotetext{
${ }^{505}$ Forsyth, op. cit., pp. 71-74; Juan Antonio Cantos Bautista, "Chukchi: un pueblo de pastores de renos y pescadores de Siberia” en http://www.suite101net/...chukchi-un-pueblo-de-pastores-de-renos-y-pescadoressibir... Consultado 8 de mayo de 2014; Naumov, op. cit., p. 48.

${ }^{506}$ Forsyth, op. cit., pp. 71-74; "Koryaks" en The Red Book of the Peoples of Russian Empire en http://www.eki:ee/books/redbook/Koryaks.shtml consultado 8 de mayo de 2014; http://www.es.wikipedia.org/wiki/Koryaks consultado 8 de mayo de 2014, Naumov, op. cit., p. 48.
} 
arpones y trampas y cazaban mamíferos marinos y zorros. Sus ropas estaban fabricadas de las pieles de todos estos animales. Aunque eran bandas igualitarias, las mujeres se adornaban con una peluca, y competían entre ellas para ceñir la mejor, entre más grande y preciosa fuera, la portadora recibía más admiración. Al igual que sus vecinos sus creencias eran animistas y se destacaban por sus conocimientos de herbolaria. Los itelmenos eran alrededor de 12000 a la llegada de los rusos ${ }^{507}$.

El oeste de los chukchi y norte de los koriacos se encontraban los yukaghirs quienes tenían una población de 5000 habitantes aproximadamente. A pesar de habitar en la tundra su cultura era un tanto diferente a la de los grupos anteriores. Los que vivían en la costa se alimentaban de pescado y de alce. Los del interior tenían rebaños de reno. A los renos salvajes los cazaban entre toda la comunidad pues los acorralaban azuzándolos y así los mataban. En verano, vivían en tiendas cónicas o yurtas igual que sus vecinos, pero en el invierno habitaban cabañas recubiertas con barro para guardar el calor. Estaban divididos en dos linajes que hablaban distintos idiomas así que no se entendían unos a otros. Cada uno de ellos tenía su propio chaman. Esto significa que los linajes no consideraban tener una ascendencia común. Cuando el chaman moría, lo descuartizaban y se repartían los huesos y la carne como reliquias, el resto del cuerpo lo enterraban en una caja de madera y esculpían su estatua. Así cada chaman muerto se convertía en objeto de culto. Los yukaghirs fueron sometidos al pago del yasak, como ellos no cazaban presas pequeñas fueron intercambiando sus bienes como trineos o renos con sus vecinos y con los propios

507 "Itelmenos" en The Red Book of the Peoples on the Russian Empire en http://www.eki.ee/books/redbook/itelmens.shtml consultado 8 de mayo de 2014; Naumov, op. cit., p. 48. 
conquistadores para cubrir el tributo. El resultado fue que poco a poco se redujeron, los sobrevivientes se mezclaron con los rusos. El pueblo yukaghir como tal desapareció ${ }^{508}$.

\subsubsection{El proceso intercultural en Siberia}

Una vez descritos a grandes rasgos los pueblos que habitaban Siberia se tratará acerca de las relaciones que rusos y cosacos entablaron con ellos, cómo los afectaron, cómo ellos influyeron en los conquistadores y cuál era la situación en Siberia en el tercer cuarto del siglo XVII. Los rusos cazadores y administradores, consideraban que el norte de Asia estaba "desocupado" porque la mayoría de sus habitantes no practicaban la agricultura. Por tanto la primera diferencia que establecieron entre los nativos y ellos fue que los rusos eran cultivadores sedentarios mientras que aquellos eran cazadores y pastores nómadas lo que implicaba que no ocupaban el territorio porque no se arraigaban en él. Hay que puntualizar que esta clasificación no era adecuada respecto de los cazadores rusos y cosacos puesto que ellos tampoco eran agricultores, sin embargo, era operativa porque después de ellos, en algún momento se avecindarían sus paisanos labradores. Por ello, cuando el tráfico de pieles decaía en alguna zona se propiciaba la inmigración de campesinos rusos para que los territorios del norte de Asia ubicados al occidente y en el centro fueran "ocupados"509.

Así pues este extenso territorio fue colonizado por labradores que huían de la Rusia europea pues ahí era casi imposible que sus señores los encontraran porque la justicia no los buscaba. El zar quería que las tierras de Siberia se cultivaran, por ello la persecución cesaba al atravesar los Urales. También sirvió de refugio a individuos fuera de la ley y

\footnotetext{
${ }^{508}$ Forsyth, op. cit., pp.74, 78; Naumov, op. cit., p. 48.

${ }^{509}$ Vernadsky, op. cit., pp. 124, 126 enfatiza el papel determinante que jugaron los cosacos de servicio en la expansión en Siberia y ellos se resistían a dedicarse a la agricultura; Slezkine, op. cit., pp.34, 42.
} 
lugar de exilio para algunas personas indeseables para el gobierno moscovita ${ }^{510}$. Para los rusos, dependiendo del estamento social al que pertenecieran, Siberia tenía dos significados: 1) la imaginaban como una tierra de oportunidades si se dedicaban al tráfico de pieles o desmontaban tierras y 2) se entendía como una especie de cárcel de la que no había escapatoria porque parecía no tener límites, situación que por lo común vivían los nobles cuando caían en desgracia y eran enviados allá o los Viejos creyentes ${ }^{511}$, algunos exiliados por el zar, otros, migrantes por decisión propia $^{512}$. En este caso, la cárcel implicaba permanecer en un lugar del que no se podían salir y también estar en un sitio incivilizado conviviendo por fuerza con seres humanos que tenían un comportamiento distinto al suyo y que les resultaba, muchas veces, repulsivo.

Ése fue el caso de uno de los cabecillas más importantes de los Viejos creyentes. Avvakum relata en su autobiografía que pasó alrededor de diez años predicando en la región ${ }^{513}$. El arcipreste narra el conflicto con Nikón y cómo fue arrestado y torturado en el monasterio de Andrónico en 1653. Después, dice, el propio zar lo puso a disposición de la Oficina de Siberia ${ }^{514}$. Fue llevado con toda su familia a Tobolsk en donde se le asignó una iglesia. Sin embargo, la propia gente de la comunidad lo acusó de conspirar en contra del zar. Al poco tiempo, un edicto ordenaba que fuera trasladado a la región del rio Lena. Todavía no llegaba al lugar, cuando llegó la orden de que se le condujera a Dauria, una aldea cercana al lago Baikal en la frontera con Mongolia, en donde serviría como ministro de culto a la guarnición que se encontraba en el lugar. Esta fuerza militar estaba al mando

\footnotetext{
${ }^{510}$ Kerner, op.cit., p. 8

${ }^{511}$ Véase

512 Para un análisis más detallado sobre las oportunidades para comerciantes y campesinos y el desprecio de la nobleza hacia la población del norte de Asia, vid., Gibson, op. cit., passim; Dimet, op. cit., p. 2.

513 “The Life of Archiprest Avvakum by Himself” en Zenkosvsky, op. cit., pp.399-448. Las desventuras relatadas fueron tomadas de esta selección.

514 Véase apartado 6.1.1 de esta tesis.
} 
de Afanasy Pashkov (¿?) quien, según Avvakum, maltrataba a sus subordinados con extrema rudeza y tenía el encargo de torturarlo. En cuanto estuvo frente a él, Pashkov lo acusó de hereje diciéndole que no merecía estar con los cosacos. Por tanto, decidió enviarlo a vivir a unas montañas cercanas ${ }^{515}$, Avvakun le escribió una carta inconformándose con su decisión. Pashkov lo mandó azotar. El traslado desde Dauria hasta el ostrog de Bratsky fue por los rápidos del río Tungusk, de manera que maltratado y herido llegó al fuerte. Durante un tiempo lo mantuvieron encerrado en un cuarto frío y después lo llevaron a una cabaña con los rehenes y los perros donde permaneció todo el invierno. Es posible interpretar que el castigo consistió, en ese momento, en convivir con los nativos que habitaban junto con los perros, ya podemos suponer la suerte que correrían aquellos cuando los castigaban.

Avvakum y su familia vivieron alrededor de siete años en Dauria, Pashkov reiteradamente lo obligaba a viajar por lo ríos lo cual, dice, era un tormento para él. Pero no siempre la pasaba tan mal, por temporadas hasta tenía personas a su servicio pues, al parecer, tenía muchos hijos. De cualquier manera, Avvakum, pescaba, cazaba, cortaba madera, en fin realizaba tareas para proveer a su familia. Como suele decirse de los hombres piadosos en las hagiografías donde consta que reciben ayuda desinteresada de sus semejantes, la esposa y la nuera de Pashkov ayudaban a su familia enviando comida sin que éste lo supiera. Más a menos al quinto año de su estancia en Dauria, hubo una tremenda hambruna, algunos nativos que vivían en el fuerte lo abandonaron pero gran parte de ellos se quedaron y ayudaron a los "rusos" a sobrevivir recolectando los vegetales que crecen en el bosque boreal y alimentándose con la carroña que los lobos y otros depredadores

\footnotetext{
${ }^{515}$ La región de Dauria era una zona fértil que se encontraba bajo el control de los chinos, Pashkov quería enviar a Avvakum tal vez a las montañas de Yablonoi. Como puede apreciarse, el zar envió al hereje a una zona de guerra. Vid., http://www.en.wikipedia.org/wiki/Sino-Russian_border_conflicts consultado 5 de mayo de 2014 .
} 
abandonaban. Pashkov estaba desesperado pero ni así tenía piedad de Avvakum y su familia, según escribió él mismo.

Avvakum refiere la expedición que Pashkov organizó en 1661 en contra de los mongoles. En este pasaje el arcipreste describe el rito de adivinación que realizó un chamán para saber si la empresa tendría éxito. A decir del chamán, se obtendría un gran botín. Avvakum confiesa que rezó para que la misión fracasara y todos los hombres murieran, de esta manera el "pueblo" -seguramente compuesto por rusos, cosacos y tunguses que vivían en esa región-, escribió, se convencería de la verdadera fe. Según Avvakum, en esa expedición participaba el hijo de Pashkov, Eremy (¿?), quien era un cristiano ortodoxo y lo había defendido de los tormentos que le infligía su padre. Apenas inició el avance, las embarcaciones zozobraron. Mientras Eremy estaba en el río le pedía a su padre que se arrepintiera, éste en respuesta le dirigió tres disparos intentando asesinarlo, pero falló. Pashkov se arrepintió de su acción y cuando su hijo logró salir del agua le pidió perdón y reconoció que su hijo estaba en lo correcto. La guerra continuó y Eremy le comunicó a su padre que había regresado vivo de la campaña en contra de los mongoles gracias a las oraciones del arcipreste, pues sólo él había sobrevivido ayudado por un nativo.

Poco después, llegó una misiva que ordenaba el regreso del arcipreste a Rusia, como él la llama, es decir, para Avvakum como para el zar, Siberia no era Rusia sino un territorio bajo su dominio habitado por pueblos incivilizados. Su primera parada fue en la orilla oriental del lago Baikal en un campamento de cazadores y pescadores rusos. El encuentro le resultó tan agradable que describió los alrededores como un edén y al lago como una fuente de riqueza. Él y su familia siguieron hacia el oeste parando en poblados rusos. Pasaron el invierno en Yenisey y al año siguiente estaban en Tobolsk. A pesar del tiempo 
vivido en Siberia, cuando Avvakum fue autorizado a regresar a Moscú describió un viaje de retorno peligroso porque Siberia era "bárbara" y los nativos "hostiles". Aunque reconoce que gracias a su condición de clérigo y a que invocaba a Dios, no fue atacado por los nativos a pesar de que en este tiempo los bashkires y los tártaros asolaban Siberia occidental. Por fin, en 1664, Avvakum regresó a Moscú en donde su suerte empeoró, pues fue juzgado y luego condenado por hereje, pero en su autobiografía no parece añorar Siberia.

Para los pueblos nativos, la presencia rusa en su territorio significó una reducción drástica de la disponibilidad de los recursos naturales que habían utilizado tradicionalmente. Aunque las pieles de marta cibelina fueron el impulso económico principal para el avance de rusos y cosacos sobre Siberia, los recién llegados tenían que satisfacer otras necesidades como alimentación, vivienda y vestido y para ello disponían de los recursos que el bosque boreal y la tundra proporcionaban. En vista de que se consideraban superiores a los lugareños esperaban que éstos se los suministraran. Su situación se agravó cuando los cotos de caza y los pastizales fueron destruidos y ocupados como parcelas para el cultivo. En efecto, en las regiones en donde se avecindaron los campesinos rusos el ecosistema se transformó de manera que las presas huían o desaparecían y los rebaños no tenían en dónde pastar. En suma, la mayor parte de los naturales fueron expoliados en beneficio de la burocracia, los comerciantes y los cazadores rusos porque se vieron forzados a pagar el yasak, a cazar para los promyshlenniki e intercambiar sus pieles con ellos. Cualquier hombre mayor de 15 años y menor de 50 tenía que cumplir estas obligaciones. Ahora bien, la exigencia del tributo en pieles obligó a los nativos a desatender sus tareas tradicionales para sobrevivir. Al iniciar el siglo XVII cada 
tributario debía entregar 22 pieles de marta cibelina al mediar el siglo tan sólo se le exigían cinco. Si ya no había martas, cubrían su cuota con la piel de otros animales como castores o zorras $^{516}$. Si criaban renos, caballos o ganado vacuno, descuidaron los rebaños que también fueron sacrificados para alimentar y servir a los conquistadores. Si los nativos vivían de la caza y la pesca tampoco acopiaban lo necesario para su consumo y el de sus familias así que en breve la mayoría terminaron tan solo sobreviviendo ${ }^{517}$.

El pueblo yukaghir es un ejemplo de esta situación. No sólo vendieron casi todas sus posesiones para conseguir las pieles que demandaban los rusos, sus relaciones de intercambio con otros pueblos fueron afectadas. Los chukchi y koriacos, buenos guerreros, presentaron una resistencia feroz en contra de rusos y cosacos e interrumpieron el trueque que tenían con los yukaghirs. Sus males aumentaron porque les robaban todos los artículos de metal, especialmente de hierro, que éstos les habían mercado a los invasores. Ante su desesperada situación, los yukaghirs pidieron la "protección” de los rusos quienes gustosos la dieron pero no los exentaron de pagar tributo. Estas condiciones tan desventajosas provocaron su desaparición ${ }^{518}$.

Ya que los rusos consideraban inferiores a los habitantes de Siberia porque tenían una cultura diferente -no eran sedentarios, no vivían de sus cosechas, no eran cristianos ortodoxos (ni siquiera monoteístas), no hablaban ruso- los mataban sin vacilar si oponían resistencia, aunque los conquistadores no practicaron el exterminio de manera sistemática. Las prácticas culturales que más repudiaban los rusos era que no respetaban los tabúes sexuales impuestos por el cristianismo ortodoxo, comían carne cruda y, cuando era

\footnotetext{
${ }^{516}$ Moss, op. cit., p. 179.

${ }^{517}$ Forsyth, op. cit., pp. 41, 43, 63, Slezkine, op. cit., p. 26

${ }^{518}$ Forsyth, op. cit., pp. 78-80.
} 
menester, practicaban el gerontocidio y el infanticidio. Estas costumbres propiciaron el mito de que también eran caníbales ${ }^{519}$. Aunque algunos de los diversos pueblos de Siberia no tuvieran esas costumbres, de cualquier forma los consideraban incivilizados porque eran trashumantes. Ya que la lógica de la expansión consistía en ganar tributarios para el zar, la ocupación del espacio no estuvo encaminada a aniquilar a los nativos. La represión fue cruenta solo contra aquellos pueblos que se resistieron con más encono como las elites de janato de Sibir, los pueblos criadores de ganado caballar al sur de Asia central donde la estepa y la taiga se confunden y aquellos que vivían en la frontera con el imperio chino. Los chukchi, itelmenos y koriacos también se enfrentaron a la saña militar rusa. Sin embargo, no se debe olvidar que todo proceso de conquista requiere del uso de la violencia $^{520}$.

Cuando el número de presas disminuía en una región los promyshlenniki sencillamente avanzaban hacia el este sin tomar en cuenta cómo habían afectado la vida de los nativos. El paulatino sometimiento de los pueblos del norte de Asia y del territorio mismo fue irreversible, los rusos y cosacos cazadores vinculados al tráfico de pieles y los colonos utilizaron diversas estrategias para sujetarlos al dominio del zar $^{521}$.

Una de ellas consistió en convertirlos al cristianismo ortodoxo, así que tras los cazadores, los comerciantes y las autoridades administrativas, llegaron los misioneros. De hecho, aunque no hubiera misioneros todo poblado fundado por los rusos y los cosacos

\footnotetext{
${ }^{519}$ Forsyth, op.cit., pp.34, 111; Slezkine, op.cit., p. 34; Marc Raeff (1923-2008), uno de los investigadores más connotados en el estudio del imperio ruso, consideraba que para el zar y sus súbditos un elemento esencial del ser ruso era pertenecer a la iglesia ortodoxa rusa, la cual, desde luego, imponía determinados valores morales que los pueblos del norte de Asia no tenían, vid., Marc Raeff, Understanding Imperial Russia. State and Society in the Old Regime. Trans. Arthur Goldhammer, Foreword John Keep. Nueva York, Columbia University Press, 1984. 284 pp., p. 2

${ }^{520}$ Collins, op. cit., p. 44.

${ }^{521}$ Fairbank, op.cit., p. 44.
} 
tenía su iglesia ${ }^{522}$. Sin embargo, los conquistadores no se empeñaron en demasía por convertir a los nativos. Muchos de quienes adoptaron el cristianismo ortodoxo no abandonaron por completo sus prácticas chamanísticas ${ }^{523}$.

Había una situación contradictoria respecto a la cristianización de los naturales, mientras no fueran cristianos debían pagar el yasak, que era la principal fuente de riqueza para el Estado, cuando se convertían, o al menos los bautizaban, se transformaban en súbditos y por tanto en servidores del zar. Los servidores del zar no pagaban tributo pero pagaban impuestos, éstos se tasaban con base en el número de arados que hubiera en un territorio cultivado o de acuerdo con el monto de las transacciones comerciales ${ }^{524}$, estas condiciones dificultaba asignarles el impuesto a los nativos y más si eran nómadas. Por eso, muchos habitantes de la región estaban bautizados pero no practicaban en cristianismo porque los promyshlenniki no estaban interesados en enseñárselos, la adopción de la fe cristiana sólo ocurría si mediaba una labor de evangelización por parte de los misioneros ortodoxos. El vayevoda era el personaje que enfrentaba día a día esta contradicción pues por una parte debía fomentar la cristianización de los nativos y, por la otra, mantenerlos sujetos al pago del yasak pues su tarea consistía en proteger los intereses del Estado. La solución parecía ser dejar libres a los nativos asiáticos sin bautizarlos pero convertirlos al cristianismo era un paso necesario para incorporarlos a la sociedad rusa y que sirvieran al zar.

En todo caso, aunque la población fuera bautizada no practicaba el cristianismo ortodoxo pues los monjes no se dedicaban sistemáticamente a la evangelización. Por lo

\footnotetext{
${ }^{522}$ Kerner, op.cit., p. 5; Black, op. cit., p.7

${ }^{523}$ Krotkin, op. cit., p. 17

${ }^{524}$ Véanse apartados 5.2 y 5.3 de esta tesis.
} 
común el trabajo de catequización era una decisión personal como lo fue la de Esteban de Perm $^{525}$. Ya que la vanguardia de rusos y cosacos rebasaba con mucho la llegada de monjes y popes, los nativos tuvieron un contacto tardío con ellos. La mayoría de los eclesiásticos que fueron a Siberia eran monjes que no se esforzaban en tratar con una población dispersa o nómada, tampoco aprendieron los idiomas de los naturales, así que realizaban todos los ritos en ruso $^{526}$. Esta limitada vocación pastoral de la iglesia ortodoxa dificultó que en Siberia central y oriental los nativos renunciaran al chamanismo.

Los promyshlenniki también usaron otras estrategias para someter a los nativos. En un principio, cuando sojuzgaban a pueblos organizados en tribus o jefaturas acordaban con quien identificaban como el jefe que cobrara el yasak a los integrantes de su comunidad. Como en realidad tales jefes no tenían autoridad sobre sus parientes se percataron de que casi nunca recaudaban el tributo. También intentaron que las comunidades hicieran un juramento de lealtad al zar pero para los nativos tales juramentos no tenían valor porque no había reciprocidad; en consecuencia eran acusados de traición. También ocurría que los pueblos aliados no recibían la ayuda solicitada a los rusos porque la tropa no tenía las armas y los hombres suficientes como para prestarles el soporte que requerían ${ }^{527}$. De cualquier forma, en estas sociedades asiáticas la solidaridad y la ayuda mutua solo operaban si eran mutuas.

También aprovechaban las rivalidades entre las diferentes comunidades, procuraban aliarse con alguna de ellas para, de esta manera, someter a sus enemigos. Estos grupos servían como tropas auxiliares, pero al correr del tiempo también quedaban sujetos al

\footnotetext{
${ }^{525}$ Véase el apartado 3.2 de esta tesis.

${ }^{526}$ Eugene Smirnoff, A Short Account of the Historical Development and Present Position of the Russian Orthodox Missions. Londres, Rivingtons, 1903. 84 pp., pp. 1-15.

${ }^{527}$ Collins, op. cit., pp. 42-43; Slezkine, op. cit., pp. 17-19, 29
} 
dominio ruso aunque gozaban de algunos privilegios. En ciertos casos fueron los propios grupos nativos quienes solicitaron la protección de los rusos. ${ }^{528}$ El enfrentamiento entre los pueblos asiáticos así como la ocupación rusa de sus territorios también propició el desplazamiento de algunos de ellos hacia otras regiones donde fueron absorbidos por las poblaciones receptoras o por los propios rusos, en consecuencia hubo comunidades que prácticamente desaparecieron mientras que otros adaptaron sus tradiciones culturales a la nueva situación y lograron sobrevivir. La sobrevivencia también fue un problema para los propios rusos y cosacos. Cuando las presas se acababan avanzaban hacia el oriente hacia nuevos cotos de caza. Esto ocurrió en aquellas zonas en las que no podía cultivarse, así que sólo permanecían algunas autoridades y los lugareños. Estos últimos explotaban el ecosistema afectado a la manera tradicional, es decir, cazando presas terrestres comestibles, aprovechando los rebaños y recolectando de acuerdo con los recursos de la taiga o la tundra según fuera el caso. Los cosacos que se quedaban adaptaban su forma de vida a la de aquellos $^{529}$.

De ninguna manera se debe suponer que los pueblos de Siberia se resignaron en seguida a someterse a los rusos y cosacos, por el contrario intentaron evitar que se establecieran en su territorio atacando a las partidas de cazadores y exploradores. Para evitar estos ataques y obligarlos a pagar el yasak, los promyshlenniki exigían la entrega de rehenes. Éstos recibían el nombre de amanat ${ }^{530}$. El relato de Avvakum indica que los rehenes vivían en las fortificaciones para asegurar que sus parientes entregaran el tributo. Entre los pueblos conquistadores, los rehenes eran dados como garantía por los vencidos

\footnotetext{
${ }^{528}$ Collins, op. cit., p. 41; Forsyth, op.cit., pp.35, 60, 91.

${ }^{529}$ Slezkine, op. cit., p.32; Forsyth, op.cit., p. 174 passim.

${ }^{530}$ Los rusos empleaban el término amanat tomado también de los tártaros para designar a los rehenes aunque al parecer es una palabra de origen turco, Preobrazhensky, op. cit., p. 6.
} 
para garantizar que pagarían el tributo y no se rebelarían. Sin embargo, en muchas ocasiones esta estrategia no funcionó pues los pueblos asiáticos asaltaban las partidas rusas a pesar de poner en riesgo la vida de los amanati. Por otra parte, como la mayoría eran nómadas, si llegaba el tiempo de migrar abandonaban a los amanati. Los rusos a veces los mataban y a veces los convertían en sus sirvientes ${ }^{531}$. En la práctica muchos de los rehenes aprendieron el ruso y se desempeñaron como traductores y guías. Asimismo enseñaban a rusos y cosacos formas alternativas de sobrevivencia. En ocasiones las mujeres eran entregadas como rehenes. En esos casos terminaban como compañeras de los promyshlenniki $^{532}$. Los ataques de los nativos también se dirigían en contra de las aldeas campesinas ya que transformaban el entorno y en muchos casos les era imposible vivir como lo habían hecho tradicionalmente, además intentaron forzarlos a labrar el campo, tarea que no sabían realizar.

Los tunguses, por ejemplo atacaban a los exploradores y cazadores e hicieron que el avance en Siberia central fuera menos dinámico. Los kets ayudaron a los rusos a someter a varias comunidades tunguses pues como estaban migrando el norte, invadían su territorio. También colaboraron como tropas auxiliares para sojuzgar a los tunguses que habitaban en el sur del bosque boreal. Así, al iniciar la cuarta década del siglo XVII, la mayoría de las tribus tunguses pagaban yasak. Al este, los tunguses que vivían junto al lago Baikal pagaban tributo a los mongoles buriatos, las fuerzas rusas conquistaron a estos últimos y por añadidura lograron que sus tributarios tunguses también pagaran yasak ${ }^{533}$.

\footnotetext{
${ }^{531}$ Forsyth, op. cit., pp.41, 46; Slezkine, op. cit., pp. 20-21.

${ }^{532}$ Krotkin, op. cit., p. 17

${ }^{533}$ Forsyth, op. cit., pp. 57-59.
} 
Los promyshlenniki procuraban esclavizar a los habitantes de Siberia para evitar compartir con el Estado la riqueza que producían. Sólo los prisioneros de guerra podían ser esclavizados porque se habían resistido a reconocer el dominio del zar. Aunque los nativos bautizados ya no estaban obligados a pagar el yasak, en el caso de los esclavos los promyshlenniki los bautizaban en cuanto se apoderaban de ellos porque si eran botín de guerra ni el cristianismo borraba su condición. Ya que las mujeres no pagaban el yasak, los recién llegados procuraban bautizarlas, sobre todo si cohabitaban con ellas. Los esclavos de cualquier género se utilizaban como sirvientes o también se vendían, en especial las mujeres. Por ello, los nativos también atacaban los poblados rusos para recuperarlos y de paso también intentaban rescatar a los rehenes ${ }^{534}$.

El papel de las mujeres nativas fue fundamental en la expansión rusa en Siberia. La mayoría de los rusos y cosacos emprendían solos su aventura, por esa razón pronto llevaron a las mujeres a cohabitar con ellos, en ocasiones eran rehenes pero en muchos casos sencillamente las habían capturado. Estas mujeres atendían las necesidades de los promyshlenniki en cuanto a casa, vestido y sustento. Además aprendían ruso así que hacían las veces de intérpretes y mediadoras. Fue así como casi al mismo tiempo que los rusos se expandieron sobre el norte de Asia apareció una población mestiza producto del apareamiento entre los promyshlenniki y las nativas ya fuera en calidad de concubinas o de sus esposas. Una muestra de esta interculturalidad fue la manera en que los rusos y cosacos hablaban el ruso, por lo común se desarrollaban variantes en función de la lengua que tenían los pueblos con los que convivían ${ }^{535}$. Estas parejas además procrear a los mestizos,

\footnotetext{
${ }^{534}$ Collins, op. cit., p. 43; Forsyth, op.cit., p.68-69; Sleznike, op. cit., pp. 40-45.

${ }^{535}$ Hector Chevigny (1904-1963), Russian America. The Great Alaskan Venture 1741-1867. Nueva York, The Viking Press, 1966. 274 pp., mapas, p.13; Riasanovsky, op. cit., p. 195; Krotkin, op. cit., p. 17; Dmytryshyn, op. cit., p. 29.
} 
fueron creando una nueva sociedad: la vida de los pueblos se transformó pues adoptaron nuevas costumbres, productos de consumo que no conocían se integraron a su dieta diaria, de igual forma los rusos hicieron suyas prácticas de sobrevivencia desarrolladas por los pueblos de la taiga y la tundra y así el intercambio y la síntesis cultural, no exenta de conflictos, hizo emerger una sociedad multicultural. El hogar fue tal vez el espacio propicio para el proceso intercultural.

Uno de los ejemplos más emblemáticos de la transformación cultural de los habitantes de Siberia fue el de los yakutos. Partiendo de Mangazeia, algunos rusos habían logrado que empezaran a pagar tributo desde 1630 (véase el mapa 16). Más tarde, otros rusos llegaron a Yakutia por mar y quisieron cobrar su propio tributo. Las jefaturas yakutas se levantaron, pero como no se aliaron entre sí finalmente los rusos y cosacos los vencieron. Entonces se estableció el distrito de Yakutia en $1639^{536}$. Para controlar a los yakutos los conquistadores nombraron a los toyones para que cobraran el tributo en sus jefaturas, así quienes en un principio habían encabezado la rebelión, se transformaron en aliados de los administradores rusos y poco a poco se convirtieron en un grupo privilegiado que ejercía el poder sobre sus propios correligionarios. Es más, en las zonas donde se podía cultivar, los miembros de los linajes que no tenían la jefatura fueron supeditados al régimen de servidumbre. Los hatos de caballos fueron puestos al servicio de este grupo privilegiado. Esta situación favoreció el desarrollo comercial de la región pues se transformó en uno de los centros donde se intercambiaban más pieles fines y otros productos. Los segmentos privilegiados de los yakutos se asimilaron culturalmente con los rusos al grado de empezar

${ }^{536}$ Véanse los apartados 6.1 .2 y 6.2 .1 de este capítulo. 
a usar patronímicos tal y como lo hacen los eslavos ${ }^{537}$. Estos yakutos se acomodaron muy bien con la sociedad rusa de manera que a mediados del siglo XVII en la región había alrededor de 2000 rusos y cosacos avecindados ahí quienes convivían sin problemas con los yakutos y se mezclaron con ellos. Hubo algunas comunidades yakutas que migraron hacia la tundra y adoptaron la vida propia de los pescadores y cazadores de mamíferos $\operatorname{marinos}^{538}$.

La conquista de los nativos fue violenta, los rusos contaron con la ventaja de poseer armas de fuego para dominarlos. ${ }^{539}$ Estas armas también fueron utilizadas para cazar. Otro factor que facilitó el dominio de los rusos sobre los nativos fue la introducción de enfermedades desconocidas por ellos. Males como el sarampión, la tuberculosis y la sífilis causaron un descenso de la población local, como ocurrió con las epidemias de viruela entre los yukaghirs en 1657 y $1694^{540}$. Las enfermedades venéreas fueron las más difundidas entre los nativos que practicaban la hospitalidad sexual. Esta costumbre causó graves conflictos pues como los rusos no llevaban mujeres consigo se apoderaban de la huésped y se oponían a que regresaran a su comunidad ${ }^{541}$.

Por su parte, desde la capital del imperio se exhortaba a los gobernadores, comerciantes, cazadores y colonos a no utilizar la violencia en contra de los nativos para evitar rebeliones y echar mano del método de intercambio de regalos para reunir el yasak. Pero si no aceptaban cambiar sus pieles por los artículos que los rusos les ofrecían podían golpearlos aumentando el castigo hasta llegar a la guerra si no había otro recurso. En

\footnotetext{
${ }^{537} \mathrm{Al}$ nombre de pila del individuo se le suma el nombre del padre con la terminación -ich para los hombres y -ova para las mujeres. El sufijo significa hijo (a) de.

${ }^{538}$ Forsyth, op. cit., pp.59-63

${ }^{539}$ Ibidem, p.1-3, 29-33, 78.

${ }^{540}$ Crosby, op. cit., pp. 51-52

${ }^{541}$ Forsyth, op. cit., p. 57, 67; Slezkine, op. cit., pp. $27-28$.
} 
consecuencia, los nativos sufrían la presión y el maltrato tanto de los rusos y los cosacos como del voyevoda porque todos querían reunir la mayor cantidad de pieles posible para su beneficio personal y para enviar el yasak a Moscú. Por tanto, los nativos tenían que cazar para satisfacer sus propias necesidades, las demandas de los promyshlenniki y las exigencias del Estado ruso, lo que significaba un trabajo enorme. Los naturales recibían en compensación por su esfuerzo, si acaso recibían algo: té, ropa, cuchillos, hachas pero sobretodo tabaco y alcohol ${ }^{542}$. Conviene señalar que los gobernadores no sólo se aprovechaban de ellos, también abusaban de los campesinos y de los cazadores rusos pobres $^{543}$. Los nativos entregaban el yasak a los recaudadores que iban a sus comunidades, o algún miembro de su pueblo lo reunía y lo llevaba a la oficina más cercana o cada tributario se presentaba en dicha oficina ${ }^{544}$. En cualquier caso, los funcionarios intentaban asegurarse de que todos pagaran.

El Estado tenía el monopolio comercial de las pieles finas en los mercados de Asia y Europa occidental. Es posible que el comercio con los pueblos asiáticos fuera más redituable que el que mantenía con las ciudades de Europa occidental. Los comerciantes rusos vendían a Persia y a los janatos uzbekos materias primas y algunas manufacturas ${ }^{545}$.

Desde el distrito de Yakutsk, los rusos avanzaron hacia el sur y entraron en contacto con los mongoles de Asia central y con los chinos. En 1654, establecieron el fuerte de Nerchinsk. Debido al intento ruso de imponer el yasak a algunas comunidades mongolas que ya eran tributarios de los chinos, los emprendedores entablaron relaciones con la

\footnotetext{
${ }^{542}$ El uso del tabaco se difundió en Rusia a finales del siglo XVI y en el siglo XVII. En cuanto al alcohol, su venta era otros de los monopolios del zar, Moss, op. cit., pp. 189-191.

${ }^{543}$ Forsyth, op.cit., pp. 41, 66; Summer, op. cit., p. 28; 66, Slezkine, op.cit., pp. 14-15, 22, 30.

${ }^{544}$ Dmytryshyn, op. cit., p. 31.

${ }^{545}$ Forsyth, op.cit., p.40; Kerner, op. cit., pp.3-8; Summer, op.cit., p 28; Wallerstein, t. I, op.cit., pp. 428, 431; Parker, op. cit., pp. 124-125.
} 
periferia del imperio chino. La influencia cultural china en la cultura rusa se nota claramente en la adopción del té que desde entonces se convirtió en una de sus principales bebidas, la otra es el vodka, ambas ayudan a aliviar la sensación de frío. El té llegó al occidente de Eurasia en 1638 aproximadamente ${ }^{546}$.

En el extremo nororiental de Asia y en Kamchatka las tierras no podían cultivarse porque permanecían congeladas todo el año de manera que los rusos y cosacos que vivían ahí tuvieron que alimentarse, al igual que los nativos, básicamente de la caza y la pesca. Por eso en este periodo, la población rusa no pudo crecer mucho pues tenía que conformarse con los recursos disponibles. No obstante, pusieron todo su empeño en someter a los nativos para aprovechar sus cotos de caza y cobrarles el yasak. El siglo XVII llegó a su fin y ninguno de los pueblos que habitaban en la costa del Pacífico pagaba tributo porque entre estas bandas el tributo no se conocía y por eso no comprendían las exigencias de los invasores. Los cosacos y rusos en su afán de obligarlos a pagar muchas veces rodeaban los campamentos o aldeas y las incendiaban dando así un castigo ejemplar ${ }^{547}$.

Por último, es preciso señalar que durante el siglo XVII hubo pueblos que habitaban el sur de la taiga que no fueron sometidos por los rusos y cosacos porque tuvieron la perspicacia para entablar relaciones de intercambio beneficiosas para ambas partes. En efecto, los productos vacunos y los caballos eran esenciales para avanzar en el norte de la taiga y la tundra, a su vez estos pueblos obtenían hierro y algunos cereales. Así algunos pueblos tártaros, los kazacos, los turcos de Altai y los kirguises mantuvieron su autonomía y frenearon la expansión rusa en la estepa.

\footnotetext{
${ }^{546}$ Summer, op. cit., p. 27; Longworth, op. cit., pp 132-133.

${ }^{547}$ Forsyth, op.cit., pp. 83, 100-101; Slezkine, op. cit., p. 17.
} 


\subsection{La llegada al norte del Pacífico}

En 1643, Semion Deynev (c. 1605-1673) junto con Mijail Stadujin (¿-1665) y Dmitri Zyrian $(i-i)$ todos cosacos vinculados con el comercio de pieles en Siberia oriental, exploraron la costa norte hasta el rio Kolyma. Deynev sirvió en Tobolsk, después en Yeniseisk y por fin llegó a Yakutsk en 1638. En seguida participó en varias expediciones de exploración del extremo oriental de Siberia y colaboró en la fundación del ostrog Nijnekolymsk. Entre 1643 y 1648 se desempeñó como recolector de tributo. En 1647, asociado con Fedor Alekseev (¿?) a su vez ligado con Usov (¿?), uno de los comerciantes más acaudalados de Moscú, intentaron salir del río Kolyma y navegar por la península de Chukota, el intento fue fallido. Al año siguiente Alekseev organizó una numerosa expedición en la que participó F. A. Popov (¿?) y consiguió el financiamiento del comerciante Gusel'nikov (¿?). Deynev fue nombrado como el funcionario del gobierno para acompañar la expedición de la que haría un informe y cobraría los impuestos si se obtenían ganancias. En la travesía participaron siete barcos y más de 90 hombres. De todos los organizadores, solo Deynev sobrevivió a la aventura. Los exploradores subieron a la desembocadura del Kolyma y navegando hacia el este bordeando la península de Chukchi llegaron a la desembocadura del río Anadyr. La ruta empezó a ser utilizada por los cazadores y comerciantes rusos y $\operatorname{cosacos}^{548}$.

${ }^{548}$ Black, op. cit., pp. 17-20; Naumov, op. cit., p. 62. 
Poco después, en 1662 Iván Rubets (¿?) cuando intentaba llegar a la desembocadura del río Anadyr llegó hasta el río Kamchatka, invernó en la península y al año siguiente navegó hacia el norte y arribó al ostrog de Anadyr fundado por Deynev en $1649^{549}$.

Cuando los chukchi les hablaron a los rusos acerca de la Gran Tierra (Bolshaia Zemlia $)^{550}$ que se encontraba en dirección al este se interesaron en realizar una expedición ${ }^{551}$. Los chukchi decían que en aquél lugar había un gran cantidad de los mamíferos marinos los que acostumbraban cazar. Esta información resultó atractiva para los promyshlenniki siempre interesados en encontrar nuevos territorios en donde obtener pieles. Los rumores de que al este de la península de Chukota había tierra firme llegaron hasta la Rusia europea y fue uno de los elementos que propició la organización de una expedición hacia América.

Otro factor que contribuyó a que los exploradores y el zar se interesaran en averiguar lo que había navegando por el norte del Pacífico en dirección al este, fue que en 1689, China y Rusia convinieron su primer tratado, el Tratado de Nerchinsk. En él se fijó la frontera entre los territorios rusos en el este de Asia y el imperio chino. El zar renunció a extenderse en la región del río Amur, la única zona en la que era posible cultivar, a cambio de comerciar con los chinos. En efecto, el tratado garantizó el comercio entre ambos imperios, los rusos enviarían una caravana a Beijin cada tres años. Precisamente, uno de los pocos productos que los chinos se interesaban en adquirir eran las pieles finas, por tanto la concesión implicaba una mayor demanda de éstas ${ }^{552}$. En consecuencia, la gran demanda del

\footnotetext{
${ }^{549}$ Black, op. cit., p. 19; Naumov, op. cit., p. 62

${ }^{550}$ Aunque los nativos no lo sabían se referían a América, tal como lo sospecharon los rusos.

${ }^{551}$ James Burney, A Chronological History of North-Eastern Voyages of Discovery; and of the Early Eastern Navigations of the Russians. Londres, impreso por Luke Hansard and Sons, 1819. 310 pp., mapas, pp.97-100. ${ }^{552}$ Fairbank, op. cit., pp. 49-51; Forsyth, op. cit., p.96-99, 105; Chevigny, op. cit., p.15-21.
} 
mercado chino empujó a los rusos a buscar nuevos territorios en donde hubiera presas, así avanzaron hacia el este y se extendieron sobre el norte del Pacífico y en América.

Ambos factores contribuyeron a que en 1719 el zar Pedro I ordenara que la Academia de Ciencias fundada por él, organizara una expedición a través del norte del Pacífico para establecer científicamente la relación de Asia con respecto a América, pero ésa ya es otra historia. 


\section{CONCLUSIONES}

Desde sus orígenes, el pueblo de los rus que devino el pueblo ruso fue una comunidad multiétnica. En su interior ocurrieron procesos de interculturalidad los cuales, de manera paulatina, propiciaron que una porción de los llamados eslavos del este impusieran su idioma sobre los demás. El predominio del eslavo ocurrió aun cuando todavía los eslavos del este no tenían una fuerza militar o política que superara a la de los pueblos vecinos. Cuando los eslavos del este se asentaron en la cuenca del rio Dniéper y hasta el curso medio del río Volga, ellos y los fineses que habitaban ese territorio, estaban organizados en comunidades agrícolas las cuales obtenían recursos del ecosistema en el que habitaban. La diferencia económica entre estas aldeas se debía a la zona que ocupaban: cerca de los ríos, en la estepa o en el bosque por lo que realizaban operaciones de trueque para allegarse recursos que no había en el lugar en donde estaban avecindadas.

En breve, los varegos se impusieron sobre los eslavos del este y los fineses esparcidos en las cuencas de los ríos Dvina, Dniéper, Don y Volga y sentaron las bases para establecer un centro político en Kiev. Este principado, Estado en ciernes, recibió influencias de los jázaros y los búlgaros del Volga, pueblos de la estepa que participaban en las redes de intercambio con Asia central. Los vínculos comerciales y culturales de todos estos pueblos con el Califato Abbasí contribuyeron a aumentar la riqueza de quienes fueron llamados por los bizantinos los rus de Kiev gracias a su participación en las rutas comerciales, fluviales, que trazaron los varegos. Asimismo, fue fundamental la influencia que ejerció el imperio bizantino. Constantinopla era otro puerto en donde se vendían los productos del bosque boreal como las pieles finas y los esclavos. 
Pero el suceso decisivo fue el bautizo de Vladimir en 988 con la consecuente incorporación de los rus a la iglesia ortodoxa. Gracias a los monjes ortodoxos se desarrolló la escritura del ruso, elemento determinante para que éste se impusiera como lengua de los rus. Con la religión y la iglesia, también llegó la cultura bizantina que fungió como elemento de cohesión para quienes en términos políticos se organizaron en principados que guerreaban entre sí y con sus vecinos. En este periodo, los campesinos, todavía vivían aglutinados en aldeas donde se reunía la asamblea de jefes de familia para decidir sobre sus asuntos internos. Ya que eran quienes producían la riqueza fundamental, es decir, la comida, sufrían la presión de los príncipes que lograban dominarlos para que pagaran tributo y así dedicarse a la guerra. También les exigían artículos, como pieles finas, para vender en los mercados a los que tenían acceso gracias a las rutas abiertas por los vikingos.

La etnogénesis de los rusos tuvo lugar en el llamado periodo de la fragmentación, cuando Kiev ya no fue un centro político y la guerra con los lituanos y polacos así como la presencia de la orden teutónica en la costa del Báltico dieron lugar a la escisión de los eslavos del este. La transculturación bizantina hacia los principados que se mantuvieron como cristianos ortodoxos que hablaban y escribían en ruso dio por resultado que se empezara a hablar de la tierra rusa como el territorio donde habitaban los rus y por tanto les pertenecía. Los rus formaban un solo pueblo a pesar de que sus élites pelearan entre sí por imponerse unos a otros.

El elemento exógeno catalizador de la emergencia del pueblo ruso fue la invasión mongola en el siglo XIII. Los príncipes rusos se afirmaron como tales frente a los conquistadores. La anexión de algunos principados rusos al janato Kipchak favoreció la consolidación del naciente pueblo ruso en varios aspectos. Los mongoles demostraron la 
importancia del tributo que aportan los pueblos sometidos, tanto en bienes como en hombres, para el gobernante que ejerce un poder centralizado siempre y cuando vigile cómo se administra. Los príncipes rusos también entendieron que el poder debía apuntalarse con un ejército entrenado y leal al gobernante para controlar el uso de la violencia. La experiencia demostraba que los integrantes de los séquitos con facilidad abandonaban o atacaban a sus señores sobre todo si estaba de por medio la propiedad de sus tierras. Asimismo, la exigencia del tributo dio lugar a que los príncipes rusos empezaran a crear mecanismos para garantizar la permanencia de la fuerza de trabajo en sus tierras pues sólo si conservaban su patrimonio produciendo riqueza podían pagar el tributo a los mongoles y financiar sus disputas. La conquista de los mongoles provocó que gran cantidad de campesinos emigraran hacia el noreste tanto para huir de ellos como de las exigencias de los terratenientes rusos. El dominio del janato Kipchak igualmente brindó a la principalidad de Novgorod la oportunidad de apropiarse del comercio con las ciudades de la Hansa. El florecimiento comercial de Novgorod fue posible gracias al suministro de productos agrícolas de sus campesinos quienes también participaban en la asamblea de la ciudad o veche, por el desarrollo manufacturero, por la educación de los habitantes como lo demuestran las tabletas con escritura que se han encontrado y por la explotación de las pieles finas en la taiga europea. Esta última experiencia fue determinante para la futura expansión rusa en Siberia como también las redes comerciales del janato Kipchak con el resto de los janatos en los que se dividió el imperio mongol.

La política que los janes emplearon para mantener su dominio sobre los príncipes rusos benefició a largo plazo al ducado de Moscovia. En efecto, los janes de Kipchak delegaban en algún príncipe ruso el cobro del yasak entre sus pares. La designación 
beneficiaba al príncipe que realizaba tal función en las luchas internas ya que contaba con el respaldo del jan. En la segunda década del siglo XIV, tal distinción fue otorgada al duque de Moscovia y así, a la sombra de los janes Kipchak, los duques moscovitas fueron incrementando su poder y su riqueza. El suceso más impactante que abonó en favor del reconocimiento del gran príncipe de Moscovia como líder de la nobleza terrateniente rusa fue la victoria de Dmitri Donskoi en Kulikovo en 1380.

El discurso elaborado por los monjes rusos señalaba al gran príncipe como defensor de la fe cristiana ortodoxa en la tierra de los rusos, esta victoria se debía a la inclinación de la divinidad a favor de los príncipes de Moscovia cuyo poder debía ser reconocido por todo el pueblo ruso: tanto nobles como plebeyos. Si bien los janes de Kipchak sumamente debilitados continuaron extrayendo yasak a los príncipes rusos, el primer paso hacia la autonomía estaba dado. Poco a poco los príncipes de Moscovia fueron imponiéndose a las principalidades rusas pero no perdían de vista las ventajas que tendrían si lograban recuperar todo el territorio de la antigua Rus de los reinos ubicados al occidente, si se apoderaban de la riqueza de la estepa todavía bajo el poder de los mongoles y controlaban los recursos de la taiga y las rutas comerciales que explotaba Novgorod. En otras palabras, los príncipes de Moscovia ambicionaban tanto las riquezas que ofrecían la taiga y estepa asiáticas como las del resto de Europa oriental. La impronta mongola despertó el interés de los rusos moscovitas por los recursos que Asia y sus pobladores tenían.

Iván III El Grande logró hacer de Moscovia y su capital Moscú el centro político de la tierra rusa. Debilitados los mongoles, la legitimación de su poder revitalizó la herencia bizantina. De nueva cuenta la síntesis de las redes interculturales hicieron del príncipe de Moscovia el defensor de la iglesia ortodoxa a la caída de Constantinopla en manos de los 
otomanos musulmanes y a Moscú la sede de la Tercera Roma. Las conquistas territoriales, a su vez, le permitieron proclamarse autócrata de todas las Rusias, es decir, de las principalidades y principados que habían sido autónomos durante el periodo de la fragmentación y del dominio mongol. Un segmento importante de la población que gobernaba no eran rusos en tanto que no hablaban el idioma ni eran cristianos ortodoxos, como era el caso de las habitantes de Yugra pero la interculturalidad, el mestizaje y la entrega de tributo los convertía en súbditos de un Estado multinacional.

Durante el gobierno de Iván IV, Moscovia se transformó en el imperio ruso. La construcción de Rusia como el Estado heredero del imperio bizantino por la iglesia ortodoxa rusa, para ese momento prácticamente independiente del Patriarcado de Constantinopla, dio a Iván IV el título de zar, es decir, de gobernante de diversos pueblos consagrado por el patriarca y, por tanto, líder supremo de la iglesia ortodoxa rusa. El zar no se conformó con los símbolos, a ellos sumó acciones concretas para consolidar el poder del Estado que gobernaba. La transformación de los campesinos en siervos adscritos a la tierra y sujetos a la voluntad de su señor corrió paralelamente con la sujeción de la nobleza boyarda al poder del zar. La oprichina fue el instrumento militar que Iván IV utilizó para transformar a la nobleza que luchaba por conservar su independencia, en una nobleza de servicio. De esta manera todos los súbditos quedaron sometidos al autócrata. El poder de un imperio tradicional dependía de la cantidad de hombres y territorio bajo su dominio de los cuales pudiera extraer riquezas en forma de tributo y mediante monopolios estatales. Las guerras hacia el occidente no fueron tan exitosas como las emprendidas al oriente. La conquista del janato de Sibir, que era la última comunidad fronteriza de la ecúmene islámica en el norte, abrió la taiga y la tundra asiáticas a la expansión rusa. 
Si la fe, el idioma y la historia de la Rus de Kiev fueron los elementos fundamentales para la etnogénesis del pueblo ruso durante el periodo de la fragmentación y bajo el dominio mongol, a fines del siglo XVI e inicio del XVII se sumó la concepción de la Santa Rusia como defensora de la ortodoxia cristiana gobernada por un autócrata dedicado a procurar el bienestar de su pueblo -nobles y plebeyos- y de quién, por ende, dependía su fortaleza y su grandeza. Todos estos factores jugaron un papel determinante durante el periodo de las tribulaciones para que el Estado ruso superara la crisis política y social pues las masas campesinas también participaron tanto en las rebeliones en contra de los nobles como en la defensa de la independencia y la autonomía del imperio ruso. Parte de esos plebeyos también le dieron el territorio cuya riqueza consolidó el poder del zar.

Cuando la crisis política fue superada con el ascenso de Mijail I Romanov al poder, el zar se encontró con un imperio que ya se había expandido en Siberia occidental. Los recursos producto del yasak que los nativos debían pagar y de los impuestos que los emprendedores debían al Estado, suministraron a la autocracia las riquezas necesarias para hacer del imperio ruso un Estado moderno poderoso. En efecto, el poder y la riqueza del imperio ruso y de sus sucesores no se explican sin tomar en cuenta la explotación de recursos naturales y humanos que se ha llevado a cabo en Siberia. Durante los siglos XVI y XVII las pieles finas fueron el artículo que nutrió, en gran medida, las arcas del imperio.

Gracias a la iniciativa de los emprendedores rusos y de los cosacos renuentes a convertirse en campesinos, los pueblos de la taiga y de la tundra asiáticas fueron conquistados y obligados a pagar tributo y a reconocer la autoridad del zar. Ante los beneficios que fluían hacia el gobierno de Moscú, el Estado también tuvo una participación fundamental en el proceso de conquista y colonización de Siberia. Para los rusos de 
cualquier grupo social así como para los cosacos, las relaciones interculturales mediante la violencia o la persuasión eran prácticas cotidianas ya con una larga historia. Siberia fue un reto en tanto que registrar y vigilar a pueblos nómadas no fue sencillo y tampoco lo fue sofocar las rebeliones de quienes se oponían al sometimiento. El ecosistema en el que vivían las bandas, las tribus y las jefaturas de la taiga y la tundra fue severamente afectado por la presencia de los rusos y los cosacos. Esta situación llevó a la mayoría de los pueblos del norte de Asia a acomodarse a la nueva situación en la que se formó una red de interdependencia entre ellos y los recién llegados. Esta interdependencia implicó procesos de interculturalidad y transculturación al mismo tiempo que se construyó un estado multicultural. Actualmente los pueblos originarios de Siberia se reconocen a sí mismos como ciudadanos rusos y su territorio como una región de la Federación Rusa.

En este proceso, los ríos de Siberia que desembocan en el Ártico fueron las vías fundamentales de comunicación. Si bien hubo otras rutas al interior de Siberia, la mayoría de los caminos cruzaban los ríos. Cuando no estaban congelados todos eran navegables y en el invierno era más sencillo viajar en trineo sobre el hielo que sobre la nieve. La navegación por el mar Ártico constituye otro ejemplo de la síntesis cultural entre la tecnología náutica de la Rusia europea y la de los pueblos costeros de Siberia, facilitó el avance hacia el este a la vez que constituyó una ruta de comunicación importante que el gobierno imperial protegió de cualquier incursión extranjera. Los ríos también proporcionaban alimentos y agua para beber. Asimismo, es necesario remarcar que los ancestros de los rusos habitaron en el bosque boreal europeo de manera que sabían cómo integrarse a este ecosistema. Los agricultores tenían experiencia en desmontar el boque y convertir la tierra en parcelas de cultivo. Pero ahí donde practicar la agricultura no fue 
posible aprendieron rápidamente de los nativos de la costa del Mar Blanco y del Ártico, a sobrevivir.

Por tanto, al iniciar el último tercio del siglo XVII el imperio ruso tenía varias de las características presentes en la actual República Federada Rusa. Era ya un Estado euroasiático, multinacional, multiétnico, multicultural y rico en recursos naturales la mayoría de los cuáles no se encuentran en la parte europea sino en la asiática. El poder que la riqueza de Siberia le dio a la autocracia rusa hizo del imperio un Estado capaz de consolidar su autonomía, su independencia y de sufragar sus futuros proyectos expansionistas.

Por último, cabe subrayar que, a partir del reinado de Iván IV se debe estudiar la historia rusa considerando su condición euroasiática que la define. Las investigaciones de historia regional son indispensables para el análisis de procesos específicos de corta duración, sin embargo, ningún estudio de caso tendrá sentido si no se enmarca en la entidad macroregional de la cual forma parte. 


\section{APENDICE 1 \\ NOTAS SOBRE LA TRANSLITERACIÓN DEL RUSO AL CASTELLANO MEXICANO.}

El alfabeto ruso consta de 33 signos llamados cirílicos. Veintiuno de ellos son consonantes y diez vocales. Además tiene dos letras sin sonido pero que indican si la pronunciación debe ser fuerte o suave. Actualmente, en Rusia se utiliza la transliteración GOST 7.79-2000 $\underline{\text { Sistemas de Estándares en la información, biblioteconomía y publicación -reglas para las }}$

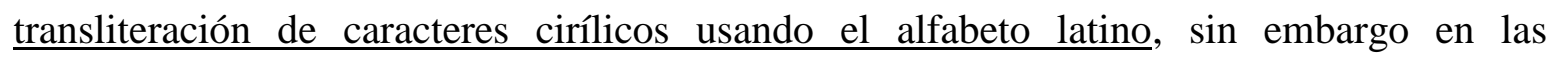
traducciones se realizan adaptaciones a los idiomas que utilizan el alfabeto latino de acuerdo con las necesidades fonéticas. En esta tesis la transliteración se hace con base en la semejanza de los sonidos de las letras rusas con los sonidos de las letras en castellano. Los sonidos de la lengua rusa sobrepasan los de la lengua castellana, por lo tanto la transliteración no puede corresponder de manera exacta de un idioma a otro. Sin embargo, la diversidad de pronunciaciones regionales que tiene el castellano nos ayudará a indicar con mayor precisión el sonido de las letras rusas. La pronunciación está basada en el castellano que se habla en el centro de México. La referencia a otras formas de pronunciación se tomó del habla de otras regiones de América Latina.

La transliteración utilizada en esta tesis difiere en cierta medida de la que se ha empleado en otros libros traducidos al español. Por lo común los traductores respetan la transliteración que los autores hacen de las palabras en ruso al idioma en el que escriben. Por esa razón la grafía de los nombres no coincide exactamente en todos los casos, menos aun cuando se realiza una búsqueda en internet en donde la transliteración más utilizada es 
la del ruso al inglés. Cuando se usan palabras de otros idiomas como el árabe o el mongol se escribieron como aparecen en las traducciones al ruso. En el caso de los nombres de los pueblos que habitaban en Siberia se recurrió a la castellanización que se ha hecho de ellos a partir de la grafía rusa. Por ejemplo, las tribus de Yakutia se nombran como yakutos y no como yakutat que es el nombre que registran en las fuentes rusas. Esto debe tenerse en cuenta al observar los mapas puesto que la mayoría tienen las leyendas en otros idiomas diferentes al español.

Cabe mencionar que los documentos leídos para este trabajo estaban escritos originalmente de acuerdo con los caracteres alfabéticos que se habían fijado en 1708. Aquéllos documentos editados a partir de 1918 así como los publicados a partir de esa fecha, se ajustan a la reforma de 1918 que eliminó cuatro letras ${ }^{553}$. La transliteración se ha hecho de acuerdo con la siguiente tabla.

${ }^{553}$ http://es.wikipedia.org/Alfabeto cir, fecha de consulta 8 de febrero de 2008 


\begin{tabular}{|c|c|c|c|c|c|}
\hline \multicolumn{2}{|c|}{ LETRAS } & \multirow{2}{*}{ VALOR } & \multicolumn{2}{|c|}{ LETRAS } & \multirow{2}{*}{ VALOR } \\
\hline Impres. & Curs. & & Impres. & Curs. & \\
\hline$A a$ & A $a$ & a & $P p$ & $\rho n$ & $\mathbf{r}$ \\
\hline 56 & $\hbar \delta$ & b & C $c$ & C c & 8 \\
\hline$B$ B & $\mathscr{B} B$ & v & $T T$ & $\pi$ & t \\
\hline$\Gamma_{r}$ & $\mathcal{T}_{2}$ & 8 & $y y$ & $y y$ & u \\
\hline$\triangle A$ & $D g$ & d & $\phi \varphi$ & $\Phi \varnothing$ & f \\
\hline$E e$ & $E e$ & ye & $X \times$ & $x x$ & j \\
\hline$\ddot{E} \ddot{e}$ & $\ddot{\mathcal{E}} \ddot{e}$ & yo & 44 & $u_{\delta} u_{\delta}$ & ts \\
\hline * & $\mathcal{K}$ & $Y^{(1)}$ & 44 & $4 u$ & ch \\
\hline 33 & 33 & $z$ & Ш & uu & $\operatorname{sh}(2)$ \\
\hline Mn & $u u$ & i & щ щ & $U_{\delta} u_{\delta}$ & $\operatorname{shch}(2)$ \\
\hline Ий & $\breve{u} \check{u}$ & i & $\mathrm{b} b$ & 6 & $\begin{array}{l}\text { signo } \\
\text { duro }\end{array}$ \\
\hline$H_{k}$ & $\mathcal{K} \kappa$ & k & bl b & $b$ & i dura \\
\hline$\Omega \Omega$ & $\lambda \varkappa$ & 1 & $b$ b & b & $\begin{array}{l}\text { signo } \\
\text { suave }\end{array}$ \\
\hline$M_{M}$ & $\mathcal{M} \mu$ & m & 33 & $\partial 3$ & $\hat{\mathbf{e}}$ \\
\hline $\mathrm{H}_{H}$ & $\mathscr{H}$ H & n & 1010 & $x 010$ & yu \\
\hline 00 & (1) $\sigma$ & 0 & Я & $g a$ & ya \\
\hline$\Pi n$ & $\pi n$ & p & & & \\
\hline
\end{tabular}


(1) $\langle\langle y\rangle>$ Se pronuncia como la y en Argentina.

(2) $<<$ sh $>>$ Se pronuncia como lo ch en el norte de México.

Fuente: La tabla fue tomada de A. Chérel, El ruso sin esfuerzo. Adaptación al castellano Paul de Munck-Loyola, ils. De Pierre Soymier y Robert Gring. Paris, Assimil, [1965]. 422pp., ils. La adaptación al castellano mexicano fue realizada por Martha Ortega Soto. 


\section{APÉNDICE 2.}

\section{GLOSARIO 554}

Amanat sustantivo aplicado a los rehenes que los pueblos de Siberia entregaban a los rusos. Atman jefe de los cosacos del Don.

Barchina prestación en trabajo que los campesinos daban a su señor.

Baskakes observadores que el jan designaba para informarle sobre las acciones de los príncipes rusos.

Beg palabra de origen turco que se utilizaba para designar al segundo en el mando del gobierno.

Bol'shie campesinos que eran dueños de animales en la época del ascenso de Moscovia.

Boyardo en ruso boyarin' deriva de la palabra turca boila voz que se utilizaba para designar a un notable o noble desde la época de la Rus de Kiev.

Bogatyres boyardos.

Bylinas cantos épicos de los eslavos del este.

Chetvert unidad de medida para los terrenos en la época del ascenso de Moscovia, equivalía a 27.31 hectáreas.

Cholop esclavo.

Dengi palabra tomada de los mongoles era la antigua denominación del kopeck, moneda fraccionaria del rublo. Actualmente se traduce como dinero.

Dokladchiki o jueces en las ciudades del periodo de la fragmentación.

Druyina el séquito de un príncipe.

Duma Consejo integrado por boyardos.

Gasudareva kazna sección encargada de las pieles que llegaban de Siberia a Moscú por el cobro del tributo.

${ }^{554}$ Los términos están ordenados de acuerdo al alfabeto castellano y no al ruso para facilitar la consulta de los lectores. 
Golova jefe de las secciones de las oficinas de gobierno en el siglo XVII.

Gosti mercaderes ricos y poderosos.

Grivenka denominación de la moneda antigua equivalente al rublo.

Guba Asambleas de plebeyos rurales y urbanas en la época de Iván IV.

Hetman jefe de los cosacos de Ucrania.

Inozemtsy forastero, designación que recibían los pueblos de Siberia. Derivado de inozemets extranjero.

Izgoi labradores que no tenían familia porque la habían perdido desde el periodo de las migraciones. En estas condiciones no eran candidatos para casarse con las hijas de una comunidad campesina ya que no podía ofrecer nada a cambio de su posible novia.

Jagan en lenguas turca y mongola significa emperador.

Jaganato imperio.

Juriltai asamblea de jefes de clanes entre las tribus trashumantes del noreste de Asia.

Karelian adjetivo utilizado por los rusos para designar a los habitantes del extremo nororiental de Europa.

Kazak Hombre libre ubicado en la estepa alrededor del Mar Negro desde la época del ascenso de Moscovia.

Kazanskii dvorets Tribunal de Kazan con jursidicción en la región de Kazán y Siberia occidentalen el siglo XVII.

ḱlew slověne raíz indoeuropea que significa personas que hablan la misma lengua. Tal vez de ella derive la palabra eslavo.

Knosty En el periodo de la fragmentación designaba un barrio en las ciudades.

Knyaz príncipe, término empleado en el periodo de la fragmentación cuando los boyardos se consolidaron como el grupo social dominante pues eran los dueños de grandes extensiones de tierras.

Knyazya plural de los príncipes emparentados entre sí que tenían la capacidad de sostener un séquito. A partir del ascenso de Moscovia designaba a los boyardos de abolengo.

Koch barco para navegar en las aguas del Ártico.

Kochevye o kochevnyek nómadas. 
Konnye jinetes.

Kormlen'e inmunidad de que gozaron los señores desde el periodo mongol.

Kremlin fortaleza al interior de la ciudad.

Krepostnoi chelovek siervo, palabra que se empleó a partir de la instauración de la servidumbre en el siglo XVII.

Krest'ianin nombre que los mongoles daban a los campesinos de la Rus que pagaban tributo.

Menestel' juglar.

Men'shaya druyina designaba a los miembros del séquito que se reclutaban de manera individual en el periodo de la Rus de Kiev.

Mestnichestvo Sistema para evaluar los méritos y servicios de una familia para decidir el puesto que podía desempeñar un noble al servicio del príncipe y zar desde la época del ascenso de Moscovia.

Monoxyla así denominaban los bizantinos a las embarcaciones que utilizaban los rus para navegar los ríos.

Nemtsy Nombre del barrio en el que vivían los extranjeros en Novgorod durante el periodo de la fragmentación.

Novgorodskii prikaz oficina encargada de los asuntos de Novgorod, Pskov, Arcángel y del territorio al este de los Urales en el siglo XVI.

Novoprijodsty Campesinos recién avecindados en un dominio en la época del ascenso de Moscovia.

Noyon jefes buriatos con hatos muy numerosos.

Obrok Prestación en especie que los campesinos debían a su señor.

Olennye pastores de ciervos o renos, derivado de olen' ciervo, venado o reno.

Oprichina cuerpo militar fundado por Iván IV para perseguir a sus enemigos, especialmente a los boyardos.

Oprichnik plebeyos que formaron la nobleza de servicio formada por Iván IV. Eran miembros de la oprichina.

Ostrog puestos militares ubicados en Asia, ahí se pagaba el yasak y se reunían los tributos que debían enviarse a la capital. 
Pashennye pueblos agricultores en Siberia, deriva de pashnya que significa campo labrado. Peshie pedestres, así se clasificaba a los pueblos siberianos nómadas cazadores y pescadores.

Poddyachie s pripisyu escribanos en Siberia encargados de enviar cuentas e informes a Moscú en el siglo XVII.

Polovnik Campesinos que arrendaban parcelas en un dominio en el período del ascenso de Moscovia.

Pomestye tierras de labranza otorgadas a la nobleza por el zar a cambio de servicio.

Pomeshchniki Miembros de la nueva nobleza beneficiaria del otorgamiento de tierras a cambio de servicio.

Pominki regalos que se intercambiaban entre los pueblos de Siberia y con los rusos.

Pomor'ie navegantes de las costas del mar Ártico.

Posad mercado semanal que se ponía en las ciudades desde la época de Iván III.

Posadnik el jefe de la veche.

Posadskie liudi habitantes de las ciudades que perdieron la libertad de mudarse sin permiso del gobierno en el siglo XVII.

Posol'skii prikaz Oficina de Asuntos Extranjeros en el siglo XVI.

Prejodsty Campesinos que no poseían animales en el periodo del ascenso de Moscovia.

Prigorod aldeas alrededor de las ciudades en los periodos de Kiev y de la fragmentación.

Prikaz Oficinas con diversas funciones administrativas creadas desde el siglo XVI.

Pomory, marinos que navegaban por la costa del Mar del Norte.

Promyshlennik se refiere tanto a aquellos que financiaban y organizaba a las partidas de cazadores para efectuar una expedición cuyo objetivo principal consistía en obtener productos que pudiesen venderse en otros mercados. En el caso de la expansión rusa en el nordeste el principal producto que buscaban eran pieles finas.

Raskoi cisma en la iglesia rusa que dio lugar al movimiento de los "Viejos creyentes".

Raspraynaya palata Ministerio que centralizó a toda la burocracia desde 1649.

Razryadnyi prikaz Oficina de Asuntos Militares en el siglo XVII. 
Razryadny stol sección encargada de los asuntos militares en Siberia con sede en Moscú.

Riadovichi campesinos que trabajaban por contrato en el periodo de Kiev.

Rod palabra eslava que significa familia extensa o linaje, de ella deriva narod palabra que significa pueblo.

Rus es un término de origen turco que pasó al finés del cual fue transmitido al eslavo. Significa navegar y navegante, al parecer así se llamaban a sí mismos los eslavos.

Russkaya pravda Código de los Rus.

Samoderyets autócrata.

Selo pequeñas unidades de tierra en el periodo de Kiev.

Serebrennik Campesinos que pagaban tributos a los señores y al príncipe de Moscovia en el periodo del ascenso de este principado.

Shapka gorro de marta cibelina que llevaban los príncipes y los boyardos a partir de la conquista mongola.

Sibirskii stol oficina encargada de Siberia, creada por Boris Godunov.

Sidiache designación para los pueblos sedentarios de Siberia. Deriva del verbo sidet' (sentarse o estar en casa).

Skomoroji juglares y artistas que entretenían a los aldeanos durante el periodo de la fragmentación y hasta el siglo XVII. En singular skomoroj.

Skotnye pastores, los que tienen ganado.

Slava palabra eslava que significa gloria, tal vez de ella derive el gentilicio eslavo.

Slova voz eslava que significa palabra probable origen del término eslavo.

Smerd campesino libre en el periodo de Kiev.

Smerdy plural de smerd.

Smort Exhibición de princesas para elegir a la que contraería nupcias con el zar. Instaurada en tiempo de Iván III.

Smutnoe vremia o smuta Época de las tribulaciones. Guerra por la sucesión dinástica.

Staraia druyina designaba a los nobles de alta jerarquía integrados a los séquitos del príncipe en el periodo de la Rus de Kiev. 
Starosta jefe de la asamblea campesina en el periodo del dominio mongol.

Straojil'tsy campesinos cuyos ancestros habían vivido en el mismo dominio en el que estaban avecindados. Utilizado durante el ascenso de Moscovia.

Strel'tsy Guardia personal reclutada por Iván IV entre los plebeyos. Más tarde, cuerpo de mosqueteros.

Subednik Código decretado por los gobernantes.

Taishi nombre de quien ostentaba la jefatura entre los buriatos.

Tamga impuesto sobre la renta que los artesanos y los comerciantes rusos debían pagar a los mongoles.

Toyon nombre de quien ostentaba la jefatura entre los yakutos.

Tysiatskii quien dirigía las tropas de la ciudad, designado por la veche durante el periodo de la fragmentación.

Udel dominios territoriales de la nobleza rus en el periodo mongol.

Udez distritos en las provincias rusas en el siglo XVII.

Ukaz decreto del zar.

Ulus comprendía a un grupo de linajes que estaban aliados y sometidos a los descendientes de Genigs Jan.

Uloyenie código elaborado bajo el gobierno de Aleksei.

Vdachi campesinos que trabajaban para pagar un favor durante el periodo de Kiev.

Veche asamblea de la ciudad.

Veliki Knyaz gran príncipe.

Voevodstvo provincias administrativas establecidas en Siberia en el siglo XVII.

Volost comunidad campesina autónoma en el periodo de la ocupación mongola.

Votchina originalmente eran las tierras que pertenecían a los boyardos. Desde el periodo de Iván IV la posesión de las mismas estaba sujeta al servicio al zar.

Voyevoda gobernador provincial desde la época de Iván IV.

Vyt Parcela asignada a una familia en un dominio en el periodo del ascenso de Moscovia. 
Yamskii prikaz Oficina de correo en el siglo XVII.

Yarlak nombramiento que recibían los príncipes de Rusia por parte de los mongoles.

Zaporoyie o cosacos de Ucrania ubicados en el bajo Dniéper.

Zavolochye la tierra que está más allá de los lagos en la cuenca del Mar Blanco.

Zakupy peones en el periodo de Kiev.

Zapovednye gody Año en el que los campesinos tenían prohibido mudarse del señorío en el que estaban, esta práctica inició con Iván IV.

Zemshchina el resto del país durante el gobierno de Iván IV.

Zemskii sobor Asamblea del pueblo integrada por boyardos y notables rusos fundada por Iván IV. En el periodo de Las tribulaciones también participaron plebeyos.

Zimov'e campamento ruso en el norte de Asia para pasar el invierno, no era un puesto militar.

Zolotniki moneda fraccionaria, 48 de ellos equivalían a un rublo en el siglo XV. 


\section{APÉNDICE 3}

\section{CRONOLOGÍA}

\begin{tabular}{|c|c|}
\hline c. $10000 \mathrm{AEC}$ & $\begin{array}{l}\text { Comunidades de cazadores recolectores habitaban al norte y noreste } \\
\text { del Mar Negro. }\end{array}$ \\
\hline c. $4000 \mathrm{AEC}$ & Inició la agricultura en las tierras al norte del Mar Negro. \\
\hline c. $3500 \mathrm{AEC}$ & Utensilios de cobre en la cuenca del Volga y del Mar Báltico. \\
\hline c. $3000 \mathrm{AEC}$ & Uso del hierro en la cuenca del Volga y la costa del Mar Báltico. \\
\hline c. $1000 \mathrm{AEC}$ & $\begin{array}{l}\text { Los cimerios llegaron al Cáucaso, Asia Menor, los Cárpatos y al sur } \\
\text { de los Balcanes. }\end{array}$ \\
\hline c. $800 \mathrm{AEC}$ & $\begin{array}{l}\text { Los escitas se apoderaron del territorio al norte del Mar Negro y del } \\
\text { Cáucaso. }\end{array}$ \\
\hline c. $700 \mathrm{AEC}$ & Se fundaron las primeras colonias griegas en la costa del Mar Negro. \\
\hline c. $400 \mathrm{AEC}$ & $\begin{array}{l}\text { Los sármatas se apoderaron del territorio al norte del Mar Negro y el } \\
\text { Cáucaso. }\end{array}$ \\
\hline c. $200 \mathrm{AEC}$ & $\begin{array}{l}\text { Grupos de eslavos antiguos se ubicaban al norte de la cordillera de } \\
\text { los Cárpatos. }\end{array}$ \\
\hline c. $558 \mathrm{EC}$ & Los ávaros entraron en contacto con el imperio romano de oriente. \\
\hline VI EC & $\begin{array}{l}\text { Los eslavos migraron hacia los Balcanes, Europa central y el este de } \\
\text { Europa (región del Dniéper hasta el alto Volga). }\end{array}$ \\
\hline Siglos VI y VII & $\begin{array}{l}\text { Expansión de los varegos desde la costa oriental del Mar Báltico } \\
\text { hasta el Mar Negro. }\end{array}$ \\
\hline Siglos VII a X & Jaganato jázaro en el Cáucaso. \\
\hline c. 680 & Fundación del Jaganato de los búlgaros del Volga. \\
\hline c. $862-879$ & Gobierno de Ryurik en Kiev. \\
\hline $879-912$ & Oleg príncipe de Kiev. \\
\hline c. 900 & Los búlgaros del Volga se c \\
\hline $912-945$ & Gobierno de Igor en Kiev. \\
\hline 945-957 & Regencia de Olga en Kiev. \\
\hline $957-972$ & Sviatoslav príncipe de Kiev. \\
\hline 965 & Destrucción del jaganato de Jazaria. \\
\hline $980-1015$ & Gobierno de Vladimir. \\
\hline 988 & Conversión oficial del principado de Kiev al cristianismo ortodoxo. \\
\hline 1015-1019 & Lucha por la sucesión en Kiev. \\
\hline 1019-1054 & $\begin{array}{l}\text { Gobierno de Yaroslav en Kiev. Derrotó a los pechenegos y ocuparon } \\
\text { ese territorio los polovotsianos. }\end{array}$ \\
\hline 1051 & Orígenes del Monasterio de las Cuevas de Kiev. \\
\hline c. $1054-1328$ & $\begin{array}{l}\text { Periodo de fragmentación de la Rus, luchas entre los príncipes de la } \\
\text { Rus. }\end{array}$ \\
\hline $1113-1125$ & $\begin{array}{l}\text { Gobierno de Vladimir Monómaco, breve unificación de los } \\
\text { principados de la Rus. }\end{array}$ \\
\hline 1147 & Moscovia aparece nombrado por primera vez en las fuentes. \\
\hline 1154-1157 & cipe de Vladimir- Suzdal. \\
\hline $1169-1175$ & Andrey Bogolyubskiy fue príncipe de Vladimir-Suzdal y Kiev. \\
\hline
\end{tabular}




\begin{tabular}{|c|c|}
\hline 1206 & Tijmundín fue designado Gengis Jan. \\
\hline 1236 & $\begin{array}{l}\text { Comandados por Batú los mongoles iniciaron la conquista de las } \\
\text { tierras de la Rus. }\end{array}$ \\
\hline 1242 & Aleksandr Nevsky de Novgorod derrotó a la Orden Teutónica. \\
\hline 1304 & Yuri Danilovich príncipe de Moscovia. \\
\hline 1315 & Yuri Danilovich se casó con Agrafa, hermana del jan Uzbek. \\
\hline $1328-1341$ & Iván Danilovich Kalita príncipe de Moscovia. \\
\hline 1332 & Uzbek nombró a Iván I Kalita Gran Príncipe de Vladimir. \\
\hline 1333 & $\begin{array}{l}\text { Vychegod y Pechora territorio de Novgorod empezaron a pagar } \\
\text { tributo a Moscovia. }\end{array}$ \\
\hline $1341-1353$ & Simeón Ivanovich Gordy, príncipe de Moscovia. \\
\hline $1352-1359$ & Iván Ivanovich II Krotky, príncipe de Moscovia. \\
\hline $1361-1389$ & Dmitri Donskoi, príncipe de Moscovia. \\
\hline 1364 & $\begin{array}{l}\text { Ustyug y todo su distrito, antes bajo el dominio de Novgorod, } \\
\text { empezó a pagar tributo a Moscovia. }\end{array}$ \\
\hline 1378 & Dmitri Donskoi derrotó a los mongoles. \\
\hline 1375 & Dmitri Donskoi derrotó a la alianza de Tver y Lituania. \\
\hline 1380 & Segunda derrota de los mongoles ante Dmitri Donskoi en Kulikovo. \\
\hline 1385 & $\begin{array}{l}\text { La alianza de Moscovia con Lituania-Polonia derrotó } \\
\text { definitivamente a la Orden Teutónica. }\end{array}$ \\
\hline 1386 & Novgorod pagó tributo a Moscovia. \\
\hline $1389-1425$ & Vasili I príncipe de Moscovia. \\
\hline 1391 & $\begin{array}{l}\text { Murió Sergio de Radoney fundador del monasterio de la Santa } \\
\text { Trinidad. }\end{array}$ \\
\hline 1395 & Tamerlán invadió el ulus Kipchak. \\
\hline 1398 & $\begin{array}{l}\text { El Gran Príncipe Vasili I envió dinero para contribuir a la defensa de } \\
\text { Constantinopla del ataque de los otomanos. }\end{array}$ \\
\hline $1425-1462$ & Vasili II príncipe de Moscovia. \\
\hline 1431 & $\begin{array}{l}\text { Yuri hermano de Vasili I inicia la guerra en contra de Vasili II por el } \\
\text { Principado de Moscovia. }\end{array}$ \\
\hline 1443 & La iglesia rusa de independiza del patriarcado de Constantinopla. \\
\hline 1445 & $\begin{array}{l}\text { Vasili II fue hecho prisionero por el jan Ulug-Mahmed. Formación } \\
\text { de los janatos de Kazan y Crimea. }\end{array}$ \\
\hline 1447 & Vasili II venció a sus parientes y recuperó el poder en Moscovia. \\
\hline 1448 & $\begin{array}{l}\text { Los obispos y arzobispos rusos nombran por primera vez a su } \\
\text { metropolitano. }\end{array}$ \\
\hline 1449 & Vasili II nombró corregente a su hijo Iván. \\
\hline 1452 & $\begin{array}{l}\text { Fundación del janto de Kasimov, el jan juró obediencia al príncipe } \\
\text { de Moscovia. }\end{array}$ \\
\hline 1453 & Caída de Constantinopla en poder de los otomanos. \\
\hline 1459 & $\begin{array}{l}\text { Vasili II conquistó la región de Viatka que enseguida recuperó su } \\
\text { autonomía. }\end{array}$ \\
\hline $1462-1505$ & Iván III el Grande, Príncipe de Moscovia. \\
\hline 1463 & Iván III sometió Yaroslav. \\
\hline 1471 & Iván III atacó Novgorod. Se firmó un tratado de paz entre Moscovia \\
\hline
\end{tabular}




\begin{tabular}{|c|c|}
\hline & y Novgorod. \\
\hline 1472 & $\begin{array}{l}\text { Enlace matrimonial de Iván III de Moscú con Sofía Paleólogo. } \\
\text { Conquista de Perm. }\end{array}$ \\
\hline 1474 & Iván III se apoderó de Rostov. \\
\hline $1475-1478$ & Conquista de Novgorod por Iván III. \\
\hline 1480 & Iván III derrotó definitivamente a los tártaros. \\
\hline 1483 & Iván III empezó a confiscar tierras en la principalidad de Novgorod. \\
\hline 1485 & Iván III conquistó Tver. \\
\hline 1489 & Viatka se sometió a Iván III. \\
\hline 1492 & Iván III se coronó Gran Príncipe de "todas las Rusias". \\
\hline 1493 & Iván III se declaró soberano de Novgorod. \\
\hline 1496 & $\begin{array}{l}\text { El jan de Kazan se refugió en la corte de Iván III cuando lo atacó } \\
\text { Mamuk jan del janato de Sibir. }\end{array}$ \\
\hline 1497 & Iván III decretó un código (Sudebnik). \\
\hline 1499 & Iván III liquidó la relación comercial entre Novgorod y la Hansa. \\
\hline $1505-1533$ & Gobierno de Vasili III en Moscovia. \\
\hline 1505 & Instauración del smort (exhibición de princesas). \\
\hline 1510 & Vasili III tomó Pskov. \\
\hline 1514 & Vasili III conquistó Smolensk. \\
\hline 1517 & Conquista de Riazan por Vasili III. \\
\hline 1526 & $\begin{array}{l}\text { Vasili III se casó con Elena Glinskaya, inició la política de } \\
\text { casamientos con mujeres de las familias de boyardos, quienes } \\
\text { participaban en la elección de la futura esposa. }\end{array}$ \\
\hline $1533-1584$ & Gobierno de Iván IV "El Terrible". \\
\hline 1533 & La regencia recayó sobre Elena Glinskaya y el Consejo de Boyardos. \\
\hline 1538 & Muerte de Elena Glinskaya, Vasili Shuiski tomó la regencia. \\
\hline 1539 & Caída de Vasili Shuiski, tomó la regencia Ivan Belski. \\
\hline 1542 & Macario fue nombrado Metropolitano en Moscú. \\
\hline 1547 & Iván IV se desposó con Anastasia Romanova y fue coronado zar. \\
\hline 1549 & El zar reunió a la zemskii sobor (Asamblea de la tierra). \\
\hline 1550 & Iván IV decretó un nuevo código (Sudebnik). \\
\hline 1551 & $\begin{array}{l}\text { Sínodo de los Cien Capítulos se definieron las relaciones entre la } \\
\text { iglesia y el estado rusos. }\end{array}$ \\
\hline 1552 & Conquista de Kazan. \\
\hline 1553 & Richard Chancellor llegó a Moscú navegando por el Ártico. \\
\hline 1555 & $\begin{array}{l}\text { Richard Chancellor regresó a Inglaterra como embajador de Rusia. } \\
\text { Inició el comercio entre ambos reinos. }\end{array}$ \\
\hline $1555-1698$ & $\begin{array}{l}\text { La Compañía de Moscovia tuvo el monopolio comercial entre } \\
\text { Inglaterra y Rusia. }\end{array}$ \\
\hline 1556 & $\begin{array}{l}\text { Reglamento sobre el servicio de los terratenientes. Conquista de } \\
\text { Astrakán. }\end{array}$ \\
\hline $1558-1583$ & Guerra de Livonia. \\
\hline 1565 & Iván El Terrible estableció la oprichina. \\
\hline 1572 & Abolición de la oprichina. \\
\hline 1580 & Iván IV declaró el primer zapovednye gody (año en que los \\
\hline
\end{tabular}




\begin{tabular}{|c|c|}
\hline & campesinos tenían prohibido mudarse de dominio). \\
\hline 1582 & Conquista de la capital del janato de Sibir. \\
\hline $1584-1598$ & Minoría de edad del heredero de Moscovia, Fedor Ivanovich. \\
\hline 1584 & Los monasterios empezaron a pagar impuestos sobre la tierra. \\
\hline 1584 & $\begin{array}{l}\text { Fundación del puerto del Arcángel en la desembocadura del rio } \\
\text { Dvina. }\end{array}$ \\
\hline 1586 & El rey de Georgia se convirtió en vasallo del zar. \\
\hline 1587 & Ukaz que ratificó la servidumbre en Rusia. \\
\hline 1588 & Boris Godunov gobernaba de hecho Moscovia. \\
\hline 1589 & $\begin{array}{l}\text { Sometimiento total del janato de Sibir a Moscovia. Establecimiento } \\
\text { del Patriarcado de Moscú. }\end{array}$ \\
\hline 1592 & $\begin{array}{l}\text { Decreto por el cual los campesinos perdieron el derecho de mudarse } \\
\text { el día de San Jorge. Los campesinos fugitivos sólo podían recobrarse } \\
\text { en los cinco años siguientes de su fuga. }\end{array}$ \\
\hline 1593 & Fundación de Berezov a orillas del río Ob. \\
\hline $1590-1595$ & Guerra entre Rusia y Suecia. \\
\hline 1597 & $\begin{array}{l}\text { Decreto por el cual los terratenientes debían devolver a los } \\
\text { campesinos a sus antiguos dueños. }\end{array}$ \\
\hline $1598-1605$ & $\begin{array}{l}\text { Muerte de Fedor Ivanovich, Boris Godunov, zar de Rusia nombrado } \\
\text { por la zemskii sobor. }\end{array}$ \\
\hline 1601 & Fundación del fuerte de Mangazeia. \\
\hline 1604 & Fundación de Tomsk. \\
\hline 1605 & $\begin{array}{l}\text { Muerte de Boris Godunov, su hijo Fiodor II fue zar por breve } \\
\text { tiempo. }\end{array}$ \\
\hline $1605-1606$ & El primer falso Dmitri fue zar. \\
\hline 1606-1607 & Rebelión encabezada por Iván Bolotnikov. \\
\hline $1606-1610$ & Vasili Shyuskii se desempeñó como zar, apoyado por Polonia. \\
\hline 1610 & Vasili IV fue depuesto por la zemskii sobor. \\
\hline $1610-1613$ & Interregno en Rusia. \\
\hline 1613-1645 & $\begin{array}{l}\text { Ascenso y reinado de Mijail Fedorovich Romanov como zar del } \\
\text { imperio ruso. }\end{array}$ \\
\hline 1617 & $\begin{array}{l}\text { Decreto por el que los habitantes de Moscú perdieron la libertad de } \\
\text { mudarse sin permiso del gobierno. }\end{array}$ \\
\hline 1619 & Fundación del ostrog de Yeniseysk. \\
\hline 1622 & Se disolvió la zemskii sobor. \\
\hline 1628 & Fundación de Krasnoyarsk. \\
\hline 1632 & Fundación de Yakustk. \\
\hline 1637 & $\begin{array}{l}\text { Se estableció la oficina encargada de los asuntos de Siberia (Sibirskii } \\
\text { prikaz). }\end{array}$ \\
\hline 1639 & $\begin{array}{l}\text { La expedición encabezada por Ivan Moskvitin llegó al Mar de } \\
\text { Ojotsk. }\end{array}$ \\
\hline $1645-1676$ & Gobierno del zar Aleksei Mijailovich. \\
\hline 1645 & Descubrimiento del río Amur por Vasili Poiarkov. \\
\hline 1646 & Fundación del puesto de Ojotsk. \\
\hline 1648 & Rebelión de la sal. Expedición que rodeó la península de Chukota. \\
\hline
\end{tabular}




\begin{tabular}{|l|l|}
\hline 1649 & Se decretó la Uloyenie que institucionalizó la servidumbre. \\
\hline 1649 & Semion Deynev fundó el ostorg de Anadyr. \\
\hline 1650 & Rebeliones en Pskov y Novgorod. \\
\hline 1661 & Fundación de Irkutsk. \\
\hline 1662 & Rebelión en contra de las monedas de cobre. \\
\hline 1664 & $\begin{array}{l}\text { Expedición de reconocimiento del Lago Baikal encabezada por } \\
\text { Kurbat Ivanov. }\end{array}$ \\
\hline 1667 & $\begin{array}{l}\text { Nuevas Reglas Comerciales, las cuales protegieron a los } \\
\text { comerciantes rusos y limitaron a los extranjeros. }\end{array}$ \\
\hline $1670-1671$ & Rebelión encabezada por Stenka Razin. \\
\hline 1689 & $\begin{array}{l}\text { Firma del Tratado de Nerchinsk entre el imperio ruso y el imperio } \\
\text { chino. }\end{array}$ \\
\hline
\end{tabular}

La cronología fue elaborada con base en todas las fuentes que están citadas en esta tesis. 


\section{ÍNDICE DE MAPAS}

Mapa 1. LA URSS EN 1991

Mapa 2. MAPA FÍSICO DE LA FEDERACIÓN RUSA Y TERRITORIOS ALEDAÑOS

Mapa 3. RÍOS DE RUSIA

Mapa 4. EL JAGANATO JÁZARO EN EL SIGLO IX

Mapa 5. UBICACIÓN DE LOS BÚLGAROS DEL VOLGA $C$. SIGLO X

Mapa 6. CENTROS COMERCIALES EN LAS RUTAS DE LOS VAREGOS

Mapa 7. EL PRINCIPADO DE KIEV

Mapa 8. LA RUS AL INICIO DEL SIGLO XIII

Mapa 9. INVASIÓN MONGOLA A LA RUS

Mapa 10. MONASTERIOS RUSOS ORTODOXOS

Mapa 11. RUTAS COMERCIALES RUSAS EN EL SIGLO XV

Mapa 12. TERRITORIO APROXIMADO OCUPADO POR LOS COSACOS EN EL SIGLO XVI

Mapa 13. EUROPA ORIENTAL EN EL SIGLO XV

Mapa 14. PUEBLOS NATIVOS DE SIBERIA CLASIFICADOS CON BASE EN EL TRONCO LINGÜÍSTICO

Mapa 15. RUSIA EUROPEA DURANTE EL GOBIERNO DE ALEKSEI

Mapa 16. RUSIA ASIÁTICA: SIBERIA EN EL SIGLO XVII

Mapa 17. PUEBLOS DE SIBERIA AL INICIAR EL SIGLO XVII 


\section{BIBLIOGRAFÍA}

\section{Artículos}

Alexseev, Mikhail reseña del libro "From Fugitive Peasants to Diaspora: The Eastern Mari in Tsarist and Federal Russia by Seppo Lallukka" en Slavic Review, 63:4, invierno de 2004, pp. 904-905 en http://www.jstor.org/stable/1520471 consultado 2 noviembre 2012.

Bassin, Mark reseña del libro "Russian Eurasianismo: An Ideology of Empire" por Mischa Gabowitsch en Salvic Review, 68:4, invierno de 2009, pp. 1016-1017 en http://www.jstor.org/stable25593850 consultado 1 de noviembre de 2012.

Bhabha, Homi K., "Culture's In-Between” en Stuart Hall y Paul du Gay, Questions of Cultural Identity. Gran Bretaña, The Cromwell Press, 1996. pp. 53-60.

Bogucki, Peter reseña del libro "Culture and Society in Early Medieval Eastern Europe" de P. M. Barford en Slavic Review, 61:2, invierno de 2002, pp. 817-818 en http://www.jstor.org/stable/3090393 consultado 3 de noviembre de 2012.

Brook, Kevin Alan, "Los khazares: un experimento europeo de construcción de un estado judío”, trad. Central Pedagógica Hebraica en http://www.khazaria.com/espanol/jazaros1.html consultado 28 de septiembre de 2011.

Butzer, Karl W., "A Human Ecosystyem Framework for Archaeology" en Moran, The Ecosystem..., op.cit., pp. 91- 130.

Butler, Francis, reseña del libro "Dynasty of Chernigov, 1146-1246" por Martin Dimnik en Slavic Review, 64:1, primavera de 2005, pp. 188-189 en http://www.jstor.org/stable/3650092 consultado 2 de noviembre de 2012.

Cantos Bautista, Juan Antonio, "Chukchi: un pueblo de pastores de renos y pescadores de Siberia" en http://www.suite101net/...chukchi-un-pueblo-de-pastores-de-renos-ypescadores-sibir... Consultado 8 de mayo de 2014.

Chulos, Chris J., reseña del libro "Popular Religion in Russia: 'Double Belief' and the Making of an Academic Myth" por Stella Rock en Slavic Review, 68:2, verano de 2009, pp. 431-432 en http://www,jstor.org/stable/27697990, consultado 1 de noviembre de 2012.

Collins, David N., "Subjugation and Settlement in Seventeenth end Eighteen-century Siberia" en Alan Wood (ed.), The History of Siberia. From Russian Conquest to Revolution. Londres, Routledge, 1991. 194 pp., mapas, pp. 37-56.

Crummney, Robert O., "Ivan IV: Reformer or Tyrant?" en www2.stetson.edu/psteeves/classes/crummey.html, 5 pp. consultado 11 de enero de 2013.

, "The Lastest from Muscovy" en Russian Review, 60:4, octubre, 2001, pp. 474-486 en http://www.jstor.org/stable/2679362 consultado 9 de noviembre de 2012. 
Derevyannykh,

Geniya,

"Bashkirs"

en http://www.russiasperiphery.blogs.wm.edu/russias.../bashkirs/ consultado 6 de mayo de 2014.

Dubina, Vera Kritika, "Explorations in Russian and Eurasian History" en Project Muse Today's Research Tomorrow's Inspiration. Vol. 9, num. 4, otoño 2008, 8 pp. en http://muse.jhu.edu/journals/kritika/v009/9.4.dubina.html.

Engels, F. "Introducción a La dialéctica de la naturaleza" en C. Marx y F. Engels, Obras escogidas. Moscú, Edit. Progreso, s.d. 832 pp., pp.354-370.

Filofei, "Moscow the Thrid Rome (excerpts)" en http://www.dur.ac.uk/a.k.harrington/3rdrome.html consultado 28 de noviembre de 2011.

Fondahl, Gail, reseña del libro de Peter Jordan, "Material Culture and Sacred Landscape: The Anthropology of the Siberia Khanty" en Slavic Review, vol. 64, no. 1, primavera de 2005, pp. 217-218 en http://www.jstor.org/stable/3650115 consultado 2 de noviembre de 2012.

Franklin, Simon, "Pre-Mongol Rus': New Sources, New Perspectives?" en Russian Review, 60:4, octubre de 2001, pp.465-473 en http://www.jstor.org/stable/2679361 consultado 9 de noviembre de 2012 .

, reseña del libro "Les Centres proto-urbains russes entre Scandinavie, Byzance

et Orient" por M. Kazanski, A. Nercessian y C. Suckerman en Slavic Review, 61:2, verano de 2002, p. 401 en http://www.jstor.org/stable/2697155 consultado 2 de noviembre de 2012.

Fried, Morton H., "Estado como institución" David L. Sills (dir), Enciclopedia internacional de las ciencias sociales. 11 vols. $1^{\text {a }}$ reimp. España, Aguilar, 1979, t. IV, pp.459- 465.

Haghayeghi, Mehrdad, reseña del libro "Islam in Russia: The Politics of Identity and Security by Shireen T. Hunter, Jeffrey L. Thomas y Alexander Melikishvili" en Slavic Review, 64:4, invierno de 2005, pp. 921- 922 en http://www.jstor.org/stable/3649960 consultado 2 de noviembre de 2012.

Hall, Stuart, “Introduction: Who Needs Identity?” en Stuart Hall y Paul du Gay, Questions of Cultural Identity. Gran Bretaña, The Cromwell Press, 1996. Pp. 1-17.

Halperin, Charles J., "George Vernadsky, Eurasianism, the Mongols, and Russia" Slavic Review, 41:3, otoño, 1982, pp. 477-493en http://www.jstor.org/stable/2497020, consultado 3 de noviembre de 2012.

_ _ reseña del libro 'Drevniaia Rus' na mezhdunarodnykh putiakh: mezhdistisiplinal'nye ocherki kul'turnykh, torgovykh, politicheskikh sviazei IX-XII" de Aleksander Vasil'evich Nazarenko en Slavic Review, 61:2, verano de 2002, pp. 401-403 en http://www.jstor.org/stable/2697156 consultado 2 de noviembre de 2012. 
, reseña del libro "Law in Medieval Russia" por Ferdinand Feldbrugge en Slavic Review, 69:1, primavera de 2010, pp. 245-246 en http://www.jstor.org/stable/25621774, consultado 1 de noviembre de 2012.

, reseña del libro Gorskii, A. A. "Moskva i Orda" [Moscú y la horda]. Moscú, Nauka, 2000, 213 pp. en Russian Review, 61:1, enero de 2002, pp. 149-150 en http://www.jstor.org/stable/2679514 consultado 9 noviembre de 2012.

, reseña del libro "Vsego esi ispolnena zemlia russkaia...': Lichnosti i mentl'nost' russkogo srednevekov'ia: Ocherki' de Anton Anatol'evich Gorskii en Russian Review, 61:4, octubre 2002, pp. 641-643 en http://www.jstor.org/stable/3664762, consultado 9 de noviembre de 2012.

Hernán Zapata, Horacio Miguel, "Los inkas frente al problema de la interculturalidad. Una introducción al estudio de la configuración del Tawantisuyu en contextos de diversidad étnica y cultural. Siglos XIV-XVI" en Antítesis, vol. 3. N.5, enero-junio de 2010. Http://www.uel.br/revistas/uel/index.php/antítesis, consultado en julio de 2010.

Janhunen, Juna, "Proto-Uralic- what, where, and when?" en The Quasquicentennial of the Finno-Ungrian Society. Suomalais-Ugrilaisen Seuran Toimituksi=Mémories de la Societé Finno-Ougrienne 258. Helsinki 2009, pp. 57-78 en www.sgr.fi/sust/sust258_janhunen.pdf consultado 20 de julio de 2013.

Jersil, Austin reseña del libro "Russia and Islam: A Historical Survey por Galina M. Yemelianova" en Slavic Review, 62:4, invierno de 2003, pp. 849-850 en http://www.jstor.org/stable/3185687 consultado 2 de noviembre de 2012.

Josuah, "Secado de piles de animales", 16 de agosto de 2008, 10 pp. en http://foro.fuentedepermacultura.org/index.php consultado 24 de noviembre de 2011.

Kerner, Robert Joseph, "The Russian Eastward Movement: Some Observations on its Historical Significance" in Morgan B. Sherwood (Ed), Alaska and its History. Seattle, University of Washington Press, 1967. 475 pp., fotografías.

Knox, Zoe, reseña del libro "Political Symbols in Russian History: Church, State, and the Quest for Order and Justice" de Lee Trepanier en Slavic Review, 67:4, invierno de 2008, pp. 1021-1022 en http://www.jstor.org/stable/27653064 consultado 2 de noviembre de 2012.

Kollman, Nancy S., "Comment: Divides and Ends-The Problem of Periodization" en Slavic Review, 69:2, verano de 2010, pp. 439-447 en http://www.jstor.org/stable/25677107 consultado 1 noviembre 2012.

Kotkin, Stephen, "Defining Territories and Empires: from Mongol Ulus to Russian Siberia 1200-1800”, Slavic Research Center, 1996 pdf en http://scholar.princeton.edu/kotkin/files/defining_territories_and_empires_from_mongol_ulus _to_russian_sibir consultado 14 de diciembre de 2012. 
Kovalev, Roman K., "Khazars" en Encyclopedia of Russian History, 2004 en http://www.encyclopedia.com/utility/printdocument.aspx?id=1G2:3404100647 consultado 28 de septiembre de 2011.

Kradin, Nikolay N., "Cultural Complexity of Pastoral Nomads", 22 pp. En http://en.wikipedia.org/wiki/Nikolay_Kradin, consultado 11 de diciembre de 2012.

, "Nomadism, Evolution and World-Systems: Pastoral Societies in Theories of Historical Development" en Journal of World-System Research, VIII, III, otoño de 2002, pp. 368-388 en http://intersci.ss.uci/wiki/ebooks/Artickles/Nomadism\%20kradin.pdf, consultado 11 de diciembre de 2012.

Lenhoff, Gail reseña del libro "Autour du mythe de la Sainte Russie: Christianisme, pouvoir et société chez les slaves orientaux (Xe-XVIIe siècles)" de Vladimir Vodoff en Salvic Review, 63:2, verano de 2004, pp. 399-400 en http://www.jstor.org/stable/3185753, consultado 2 de noviembre de 2012.

Levin, Eve, reseña de Simon Franklin, "Writing,Society and Culture in Early Rus, c. 9501300" en Slavic Review, 62:4, invierno de 2003 , p. 874 en http://www.jstor.org/stable/31855709 consultada 2 de noviembre de 2012.

Martin, Russel E., reseña de "The Sovereign and His Counsellors: Ritualised Consultations in Muscovite Political Culture, 1350s-1570s" de Sergei Bogatyrev en Russian Review, 61:2, abril de 2002, pp. 301-302 en http://www.jstor.org/stable/3664288 consultado 9 de novimbre de 2012.

,"The Petrine Divide and the Periodization of Early Modern Russian History" en Slavic Review, 69:2, verano 2010, pp. 410-425 en http://www.jstor.org/stable/25677105 consultado 1 de noviembre de 2012.

"Mediaval Sourcebook: Privileges Granted to German Merchants Novgorod, 1229", selección de Paul Halsall, octubre de 1998 tomado de G. F. Sartorius, ed. Urkundliche Geschichte des Deutschen Hanse. J. Lappenberg, rev., (Hamburgo, 1830), vol. II, p. 29; reimpreso en Roy C. Cave y Herbert H. C. eds., A Source Book of Medieval Economic History, (Milwaukee; The Bruce Publishing Co., New York: Biblio and Tannen, 1965), pp. 225-231 en http://www.fordham.edu/Halsall/source/1229novgorod-germans.asp consultado 15 de noviembre de 2012.

Moran, Emilio F., "Ecosystem Ecology in Biology and Anthropology: A critical Assessment" en Emilio F. Moran (Ed.) The Ecosystem Approach in Anthropology. From Concept to Practice. Estados Unidos, Ann Arbor/The University of Michigan Press, 1990. 478 pp., pp. 340.

O'Rourke, Shane, reseña del libro "The Cossacks and Religion in Early Modern Ukraine" de Serhii Plokhy en Slavic Review, vol. 62, no. 4, invierno de 2003, pp.844-845 en http://www.jstor.org/stable/3185683 consultado 2 de noviembre de 2012.

Pohl, Walter, "Conceptions of Ethnicity in Early Medieval Studies" en Lester K. Little y Barbara H. Rosenwein, Debating the Middle Ages: Issues and Readings, [s. 1.], Blackwell 
Publishers, 1998, pp. 13-24 consultado en http://www.kroraina.com/bulgar/pohl_etnoicity.html 16 de septiembre de 2011.

"Povest' o bitve ha reke Kalke" en Drevnerusskaya literatura en http://www.drevne.ru/lib/kalka.htm 3 pp., consultado 28 de septiembre de 2011.

Raffensperger,Christian, "Shared (Hi)Stories: Vladimir of Rus' and Harald Fairhair of Norway" en The Russian Review, no. 68, octubre de 2009, pp.569-582 en http://onlinelibrary.wiley.com/doi/10.1111/j.1467-9434.2009.00539.x/abstract consultado 28 de septiembre de 2011.

Rappaport, Roy A., "Ecosystems, Populations and People" en en Emilio F. Moran (Ed.) The Ecosystem Approach in Anthropology. From Concept to Practice. Estados Unidos, Ann Arbor/The University of Michigan Press,1990. 478 pp., pp. 41-71.

, "IX. Naturaleza, cultura y antropología ecológica" en Shapiro, Harry L., Hombre, cultura y sociedad. $1^{\mathrm{a}}$ reimp. De la 1a ed. en español, México, Fondo de Cultura Económica, 1980. 480pp. (Sección obras de antropología), pp. 261-292.

Riasanovsky, Nicholas V., reseña de "Russia and the Russians: A History" por Geoffrey Hosking en Slavic Review, 62:2, verano de 2002, p. 400 en http://www.jstor.org/stable/269154 consultado 2 de noviembre de 2012.

Romaniello, Matthew P., reseña del libro "Nomads and Their Neighbors in the Russian Steppe: Turks, Khazars, and Qipchags" por Peter B. Golden, Russian Review, 63:2, abril de 2004, pp. 328-329 en http://www.jstor.org/stable/3664094 consultado 9 de noviembre de 2012.

Ruskaia Pravda tomada de The Russian Primary Chronicle en http://www.dur.ac.uk/a.k.harrington/russprav.html consultada 28 de septiembre de 2011.

Russian Primary Chronicle en http://web.ku.edu/russcult/culture/handouts/chronicle_all.html consultada 28 de septiembre de 2011.

Simenova, Liliana, reseña del libro de Francis J. Thompson, "The Reception of Byzantine Culture in Medieval Russia" en Russian Review, 60:2, abril 2001, pp. 284-285 en http://www.jstor.org/stable/2679552 consultado 1 de noviembre de 2012.

Shields Kollman, Nancy, reseña de "The Sovereign and His Counsellors: Ritualised Consultations in Muscovite Political Culture, 1350s-1570s" de Sergei Bogatyrev en Salvic Review, 60:3, otoño de 2001, pp. 645-646 en http://www.jastor.org/stable/2696859 consultado 3 noviembre de 2012.

Skinner, Barbara, reseña del libro "Ukraine and Russia: Representations of the Past" por Serhii Plohy en Slavic Review, 68:3, otoño de 2009, pp. 680-681 en http://www.jstor.org/stable/25621676 consultado 1 de noviembre de 2012. 
Skazanie o Mamaevom poboishche en Obrazovatel'ny portal "Drebnerysskaya literatura", 2002-2011, 20 pp. en http://www.drevne.ru/lib/mamay.htm consultado 28 de noviembre de 2011.

Solov'ev', I., Jronologiya po russkoi istorii. Jronologiya, rodosplovniya, vnutrennyaya i vnishnayaya diyatel'nost' gosudarei, napallel'niya sobitiya ebropeiskoi istrorii. Odessa, Izdanie kniynago kagazina "Znanie", 1912. 56 pp.

Soojung Lim, Susan, "Between Spiritual Self and Other: Vladimir Solov'ev and the Question of East Asia" en Slavic Review, 67:2, verano de 2008, pp. 321-341 en http://www.jstor.org/stable/2762846 consultado 1 noviembre 2012.

Sorokin, Petr, "Waterways and Shipbuilding in North-western Russia in the Middle Ages", 13 pp. en http://www.abc.se/ pa//mar/rus-ship.htm consultado 14 de septiembre de 2011.

Szaryez, Ireneusz, reseña del libro "Josef Dobrovský and the Origins of the Igor's Tale" por Edward L. Keenan en Slavic Review, 64:1, primavera, 2005, pp. 218-219 en http://www.jstor.org/stable/3650116 consultado 2 de noviembre de 2012.

The Chronicle of Novgorod 1016-1417. Trad. Del ruso de Robert Michell y Nevill Forbes (1883-1929). Introd. Raymond Beazby en http://faculty.washington.edu/dwaugh/rus/texts/MF1914.pdf consultada 28 noviembre de 2012.

The Life, Acts, and Miracles of Our Revered and Holy Father Abbot Sergius en http://www.dur.ac.uk/a.k.harrington/sergrado.html consultado 29 de septiembre de 2011.

Turkic World, "Ahmad Ibn-Fadlan, Rislaya. Ibn-Fadlan's Travel to Bulgaria. Edition: IbnFadlan's Travel to Volga". Translation and the comment under editorship of academician I. Yu. Krachkovsky. Moscow-Leningrad, 1939 http://s155239215.onlinehome.us/turkic/10_History/IbnFadlan.htm 24 pp. consultado 29 de noviembre de 2011.

Vot povesti minubshij let, otkuda poshla russkaya zemlya, kto v Kieve stal pervim knyiyit' i kak voznikla russkaya zemlya en http://www.drevne.ru/lib/pvl_1.htm?print consultado 28 de septiembre de 2011.

Waugh, Daniel C., $\quad$ Primary $\quad$ Sources, 2002-2004. 3 pp. http://faculty.washington.edu/dwaugh/rus/rusprim.html consultado 28 de septiembre de 2011.

"The Pax Mongolica", 2000, 5 pp. en http://www.sik$\overline{\mathrm{road} . c o m / a r t l / p}$ axmongolica.shtml consultado 13 de noviembre de 2012.

White, Monica, "A Byzantine Tradition Transformed: Military Saints under the House of Suzdal", en Russian Review, 63:3, julio de 2004, pp. 493-513 en http://www.jstor.org/stable/3664652 consultado 9 noviembre de 2012.

Wickenden of Thantet, Paul, A Dictionary of Russian Names en http://www.heraldy.sca.org/names/paul/h-j.html consultado 3 agosto de 2013. 
Wiik, Kalevi, “¿La lengua más antigua de Europa” en www.angelfire.com/folk/celtiberia/eurolenguas.html consultado 19 de julio de 2013.

Willets, Henry, “Los países eslavos. Polonia y la evolución de Rusia” en Hugh TrevorRoper, Historia de las civilizaciones: 8. La época de la expansión. Europa y el mundo desde 1559 hasta 1660. Trad. Juan Andrés Iglesias Sanz. México, Alianza Edit./ Edit. Labor, 1989. Pp. 357-415 (El libro de bolsillo, 1346).

Wixman, Ronald, reseña del libro Seppo Lallukka, "From Fugitive Peasants to Diaspora: the Eastern Mari in Tsarist and Federal Russia" en Slavic Review, vol. 63, no. 4, invierno de 2004, pp. 904-905 en http://www.jstor.org/stable/1520471 consultado 2 de noviembre de 2012.

Yangulova de C., Svetlana, "Visita de archivistas mexicanos al Servicio Archivístico de la Federación Rusa" en Secretaría de Gobernación, Archivo General de la Nación, Boletín 7. México, 6 a época, enero-marzo 2005, pp. 137-155

\section{Libros}

Anderson, Perry, El estado absolutista, Trad, Santos Juliá. 2ª ed. México, Siglo XXI, 1980. 594 pp. (Historia).

Baczko, Bronislaw, Los imaginarios sociales. Memorias y esperanzas colectivas. Trad. Pablo Betesh. Buenos Aires, Ediciones Nueva Visión, 1991. 200 pp.

Bádenas de la Peña, Pedro. Antonio Bravo García, Inmaculada Pérez Martín (eds.), El cielo en la tierra. Estudios sobre el Monasterio Bizantino. [España], Consejo Superior de Investigaciones Científicas, 1997, 352 pp. (Nueva Roma, 3).

Bergin, Joseph, El siglo XVII. Europa 1598-1715. Trad. Antonio Desmonts. Barcelona, Crítica, 2002. (Historia de Europa Oxford).

Black, Lydia T., Russians in Alaska 1732-1867. Fairbanks, Alaska, University of Alaska Press, 2004. 328 pp., ils., y mapas.

Blum, Jerome, Lord and Peasant in Russia. From the Ninth to the Nineteenth Century. Princeton, Nueva Jersey, Princeton University Press, 1972. 656 pp., cuads. y mapas.

Braudel, Fernand, Las civilizaciones actuales. Estudio de historia económica y social. Trad. J. Gómez y Gonzalo Anes. México, Rei, 1991. 500 pp., cuads. y mapas.

Burney, James, A Chronological History of North-Eastern Voyages of Discovery; and of the Early Eastern Navigations of the Russians. Londres, impreso por Luke Hansard and Sons, 1819. 310 pp., mapas

Cameron, Euan, (ed.), El siglo XVI. Trad. Teófilo de Lozoya y Juan Rabasseda-Gascón. Barcelona, Crítica, 2006. (Historia de Europa Oxford).

Cantar de la hueste de Ígor. Trad. Antonio Contreras Martín. Madrid, Gredos, 1997. 75 pp. (Clásicos medievales). 
Christian, David, Mapas del tiempo. Introducción a la $<<$ Gran Historia $>>$. Prefacio William H. McNeill, Trad. Antonio Prometeo Maya. Barcelona, Crítica, 2007. 726 pp., ils., cuads., grafs. y mapas.

Cantos épicos rusos. Ciclo mitológico, ciclo de Kíev, ciclo de Novgorod. Introd., trad. Y notas Susana Torres Prieto. [Madrid], Edit. Gredos, 2003. 240 pp. (Biblioteca universal Gredos).

Clark, George, La Europa moderna. 1450 -1720. Trad. Francisco González Arámburu. 4a. reimp. México, Fondo de Cultura Económica, 1986. 224 pp., mapa (Breviarios, 169).

Crosby, Alfred W., Imperialismo ecológico. La expansión biológica de Europa, 900-1900. Trad. Montserrat Iniesta. Barcelona, Edit. Crítica, 1988. 352 pp., ils., cuads., mapas (Historia y teoría).

Chartier, Roger, El mundo como representación. Estudios sobre historia cultural. Trad. Claudia Ferrari. [Barcelona], Edit. Gedisa, 1992. 276 pp.

Chérel, A., El ruso sin esfuerzo. Adaptación al castellano Paul de Munck-Loyola, ils. De Pierre Soymier y Robert Gring. París, Assimil, [1965]. 422 pp., ils.

Chevigny, Hector, Russian America. The Great Alaskan Venture 1741-1867. Nueva York, The Viking Press, 1966. 274 pp., mapas.

Czaplicka, M. A., Samanism, ceremonii si ritualuri arhaice. Traducere bin limba engñleza Marilena Constantinescu. Bucaresti, Editura Herald, [2014]. 256 pp., ils.

Diment, Galya y Yuri Slezkine (Eds), Between Heaven and Hell. The Myth of Siberia in

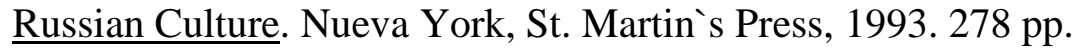

Dukes, Paul, A History of Russia. Medieval, Modern, Contemporary. 2a ed., [Hong Kong], MacMillan, 1990. 426 pp., mapas.

Dulmen, Richard van, Los inicios de la Europa moderna (1550-1648). Trad. Ma. Luisa Delgado y José Luis Martínez. 3a ed. México, Siglo XXI, 1986. 470 pp., (Historia universal siglo XXI, 24).

Earl, Alan, Breve Historia de Rusia. Trad. J. Ferrer Alan. Barcelona, Rotativa, 1973. 188 pp., mapas.

El libro secreto de los mongoles. Versión e introd. José Manuel Álvarez Flórez. Barcelona, Muchnik editores, 1985. 240 pp., mapa.

Encinas Moral, Ángel Luis, La Rus vista por el viajero andalusí Abu Hamid al Garnati (1080-1169) 10 pp. en WebIslam.com consultado 24 de septiembre de 2010.

Fairbank, John King, East Asia: the Modern Transformation. Edwin O. Reischauer and Albert M. Craig. Boston, Houghton Mifflin, 1965. 955 pp., ils. (A History of East Asian Civilization, 21). 
Fisher, Raymond H., The Russian Fur Trade 1500-1700. Reimpresión History E-Book Project, Berkeley y Los Angeles, University of California Press, 1943. XII/276 pp., ils. y cuadros.

Forsyth, James, A History of the Peoples of Siberia. Russian North Asian Colony 5811990. Gran Bretaña, Cambridge University Press, 1994. 456 pp., ils. y mapas.

García de Cortázar, José Ángel y José Ángel Sesma Muñoz, Historia de la Edad Media. Una síntesis interpretativa. Madrid, Alianza Editorial, 1997. 1000 pp. (Alianza Universidad, 894).

Geertz, Cliford, La interpretación de las culturas. Trad. Alberto L. Bixio, [Barcelona], Gedisa, 1996. 388 pp.

Gogol, Nicolás, Tarás Bulba. Sin trad. [Barcelona], Ediciones Orbis, s.d. 128 pp., ils. (Las grandes novelas de aventuras, 48).

Graham-Campbell, James, Los vikingos. Barcelona, Ediciones Folio, 2005. 258 pp., ils. y mapas.

Grimsted, Patricia Kennedy, Archives and Manuscript Repositories in the USSR. Moscow and Leningrad. Princeton, Columbia University, Studies of the Russian Institute, 1972. 440 pp.

Archives and Manuscript Repositories in the USSR. Moscow and Leningrad.

Supplement 1, Bibliographical Addenda. Switzerland, Inter Documentation Company Agzug Switzerland, [1976] . XIV-204 p. (Bibliotheca Slavica, 9).

Hale, J. R., La Europa del Renacimiento 1480-1520. Trad. Ramón García Cotacelo. $7^{a}$ ed. en castellano. Madrid, Siglo XXI editores, 1986. 410 pp., (Historia de Europa Siglo XXI).

Halsall Mar, Paul, Medieval Sourcebook: The Novogorod Chronicle: Selected Annals. 1996, 6 pp. en http://www.forham.edu/halsall/source/novgorod1.asp consultada 28 de septiembre de 2011 apud. Robert Michell and Nevill Forbes, (translators) The Chronicle of Novgorod, 1016-1417. Camden Third Series. Vol. 25. London: The Camden Society, 1914. Passim et seriatim, reprinted in Warren Walsh, Reading in Russian History, (Syracuse NY: Syracuse University Press, 1948).

Hambly, Gavin (comp.), Asia central. Trad. Maribel Carrillo, 2a ed., Madrid, Siglo XXI, 1973. 350 pp., mapas. (Historia Universal Siglo veintiuno, 16).

Heather, Peter, Emperadores y bárbaros. El primer milenio de la historia de Europa. Trad. Teófilo de Lozoya y Juan Rabasseda-Gascón. Barcelona, Critica, 2010, (Serie mayor).

Hellmann, Manfred, C. Goehrke, P. Schubert, et al., Rusia. Trad. María Noela. Madrid, Siglo XXI, 1975. 370 p., mapas. (Historia Universal Siglo Veintiuno, 31).

Herodoto, Los nueve libros de la historia. Introd. Edmundo O'Gorman, $2^{\mathrm{a}}$ ed. México, Edit. Porrúa, 1974. 442 pp. ("Sepan cuantos...", 176). 
Jobert, Ambroise, Breve historia de Polonia. Trad. Sara E. Billino. Buenos Aires, "El Ateneo", 1966. 160 pp., ils. y mapas.

Jones, Gwyn, A History of the Vikings. $2^{\text {nd }}$ edition, reedición 2001. Great Britain, Oxford University Press, 1984. 504 pp., ils. y mapas.

Jordanes, The Gothic History of Jordanes in English version with an introduction and commentary by C. C. Mierow. Princeton, Princeton University Press, 1915. 188pp. en http://openlibrary.org/books/OL7152708M/the_gothic_history_of_Jordanes consultado 12 de octubre de 2012.

Kaiser, Daniel H. y Gary Marker (comps.), Reinterpreting Russian History. Readings, 860-

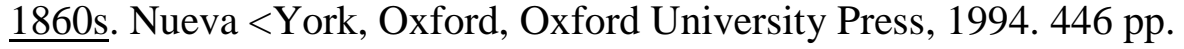

Kaliskov, D., J., Smernov, A. Kopaniov (et al.), Historia de la URSS. Primera parte. Desde la antigüedad hasta la Revolución Socialista de Octubre. $2^{\mathrm{a}}$ ed. Trad. L. Vladov. Presentación M. Shlosberg. Moscú, Edit. Progreso, [1977] 384 pp., ilus.

Kamen, Henry, La sociedad europea, 1500 -1700. Trad. Ma. Luisa Balseiro. Madrid, Alianza Editorial, 1986. 352 pp. (Alianza Universidad, Historia, 475) .

Kinder, Herman y Werner, Hilgemann. Altas histórico mundial. De los orígenes a la Revolución Francesa. Trad. Carlos Martín Álvarez, Antón Dietrich Thomas. Cartografía Herald y Ruth Bukor. Realizado por A. Campos J. Díaz del Valle y F. Romero. Madrid, Ediciones Istmo, 1970. 312 pp. mapas, cuadros. (Colección fundamentos, 1).

Le Goff, Jacques, La Baja Edad Media. Trad. Lourdes Ortiz. 4a ed. España, Siglo XXI, 1974. 336 pp. (Historia universal siglo veintiuno, 11).

Longworth, Philip, Russia. The Once and Future Empire from Pre-history to Putin. Nueva York, St. Martin's Press, 2005. 398 pp., ils. y mapas.

Maier, Franz Goerg, Las transformaciones del mundo mediterráneo del siglo III / VIII. $11^{\mathrm{a}}$ ed. en español. Trad. Pedro de Viadero. México, Silgo XXI, 1986. 416 pp., mapas (Historia Universal Siglo veintiuno, 9).

Malinowski, Bronislaw, Una teoría científica de la cultura. Trad. A.R. Cortázar, [España], Sarpe, 1984. 248 pp, (Los grandes pensadores, 43).

Mathew, Donald, Europa medieval. Raíces de la cultura moderna. Barcelona, Ediciones Culturales Internacionales, 2002. 240 pp., (Atlas culturales del mundo).

McGlynn, Sean, A hierro y fuego. Las atrocidades de la guerra en la Edad Media. Trad. Tomás Fernández y Beatriz Eguibar. Barcelona, Crítica, [2009], 478 pp.

McNeill, J. R. y William H. Mc Neill, Las redes humanas. Una historia global del mundo. Trad. Jordi Beltrán. Barcelona, Crítica, [2003]. 412 pp., cuads y mapas. 
Meyendorff, John, Byzantium and the Rise of Russia. A Study of Byzantino-Russian Relations in the Forteenth Century. Reimp. Nueva York, ST. Vladimir's Seminary Press, 1989. $326 \mathrm{pp}$.

Milner-Gulland, Robin y Nikolai Dejevsky, Rusia y la antigua Unión Soviética. Barcelona, Ediciones Folio, 2007. 240 pp., ils., cuadros y mapas (Grandes civilizaciones del pasado).

Mollat, Michel, Los exploradores del siglo XIII al XVI. Primeras miradas sobra nuevos mundos. Trad. Ligia Arjona Mijangos. México, Fondo de Cultura Económica, 1990. 216 pp. (Sección de obras de Historia).

Moss, Walter G., A History of Russia. Vol I: to 1917. $2^{\text {nd }}$ ed., Londres, Anthem Press, 2005. 638 pp., ils. y mapas.

Naumov, Igor V. y David N. Collins (ed.), The History of Siberia. Londres y Nueva York, Routledge, Taylor and Francis Group, 2006. 242 pp., ils. y mapas.

Ortiz, Fernando, Contrapunteo cubano del tabaco y el azúcar. Prolg. y cronología Julio le Riverend. Caracas, Biblioteca Ayacucho, [1978]. 600 pp., ils.

Ostrowksi, Donald, y Marshall T. Poe, Portraits of Old Russia. Imagined Lives of Ordinary People, 1300-1725. Nueva York y Londres, M. E. Sharpe, 2011. 324/XXVIII pp., ils.

Parker, Geoffrey, Europa en crisis 1598 -1648. Trad. Alberto Jiménez. 2a ed. en esp. [España], Siglo XXI, 1981. 466 p., cuads., mapa, (Historia de Europa Siglo XXI).

Porphyrogenitus, Constantine, De Administrando Imperio. Trad. R. J. H. Jenkings, editor GY. Moravcsik, reimp. De la 2a ed., Washington, Dumbarton Oaks, 2006. 354 pp. (Harvard University Center for Byzantine Studies, I).

Poulantzas, Nicos, Estado, poder y socialismo. Trad. Fernando Claudín. Sexta Ed. México, Siglo XXI editores, 1986. 328 pp. (Sociología y Política).

Radding, Cynthia, Paisajes de poder e identidad. Fronteras imperiales en el desierto de Sonora y los bosques de la Amazonia. Trad. Rose Marie Vargas Jastram. México, El Colegio de Sonora, CIESAS, Universidad Autónoma Metropolitana Azcapotzalco, 2005. 524 pp., ils. y mapas.

Raeff, Marc, Understanding Imperial Russia. State and Society in the Old Regime. Trad. Arthur Goldammer, Foreword John Keep. Nueva York, Columbia University Press, 1984. $284 \mathrm{pp}$.

Ranke, Leopold von. Pueblos y estados en la historia moderna. Estudio de C.P. Gooch. Trad. Wenceslao Roces, 2a reimp., México, Fondo de Cultura Económica, 1986. 544 pp.

Riasanovsky, Nicholas V., A History of Russia. $5^{\text {th }}$ ed. Nueva York/Oxford, Oxford University Press, 1993. 712 pp., ils., mapas, fotografías. 
Sahlins, Marshall, Cultura y razón práctica. Contra el utilitarismo en la teoría antropológica. Trad. Gregorio Valdivia. Barcelona, Edit. Gedisa, 1988, 243 pp., ils.

Service, Elman, Origins of the State and Civilization. The Porcess of Cultural Evolution. Nueva York, W. W. Norton \& Company Inc., 1975. XIX/361 pp., apéndices.

Sixsmith, Martin, Russia a 1, 000 Year Chronicle of the Wild East, Nueva York, The Overlook Press, 2012. XI/612 pp., ils.

Slezkine, Yuri, Arctic Mirrors Russia and the Small Peoples of the North. Ithaca and London, Cornell University Press, 1994. 456 pp.

Smirnoff, Eugene, A Short Account of the Historical Development and Present Position of the Russian Orthodox Missions. Londres, Rivingtons, 1903. 84 pp.

Solov'ev', I. Jronologiya po russkoi istorii. Jronologiya, rodoslovniya, vnutrennyaya i vnishnayaya diyatel'nost' gosudarei, parallel'niya sobitiya ebropeiskoi istrorii, Odessa, Izdanie kniynago kagazina “Znanie”, 1912. 56 pp.

Summer, B. H., Una retrohistoria de Rusia. Trad. Teodoro Ortiz. 2a ed. México, Fondo de Cultura Económica, 1985. 446 pp. (Sección de Obras de Historia).

Talbot Rice, David (dir.), Historia de las civilizaciones 5.La Alta Edad Media. Hacia la formación de Europa. Trad. Mirela Bofill, México, Alianza Editorial/Edit. Labor, 1989. 520 pp., ils. y mapas (El libro de bolsillo,1330).

The Secret History of the Mongols. The Life and Times of Chinggis Khan. Trans., notas e introd. Urgune Onon. Londres y Nueva York, RoutledgeCurzon, Taylor and Francis Group, 2001. 307 pp., mapa e ils.

The Russian Primary Chronicle. Laurentian Text. Ed. Y trad. Samuel Hazzard Cross y Olgerde P. Sherbowitz-Wetzor. Cambridge, Massachusettrs, The Medieval Academy of America, [2013]. 340 pp. (The Medieval Academy of America Publication No. 60).

Tikhmenev, P.A. A History of the Russian-American Company. Trand. y ed. Richard A. Pierce y Alton S. Donnelly. Seattle y London, University of Washington Press, 1978. 552 p., ils., mapas.

Vernadsky, George, A History of Russia. Sixth Revised ed. New Haven, Yale University Press, 1969. 532 pp., cuads. y mapas.

, Kievan Russia. New Haven y Londres, 1976. 418 pp., mapas.

Wallerstein, Immanuel, El moderno sistema mundial. La agricultura capitalista y los orígenes de la economía -mundo europea en el siglo XVI. Trad. Antonio Resines, 5a ed., [México]. Siglo XXI, editores, 1989.582 pp., ils., (Historia). 
, El moderno sistema mundial II. El mercantilismo y la consolidación de la economía mundo europea, 1600-1750. Trad. Pilar López Máñez. 2ª ed. México, Siglo XXI, 1984. 526 pp. (Historia).

Waugh, Daniel C., selección de pasajes de Constantine Porphyrogenitus De Adminstrando

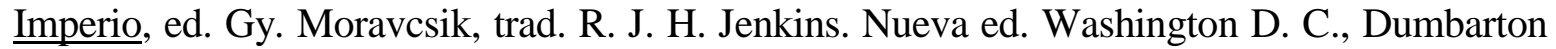
Oaks Center for Byzantine Studies, 1967, pp. 49-51, 57-63 y 167-171 en http://faculty.washington.edu/dwaugh/rus/texts/constp.html consultado 18 de noviembre de 2012.

Wood, Alan (ed.), The History of Siberia. From Russian Conquest to Revolution. Londres, Routledge, 1991. 194 pp., mapas

Zenkovsky, Serge A. (ed., trad., introd.), Medieval Russia's Epics, Chronicles and Tales. Estados Unidos, A Meredian Book, [1974]. 526 pp., ils. y mapa.

Diccionarios

Oxford Learner's Pocket Dictionary. Nueva edición, Oxford University Press, 1991.

Nogueira, J., G. Turover, Diccionario ruso-español. Comprende 57000 vocablos. $5^{\text {a }}$ ed. Estereotipada. Moscú, Edit. 〈<Ruso〉>, 1995. 976 pp.

Preobrazhnensky, A. G., Etymological Dictionary of the Russian Language. Nueva York, Columbia University Press, 1951. 416/144 pp.

Slovar' ispansko-russkii russko-ispanskii. Dopushcheno Ministerstvom obrazovaniya Ukrainy kak posobie dliya obshcheobrazobatel'nij shkol i vysshij uchebnyj zavedenii. Kiiv, Irpin', 1996. 536 pp.

Tesoro de la lengua castellana o española. Compuesto por el licenciado Don Sebastian de Cobarruvias Orozco, Capellan de Su Magestad, Maestreescuela y Canonigo de la Santa Iglesia de Cuenca, y consultor del Santo Oficio de la Inquisicion. Dirigido a la Magestad Católica del Rey Don Felipe III nuestro señor con Pivilegio, por Luis Sanchez,impresor del Rey N. S. año del Señor MDCXI. 1403 pp. en Http://www.fondosdigitales.us.es/fondos/libros/765/1158/tesoro-de-la-lengua-castellana-oespañola consultado 13 de agosto de 2013.

\section{CIBERFUENTES}

http://es.wikipedia.org/Alfabeto_cir, fecha de consulta 8 de febrero de 2008.

http://astrakhan.name/index.php?razd=2 consultado 24 de mayo de 2011. http://www.telefonica.net/web2/jgarciaf/cambio_climatico/glaciaciones.htm, consultado 23 de octubre de 2011. 
http://www.jmarcano.com/nociones/bioma/tundra.html consultado 22 de noviembre de 2011.

http://www.ucmp.berkeley.edu/exhibits/biomes/tundra.php consultado 22 de noviembre de 2011.

http//www.windows2universe.org/earth/Taiga_ecosystem.html consultado 23 de noviembre de 2011.

http://www.ri.net/schools/west_warwick/manateeproject/taiga/land.htm consultado 23 de noviembre de 2011.

http://www.barrameda.com.ar/ecologia/estepas.htm consultado 23 de noviembre de 2011.

http://geografia.laguia2000.com/biogeografia/la-estepa consultado 23 de noviembre de 2011.

http://clover.slavic.pitt.edu/pvl/ost1.html consultada 4 de enero de 2012.

http://litopys.org.ua/ consultado 19 de octubre de 2012.

http://es.wikipedia.org/wiki/pueblos_eslavos\#origen_del_t.c3.A9rmino_eslavo consultado 11 de octubre de 2012.

http://etimologias.dechile.net/?eslavo consultado11 de octubre de 2012.

http://eslavoteca.blogspot.mx/2009/02/origen_del_termino_eslavo.html consultado 11 de octubre de 2012.

http://es.wikipedia.org/wiki/kan consultado 16 de octubre de 2012.

http://es.wikipedia.org/wiki/bey consultado 16 de octubre de 2012.

http://es.wikipedia.org/wiki/Ri\%C3\%BArik consultado 19 de octubre de 2012.

http://es.wikipedia.org/wiki/Oleg_de_N\%C3\%B3vgorod consultado 19 de octubre de 2012. http://es.wikipedia.org/wiki/Olga consultado 15 de noviembre de 2012.

http://en.wikipedia.org/wiki/Posadnik consultado 28 de noviembre de 2012.

Boris y Gleb en http://orthodoxworld.ru/es/sviatye/2/index.htm consultado 28 de noviembre de 2012.

http://en.wikipedia.org/wiki/Khagan, consultado 11 de diciembre de 2012.

http://en.wikipedia.org/wiki/Khanate_of_Sibir consultado 14 de diciembre de 2012.

http://www.referencebooks.brillonline.com/entries/encyclopedia-of-the-medieval-chronicle 18 de diciembre de 2012. 
http://www.encyclopedia2.thefreedictionary.com/chetvert consultado 23 de diciembre de 2012.

http://www.coldsiberia.org/webdoc9.htm=Its\%20message consultado 30 de diciembre de 2012.

http://www.es.wikipedia.org/wiki/Ushanka consultado 30 de diciembre de 2012.

http://genealogy.euweb.cz/russia/rurik13.html consultado 2 de enero de 2013.

http://www.es.wikipedia.org/wiki/Compañía_de_Moscovia consultada 13 de enero de 2013.

http://www.worlmapfinder.com consultado 31 de enero de 2013.

http://www.es.wikipedia.org/wiki/Borís_Godunov consultado 1 de febrero de 2013.

http://www.latin.ru/es/anillo/anillo2.shtml consultado 5 de febrero de 2013.

http://www.en.wikipedia.org/wiki/False_Dmity_I consultado 7 de marzo de 2013.

http://www.answers.com/topíc/ivan-bolotnikov consultado 7 de marzo de 2013.

http://www.en.wikipedia.org/wiki/False_Dmity_II consultado 7 de marzo de 2013.

http://www.encyclopedia2.thefreedictionay.com/mikhail+skopinshuiskii consultado 8 de marzo de 2013.

http://www.tradizione.oodegr.com/tradiziones_index/vitesanti/hermogen.htm consultado 8 de marzo de 2013.

http://www.en.wikipedia.org/wiki/Trubetskoy_family\#Time_of_Troubles consultado 8 de marzo de 2013.

http://www.es.wikipedia.org/wiki/Iván_Zarutski consultado 8 de marzo de 2013.

http://www.es.wikipedia.org/wiki//Kuzmá_Minin consultado 8 de marzo de 2013.

http://www.lavra.ru/palomnikam/istoriya-monastyrya consultado 8 de marzo de 2013.

http://www.orthodoxwiki.org/Philoteus_of_Pskov consultado 11 abril 2013.

http://www.saints.sqpn.com/saintjb3.htm consultado 11 abril 2013.

http://www.weva2008.ru/img/russia_map_big.jpg consultado 15 abril de 2013.

http://www.es.orthodoxwiki.org/Iglesia_Ortodoxa_de-Rusia\#tLista_de_los-

Patriarcas_de_Mosc.C3.BA consultado 23 abril de 2013.

http://www.es.wikipedia.org/wiki/Sigismund_Herberstein consultado 26 abril de 2013.

http://www.treccani.it/enciclopedia/paolo-cantelli-centurione_(Dizionario-Biografico)/ consultado 26 de abril de 2013. 
http://www.iisg.ne/archives/en/files/b/ARCH00026full.php\#N10CB9 consultado 1 de mayo de 2013.

http://www.commons.wikimedia.org/wiki/File:Chaseren.jpg consultado 3 de mayo de 2013.

http://www.google.com.mx/imgres?imgurl=http://upload.wikimedia.org/wikipedia/commo ns/thumb/1/1f/Siberiariverroutemap.png/6 consultado 3 de mayo de 2013.

http://www.wikimedia.org/wikipedia/commons/f/f8/premongolEurasia.png consultado 4 de mayo de 2013.

http://www.es.wikipedia.org/wiki/Cimerio consultado 12 de junio de 2013.

http://wwwooaties.org/linguaeimperii/Slavic/slavic_es.html consultado 19 de julio de 2013. http://www.es.wikipedia.org/wiki/Pueblos_bálticos consultado 19 de julio de 2013.

http://www.es.wikipedia.org/Lenguas_ugrofinesas consultado 19 de julio de 2013.

http://www.first_names.enacademic.com/2361/Jaropelk consultado 1 de agosto de 2013.

http://www.es.wikipedia.org/wiki/Teodoro_el_Estudita consultado 7 de agosto de 2013.

http://www.es.wikipedia.org/wiki/Rus_de_Kiev consultado 8 de agosto de 2013.

http://www.es.wikipedia.org/wiki/Historia_de_Bielorrusia consultado 12 de agosto de 2013.

http://es.wiki/Guerras_moscovita-lituanas consultado 12 de agosto de 2013.

http://www.es.wikipedia.org/wiki/principado_de_Smolensk consultado 12 de agosto de 2013.

http://www.es.wikipedia.org/wiki/Ucrania\#Edad_de_oro_de_Kiev consultado 12 de agosto de 2013.

http://www.es.wikipedia.org/wiki/Ostrog 16 de febrero de 2014.

http://www.es.wikipedia.org/wiki/Circasia consultado 23 de abril de 2014.

http://www.es.wikipedia.org/wiki/Adam_Wisniowiescki consultado 24 de abril de 2014.

http://www.es.wikipedia.org/wiki/Stenka_Razin consultado 29 de abril de 2014.

http://www.ilibrariana.wordpress.com/.../de-familie-marcelis-in-r... consultado 1 de mayo de 2014.

http://www.es.wikipedia.org/wiki/Borís_Morózov consultado 1 de mayo de 2014.

http://www.es.wikipedia.org/wiki/Lenguas_samoyedas consultado 5 de mayo de 2014 .

http://www.es.wikipedia.org/wiki/Lenguas_tunguses consultado 6 de mayo de 2014. 
http://www.es.wikipedia.org/wiki/Pueblos_tunguses consultado 6 de mayo de 2014. http://www.centrodeartigos.com/artículos-enciclopédicos/article_88121.html consultado 6 de mayo de 2014.

"Koryaks" en The Red Book of the Peoples of Russian Empire en http://www.eki:ee/books/redbook/Koryaks.shtml consultado 8 de mayo de 2014.

http://www.es.wikipedia.org/wiki/Koryaks consultado 8 de mayo de 2014.

"Itelmenos" en The Red Book of the Peoples on the Russian Empire en http://www.eki.ee/books/redbook/itelmens.shtml consultado 8 de mayo de 2014.

www.todoatlas.com/union-sovietica.html consultado 7 de junio de 2014.

http://www.es.wikipedia.org/wiki/Filología y http://es.wikipedia.org/wiki/Idioma_ruso consultados el 7 de junio de 2014.

http://www.en.wikipedia.org/wiki/Slavic_Greek_Latin_Academy consultado 7 de junio de 2014.

http://www.es.wikipedia.org/wiki/Vasily_Bartold consultado 7 de junio de 2014.

https://openlibrary.org/...Vasiii_Vladimirovich_Bartold... Consultado 7 de junio de 2014.

http://www.freeworldmaps.net/e/rusia-mapa.jpg consultado 8 de junio de 2014.

http://www.es.wikipedia.org/wiki/Pechenego consultado 20 de junio de 2014.

http://www.es.wikipedia.org/wiki/Alfabeto_cirílico consultado 21 de junio de 2014.

http://www.remilitari.com/cronolog/bizancio.com consulado 21 de junio de 2014.

http://www.es.wikipedia.org/wiki/Gengis_Kan consultado 28 de junio de 2014.

http://www.en.wikipedia.org/wiki/Sophia_Palaiologina consultado 6 de agosto de 2014 .

http://www.rusopedia.rt.com/economia/issue_21.html consultado 6 de agosto de 2014.

http://www.accordeonworld.weebly.com/stenka-razin-lyrucs.html consultado 8 de agosto de 2014.

http://www.es.wikipedia.org/wiki/Yakutos consultada 9 de agosto de 2014.

http://www.taringa.net/posts/info/16821812/Origen-de-los-Esquimales.html consultado 10 de agosto de 2014.

http://mmedia.nsu.ru/remezov/vbook/obj8/title.htm consultado 12 de agosto de 2014.

http://mmedia.nsu.ru/remezov/vbook/obj8/title.htm consultado 12 de agosto de 2014. 